\title{
AVALIAÇÃO DO CICLO DE VIDA: PRINCIPAIS MÉTODOS E ESTUDO COMPARATIVO ENTRE O CESTO DE PLÁSTICO E DE INOX DE UMA LAVADORA DE ROUPA
}

Dissertação apresentada à Escola de Engenharia de São Carlos da Universidade de São Paulo, como parte dos requisitos para a obtenção do Título de Mestre em Engenharia de Produção.

ORIENTADOR: Prof. Dr. Aldo Roberto Ometto

São Carlos

2009 


\section{Agradecimentos}

A DEUS pela vida e saúde plena durante o período de trabalho.

A toda minha família, em especial aos meus pais José e Zuleica ao meu irmão Jeferson e ao meu sobrinho Leonardo, que estiveram sempre ao meu lado e souberam compreender as minhas ausências quando necessário.

À minha noiva Sabrina Eloisa Oliva em especial, por estar sempre ao meu lado, me apoiando, ajudando e incentivando durante este trabalho.

Ao meu amigo Ademir Brescansin, pelo apoio e ajuda para o inicio da realização deste trabalho.

Ao meu Orientador Prof. Dr. Aldo Roberto Ometto, pelos ensinamentos, pela orientação e pela amizade.

Aos amigos André Tachard e Américo, pelas conversas, que sempre foram pontos de reflexão importantes.

E a todos os funcionários do Departamento de Engenharia de Produção da USP pelo apoio para o desenvolvimento deste trabalho. 


\section{Resumo}

BORTOLIN, A.R. (2009) Avaliação do Ciclo de Vida: principais métodos e estudo comparativo entre o cesto de plástico e de inox de uma lavadora de roupa. 100p. Dissertação de Mestrado - Escola de Engenharia de São Carlos, Universidade de São Paulo, 2009.

Os produtos podem causar impactos negativos ao meio ambiente em uma das suas etapas do ciclo de vida, quais sejam: aquisição de matéria-prima, fabricação, distribuição, uso e disposição final. A integração dos aspectos ambientais no projeto e no desenvolvimento de produto busca prevenir e minimizar os possíveis impactos ao longo de seu ciclo de vida. Esses impactos variam quanto à categoria, magnitude, extensão e duração. A principal metodologia para avaliar os impactos ambientais do ciclo de vida do produto é a Avaliação do Ciclo de Vida (ACV). Contudo há diversos métodos e formas de aplicações desta metodologia. O primeiro objetivo é identificar os principais métodos da ACV, por meio de uma revisão sistemática, O segundo é realizar um estudo de caso comparativo da ACV entre dois tipos de cestos (de plástico e de aço inox) utilizados nas lavadoras de roupas automáticas, identificando os potenciais impactos ambientais, baseado no método EDIP. Os principais métodos identificados na revisão sistemática foram: Ecoindicator 99, EPS, CML Ecological Footprint e EDIP. A comparação do ciclo de vida dos dois cestos demonstra que, para as categorias de impactos de potencial de aquecimento global, acidificação, eutrofização, ecotoxidade e toxidade humana, o cesto inox tem uma maior contribuição para os potencias impactos ambientais em relação ao cesto de plástico, principalmente devido à maior distância transportada da matéria-prima do aço até a fabricação do cesto.

Palavras-chave: Avaliação do Ciclo de Vida (ACV), métodos de ACV, cesto da lavadora de roupa, plástico, aço inox. 


\begin{abstract}
BORTOLIN, A.R. (2009) Life Cycle Assessment: main methods and comparative study between the plastic and stainless steel of the washer machine's basket. 100p. M.Sc. Dissertation - Escola de Engenharia de São Carlos, Universidade de São Paulo, 2009.
\end{abstract}

The products can cause negative impacts to the environment in one of their stages of the life cycle, which are: raw material acquisition, production, distribution, use and final disposition. The integration of the environmental aspects in the project and in the product development it looks for to prevent and to minimize the possible impacts along his life cycle. Those impacts vary as for the category, magnitude, extension and duration. The main methodology to evaluate the environmental impacts of the life cycle of the product is the Life Cycle Assessment (LCA). However there are several methods and forms of applications of this methodology. The first objective is to identify the main methods of LCA, through a systematic revision, THE second is to accomplish a study of comparative case of LCA among two types of baskets (of plastic and of stainless steel) used in the washers of automatic clothes, identifying the potentials environmental impacts, based on the method EDIP. The main identified methods in the systematic revision were: Echo-indicator 99, EPS, CML Ecological Footprint and EDIP. The comparison of the cycle of life of the two baskets demonstrates that, for the categories of impacts of potential of global warming, acidification, nutrient enrichment, ecotoxicity and human toxicity, the basket stainless steel has a larger contribution for the potencies environmental impacts in relation to the basket of plastic, mainly due to the largest transported distance of the raw material of the steel to the production of the basket.

Keywords: Life Cycle Assessment (LCA), LCA Methods, washer machine's basket, Plastic, Stainless steel. 


\section{Lista de Figuras}

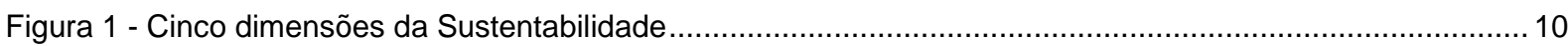

Figura 2 - Paradoxo entre o tempo do projeto e o grau de liberdade para as melhorias ambientais .................... 18

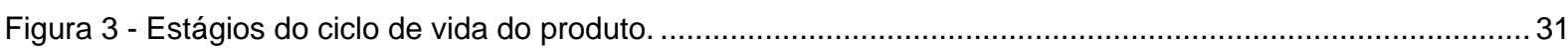

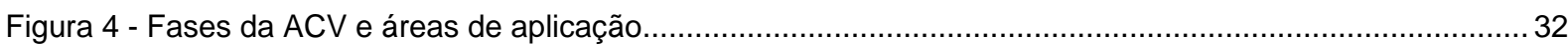

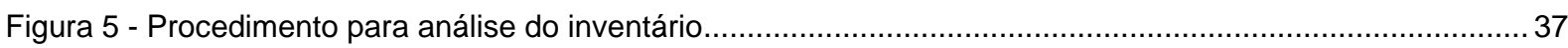

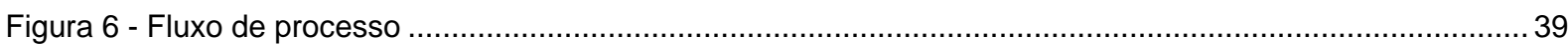

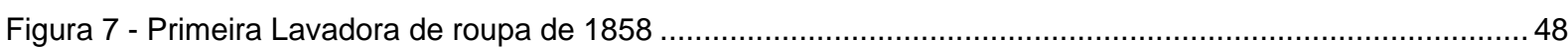

Figura 8 - Propaganda da Máquina de espremer roupas. ........................................................................ 48

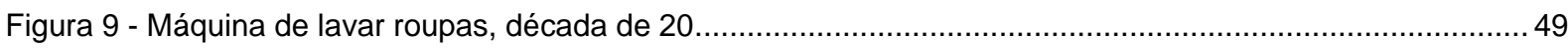

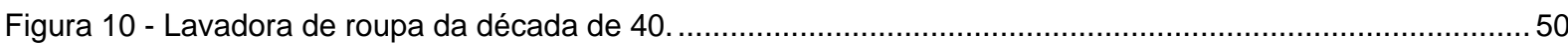

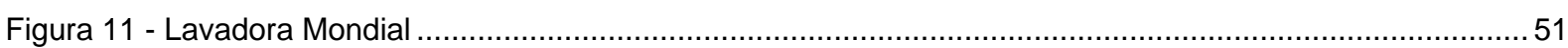

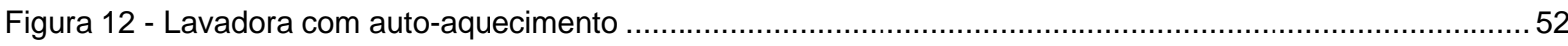

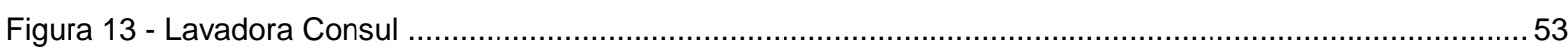

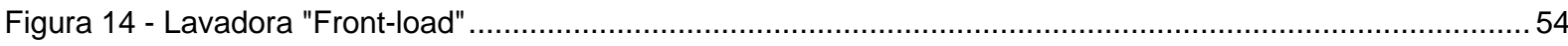

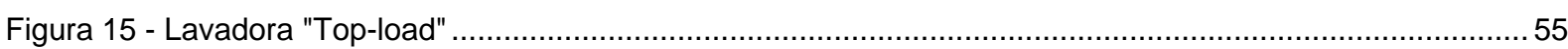

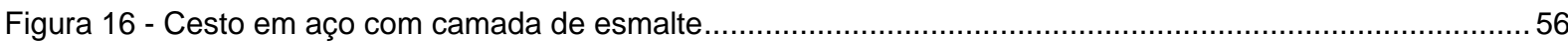

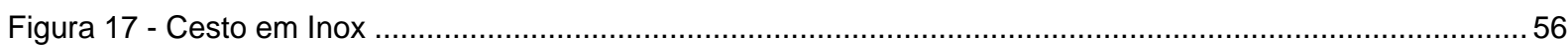

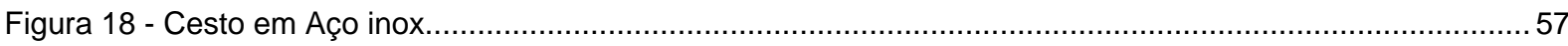

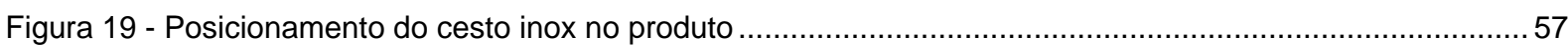

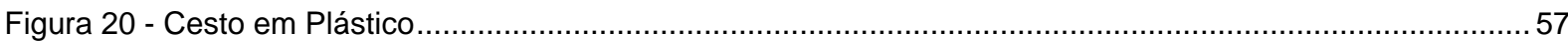

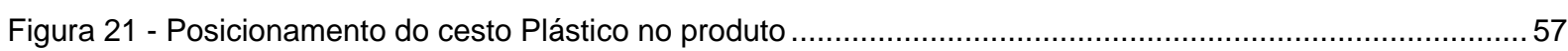

Figura 22 - Sistemas do Cesto Inox e Plástico............................................................................... 74 


\section{Lista de tabelas}

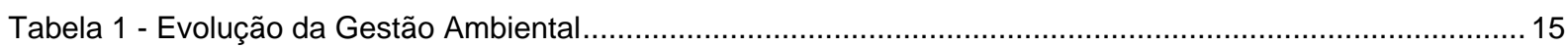

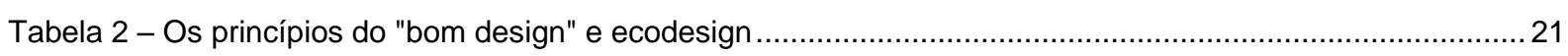

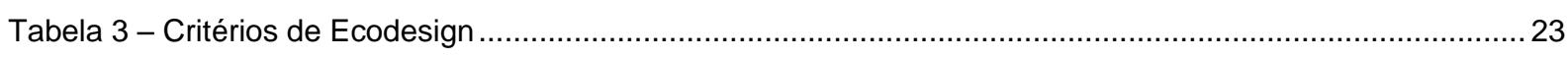

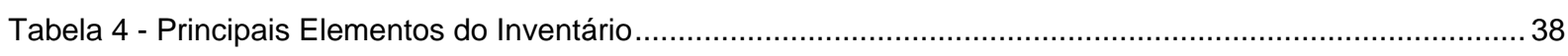

Tabela 5 - Quantidade de substâncias emitidas para atmosfera no ciclo de vida do cesto plástico ...................... 81

Tabela 6 - Quantidade de substâncias emitidas para atmosfera no ciclo de vida do cesto Inox ..........................81

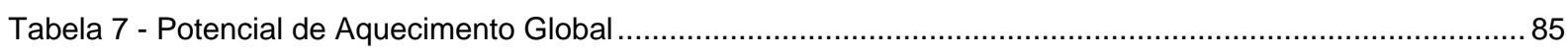

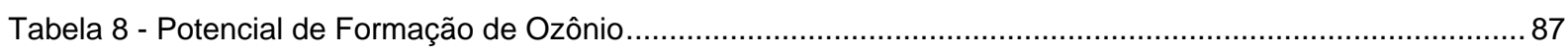

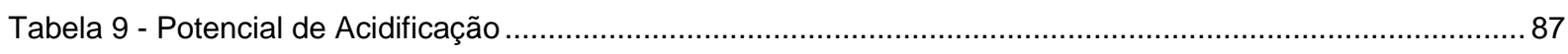

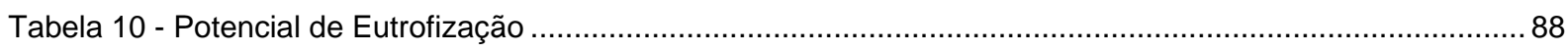

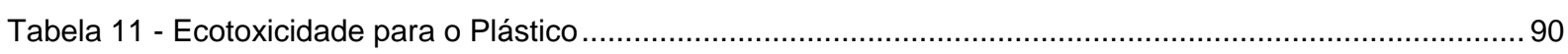

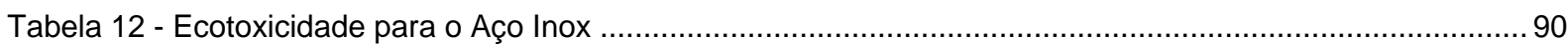

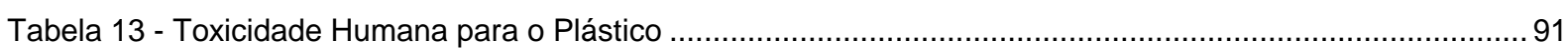

Tabela 14 - Toxicidade Humana para o Aço Inox ................................................................................ 91

Tabela 15 - Anexo A - Levantamento Bibliográfico para análise sistemática................................................... 124

Tabela 16 - Anexo B - Inventário do ciclo de vida do cesto plástico ........................................................... 129

Tabela 17 - Anexo C - Inventário do ciclo de vida do cesto inox ................................................................. 140 


\section{Lista de Gráficos}

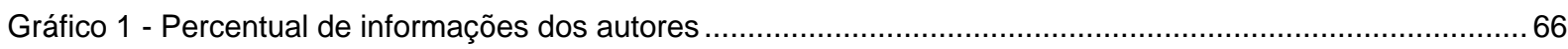

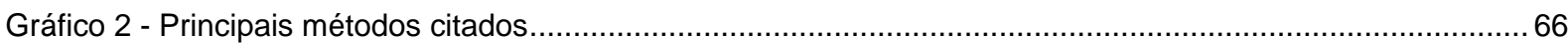

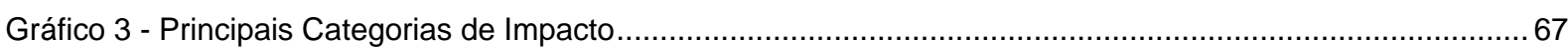

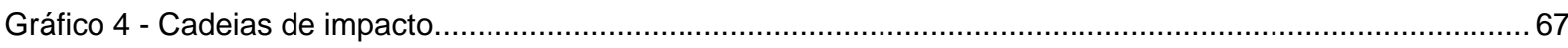

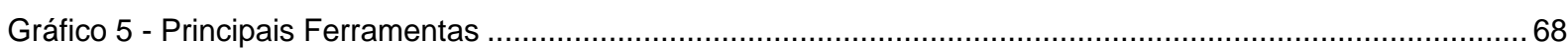

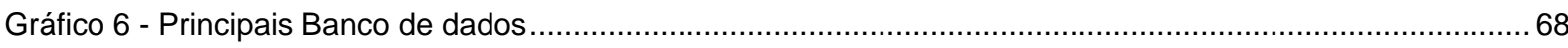

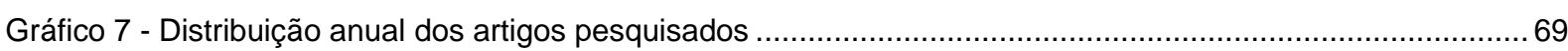

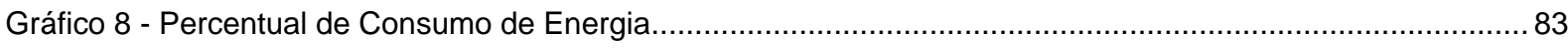

Gráfico 9 - Percentual de Consumo de Recursos Renováveis .................................................................. 83

Gráfico 10 - Percentual de consumo de Recursos Não Renováveis ........................................................... 84

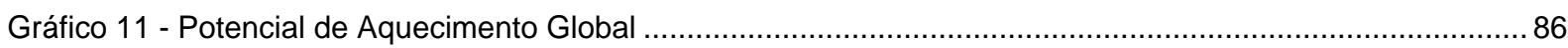

Gráfico 12 - Comparativo do Potencial de Formação de Ozônio Fotoquimico ..............................................8 87

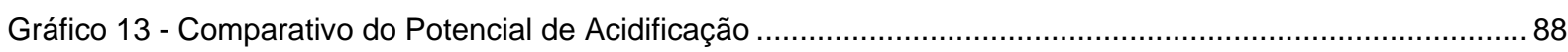

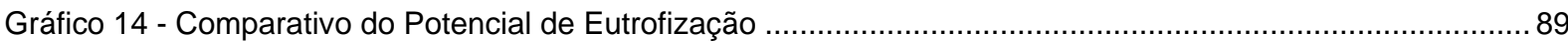


Sumário

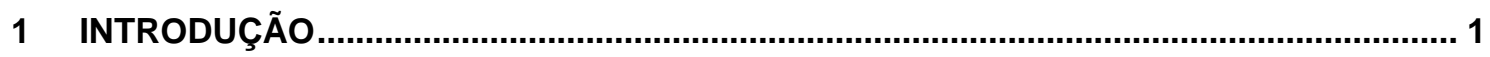

2 OBJETIVO

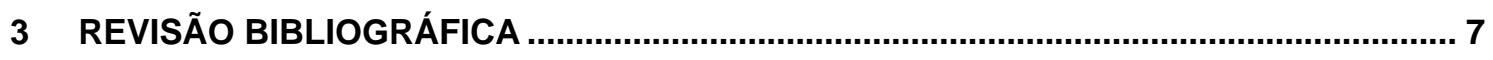

3.1 DESENVOLVIMENTO SUSTENTÁVEL E SUSTENTABILIDADE ........................................ 7

3.2 EVOLUÇÃO DA INTEGRAÇÃO DAS QUESTÕES AMBIENTAIS NO ÂMBITO EMPRESARIAL............. 14

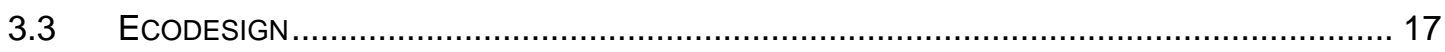

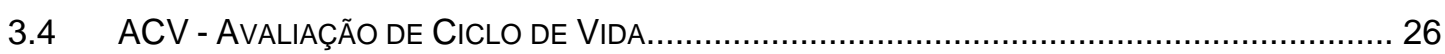

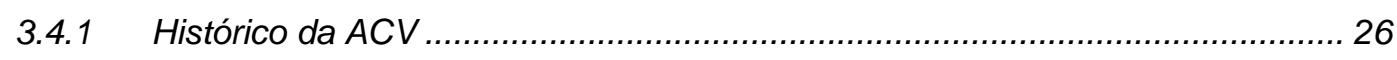

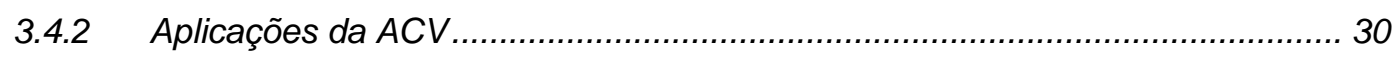

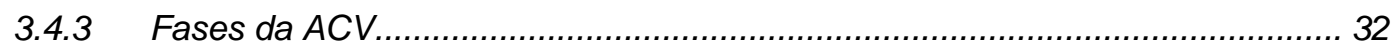

3.5 O OBJeto do Estudo de CASO: Cesto da LaVAdora de Roupa .................................. 47

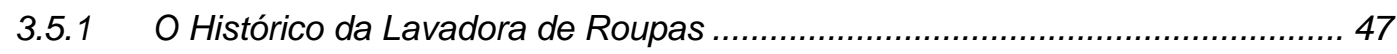

3.5.2 Características das Lavadoras de Roupa ................................................. 53

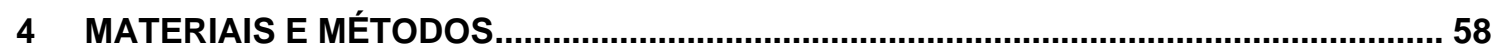

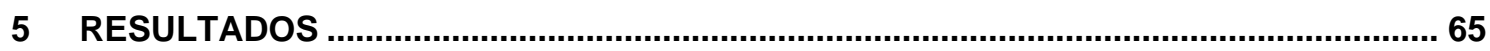

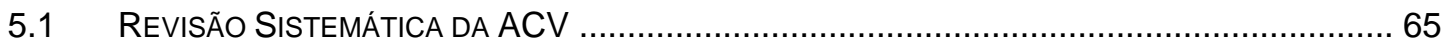

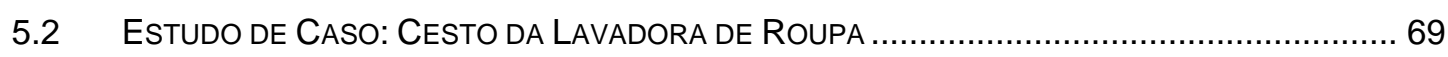

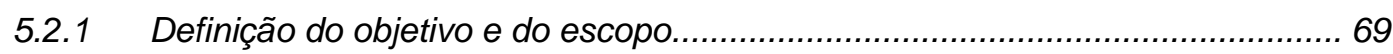

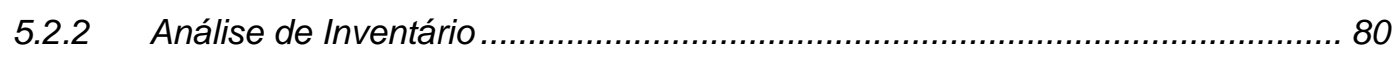

5.2.3 Avaliação de Impacto .......................................................................... 84

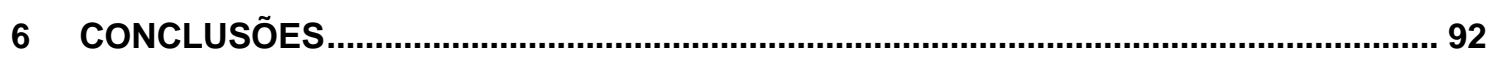

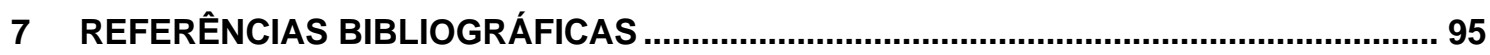

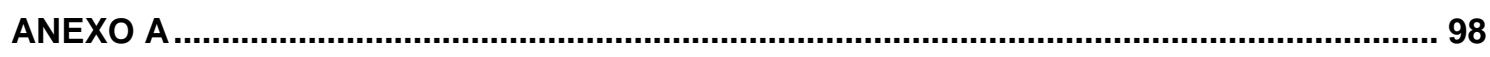

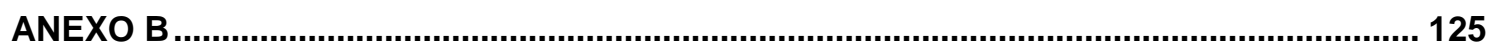

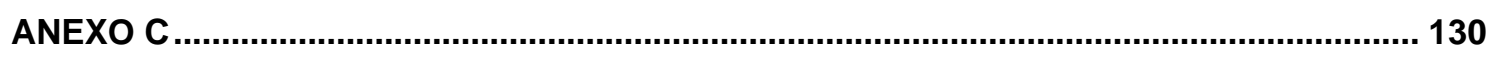




\section{Introdução}

O ritmo acelerado da economia atual obriga que as empresas mantenham os seus produtos atualizados e competitivos para o mercado, o qual retorna cada dia mais exigente. Para superar esses desafios, os produtos devem ser inovadores e constantemente melhorados, tudo isso se processa com uma velocidade tal que está forçando as empresas a se reestruturarem em várias frentes (SILVA, 2007).

As primeiras manifestações por mudanças foram determinadas pelo esgotamento dos recursos, como no caso da escassez da madeira para fundição do ferro, construção de moradias, fortificação, mobiliário, instrumentos, armas e combustíveis para aquecimento e preparação de alimentos, cuja exploração era intensiva desde a era medieval e as ações para reduzir a poluição somente foram iniciadas a partir da Revolução Industrial (BARRETO et. al, 2007).

A integração entre os aspectos econômicos e ambientais para os produtos vem sendo considerado um desafio para as empresas, as quais buscam produzir sem comprometer o meio ambiente, ou seja, promover o desenvolvimento sustentável.

O termo desenvolvimento sustentável foi utilizado pela primeira vez em 1987, no relatório de Brundtland, produzido pela ONU. O termo foi definido como o desenvolvimento que satisfaz as necessidades do presente, sem comprometer a capacidade das futuras gerações de satisfazerem suas próprias necessidades (BRUSEKE, 1995).

O desenvolvimento sustentável, segundo Souza (2000), pode ser realizado por meio de aplicação de instrumentos legais ou pela exigência do mercado consumidor adquirindo produtos ambientalmente adequados. Esta demanda torna o aspecto ambiental uma oportunidade competitiva e uma estratégia de negócio. 
Para colocar este conceito em prática, as empresas devem buscar reduzir os impactos ambientais de suas atividades, como a redução de emissão dos resíduos para o meio ambiente e o uso de recursos naturais não renováveis, além de promover o desenvolvimento econômico e social.

Segundo a ISO 14062 (2004), muitas organizações já estão se conscientizando da importância e dos benefícios da integração dos aspectos ambientais no projeto e desenvolvimento do produto. Entre alguns dos benefícios identificados, está a redução de custos com a utilização de materiais mais baratos ou redução na massa de componentes, estímulo a inovação de novas alternativas, oportunidades de novos negócios e melhoria na qualidade dos produtos.

As etapas iniciais do desenvolvimento de um produto são as mais importantes para que as questões ambientais sejam consideradas, em todas as diferentes etapas do ciclo de vida ${ }^{1}$ do produto, podendo identificar os potenciais impactos ambientais que o produto possa gerar. No Processo de Desenvolvimento do Produto (PDP), as decisões adotadas têm efeito direto em todo ciclo de vida do produto (BHANDER et. al., 2003)

Considerar potenciais impactos ambientais ao longo do ciclo de vida do produto significa incorporar uma noção de limites em relação à capacidade da natureza, tanto para fornecer recursos quanto para receber rejeitos (MALAGUTI, 2005).

Segundo Wenzel et.al. (1997), o envolvimento das considerações ambientais no desenvolvimento do produto, deveriam ser tratadas da mesma forma que outras considerações, como custo, qualidade, facilidade de montagem e estilo.

\footnotetext{
${ }^{1}$ Segundo a NBR ISO 14040 (2001), ciclo de vida é composto pelos estágios sucessivos e encadeado de um sistema de produto, desde a aquisição da matéria-prima até a disposição final.
} 
Além disso, com a globalização dos mercados, mudanças de fornecedores, fabricação e distribuição influenciam toda a cadeia de suprimentos, resultando em impactos ambientais, que devem ser considerados já no desenvolvimento do produto (ABNT ISO/TR 14062; 2004).

Para que isso seja possível, as empresas devem introduzir metodologias como a Avaliação do Ciclo de $\operatorname{Vida}^{2}(\mathrm{ACV})$, para contribuir na tomada de decisões funcionando como um instrumento proativo na prevenção dos impactos ambientais.

A melhoria de qualidade e a importância da proteção ambiental e os possíveis impactos associados aos produtos, ambos manufaturados e consumidos, foram aumentando o interesse em desenvolver métodos para melhorar a compreensão e identificação desses impactos. Uma dessas técnicas desenvolvida para este propósito é a Avaliação do Ciclo de Vida - ACV (ISO 14040, 2006)

As origens da ACV remontam ao final doa anos 60 e começo dos anos 70 , quando estudos ambientais aplicados a perspectiva do ciclo de vida foram usados para estimar o impacto ambiental, neste caso, a companhia Coca-Cola realizou em 1969 um estudo para comparar o consumo de recursos e o lançamento ambientais associados aos recipientes de bebida (JENSEN et al.,1997).

O primeiro guia para a ACV foi publicado em 1993, chamado de "Código de Prática" e desenvolvido por um grupo de trabalhadores na Society of Environmental Toxicology and Chemistry (SETAC), colocando a ACV como um termo amplamente aceito e como uma técnica para avaliar a performance ambiental de produtos. Mais tarde, o "Código de Prática" foi substituído por um conjunto de padrões

\footnotetext{
${ }^{2}$ A avaliação do ciclo de vida (ACV), é a compilação e avaliação das entradas, das saídas e dos impactos ambientais potenciais de um sistema de produto ao longo do seu ciclo de vida (NBR ISO 14040, 2001).
} 
internacionais desenvolvido pela International Organization for Standardization (ISO) (JENSEN et al.,1997).

A ACV conforme a NBR ISO 14040 (2001), é uma técnica para avaliar os aspectos ambientais e os potenciais impactos ambientais ao logo do ciclo de vida do produto através da compilação de um inventário de entradas e saídas pertinentes ao sistema do produto.

Para se formalizar um estudo de ACV, a ISO 14040 (2001) estabelece quatro fases, a definição do objetivo e do escopo, a análise de inventário, a avaliação do impacto e a interpretação dos resultados.

A utilização desta técnica de Avaliação de Ciclo de Vida pode ajudar na identificação de oportunidade de melhoria de produtos e processos, na tomada de decisões, na seleção de indicadores e no marketing, pois a ACV é muito aplicada para quantificar impactos ambientais gerados durante o ciclo de vida do produto e é para comparar produtos funcionalmente semelhantes (ISO 14040, 2001).

As características ambientais estão ganhando espaço dentro dos fabricantes dos produtos de linha branca e se tornando fatores influentes nas tomadas de decisões quanto às características dos produtos.

Um exemplo é o selo PROCEL ${ }^{3}$ que tem por objetivo orientar o consumidor no ato da compra, indicando os produtos que apresentam os melhores níveis de eficiência energética dentro de cada categoria, proporcionando assim economia na sua conta de energia elétrica. Também estimula a fabricação e a comercialização de produtos mais eficientes, contribuindo para o desenvolvimento tecnológico e a preservação do meio ambiente (ELETROBRÁS, 2009).

\footnotetext{
${ }^{3}$ Selo Procel foi desenvolvido e concedido pelo Programa Nacional de Conservação de Energia Elétrica, coordenado pelo Ministério de Minas e Energia - MME (ELETROBRÁS, 2009)
} 
A maioria dos fabricantes de lavadora de roupa possui produtos com o cesto de roupa em dois materiais; em aço inox ou plástico. A escolha do material é feita pelo produtor baseando-se nos aspectos mercadológicos como, família de produtos, público alvo, custo de venda etc.

Para o desenvolvimento desta dissertação, o trabalho está dividido em: Introdução, objetivo, revisão bibliográfica, materiais e métodos, resultados e conclusões.

O trabalho desenvolvido para esta dissertação de mestrado está na interface das áreas de atuação de dois grupos de pesquisa do Núcleo de Manufatura Avançada (NUMA), do Departamento de Engenharia de Produção, da Escola de Engenharia de São Carlos, (EESC), Universidade de São Paulo (USP), que atuam sinergicamente: o Grupo de Engenharia do Ciclo de Vida (ECV), que busca analisar e melhorar o ciclo de vida dos produtos de forma a minimizar os seus impactos ambientais em busca da sustentabilidade; e o Grupo de Engenharia Integrada e Engenharia de Integração (El2), que trata da gestão do processo de desenvolvimento de produtos (GDP) e da gestão do ciclo de vida de produtos (PLM - product life-cycle management). 


\section{Objetivo}

Os objetivos gerais do trabalho são analisar os principais métodos de ACV e realizar um estudo de caso comparativo entre os cestos de uma lavadora de roupa, produzidos de aço inox e de plástico. Os objetivos específicos são:

- Identificar os principais métodos de ACV e suas características principais;

- Analisar os principais métodos de ACV de acordo com suas características;

- Definir o objetivo e escopo para o estudo de caso;

- Realizar a análise do inventário para o estudo de caso;

- Realizar a avaliação dos impactos do ciclo de vida para o estudo de caso. 


\section{Revisão Bibliográfica}

Este capítulo tem como objetivo indicar os principais temas abordados pelas referências disponíveis na literatura, sobre desenvolvimento sustentável, a evolução da integração das questões ambientais no âmbito empresarial, o Ecodesign, Avaliação do Ciclo de Vida (ACV) e o objeto de estudo de caso que é o cesto da lavadora de roupa.

\subsection{Desenvolvimento Sustentável e Sustentabilidade}

O conceito de desenvolvimento sustentável foi introduzido no debate internacional pelo documento do World Commission for Environment Our Common Future. Esta foi a base da conferência da UNCED (United Nations Conference on Environment and Development), que se desenvolveu no Rio de Janeiro em 1992 (MANZINI E VEZZOLI, 2002).

O objetivo do desenvolvimento sustentável é "satisfazer as necessidades do presente sem comprometer a capacidade das gerações futuras de suprir suas próprias necessidades". Como forças fundamentais na sociedade, as organizações de todos os tipos têm um papel importante a desempenhar em seu alcance (GRI, 2006).

O desenvolvimento sustentável, além de equidade social e equilíbrio ecológico, segundo Donaire (1999), apresenta, como terceira vertente principal, a questão do desenvolvimento econômico. Induz um espírito de responsabilidade comum como processo de mudança no qual a exploração de recursos materiais, os investimentos financeiros e as rotas do desenvolvimento tecnológico deverão adquirir sentidos harmoniosos. Neste sentido, o desenvolvimento da tecnologia deverá ser orientado para metas de equilíbrio com a natureza e de incremento da capacidade de 
inovação dos países em desenvolvimento, e o progresso será entendido como fruto de maior riqueza, maior benefício social eqüitativo e equilíbrio ecológico.

Um dos principais desafios do desenvolvimento sustentável é a exigência de escolhas inovadoras e novas formas de pensar. Se por um lado, o desenvolvimento de conhecimento e de tecnologia contribui para o crescimento econômico, por outro, também pode contribuir para solucionar os riscos e danos que esse crescimento traz à sustentabilidade de nossas relações sociais e do meio ambiente ${ }^{4}$.

Novos conhecimentos e inovações em tecnologia, em gestão e em políticas públicas cada vez mais desafiam as organizações a fazer novas escolhas em relação ao impacto de suas operações, produtos, serviços e atividades sobre as economias, as pessoas e o planeta (KATES, PARRIS, LEISEROWTZ, 2005).

A sustentabilidade tem sido talvez, o objeto de maior discussão desde o ECO92 por cientistas, políticos e pela sociedade em geral. Pode-se dizer que a preocupação com o desenvolvimento humano e a conservação teve seu primeiro marco em 1972 na Conferência das Nações Unidas sobre o Ambiente Humano em Estocolmo, mas o grande passo foi dado em 1992 na Conferência das Nações Unidas sobre Ambiente e Desenvolvimento no Rio de Janeiro ECO-92. Inicialmente o termo sustentabilidade era uma coisa vaga, depois foi tomando forma e ficando complexo e, às vezes, se torna difícil entendermos seu significado.

Segundo Chehebe (1997), durante a década de 80, deu-se início principalmente na Europa, a uma grande discussão entre os ambientalistas sobre a necessidade de estabelecimentos de novas políticas que analisassem a questão ambiental sob enfoque holístico e não mais centrado no sistema produtivo industrial. 
Durante o processo de fabricação, as emissões para o meio ambiente, decorrentes do transporte e da distribuição do produto, as emissões e a geração de resíduos durante a fase de utilização e finalmente, ao seu descarte após o uso que pode contaminar o solo gerando outros impactos ambientais (RAMOS, 2001).

Para Manzini e Vezzoli (2002), junto com outros fatores como custo, assistência ao consumidor, aspectos legais, culturais e estéticos, os requisitos ambientais devem ser levados em consideração desde a primeira fase do desenvolvimento do produto, pois é muito eficaz agir preventivamente, já no conceito do projeto, do que buscar soluções de recuperações para os danos já causados.

Nos desenvolvimentos globais, a sustentabilidade está em foco, como uma meta explícita. Mas o conceito tem que ser traduzido nas dimensões práticas da realidade do mundo para tornar isso operacional. Nós devemos reconhecer a presença ou ausência da sustentabilidade, ou de ameaças para sustentabilidade (BOSSEL,1999).

Como pode ser observado na Figura 01, Sachs (1993) apresenta cinco dimensões que o termo sustentabilidade envolve:

- Sustentabilidade social: onde a civilização se apresenta com maior equidade na distribuição de renda e de bens.

- Sustentabilidade econômica: envolve o gerenciamento e alocação mais eficiente dos recursos, proporcionando um fluxo constante de investimentos públicos e privados.

- Sustentabilidade ecológica: limita o consumo de combustíveis fósseis e de outros recursos esgotáveis. Objetiva-se a redução da geração de resíduos e de poluição, por meio da reciclagem, da conservação de energia e de recursos. 
- Sustentabilidade espacial: configura uma população rural/urbana mais equilibrada e uma melhor distribuição territorial dos assentamentos humanos e das atividades econômicas.

- $\quad$ Sustentabilidade cultural: para que os processos de modernização facilitem a geração de soluções específicas para a preservação do local, do ecossistema e da cultura.

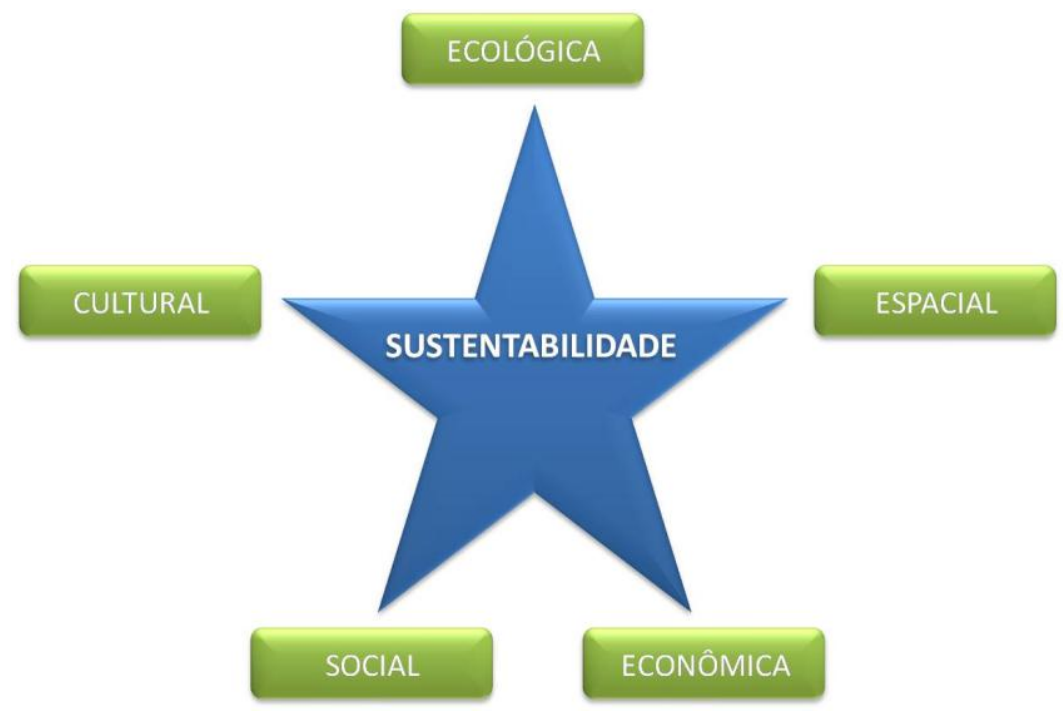

Figura 1 - Cinco dimensões da Sustentabilidade Fonte: Adaptado Sachs (1993), apud Millani (2007)

Hoje, a principal ferramenta de escolha de ações de empresas com responsabilidade social e ambiental é o Índice Dow Jones de Sustentabilidade (DJSI, em inglês Dow Jones Sustainability Group Index). O DJSI foi lançado em setembro de 1999 pela Dow Jones e a Sustainable Asset Management (SAM), gestora de recursos da Suíça especializada em empresas comprometidas com a responsabilidade social e ambiental (KRAEMER, 2003)

Os índices de sustentabilidade fornecem marcas de nível objetivas para os produtos financeiros que são ligados aos critérios econômicos, ambientais e sociais. Oferecem uma linha de base do desempenho como uma marca de nível e universo 
do investimento para o número crescente de fundos mútuos, de certificados e de outros veículos de investimento que são baseados no conceito de sustentabilidade.

As empresas que integram a lista do DJSI têm vários benefícios como:

- Reconhecimento público da preocupação com a área ambiental e social.

- Reconhecimento dos stakeholders importantes tais como: legisladores, clientes e empregados (por exemplo, conduzir a uma lealdade melhor do cliente e do empregado).

- Benefício financeiro crescente pelos investimentos baseados no índice.

- Os resultados altamente visíveis, internos e externos à companhia, como todos os componentes são anunciados publicamente pelo Boletim do Índice e a companhias são intituladas a usar "membro da etiqueta oficial de DJSI".

Verifica-se, portanto, que as empresas estão cuidando dos aspectos sociais e ambientais e muitas delas têm um ganho econômico e maior durabilidade a longo prazo, ou seja, o risco do investidor é menor.

O rápido desenvolvimento econômico traz impactos ambientais devido à falta de controle e manutenção dos recursos naturais. A conseqüência pode ser poluição, uso incontrolado de recursos como água e energia etc. Outras vezes as áreas são impactadas por causa do subdesenvolvimento que traz como conseqüência a ocupação urbana indevida em áreas protegidas e falta de saneamento básico.

Segundo Silva et.al. (2005), as diferenças entre desenvolvimento sustentável e sustentabilidade surgem como um processo em que o desenvolvimento sustentável se relaciona com o fim ou objetivo maior e a sustentabilidade com o meio. 
Desta forma, o desenvolvimento sustentável procura manter um equilíbrio entre o progresso, a industrialização, o consumo e a estabilidade ambiental e a sustentabilidade tem como objetivo o bem estar da sociedade.

De maneira geral, os impactos ambientais mais significativos encontram-se nas regiões industrializadas, que oferecem mais oportunidades de emprego e infraestrutura social, acarretando assim, as maiores concentrações demográficas.

A expressão "impacto ambiental" teve uma definição mais precisa, entre os anos 1970 e 1980, quando diversos países perceberam a necessidade de estabelecer diretrizes e critérios para avaliar efeitos adversos das intervenções humanas na natureza.

No Brasil, a obrigatoriedade do estudo prévio de impacto é uma imposição constitucional. A legislação básica sobre o Estudo de Impacto Ambiental (EIA) e Relatório de Impacto Ambiental (RIMA) é regida pelos documentos abaixo:

- Constituição Federal, art. 225, inciso IV, parágrafo primeiro;

- $\quad$ Lei no 6.803 , de 2 de julho de 1980 ;

- Lei no 6.938, de 31 de agosto de 1981 (art. 9o, III);

- Resolução Conama número 1, de 23 de janeiro de 1986;

- Resolução Conama número 9, de 3 de dezembro de 1987; e

- Resolução Conama número 1, de 13 de junho de 1988. 
Impacto ambiental é definido, segundo a resolução Conama número 1, de 23 de janeiro de 1986, como:

\begin{abstract}
"qualquer alteração das propriedades físicas, químicas e biológicas do meio ambiente causada por qualquer forma de matéria ou energia resultante das atividades humanas que, direta ou indiretamente, afetam: I. A saúde, a segurança e o bem-estar da população; II. As atividades sociais e econômicas; III. A biota; IV. As condições estéticas e sanitárias do meio ambiente; V. A qualidade dos recursos ambientais".
\end{abstract}

Segundo a ISO 14001 (2004), impacto ambiental é qualquer modificação do meio ambiente adversa ou benéfica, que resulte, no todo ou em parte das atividades, produtos ou serviços de uma organização.

Para cada ação do ser humano, há uma absorção de recursos naturais, e conseqüentemente acontece a liberação de agentes químicos e físicos para o meio ambiente.

Em outros termos, a extração dos recursos e a liberação de várias emissões determinam os impactos que não são absorvíveis pelo nosso ecossistema de uma forma que compromete o equilíbrio de sobrevivência da flora, da fauna bem como do próprio homem (MANZINI E VEZZOLI, 2002).

De um modo geral, segundo Wenzel et. al. (1997), os impactos podem ter os seguintes efeitos de extensão geográfica:

- $\quad$ Nível local, quando os efeitos estão no próprio lugar de produção, na rua ou em um depósito urbano;

- Nível regional, quando os efeitos se alargam em uma determinada área geográfica, por exemplo, a região vizinha às próprias regiões industriais;

- $\quad$ Nível global, como, por exemplo, as mudanças climáticas da terra. 
Para Torres (1997), mesmo os problemas ambientais sendo inúmeros, e suas causas também, para base de um estudo, os impactos mais relevantes devem ser separados previamente.

\subsection{Evolução da integração das questões ambientais no âmbito empresarial.}

A consciência ambiental surgiu nas décadas de 60 e 70, ganhou dimensão e situou o meio ambiente como um dos princípios fundamentais do Homem moderno. Nos anos 80 e 90, os gastos com proteção ambiental começaram a ser vistos pelas empresas líderes não como custos, mas como investimentos para o futuro e, também, como vantagem competitiva. Atitude e postura dos gestores das organizações em todos os segmentos econômicos nos anos 90 passaram de defensivas e reativas para ativas e criativas (CAMPOS, 2001).

As primeiras intervenções no âmbito ambiental se colocavam de fato como soluções pontuais e locais de cunho emergencial, dado um efeito indesejado das atividades humanas, tratava-se de neutralizá-lo sem intervir em suas causas, soluções definidas como end-of-pipe (MANZINI E VEZZOLI, 2002).

Para Manzini e Vezzoli (2002), as intervenções foram aos poucos sendo feitas nas tecnologias que geram os efluentes poluentes através de uma proposta de produção mais limpa, passando por uma redefinição dos produtos, propondo produtos mais limpos e a orientação da demanda que motiva a produção destes produtos, através de instrumentos econômicos e normativos, incentivando o consumo mais sustentável.

As discussões relacionadas ao meio ambiente normalmente não possuem um consenso, pois de um lado estão os ambientalistas desconfiados da eficácia das 
ações tomadas pelas empresas para reduzir os impactos gerados ao meio ambiente.

Do outro lado os empresários estão preocupados com as questões econômicas através da redução de custos e aumento nos lucros e entre os dois grupos estão as entidades reguladoras que geram as leis e fazem pouco para que estas leis sejam implementadas.

Desta forma, as empresas passaram de uma abordagem reativa, chegando a uma abordagem pró-ativa e sistêmica, no qual o meio ambiente passou a fazer parte das decisões estratégicas da empresa. De acordo com Moreira (2001) essa evolução pode ser sintetizada em três fases, conforme tabela 01.

\begin{tabular}{|c|c|c|}
\hline FASES & CARACTERISTICAS & POSTURAS BÁSICAS \\
\hline $\begin{array}{c}\text { 19 fase: antes dos anos } \\
1970\end{array}$ & Alienação & $\begin{array}{l}\text { Aceitação da idéia de que os } \\
\text { prejuízos ambientais devem ser } \\
\text { assumidos pela sociedade, em } \\
\text { favor do desenvolvimento } \\
\text { econômico. }\end{array}$ \\
\hline $\begin{array}{c}\text { 2ªse: décadas de } 1970 \text { e } \\
1980\end{array}$ & Gestão ambiental passiva & $\begin{array}{l}\text { Preocupação das empresas em } \\
\text { atender às exigências dos } \\
\text { órgãos ambientais. Criação de } \\
\text { departamentos ambientais } \\
\text { vinculados à área de produção } \\
\text { das empresas. }\end{array}$ \\
\hline $\begin{array}{l}3^{a} \text { fase: a partir dos anos } \\
1990\end{array}$ & Gestão ambiental pró-ativa & $\begin{array}{l}\text { Integração das questões } \\
\text { ambientais à estratégia do } \\
\text { negócio; gestão ambiental vista } \\
\text { como um diferencial } \\
\text { competitivo e um fator de } \\
\text { melhoria organizacional. }\end{array}$ \\
\hline
\end{tabular}
Fonte: Moreira (2001)

As organizações de todos os tipos estão cada vez mais preocupadas com o atendimento e demonstração de um desempenho ambiental correto, por meio do controle dos impactos de suas atividades, produtos e serviços sobre o meio ambiente, coerente com sua política e seus objetivos ambientais. Agem assim dentro de um contexto de legislação cada vez mais exigente, do desenvolvimento de políticas econômicas e outras medidas visando adotar a proteção ao meio ambiente 
e de uma crescente preocupação expressa pelas partes interessadas em relação às questões ambientais e ao desenvolvimento sustentável (NBR ISO 14001, 2004).

Muitas organizações têm efetuado "análises" ou "auditorias" ambientais para avaliar seu desempenho ambiental. Por si só, entretanto, tais "análises" ou "auditorias" podem não ser suficientes para proporcionar à uma organização a garantia de que seu desempenho não apenas atenda, mas continuará a atender aos requisitos legais e aos de sua política. Para que sejam eficazes, é necessário que esses procedimentos sejam realizados dentro de um sistema da gestão estruturado que esteja integrado na organização (NBR ISO 14001, 2004).

As normas de gestão ambiental têm por objetivo prover as organizações de elementos de um Sistema de Gestão Ambiental (SGA) eficaz que possam ser integrados a outros requisitos da gestão, e auxiliá-las a alcançar seus objetivos ambientais e econômicos (NBR ISO 14001, 2004).

Concluiu-se, ao longo do tempo, que seria necessário que essas comprovações de desempenho ambiental e de sua permanência e continuidade no tempo, fossem realizadas dentro de um sistema de gestão, estruturado nas organizações e a elas integrado (FIESP, 2007).

A ISO 14001 (2004) especifica os requisitos relativos a um Sistema de Gestão Ambiental (SGA) que uma organização deve levar em conta ao desenvolver e implementar uma política ambiental e cumprir os objetivos ambientais decorrentes.

Os requisitos são: o que é necessário fazer para se ter um SGA implementado e funcionando, cumprindo a política ambiental, praticando a prevenção da poluição e comprovando a melhoria contínua do desempenho ambiental, adotando-se a abordagem com inspiração nos sistemas de gestão da qualidade, foi concebido o 
formato fundamentado no chamado Ciclo PDCA - Planejar, Executar, Verificar e Agir (Plan, Do, Check, Act, em inglês) (FIESP, 2007)

Segundo Ometto (2005), tal postura pode compor o SGA da empresa, o qual pode ser baseado no processo ou no produto:

- Gestão do processo: controle e prevenção da poluição, por meio de técnicas de redução de perdas, de melhoria da eficiência, entre outras, aplicadas ao processo produtivo, conhecida como Produção mais Limpa $(\mathrm{P}+\mathrm{L})$;

- Gestão do produto: a gestão do produto baseia-se em minimizar não só a poluição durante a produção, mas todos os impactos ambientais associados ao ciclo de vida completo de um produto, desde a extração da matéria-prima, o beneficiamento, o transporte, a produção, a distribuição, o consumo, a reciclagem até a disposição final dos produtos.

Uma alternativa para o desenvolvimento industrial compatível com a qualidade ambiental desejada é através de uma mudança radical nos sistemas de produção, levando para dentro da empresa a responsabilidade ambiental, reprojetando os sistemas industriais para alcançar uma melhor qualidade ambiental e eficiência econômica. Desta forma, o desenvolvimento sustentável por intermédio da ecoeficiência tem se tornado lema de muitas empresas que descobrem as vantagens competitivas na conservação dos recursos naturais e consciência ambiental.

Dentro deste contexto surge o conceito de Projeto para o Meio Ambiente ou Ecodesign.

\subsection{Ecodesign}

Sem dúvida em primeiro nível de compreensão, a palavra ecodesign é dotada de uma boa capacidade auto-explicativa, pois o seu significado mais geral se 
destaca de maneira imediata dos dois termos que a compõem: ecodesign é um modelo de projeto (design), orientado por aspectos ecológicos (MANZINI E VEZZOLI, 2002).

Quando há a necessidade de um novo produto, os resultados para esta necessidade são as várias decisões que devem ser tomadas diante do principal conceito do produto, os detalhes do produto são discutidos e os problemas para seu funcionamento são resolvidos, neste momento as decisões ambientais significativas devem ser feitas (WENZEL et. al., 1997).

Bhander et. al. (2003) demonstra na figura 02, o paradoxo entre os graus de liberdade do projeto, as possibilidades de soluções ambientais e o nível de conhecimento do projeto.

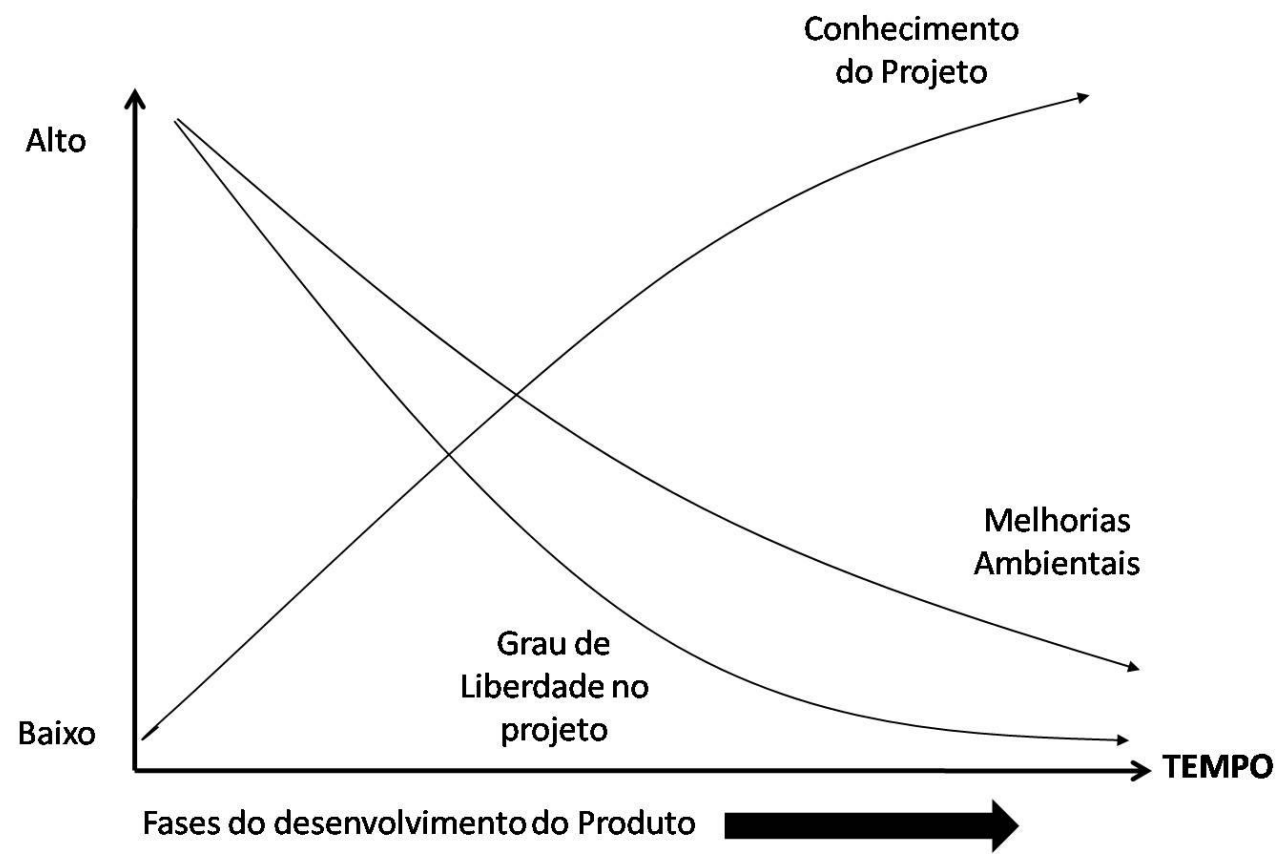

Figura 2 - Paradoxo entre o tempo do projeto e o grau de liberdade para as melhorias ambientais Fonte: Adaptado de Bhander et.al. (2003)

Com o passar do tempo e as fases do projeto, o grau de liberdade para as melhorias nas questões ambientais vão diminuindo, isso faz com que as melhorias 
mais significativas para o projeto devem ser feitas logo nas fases iniciais do desenvolvimento do produto.

Tendência dos materiais para serem selecionados com mais prudência e usados de forma mais eficiente, as considerações sobre os materiais alternativos ou fontes de energia é gerada dentro do projeto. Estas características nos produtos, que reduzem os impactos ambientais de todo o ciclo de vida de um produto, gerando ganhos de custo significativos através de redução de resíduos e facilidade no processo de manufatura (KURK e MCNAMARA, 2006).

Para Régis (2004), o ecodesign consiste no método de projetar, que visa evitar ou diminuir, os impactos ambientais. Não se trata apenas de "limpar", mas principalmente de "não sujar", levando-se isso em conta em todas as fases do projeto.

Segundo Kmita (2000), a introdução do ecodesign para o desenvolvimento de processo, deve seguir os seguintes passos:

Nível estratégico

- Organização de um projeto piloto;

- $\quad$ Seleção de um produto;

- $\quad$ Análise do problema e definir estratégias.

Nível operacional

- Geração e seleção de idéias;

- Desenvolver um conceito em detalhes;

- Planejar o marketing e a produção;

- Evolução e estabelecimento das atividades follow-up (acompanhamento). 
Portanto, podem-se utilizar modelos simplificados da ACV no início do desenvolvimento do produto, para utilizar a ACV completa quando as informações quantitativas do produto estiverem definidas.

Os produtos desenvolvidos a partir dos princípios do Ecodesign são produtos não só ecologicamente corretos, mas também economicamente, culturalmente e socialmente corretos. Tradicionalmente, o projeto de design busca satisfazer as necessidades do consumidor, e atender também o setor produtivo, usando um conjunto de requisitos de várias origens que determinam o desenho de um produto e o objetivo primário do Design é atender o mercado, criando produtos para venda (MARGOLIN, 2004).

Segundo Manzini e Vezzoli (2002), para o ecodesign, não basta apenas que sejam criados produtos mais adequados, do ponto de vista ambiental, tais propostas precisam ser atrativas social e culturalmente. Portanto fazer ecodesign não significa abrir mão dos critérios que compõem o "bom design". Na verdade muitos princípios do "bom design" incluem aspectos ligados ao ecodesign conforme mostrados na tabela 02.

\begin{tabular}{|c|c|}
\hline Bom Design & Ecodesign \\
\hline Emprego de materiais apropriados & $\begin{array}{l}\text { Uso sustentado e otimizado de recursos } \\
\text { naturais e energia }\end{array}$ \\
\hline Eficiência de fabricação & Redução e reciclagem do lixo \\
\hline Facilidade de uso e manutenção & $\begin{array}{l}\text { Redução de prejuízos ambientais pelo mau } \\
\text { uso do produto }\end{array}$ \\
\hline Aparência atrativa & Projeto da fase pós-uso \\
\hline Valor agregado & Proteção da biosfera \\
\hline Bom desempenho & Parâmetros excepcionais de desempenho \\
\hline
\end{tabular}


Para atender aos requisitos ambientais, no entanto, além dessas metas, deve haver outras metas específicas para que o produto seja ecoeficiente, e para se tornar operacional, o Ecodesign segue princípios ou critérios que permitem um desempenho ambiental otimizado. Diferentes critérios podem ser usados de maneira sistemática tal como visto na tabela 03:

\begin{tabular}{|c|c|}
\hline Critérios & Ações \\
\hline $\begin{array}{r}\text { Emprego de materiais } \\
\text { apropriados }\end{array}$ & $\begin{array}{l}\text { - Simplificação da forma; } \\
\text { - } \quad \text { Agrupar funções / multi-funcionalidade / multi-configuração / } \\
\text { modularidade; } \\
\text { - } \quad \text { Evitar super dimensionamentos; } \\
\text { - } \quad \text { Diminuir volume e peso; } \\
\text { - } \quad \text { Diminuir uso de água; } \\
\text { - Usar materiais vindos de fontes abundantes; } \\
\text { - Usar materiais abundantes e sem restrição de uso; } \\
\text { - } \quad \text { Reduzir o número de tipos de material de fabricação; }\end{array}$ \\
\hline $\begin{array}{r}\text { Redução do uso de } \\
\text { energia }\end{array}$ & $\begin{array}{ll}\text { - } & \text { Reduzir energia na fabricação; } \\
\text { - } & \text { Reduzir energia na utilização do produto; } \\
\text { - } & \text { Reduzir a energia no transporte; } \\
\text { - } & \text { Usar fontes de energia alternativas, renováveis e limpas; }\end{array}$ \\
\hline Redução de resíduos & $\begin{array}{l}\text { - Usar materiais reciclados e recicláveis; } \\
\text { - Usar materiais compatíveis entre si; } \\
\text { - Usar materiais que provenham de refugos de processos produtivos; } \\
\text { - Evitar material que produza emissões, resíduos ou efluentes tóxicos; } \\
\text { - Usar tecnologias e processos produtivos de baixo impacto e } \\
\text { ecoeficientes; }\end{array}$ \\
\hline $\begin{array}{l}\text { Aumentar a } \\
\text { durabilidade }\end{array}$ & $\begin{array}{ll}\text { - } & \text { Facilitar manutenção e substituição de peças; } \\
\text { - } & \text { Incentivar mudanças culturais (p. ex: descartável x durável); }\end{array}$ \\
\hline
\end{tabular}




\begin{tabular}{|c|c|}
\hline Projetar para o reuso & $\begin{array}{l}\text { - } \\
\text { - } \\
\text { - } \\
\text { - } \\
\text { - } \\
\text { Possibilidade mesmara reconhecer peças e materiais; } \\
\text { Projeto para revenda, redistribuição; }\end{array}$ \\
\hline $\begin{array}{l}\text { Projetar para a } \\
\text { remanufatura }\end{array}$ & $\begin{array}{l}\text { - Facilitar desmontagem; } \\
\text { - Possibilidade de ser recriado (re-design), sofrer adaptações } \\
\text { melhorias e atualizações tecnológicas; } \\
\text { - Projetar intercâmbio das peças; }\end{array}$ \\
\hline $\begin{array}{r}\text { Projetar para a } \\
\text { reciclagem }\end{array}$ & $\begin{array}{ll}\text { - } & \text { Facilitar desmontagem; } \\
\text { - } & \text { Identificar diferentes materiais; } \\
\text { - } & \text { Agregar valor estético aos materiais reciclados; }\end{array}$ \\
\hline Otimizar a logística & $\begin{array}{l}\text { - Projeto para facilitar transporte e armazenamento; } \\
\text { - Projeto para logística reversa, facilitando a recolha e transporte do } \\
\text { produto após o uso para reuso ou reciclagem; } \\
\text { - Projetar para que os produtos usem menos embalagem ou mesmo } \\
\text { não usá-las; } \\
\text { - } \quad \text { Produção na exata demanda do consumo; } \\
\text { - Trocar produtos por serviços; }\end{array}$ \\
\hline $\begin{array}{r}\text { Planejar o final da } \\
\text { vida útil dos produtos } \\
\text { e materiais }\end{array}$ & $\begin{array}{l}\text { - Utilizar materiais biodegradáveis e/ou compostáveis em produtos de } \\
\text { vida útil breve; } \\
\text { - Possibilidade de ser usado como matéria prima para outros } \\
\text { processos produtivos; } \\
\text { - Utilizar materiais que possam ser incinerados para a geração de } \\
\text { energia sem que produzam emissões tóxicas; }\end{array}$ \\
\hline Leis e normas & - $\quad$ Alcançar ou exceder metas regulatórias; \\
\hline $\begin{array}{r}\text { Projetar para a } \\
\text { sustentabilidade } \\
\text { sócio-ambiental }\end{array}$ & $\begin{array}{l}\text { - Preservar culturas, desenvolvendo produtos que preservem os } \\
\text { recursos culturais e naturais locais; } \\
\text { - Gerar trabalho e empregos; } \\
\text { - Buscar a manutenção de recursos humanos e econômicos nas } \\
\text { comunidades locais, principalmente em zonas mais pobres evitando o êxodo } \\
\text { para zonas ricas e populosas; } \\
\text { - Contribuir para a educação sócio-ambiental dos usuários e seus } \\
\text { vizinhos } \\
\text { - Ser benéfico à saúde dos seres vivos e do eco-sistema }\end{array}$ \\
\hline Diminuição de custos & $\begin{array}{l}\text { - Promover custos competitivos sendo alternativa a produtos similares } \\
\text { convencionais; }\end{array}$ \\
\hline
\end{tabular}


- Permitir ser testado nos mesmos parâmetros técnicos de produtos convencionais;

- Economizar custos finais da produção.

Tabela 3 - Critérios de Ecodesign

Fonte: baseado em Ramos e Sell (2002) e complementado por Manzini (2002); Morimoto (2001); Masui (2000); Lindbeck (1995); Lima e Filho (2002); Barbosa (2002), Sousa (2002), Kiperstok (2003); Leite (2003); Castilhos (2003), Júnior (2003), Rose (2002), Idhea (2004 apud Teixeira, 2005).

Manzini e Vezzoli (2002) citam quatro níveis fundamentais de interferência em produtos e/ou serviços para a aplicação do ecodesign.

- O redesign ambiental do existente: trata-se de melhorar a sua eficiência global em termos de consumo de matéria e energia, além de facilitar a reciclagem de seus materiais e a reutilização de seus componentes, considerando o seu ciclo de vida.

- Projeto de novos produtos ou serviços: trata-se de individualizar aqueles que oferecem os serviços ecologicamente mais favoráveis em relação aos demais.

- Projeto de novos produtos-serviços intrinsecamente sustentáveis: tratase de oferecer uma maneira mais sustentável, que busque a obtenção de resultados socialmente positivos e, ao mesmo tempo, radicalmente favoráveis o meio ambiente.

- Proposta de novos cenários que correspondam a "estilos de vida sustentáveis": trata-se, no caso, de desenvolver atividades no plano cultural que tendam a promover novos critérios de qualidade e, em prospectiva, modificar a própria estrutura da busca de resultados.

A consciência ambiental envolve igualmente a criação de uma imagem de marca positiva, tornar-se visível no mercado. A atual seleção de fornecedores dos maiores Fabricantes Originais de Equipamento (OEM's) considera o perfil ambiental do fornecedor. Para alguns consumidores, que estão mais conscientes para a 
proteção ambiental e que podem valorizar os produtos "ecológicos" pela sua maior eficiência, o valor "ecológico" pode representar maiores vendas.

Existem diversos rótulos ecológicos para certificar e comunicar as propriedades ambientais superiores dos produtos. Além da sua maior eficiência, os produtos ambientalmente concebidos oferecem maior segurança ao consumidor, são mais fiáveis e de melhor qualidade. Freqüentemente, as estratégias ambientais são tomadas pelas empresas como demasiado onerosas, mas na maioria dos casos, o ecodesign promove a redução de custos. Por exemplo, a redução do uso de materiais e geração de resíduos na produção de produtos, com menores consumos de energia, resulta em benefícios diretos para o fabricante, sem esquecer a redução dos riscos associados para os trabalhadores e a maior motivação destes mesmos.

Existe um elevado número de rótulos ecológicos estabelecidos em diferentes países, para diferentes grupos de produtos. No final do ano 2002, aproximadamente 10.000 produtos estavam incluídos pelos sistemas de rótulos nacionais Europeus, ou mesmo pelo rótulo Europeu (EU-flower). Na Alemanha, em 2004, cerca de 83\% dos consumidores conheciam o rótulo ecológico alemão (Anjo Azul). Destes, 49\% afirmavam que o Anjo Azul era importante na sua decisão de compra (TUKKER e EDER, 2000)

Os rótulos ecológicos são importantes, não apenas para os consumidores privados, mas também o são na decisão de compra no enorme setor de compras públicas, no qual as propriedades ambientais dos produtos desempenham um papel significativo. O preço, a funcionalidade e o nível de serviço estão no topo das decisões de compra, contudo, o fator "ecológico" pode ser o argumento adicional que decide em favor de determinada escolha. 
Questionados sobre a sua disponibilidade para pagar mais por um produto com características mais amigáveis para o ambiente, $10 \%$ dos consumidores alemães responderam "sem dúvida que sim", sendo que outros $53 \%$ se encontram disponíveis para pagar mais, de acordo com o estudo realizado pela German Federal Environmental Agency. Isto não significa que os produtos ambientalmente concebidos sejam necessariamente mais caros, de fato eles podem ser mais baratos, especialmente tendo em conta todos os custos do ciclo de vida (TUKKER e EDER, 2000)

O cumprimento da legislação é uma exigência e um motor para os esforços de melhoria ambiental. Contudo, a legislação não deve ser encarada como a única razão para as atividades ecológicas, dado que por si só não irá levar a estratégias inovadoras.

Nos últimos anos, a UE tem promovido diversas atividades visando a criação de legislação ambiental, que afeta especialmente a indústria elétrica e eletrônica. A legislação e as políticas de produto mais importantes são:

- $\quad$ IPP - Integrated Product Policy - Política Integrada de Produto

- $\quad$ EuP - Energy-using Products - Diretiva de Eco-Design de Produtos que utilizam Energia

- WEEE - Waste Electrical and Electronic Equipment - Diretiva de Resíduos de Equipamentos Elétricos e Eletrônicos

- RoHS - Restriction of the use of certain Hazardous Substances - Diretiva que restringe a utilização de determinadas Substâncias Perigosas

De acordo com o Environmental Management and Audit Scheme (EMAS) ou ISO 14001, os sistemas de gestão ambiental tradicionalmente estabelecem a 
ênfase, em medidas de produção mais limpa, contudo, existem sobreposições com o ecodesign. Assim, um sistema de gestão ambiental é um ponto de partida apropriado para se iniciar no processo de ecodesign de produtos.

Dispondo dos indicadores, pode estabelecer-se um benchmark de produtos. De forma a melhorar estes indicadores chave, as metas podem ser estabelecidas dentro do próprio sistema de gestão ambiental e este é também um primeiro passo na procura de melhoramentos ao nível do produto e do ecodesign. Contudo, deverá referir-se que este conjunto de indicadores baseados em unidades de produção não possui a perspectiva de ciclo de vida (TUKKER e EDER, 2000)

Para a aplicação do ecodesign, é necessária a utilização de métodos e ferramentas para obter resultados quantitativos, possibilitando analisar e confrontar os resultados obtidos para a escolha da melhor proposta. Segundo Manzini e Vezzoli (2002), dentre as metodologias a ACV - Avaliação do Ciclo de Vida é a mais segura e promissora.

\subsection{ACV - Avaliação de Ciclo de Vida}

\subsubsection{Histórico da ACV}

Os primeiros estudos sobre a ACV tiveram início de forma tímida durante a primeira crise do petróleo (meados da década de 60). De certa forma, o mundo despertou para a necessidade de uma melhor utilização dos recursos naturais. Foram realizados estudos para avaliar os processos produtivos, a fim de racionalizar o consumo energético, que ficaram conhecidos como Resource Environmental Profile Analysis - REPA.

Um dos primeiros estudos quantificando as necessidades de recursos, emissões e resíduos originados por diferentes embalagens de bebidas foi conduzido 
pelo "Midwest Research Institute" (MRI) para a Companhia Coca Cola em 1969. Este estudo nunca foi publicado devido ao caráter confidencial do seu conteúdo, sendo, no entanto utilizado pela companhia, no início dos anos setenta como um "input” nas suas decisões sobre embalagens (FERREIRA, 2004).

No final de 1972 o mesmo instituto (MRI) iniciou um estudo nas embalagens de cervejas e sumos, encomendado pela "U.S. Environmental Protection Agency" (USEPA), o qual marcou o início do desenvolvimento da ACV como se conhece hoje. A intenção da USEPA era examinar as implicações ambientais da utilização de embalagens de vidro reutilizáveis em vez de latas e garrafas não reutilizáveis, porque na altura as garrafas reutilizáveis estavam a ser rapidamente substituídas por embalagens não-reutilizáveis (FERREIRA, 2004).

Após um longo período de baixo interesse público em ACV, em 1984 o Laboratório Federal Suíço para Teste e Investigação de Materiais (EMPA) publicou um importante relatório com base no estudo "Balanço Ecológico de Materiais de Embalagem" iniciado pelo governo, que tinha como objetivo estabelecer uma base de dados para os materiais de embalagem mais importantes: alumínio, vidro, plásticos, papel, cartão e chapas de lata. O estudo também introduziu um método para normalizar e agregar emissões para o ar e para a água utilizando as normas (legislação) para aquelas emissões e agregando-as, respectivamente nos chamados "volume crítico de ar" e "volume crítico de água". De alguma forma, esta filosofia de avaliar os impactos ambientais foi mais tarde desenvolvida e refinada por Ahbe, Braunschweig e Müller-Wenk no relatório Metodologia dos Ecobalanços (FERREIRA, 2004).

O primeiro guia para a ACV foi publicado em 1993, e foi chamado de "Código de Prática", desenvolvido por um grupo de trabalho na Society of Environmental 
Toxicology and Chemistry (SETAC). O código de práticas colocou o ACV na agenda como um termo amplamente aceito como método para avaliar a performance ambiental dos produtos (TAKEDA, 2008).

A Organização Internacional para a Normalização (ISO) criou em 1992 um comitê técnico (TC 207/SC 5) tendo em vista a normalização de um número de abordagens de gestão ambiental, incluindo ACV. Até o momento foram publicadas as seguintes normas relacionadas com ACV:

- ISO 14040: 2006 Environmental management -- Life cycle assessment -Principles and framework (em vigor);

- ISO 14041: 1998 Environmental management -- Life cycle assessment -- Goal and scope definition and inventory analysis (substituída pela ISO 14044:2006);

- ISO 14042: 2000 Environmental management -- Life cycle assessment -- Life cycle impact assessment (substituída pela ISO 14044:2006);

- ISO 14043: 2000 Environmental management - Life cycle assessment -- Life cycle interpretation (substituída pela ISO 14044:2006);

- ISO 14044: 2006 Environmental Management - Life cycle assessment Requirements and guidelines (em vigor).

- ISO/TR 14049: 2000 Environmental management -- Life cycle assessment -Examples of application of ISO 14041 to goal and scope definition and inventory analysis

- ISO/TS 14048: 2002 Environmental management -- Life cycle assessment -Data documentation format 
- ISO/TR 14047: 2003 Environmental management -- Life cycle impact assessment -- Examples of application of ISO 14042

- ISO/TR 14062: 2002 Environmental management -- Integrating environmental aspects into product design and development.

A ABNT, a correspondente normativa da ISO no Brasil, apresenta normas:

- NBR ISO 14040: 2001 Gestão Ambiental - Avaliação do ciclo de vida Princípios e estrutura

- NBR ISO 14041: 2004 Gestão Ambiental - Avaliação do ciclo de vida Definição do objetivo e escopo e análise de inventário

- NBR ISO 14042: 2004 Gestão Ambiental - Avaliação do ciclo de vida Avaliação do impacto do ciclo de vida

- NBR ISO 14043: 2000 Avaliação do Ciclo de Vida - Interpretação do Ciclo de Vida

- NBR ISO 14048: 2002 Avaliação de Ciclo de Vida - Formato da Apresentação de Dados

O conceito de ciclo de vida tem-se estendido para além de um simples método para comparar produtos, sendo atualmente visto como uma parte essencial para conseguir objetivos mais abrangentes, tais como sustentabilidade. A interligação dos sistemas de produto, que não se limitam por fronteiras geográficas, requer que se continue a desenvolver a metodologia ACV a um nível internacional (FERREIRA, 2004). 


\subsubsection{Aplicações da ACV}

A ACV é uma das ferramentas mais utilizadas na aplicação do consumo sustentável, é aplicada para a verificação do impacto ambiental e para a identificação de oportunidades de melhorias ambientais (NOVAK, 2006).

O uso da ACV quantifica a geração de poluentes e consumo de matéria-prima nas etapas do ciclo de vida do produto, o uso desta metodologia é importante em face de apresentar uma decisão sobre os melhores rumos a serem seguidos do ponto de vista ambiental para um produto, processo ou atividade (NOVAK, 2006).

Segundo Ometto (2005), a ACV se apresenta como uma importante ferramenta para subsidiar as etapas do desenvolvimento do produto, a gestão da produção, o pós-uso, a logística convencional e a reversa, entre outras, a partir da compilação de informações e das avaliações técnicas.

Para Manzini e Vezzoli (2002), a ACV leva em consideração, particularmente, os impactos ambientais dos sistemas em estudo em âmbitos da saúde ecológica, da saúde humana e do esgotamento dos recursos naturais, sem considerar os fatores econômicos e sociais.

Segundo Takeda (2008), para as empresas, a ACV deve ser aplicada com o propósito de documentação ou como material estratégico no desenvolvimento de produtos com perspectiva de longo prazo, é importante que a ACV inclua reflexões sobre o perfil ambiental do produto.

Tratando da afirmação que a ACV deve ser utilizada no desenvolvimento de produtos com uma perspectiva a longo prazo, não há referências que indiquem um determinado período de vida útil do produto, para que se possa aplicar a ACV. 
Isso faz com que os pesquisadores e profissionais da área de desenvolvimento de produtos determinem um critério próprio para a utilização do ACV conforme o tempo estimado de vida útil do produto.

Uma questão que deve ser analisada é conseguir afirmar se há um período mínimo de vida útil dos produtos para a ACV ou ela deve ser aplicada a todos os produtos indiferentemente de sua via útil.

O termo "ciclo de vida" refere-se à maioria das atividades no decorrer da vida do produto desde a sua fabricação, utilização, manutenção e disposição final, incluindo a aquisição de matéria-prima necessária para a fabricação do produto, na figura 03, mostra os possíveis estágios do ciclo de vida que podem ser considerados em uma ACV com as típicas entradas e saídas.

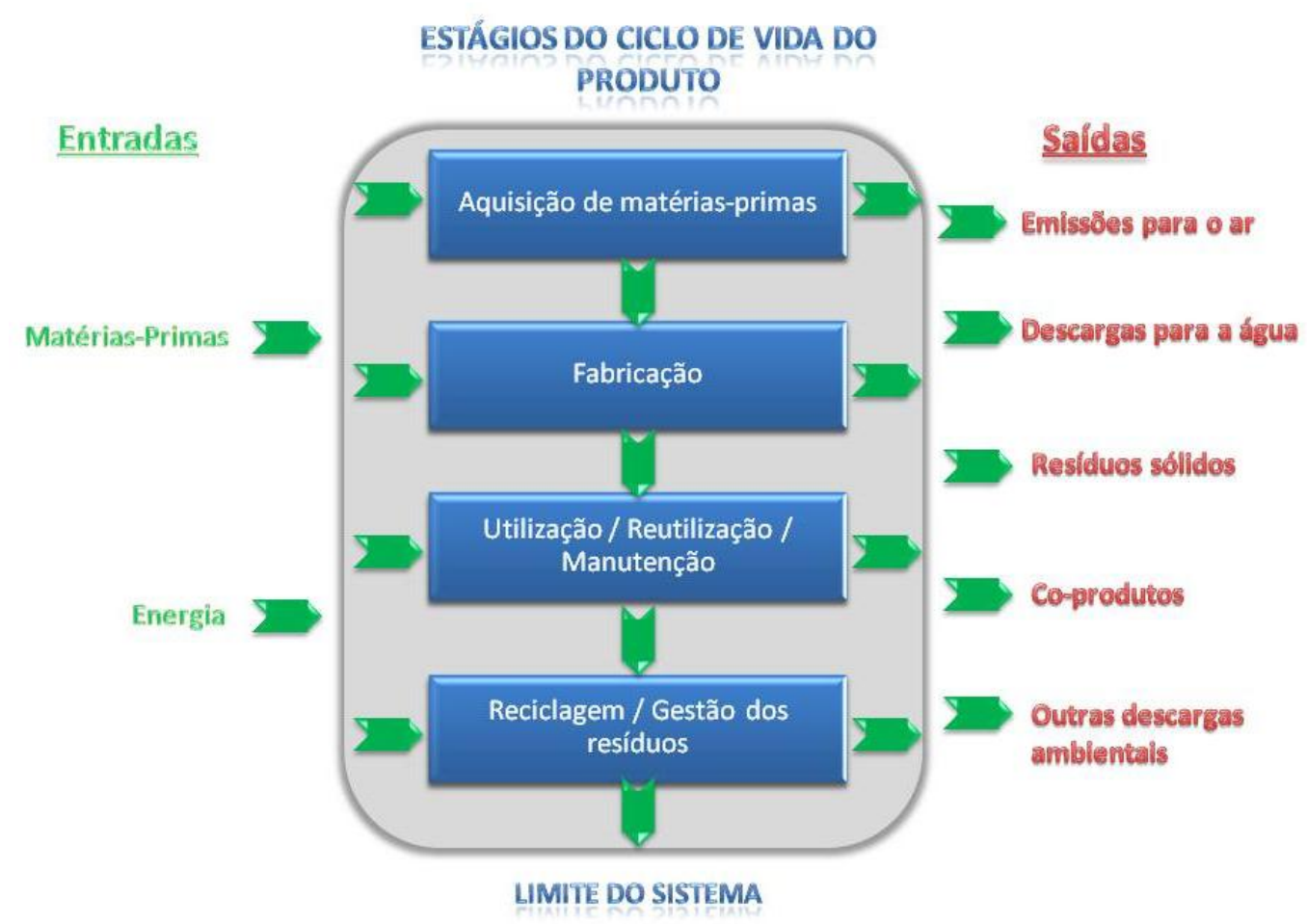

Figura 3 - Estágios do ciclo de vida do produto. Fonte: Adaptado de Ferreira (2004). 
Para que a ACV obtenha sucesso, em apoiar a compreensão ambiental de produtos, é essencial que a ACV mantenha sua credibilidade técnica ao mesmo tempo em que proporciona flexibilidade, praticidade e efetividade de custo na sua aplicação. Isto é particularmente verdadeiro se pretende aplicar ACV no âmbito nas pequenas e médias empresas (ISO 14040, 2001).

\subsubsection{Fases da ACV}

O estudo da ACV conforme ISO 14040 (2001) possui quatro fases conforme ilustração da figura 04.

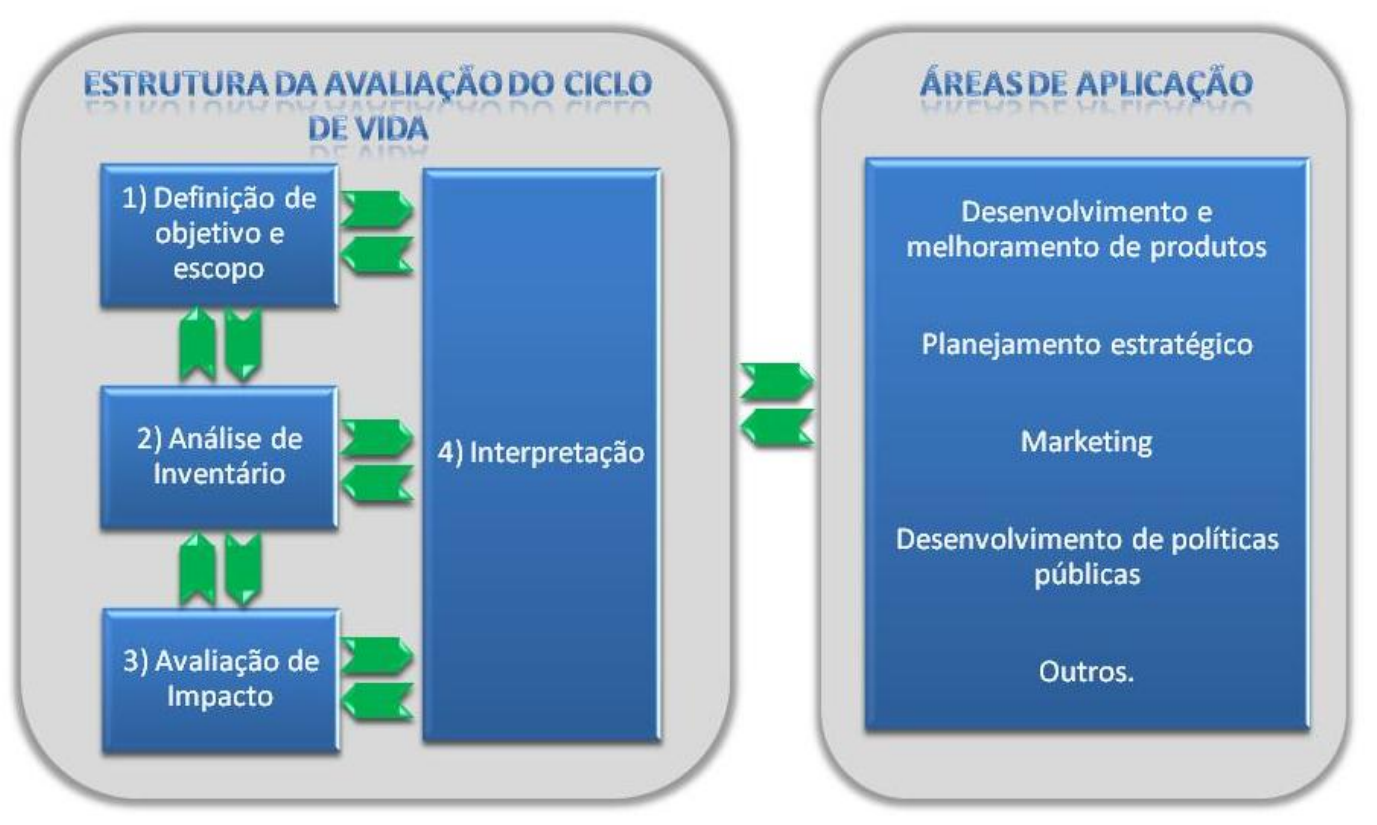

Figura 4 - Fases da ACV e áreas de aplicação Fonte: Adaptação ISO 14040:2006

\subsubsection{Definição do Objetivo e do escopo}

Deve ser definido claramente e de forma consistente com a aplicação pretendida, o motivo da realização do estudo. O objetivo do estudo é descrito em termos de uma unidade funcional, um resumo dos processos relevantes e a metodologia aplicada também é descrita nesta parte do processo. 
É fundamental para a condução do estudo, embora pareça simples e óbvia esta fase é crucial para o sucesso da condução do estudo e para a sua relevância e utilidade. Isto envolve a definição da chamada "unidade funcional", o que pode não ser trivial, mas que está intimamente ligada ao uso, à finalidade do sistema de produto.

Segundo a NBR 14040 (2001), o objetivo e o escopo de um estudo da ACV devem ser consistentes com a aplicação pretendida e devem ser claramente definidas.

Segundo as normas contidas em ABNT (2001) e ABNT (2004a), além do objetivo do estudo claramente definido, o escopo deve apresentar, principalmente:

\section{Função do sistema}

Define a função do objeto do estudo, bem como suas características de desempenho.

\section{Unidade funcional}

Medida que define a quantifica das funções identificadas, um dos seus principais propósitos é estabelecer uma referência na qual os dados de entradas e saídas sejam padronizados (num sentido matemático). Assim, a unidade funcional deve ser claramente definida e mensurável, consistente com o objetivo e escopo.

\section{Fluxo de referência:}

Quantidade do produto necessária para cumprir a função expressa pela unidade funcional.

\section{Sistema de produto}


Conjunto de unidades de processo abordadas no estudo, conectadas material e energeticamente, que realizam uma ou mais funções definidas dentro do ciclo de vida.

\section{Fronteiras do sistema de produto}

Interface entre o sistema de produto e o meio ambiente. As fronteiras definem os processos elementares a serem incluídos no sistema de produto, recomenda-se que este seja modelado de tal forma que as entradas e saídas nas suas fronteiras sejam fluxos elementares. Para determinação das fronteiras, deve ser estabelecido um critério de corte (massa, energia ou relevância ambiental) que esteja de acordo com os objetivos do estudo.

A razão para dividir um sistema relacionado a um produto em unidades de processo é para facilitar a identificação das entradas e saídas.

A Avaliação do Ciclo de Vida (ACV) é uma técnica interativa. Durante o decorrer do estudo, em função de uma série de fatores, pode ser necessária a modificação do escopo do estudo.

\subsubsection{Análise do Inventário}

A Análise do Inventário refere-se à coleta de dados e ao estabelecimento dos procedimentos de cálculo para que se possa facilitar o agrupamento destes dados em categorias ambientais normalmente utilizáveis e comparáveis, de modo semelhante a um balanço contábil (ISO 14040, 2001).

Nesta fase são separadas as entradas (inputs) e as saídas (outputs), do sistema em análise, tendo como base o que já foi definido na fase anterior.

Os dados devem estar relacionados com a unidade funcional definida no objetivo e escopo do estudo de modo a identificar e quantificar os recursos 
necessários para o produto e seu processo produtivo que está sendo avaliado e suas emissões para o ambiente.

Seguindo as normas contidas na ABNT (2004a), o procedimento para obtenção dos dados que compõe o inventário deve seguir os seguintes passos:

Preparação para a coleta de dados, que inclui:

- Desenho do diagrama de fluxos do processo, incluindo todas as unidades de processo que serão modeladas, inclusive inter-relacionamentos;

- Descrição detalhada de cada unidade de processo e listagem das categorias de dados associadas a cada unidade de processo;

- $\quad$ Listagem definindo as unidades de medida;

- Descrição das técnicas de coleta de dados e de cálculos para cada categoria de dados;

- Definição de instruções para casos especiais, irregularidades etc;

Procedimentos de cálculo, que inclui:

- Validação dos dados;

- Relacionar os dados com as unidades de processo;

- Relacionar os dados com a unidade funcional;

- Agregação dos dados;

- Refinamento das fronteiras do sistema;

Alocação dos fluxos e emissões, em caso de mais de um produto. 
Para Manzini e Vezzoli (2002), após ter definido o sistema e os seus limites, e descrito os processos, passa-se para a fase de tratamento de dados. Esta parte é caracterizada pelas seguintes atividades:

- Recolhimento de dados;

- Definição dos procedimentos de cálculo;

- Construção das tabelas de levantamento;

- Análise de sensibilidade da variabilidade dos dados;

- Definição das omissões deliberadas.

Por fim, são definidos os processos relativos a:

- Co-produtos;

- Processo de tratamento de lixo;

- Reciclagem.

Considera-se nessa fase que tudo que entra deve ser igual ao que sai do sistema em estudo, em termos de energia ou massa, desde a extração das matérias-primas até o descarte final do produto.

Esta fase da Avaliação do Ciclo de Vida pode-se tornar uma das mais difíceis e trabalhosas, em função da não disponibilidade de dados, da qualidade dos dados disponíveis ou da necessidade de estimá-los.

Portanto, deve-se levar em consideração:

- A necessidade de uma estratégia cuidadosa na preparação para a coleta de dados;

- A coleta de dados; 
- O refinamento dos limites do sistema;

- A determinação dos procedimentos de cálculo, e;

- Os procedimentos de alocação.

Como essas atividades devem ser realizadas em acordo com o objetivo e o escopo do produto, a figura 05 mostra as etapas que devem ser realizadas durante esta fase:

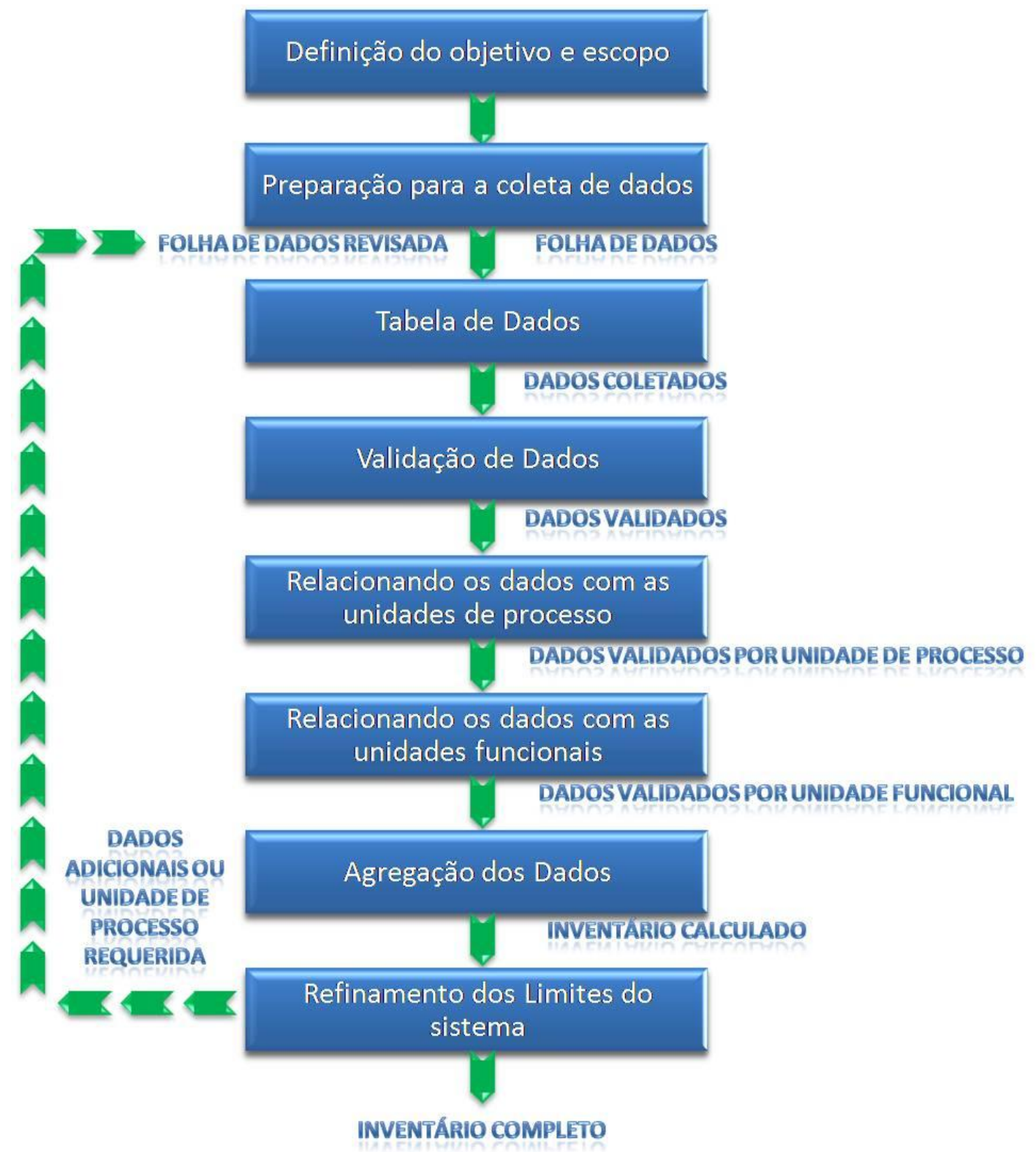

Figura 5 - Procedimento para análise do inventário Fonte: ISO 14040 (2006) 
O processo de coleta dos dados para o inventário, é iterativa, à medida que os dados são conhecidos e mais informações são levantadas, novos requisitos de dados ou limitações podem ser identificados, exigindo uma alteração nos procedimentos para coleta dos dados, ou até mesmo nos próprios objetivos dependendo dos pontos identificados durante a coleta de dados.

Segundo Takeda (2008), esta fase provavelmente é a que consome mais tempo, no qual os dados são tratados e coletados e os principais elementos desta fase estão descritos na tabela 04.

\section{Análise do Inventário do Ciclo de Vida - Principais Elementos}

Aquisição dos dados:

- Descrição do processo;

- Aquisição de dados quantitativos e qualitativos para trocas relevantes associadas ao sistema
Tratamento e descrição dos dados:

- Tratamento de dados (relacionados à unidade funcional);

- Avaliação da Qualidade dos dados;

- Apresentação e discussão dos resultados (opcional).

\section{Tabela 4 - Principais Elementos do Inventário}

Fonte: Adaptado Takeda (2008)

\subsection{Aquisição de dados}

Segundo Ferreira (2004), para a análise do inventário deve ser coletado dado quantitativo e qualitativo para cada processo unitário que esteja incluído dentro dos limites do sistema.

A coleta de dados é feita através de dois tipos de fluxos, de entrada e de saída conforme ilustrado na figura 06. 


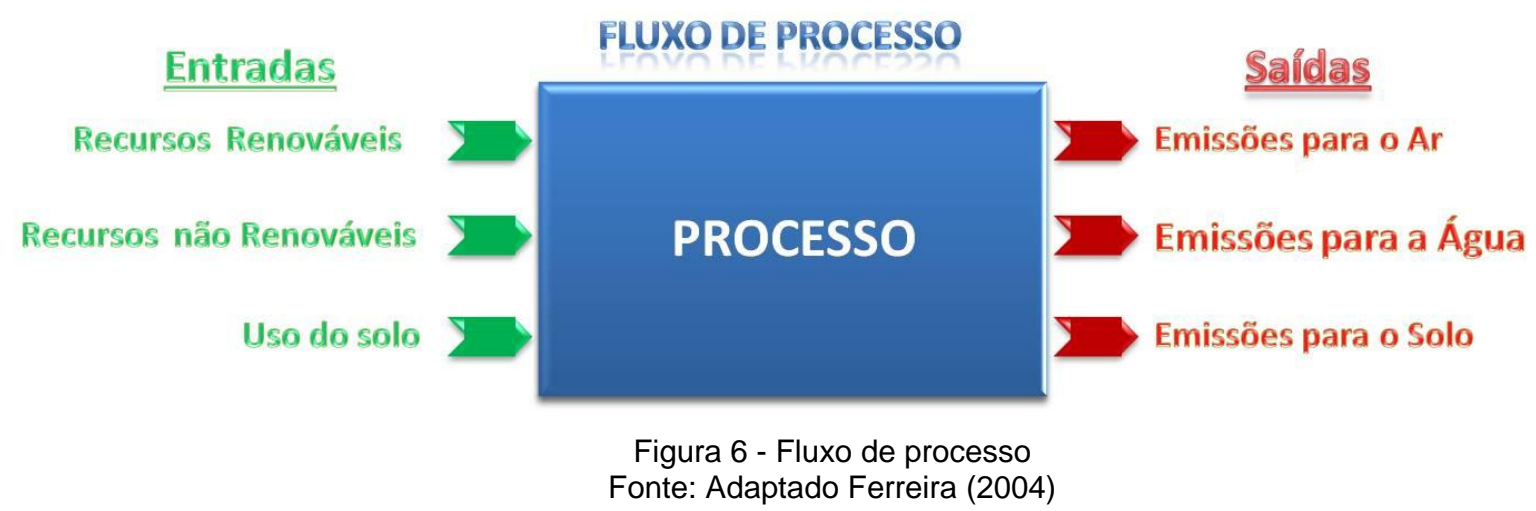

\subsubsection{Avaliação dos impactos do Ciclo de Vida}

A Avaliação do Impacto refere-se à identificação e avaliação em termos de impactos potenciais ao meio ambiente que podem ser associados aos dados levantados no inventário.

Segundo Takeda (2008), a Avaliação de Impacto do Ciclo de Vida, consiste em diferente sub-etapas, onde as informações do inventário são agregadas em pontos por efeitos, utilizando fatores de equivalência. Esta é uma etapa obrigatória em qualquer ACV, segundo a ISO 14042 (2004), chamada de classificação / caracterização.

Segundo Millani (2007), nesta fase as diversas intervenções ambientais são agrupadas e convertidas em impactos ambientais potenciais. Além disso, esses impactos potenciais podem ser comparados pela aplicação de pesos. O primeiro elemento na análise (determinação) dos impactos é a caracterização das intervenções ambientais em relação aos tipos de impactos ambientais conhecidos.

As categorias de impactos abordadas neste estudo e os modelos de caracterização para o método EDIP são indicados por Wenzel et. al. (1997). Na fase de Avaliação de Impacto, o inventário é traduzido em potenciais contribuições, de 
acordo com os impactos relativos ao ambiente estudado, baseado especialmente no consumo de recursos e nas emissões ao meio.

Segundo Wenzel et. al. (1997), o efeito dos impactos são mensurados em uma escala local, regional e global. Impactos de efeito local são aqueles que apresentam influência num raio de poucos quilômetros de sua fonte geradora; impactos regionais causam efeitos num raio de 100 a 1000 quilômetros, dependendo da natureza do impacto e da sensibilidade do ambiente; impactos de escala global têm influência em todo planeta, essas substâncias são emitidas em grandes quantidades e geralmente apresentam alta mobilidade e vida longa no ambiente.

Os impactos de ambientais de efeito local, são aqueles que ocorrem sobre fontes individuais significativas, são limitados pela vizinhança imediata da fonte da influencia do impacto, onde o efeito no máximo abrange o raio de alguns quilômetros (WENZEL et al., 2001).

Os impactos regionais causam efeitos em um raio entre 100 e 1000 quilômetros, isto está diretamente relacionado com a natureza do impacto e da sensibilidade do ambiente. Os impactos regionais podem ter origem de fontes difusas, isto é não podem ser rastreados até que seja identificado um ponto especifico gerador (WENZEL et al., 2001).

Os impactos globais são os que influenciam toda a Terra, e as substâncias que causam impactos de efeitos globais apresentam as seguintes características:

- Vida longa no ambiente, com alta dispersão antes de serem degradados ou dispersados;

- Alta mobilidade no ambiente, atingindo todas as partes do ambienta global. 
As substâncias de efeito global são, freqüentemente, emitidas em grandes quantidades, podendo apesar de sua diluição durante a dispersão causar efeitos sentidos globalmente.

A explicação de cada categoria de impacto para os insumos é dada a seguir: Consumo de Recursos renováveis e não renováveis

Os recursos são utilizados na maioria das vezes como matéria-prima para a transformação de materiais e este processo envolve energia, e a liberação de substâncias. Os recursos são classificados em renováveis e não renováveis (WENZEL et al., 2001).

Os recursos renováveis são aqueles que podem ser regenerados, e que não são esgotados pela exploração humana, dependendo da freqüência e o processo de extração (WENZEL et al., 2001).

Os recursos não-renováveis são os que não são regenerados, ou que são regenerados a uma taxa praticamente insignificante frente à sua quantidade disponível (WENZEL et al., 2001).

\section{Consumo de Energia}

Os impactos gerados pelo consumo de energia dependem da forma que esta energia esta sendo usada e gerada (WENZEL et al., 2001).

A explicação de cada categoria de impacto para emissões é dada a seguir:

\section{Potencial de aquecimento global}

Segundo Wenzel et al. (1997), a atmosfera da Terra absorve parte da energia emitida como radiação infravermelha e se esquenta. Tal efeito de aquecimento natural da Terra vem-se intensificando nos últimos séculos pelas atividades humanas, levando à acumulação demasiada dos gases que aprisionam o calor na 
Terra. As conseqüências desse acúmulo ocasionado pelo Homem são de efeito global e podem incluir o aumento da temperatura média global e mudanças climáticas regionais repentinas.

Para a substância ser considerada como causadora de efeito estufa, ela precisa ser um gás, nas condições normais de temperatura e de pressão, e apresentar, no mínimo, uma destas duas características:

- Ser capaz de absorver radiação infravermelha e ser estável na atmosfera com tempo de residência de anos a séculos;

- Ser de origem fóssil e convertido em $\mathrm{CO} 2$ na degradação para a atmosfera.

\section{Acidificação}

Quando os ácidos, e outros compostos que podem ser convertidos em ácidos, são emitidos para atmosfera, lançados nas águas ou depositados no solo, podem por meio da adição de íons de hidrogênio resultar na diminuição do $\mathrm{pH}$, causando uma acidificação do meio (WENZEL et al., 2001).

O cálculo para a equivalência para acidificação é baseado no número de íons de hidrogênio que podem, teoricamente, ser liberados da substância diretamente ou após todas as conversões sofridas no ambiente. O potencial de acidificação é expresso em uma quantidade equivalente de dióxido de enxofre, substância utilizada como referência para acidificação que apresenta impactos em escala local e regional (WENZEL et al., 2001).

\section{Eutrofização}

A eutrofização é um impacto causado por substâncias ricas em nutrientes, principalmente em Nitrogênio e Fósforo. A disponibilidade desses nutrientes é um fator que favorece a proliferação de algas e plantas. Em ecossistemas aquáticos, o 
excesso de nutrientes pode causar situações de falta de oxigênio, pois o ecossistema passa a produzir mais matéria orgânica do que é capaz de consumir ou decompor. A eutrofização é um impacto que afeta o ambiente em uma escala local e regional (WENZEL et al., 2001).

\section{Ecotoxicidade}

Os produtos químicos emitidos em conseqüência das atividades humanas contribuem para ecotoxicidade se afetarem a função e a estrutura dos ecossistemas, causando efeitos tóxicos nos organismos expostos. Se as concentrações das substâncias emitidas forem altas o suficiente, o efeito tóxico é chamado de ecotoxicidade aguda e resulta na morte dos organismos expostos. Efeitos tóxicos que apresentam seus sinais a longo prazo são chamados de ecotoxicidade crônica. Em alguns casos, o efeito crônico é causado freqüentemente por substâncias que apresentam uma baixa degradabilidade e que podem permanecer no ambiente muito tempo após sua emissão. Algumas substâncias apresentam a tendência de se acumular em organismos vivos, assim o efeito crônico de um composto é determinado por sua toxicidade, por sua degradabilidade e por sua habilidade de se acumular em organismos vivos. O potencial de ecotoxicidade é expresso pelo volume do ambiente impactado, no caso o volume $\left(\mathrm{m}^{3}\right)$ de água impactada. A ecotoxicidade, na maioria das vezes, apresenta impactos de escala local ou regional. Quando a substância apresenta um baixo grau de degradabilidade e uma alta tendência de permanência no ambiente, seu impacto poderá ser considerado de escala global (WENZEL et al., 2001). 


\section{Toxicidade humana}

Os produtos químicos emitidos em conseqüência das atividades humanas podem contribuir para toxicidade humana por meio da sua exposição no ambiente. Este é o caso de substâncias consideradas venenosas, que de alguma forma entram em contato com os seres humanos. As rotas mais fáceis de contaminação são por meio do ar respirado ou por meio de ingestão oral (WENZEL et al., 2001).

Quando as concentrações das substâncias perigosas emitidas forem altas, os efeitos tóxicos podem ocorrer imediatamente após a exposição, o que é chamado de toxicidade aguda, enquanto os efeitos que aparecem após um longo prazo são chamados de efeito crônico. A toxicidade crônica é causada freqüentemente por substâncias que apresentam uma baixa degradabilidade e que podem permanecer no ambiente muito tempo após sua emissão. Algumas substâncias têm a tendência de se acumular em organismos vivos, que funcionam como alimento para os seres humanos, assim o efeito crônico de um composto é determinado por sua toxicidade, por sua degradabilidade e por sua habilidade de se acumular em organismos vivos.

O potencial de toxicidade humana é expresso $\mathrm{em}^{3}$, que significa o volume impactado pela emissão. A toxicidade humana apresenta impactos de escala local e regional. Algumas substâncias que possuam um alto grau de toxicidade, ligações difíceis de serem quebradas e que possam ser facilmente transportadas, podem apresentar impactos em escala global (WENZEL et al., 2001).

\subsubsection{Interpretação do Ciclo de Vida}

É uma das etapas mais sensíveis, pois as hipóteses estabelecidas durante as fases anteriores, assim como as adaptações que podem ter ocorrido em função de ajustes necessários, podem afetar o resultado final do estudo. 
O relatório final deve ser elaborado de forma a possibilitar a utilização dos resultados e sua interpretação de acordo com os objetivos estabelecidos para o estudo. Apesar de toda a orientação normativa, os estudos de ACV continuam a ser descrições imperfeitas do sistema de produção. Existe um potencial de incerteza relativa à qualidade dos dados, e mesmo involuntariamente, certa subjetividade pode estar presente desde o início dos estudos.

Para reduzir os riscos de manipulações, abusos na condução ou mesmo erros involuntários devido à complexidade dos estudos, a norma NBR ISO 14.040 salienta que uma revisão crítica pode ser realizada por um especialista independente do estudo de ACV.

Contudo, quando se tratar de afirmações comparativas ou públicas, estas devem passar obrigatoriamente por uma revisão crítica externa independente. Isto porque o uso de resultados de ACV para apoiar afirmações comparativas levanta preocupações especiais e requer análise crítica, uma vez que esta aplicação provavelmente afeta partes interessadas que são externas ao estudo de ACV.

Para diminuir a probabilidade de mal-entendidos ou efeitos negativos em relação às partes interessadas externas, devem ser conduzidas análises críticas em estudos de ACV quando os resultados são usados para apoiar afirmações comparativas. O fato de uma análise crítica ter sido conduzida não implica de modo algum um endosso de qualquer afirmação comparativa que seja baseada em um estudo de ACV.

A análise crítica externa pode ser efetuada tanto por um especialista externo quanto por uma comissão, a qual pode incluir representantes das partes interessadas. A declaração sobre a análise crítica e o relatório da comissão de análise crítica, assim como comentários do especialista e quaisquer respostas às 
recomendações feitas pelo analista ou pela comissão, deve ser incluída no relatório de estudo de ACV.

Para Manzini e Vezzoli (2002) existem três razões fundamentais que torna a operação da ACV complexa:

- Deve-se considerar que o impacto ambiental não é determinado por um produto, e menos ainda por um material que compõe, mas pelo conjunto dos processos que o acompanham durante todo o seu ciclo de vida, sendo necessário, preparar e sistematizar um modelo de ciclo de vida do produto como um todo, considerando desde a extração da matéria-prima até a sua eliminação final;

- Uma vez definido o perfil do ciclo de vida inteiro do produto, ficam muitas dúvidas sobre os reais impactos ambientais dos processos utilizados, faltando dados preciosos para a análise;

- O conhecimento sobre o ambiente que nos circunda ainda é limitado, o ambiente é particularmente complexo e torna-se difícil defini-lo com um modelo apenas.

Em síntese é um modelo que pode levantar duas críticas:

- Um método complexo e caro, por isso, não utilizado pelas indústrias;

- Um método simples demais, onde seus resultados não são confiáveis.

Na prática, estabelece-se um compromisso entre a prática e a complexidade na utilização da análise do ciclo de vida. Normalmente o grau de complexidade é definido em função do objeto de análise. 
A Avaliação do Ciclo de Vida (ACV) é, com certeza, a metodologia mais conhecida e que, melhor que as outras, enfrenta os problemas antes citados (MANZINI E VEZZOLI, 2002).

\subsection{O objeto do estudo de caso: Cesto da Lavadora de Roupa}

\subsubsection{O Histórico da Lavadora de Roupas}

Uma das primeiras invenções de lavadora foi registrada na Inglaterra no ano de 1780. No entanto, a maioria das patentes de lavadora foi emitida durante o século XIX e estava baseada nos vários métodos de fricção de lavar: esfregar, bater e arrastar as roupas em uma solução de água e sabão. Isso era feito mecanicamente, com o operador que geralmente exercia a força. Depois os novos desenvolvimentos usaram outras fontes de forças para guiar a lavadora, WHIRLPOOL (1975).

O norte-americano Hamilton E. Smith inventou a máquina mecânica de lavar roupa em 1858 (o modelo elétrico surgiria apenas em 1906). A figura 07 mostra um modelo do primitivo aparelho mecânico, anunciado no tablóide American Agriculturist (O Agricultor Norte-Americano) de janeiro de 1864 (AGUIAR, 2004). 


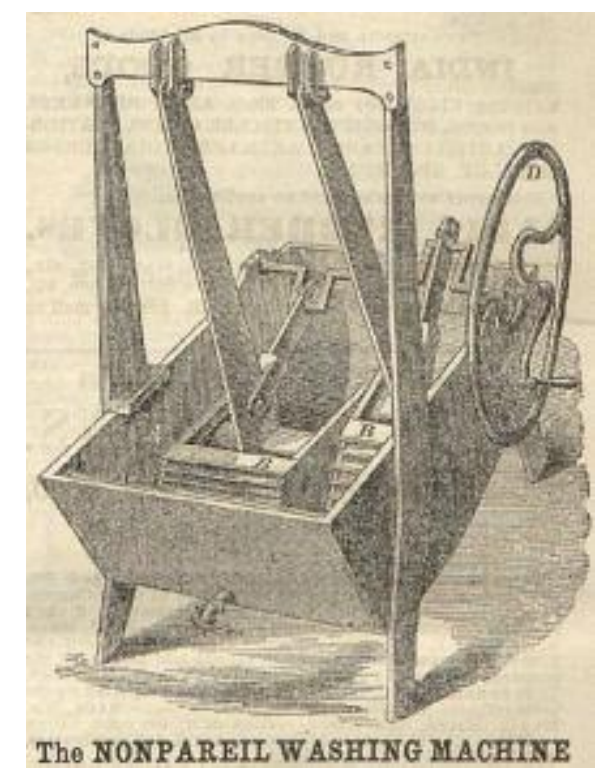

Figura 7 - Primeira Lavadora de roupa de 1858 Fonte: AGUIAR (2004)

Depois da lavagem, era necessário secar as vestes. O sistema desenvolvido para secar as roupas (figura 8), consistia de rolos que comprimiam a roupa, de modo a retirar parte excesso de líquido absorvido durante a lavagem.

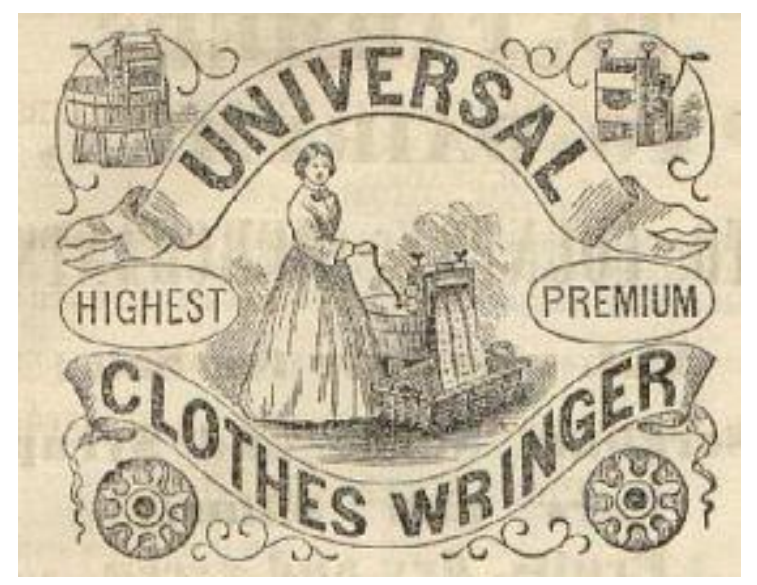

Figura 8 - Propaganda da Máquina de espremer roupas. Fonte: AGUIAR (2004)

A primeira variação dos antigos princípios foi uma máquina que usava um tambor rotativo, que com intermitência, invertia a direção das peças a serem lavadas. Isso forçava as roupas a cair e movimentarem-se na água ensaboada. Outros avanços estavam sendo feitos, como um equipamento que extraía o excesso 
de água das roupas através de dois rolos, conhecido como wringer. O resultado dessa invenção (figura 9), usando rolos de borracha e uma braçadeira em arranjo para prendê-los no lado de um recipiente de lavagem ou mesa, ganhou popularidade ao término do século XIX (AGUIAR, 2004).

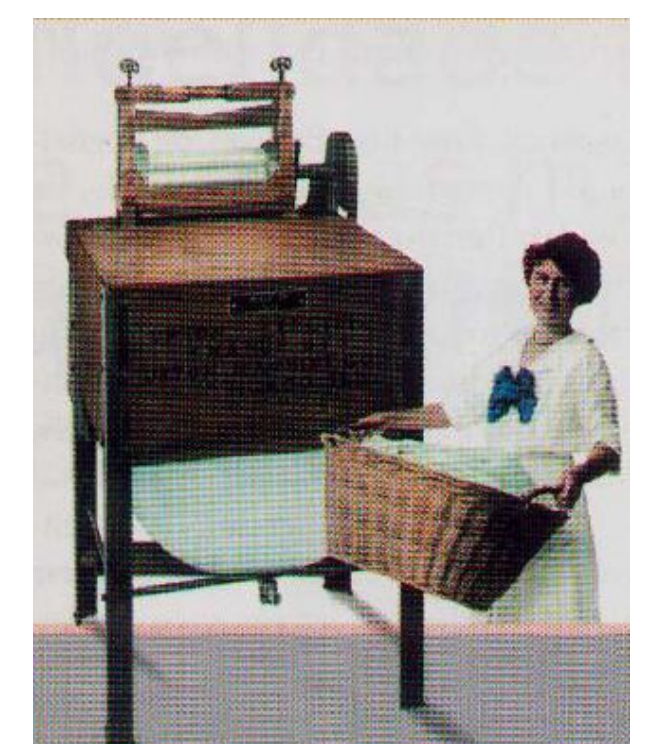

Figura 9 - Máquina de lavar roupas, década de 20 Fonte: AGUIAR (2004)

Já no início do século XX, o desenvolvimento de um modelo utilizando a energia elétrica ofereceu à dona-de-casa um menor esforço para o processo de lavagem e secagem de roupa, pois a água das roupas era eliminada por força centrífuga, não precisando de sua intervenção. Esse método continua sendo o mesmo usado nas lavadoras automáticas de hoje (AGUIAR, 2004).

A segunda guerra mundial (1942-1945) interrompeu toda a produção de lavadora. Porém, uma máquina de lavar completamente automática estava sendo preparada, e após a guerra, a maioria dos fabricantes de lavadora retomaram a produção da máquina de Wringer (AGUIAR, 2004). 
Em 1947, outro conceito de lavadora automática foi introduzido, agora mais aceito pelos americanos (figura 10). Era uma top-loading ${ }^{5}$, com ação por agitador, uma única velocidade, um único ciclo automático. Oferecia água quente ou morna, com enxágüe em água morna (AGUIAR, 2004).

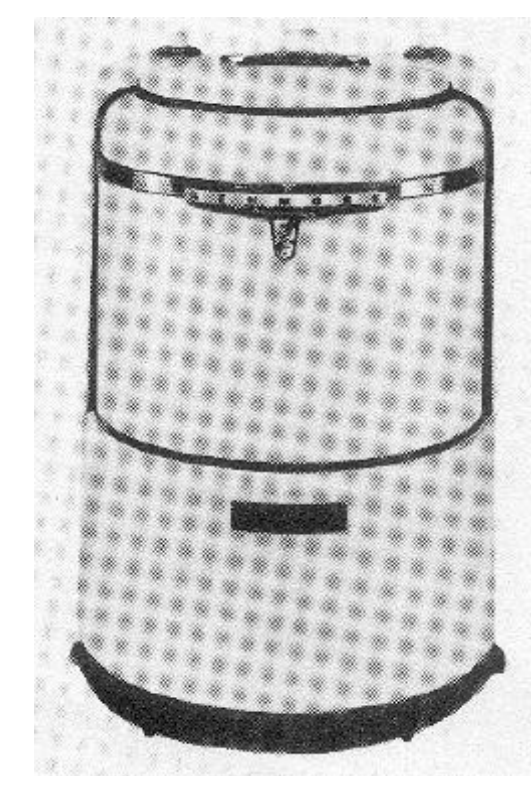

Figura 10 - Lavadora de roupa da década de 40. Fonte: AGUIAR (2004)

No início dos anos 60 , os eletrodomésticos eram novidade para a maioria das donas-de-casa brasileiras. Na maior parte do país, lavava-se a roupa no tanque ou até mesmo no rio..

No início da década de 70 essas lavadoras foram lançadas nas cores amarela e azul, além do tradicional branco. Esses modelos foram produzidos até o final da década de setenta (CDM - MULTIBRÁS, 2002).

\footnotetext{
${ }^{5}$ Top-loading é o termo usado para as lavadoras de roupa em que o abastecimento de roupas e insumos é feita na parte superior do produto.
} 
Em setembro de 1990, a Brastemp lançou a lavadora Mondial (Figura 11), que era produzida na Unidade Rio Claro da Multibrás, inaugurada em julho do mesmo ano. Compacta, vendia o conceito de praticidade. No início da produção a fábrica fazia 20 mil lavadoras por mês. Tanto a lavadora quanto a nova unidade representaram novidades para o mercado: a fábrica foi planejada para que a produção fosse mais rápida e econômica e com um produto de maior qualidade. Esse modelo apresentou uma inovação no material utilizado em sua construção, a tampa, que era em aço, passou a ser em plástico polipropileno (pp) e o cesto da lavadora fabricados com o aço inox produzido pela Acesita. Essa lavadora é menor do que a antiga lavadora Luxo da Brastemp. Ela pesa 40 quilos, menos que a metade do peso da lavadora antiga. A versão Baby Mondial é menor ainda, mas também lava 4 quilos de roupa. $O$ cesto da lavadora antiga era de aço comum. $O$ da lavadora Mondial é de aço Inox e por isso não enferruja CDM - MULTIBRÁS (2002).

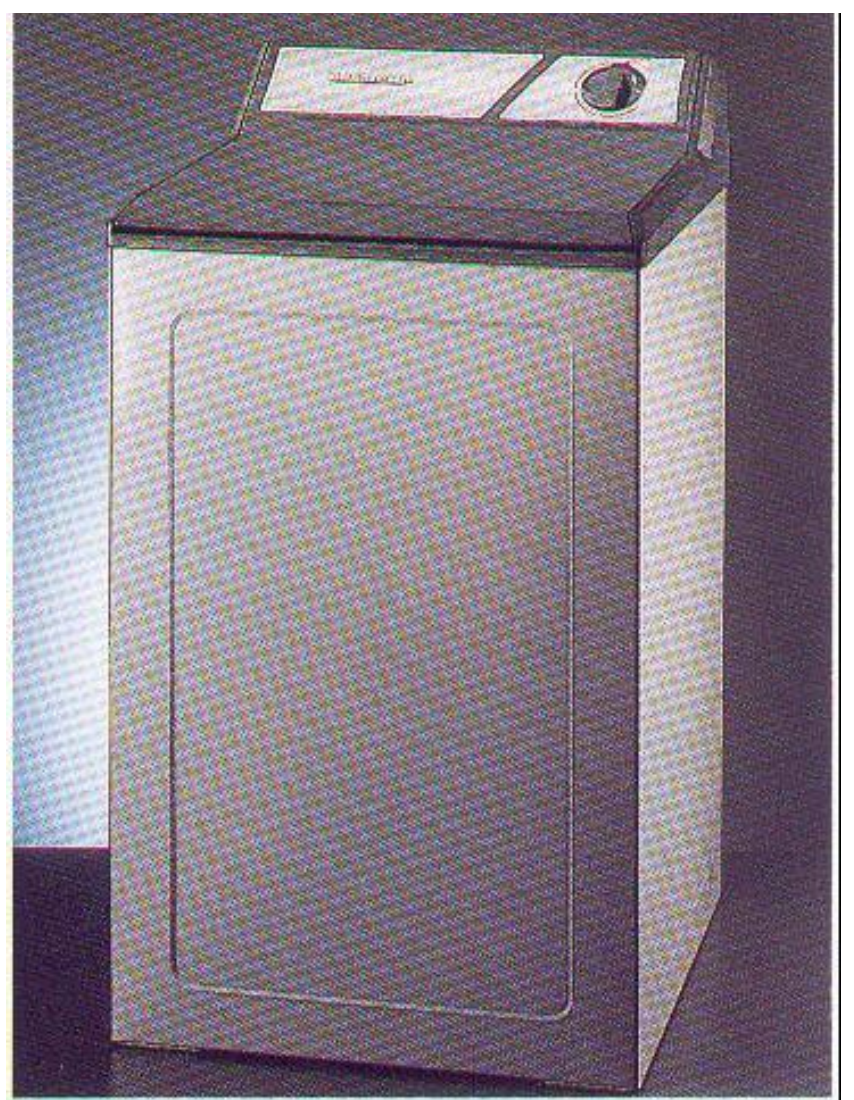

Figura 11 - Lavadora Mondial Fonte: AGUIAR (2004) 
Em 1998, lança a linha de lavadoras Eletrônicas (Figura 12) com tecnologia e design diferenciados, a única linha de lavadoras com abertura superior da tampa que tem multidispenser, para distribuir automaticamente os insumos; pés antiderrapantes e reguláveis; painel de comando eletrônico, o qual oferece maiores possibilidades de programação; agitador dual action; tampa de vidro temperado; auto aquecimento, CDM - MULTIBRÁS (2002).

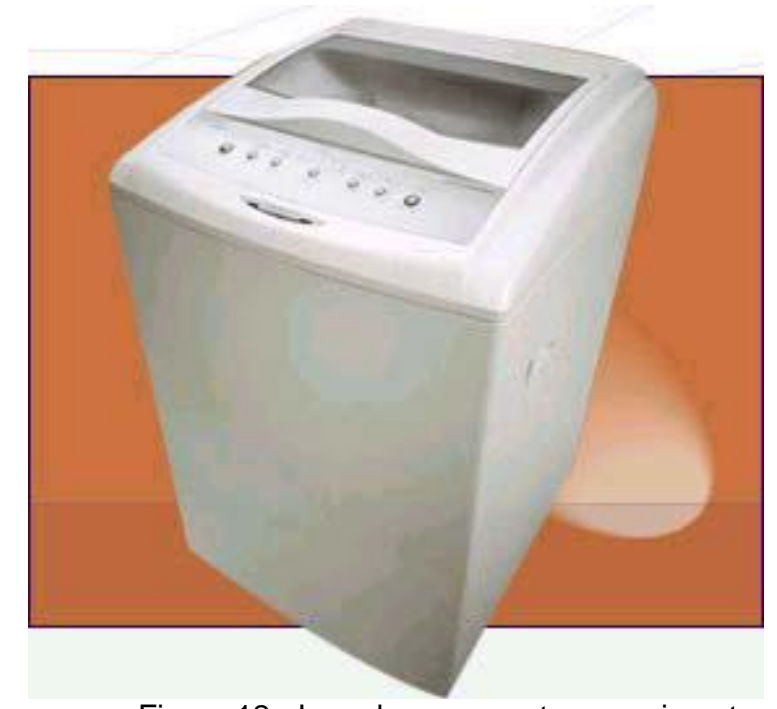

Figura 12 - Lavadora com auto-aquecimento Fonte: AGUIAR (2004)

Em julho de 1999, a Multibrás inaugurou em Rio Claro a nova linha de lavadoras Consul (Figura 13), lançando um modelo de lavadora automática com duas capacidades: $5,0 \mathrm{Kg}$ de roupa seca $7,0 \mathrm{Kg}$ de roupa seca. 


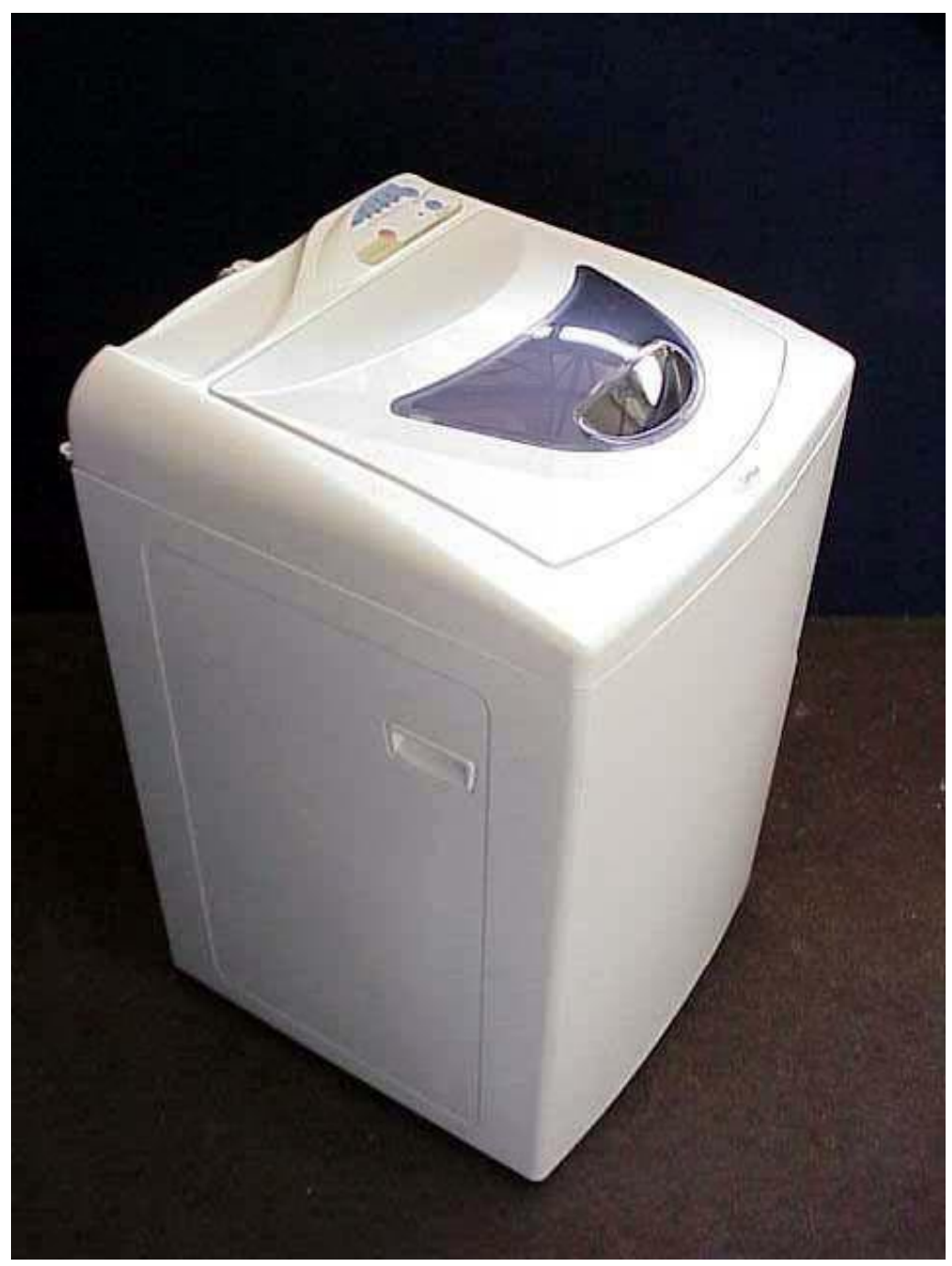

Figura 13 - Lavadora Consul Fonte: AGUIAR (2004)

O desenvolvimento de novos produtos e o lançamento deles no mercado ficou cada vez mais intenso na década de 90. Com a concorrência cada vez mais acirrada é preciso, além de inovar, oferecer produtos com qualidade superior, para manter o "foco no consumidor".

\subsubsection{Características das Lavadoras de Roupa}

Segundo Aguiar (2004), as lavadoras automáticas de uso doméstico, divide-se em dois grupos: a de abertura frontal e a de abertura superior. 
As lavadoras de abertura frontal - eixo horizontal (figura 14), o sistema de lavagem é por tombamento. Esse tipo de sistema consiste em montar um tambor interno perfurado, rotativo dentro de um tambor fixo. O tambor interno é denominado "cesto" e permite que a solução de lavagem passe dele para o tambor fixo e viceversa. No interior do cesto existem pás que, por meio de movimento rotatório, levam a roupa até a certa altura, deixando-a cair novamente na solução de lavagem. Nesse movimento, existem fricções de roupa contra roupa, e roupa contra o cesto, e a queda da peça na solução de lavagem. Essa ação conjunta de esfregar e bater a roupa denomina-se ação mecânica.

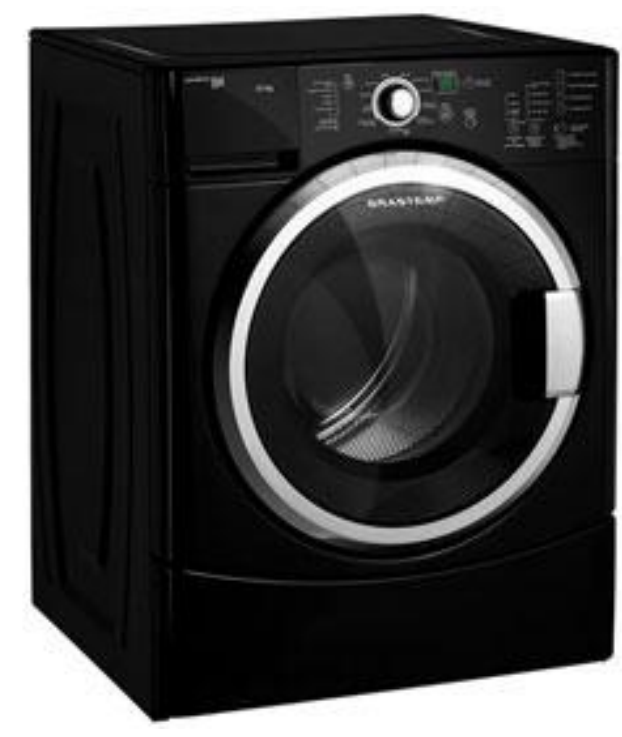

Figura 14 - Lavadora "Front-load"

As lavadoras de abertura superior - eixo vertical (figura 15), o sistema de lavagem pode ocorrer por agitação ou turbilhonamento, muito conhecido como impeller. Tal sistema consiste, também, em montar um tambor interno perfurado, rotativo, dentro de um tambor fixo. No entanto, as pás são substituídas por um agitador ou impeller que ficam posicionadas no eixo vertical da lavadora e, que transferem a energia mecânica do motor para a água da lavagem e para as roupas. 


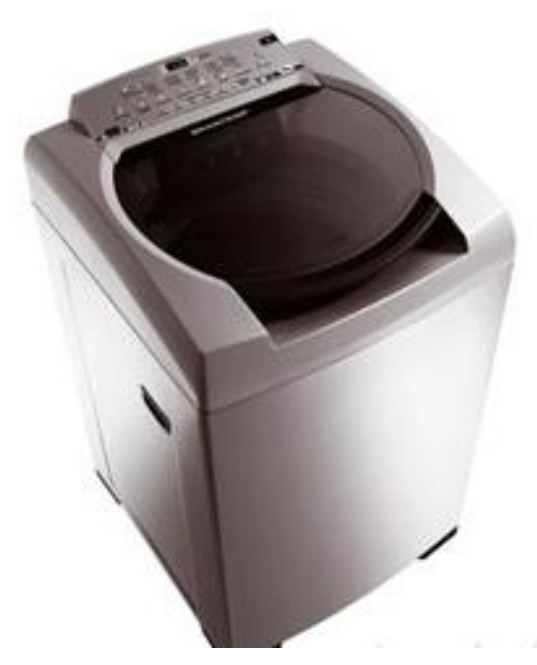

Figura 15 - Lavadora "Top-load"

Ambos os grupos de lavadoras, abertura frontal e superior, têm como finalidade provocar, sem intervenção manual direta, um trabalho mecânico que visa: causar fricção, aumentar a velocidade de passagem da água com detergente através das fibras e facilitar a formação de emulsão e dispersões. O fator mecânico, combinado com os demais fatores - químico, temperatura e tempo - removem a sujeira dos tecidos.

Atualmente, os cestos das lavadoras do mercado brasileiro são produzidos em dois materiais, em aço inoxidável e plástico. As lavadoras mais antigas, que ainda podem ser encontradas em funcionamento em algumas residências possuem o cesto em aço, com acabamento vítreo através do processo de esmaltação (figura 16). 


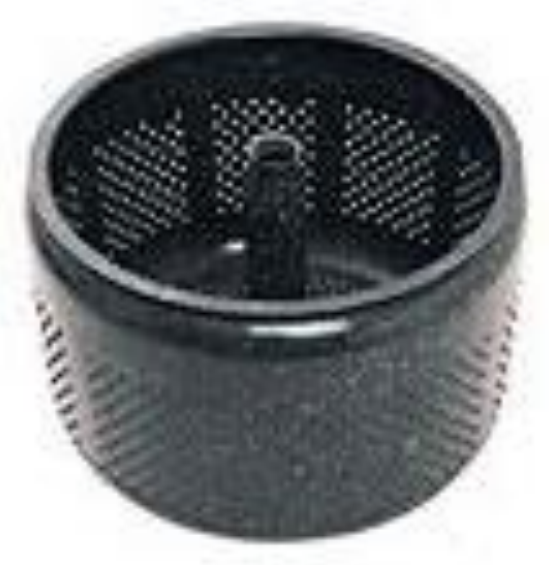

Figura 16 - Cesto em aço com camada de esmalte

Este processo além de ser caro e gerar muitos impactos, fez com que as empresas migrassem para materiais e processos mais baratos que mantenham a característica de resistência a corrosão pelos ataques químicos sofridos durante o processo de lavagem.

O componente escolhido para desenvolver a metodologia proposta foi o cesto da lavadora de roupas, que tem como principal finalidade acomodar a roupa dentro do produto que exerce uma ação mecânica sobre a roupa, que bate e esfrega a roupa, imitando o trabalho de uma lavadeira que esfrega a roupa no rio.

Os cestos que serão utilizados para este estudo, são produzidos em dois materiais:

O cesto em aço inox, figura 18, é formado por duas partes: o fundo do cesto e a lateral do cesto. As duas partes são confeccionadas em aço inox e são fornecidos pela usina em forma de bobinas, manufaturados, e montados na lavadora (figura 19). 


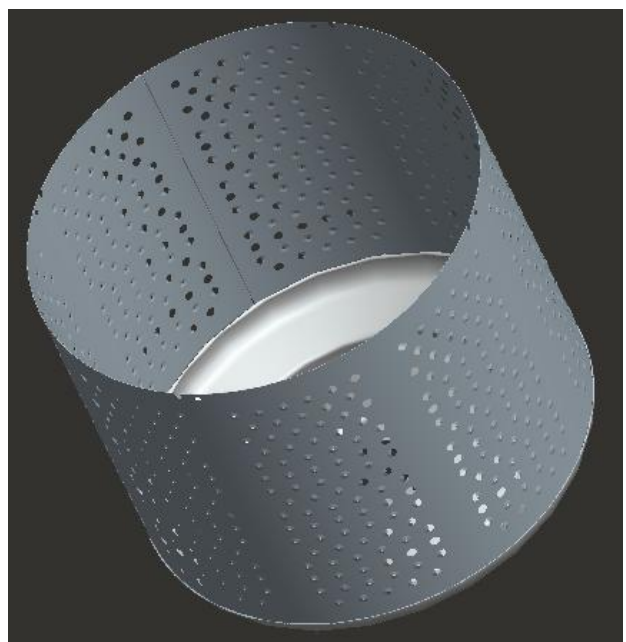

Figura 18 - Cesto em Aço inox

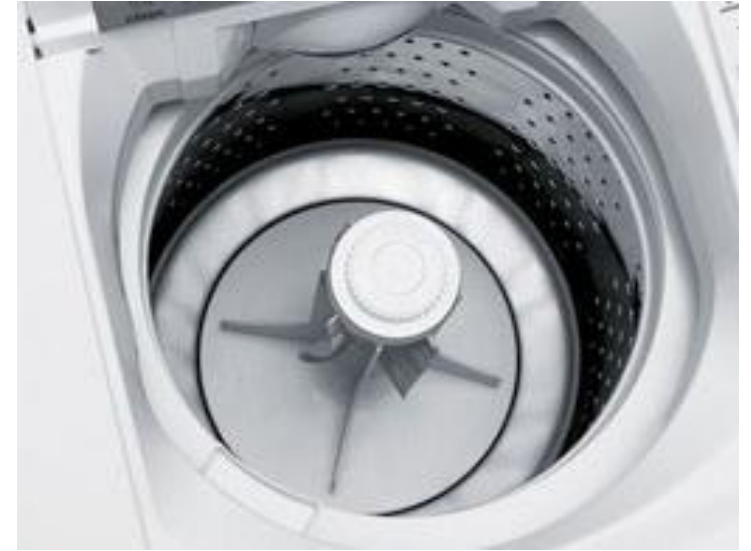

Figura 19 - Posicionamento do cesto inox no produto

O cesto em plástico (figura 20) é produzido através conformação por injeção em molde, diferentemente do cesto inox, o cesto plástico é produzido em uma única peça. A matéria-prima é fornecida em forma de grãos, passa pelo processo de manufatura e montagem no produto (figura 21).

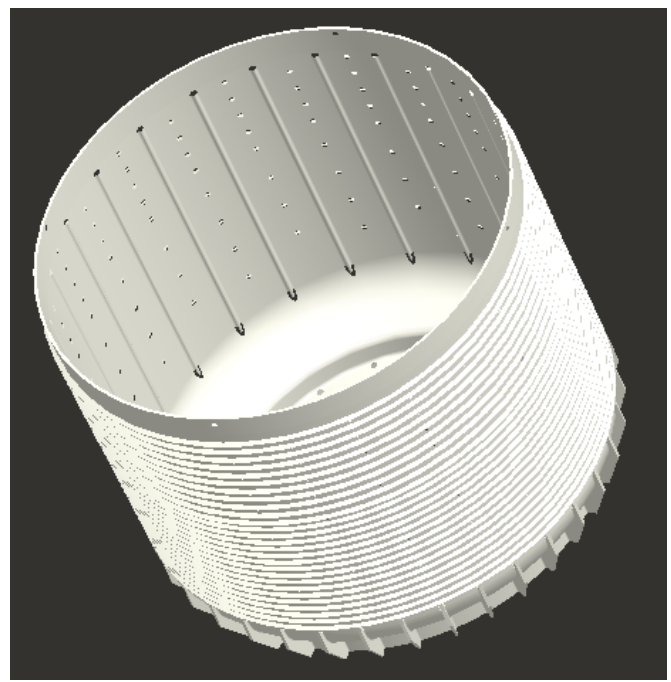

Figura 20 - Cesto em Plástico

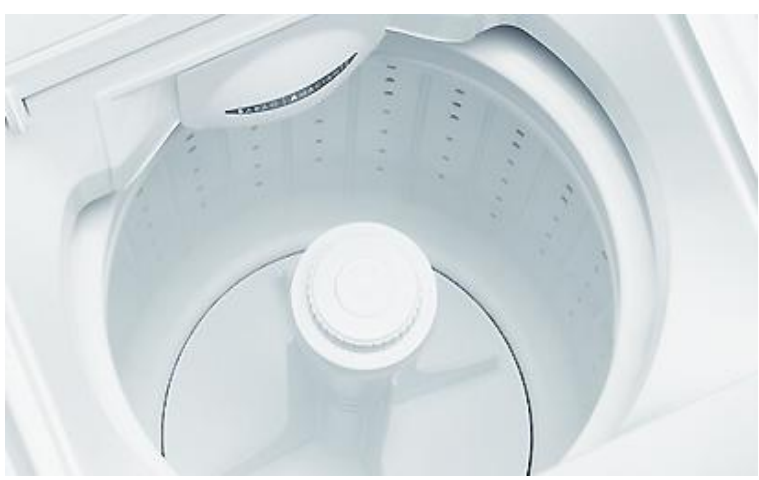

Figura 21 - Posicionamento do cesto Plástico no produto 


\section{Materiais e Métodos}

Esta dissertação do ponto de vista da sua natureza é uma pesquisa aplicada, pois os conhecimentos originados terão aplicações práticas advindas dos resultados adquiridos por meio dos dados quantitativos do inventário. Do ponto de vista de seus objetivos se trata de uma pesquisa exploratória e os procedimentos técnicos utilizados são: a pesquisa bibliográfica e estudo de caso dos dois tipos de cesto utilizados nas lavadoras de roupa.

Foi realizada uma revisão bibliográfica sobre os itens: desenvolvimento sustentável, a evolução da integração dos aspectos ambientais no âmbito empresarial, o ecodesign, a ACV, e sobre o objeto de estudo de caso, o cesto da lavadora de roupa. Além disso, utilizou-se a revisão sistemática sobre os principais métodos de $A C V$.

Desse modo algumas as questões utilizadas na revisão sistemática foram:

Quais são os principais métodos utilizados nos estudos de ACV e quais são as principais características e diferenças?

Para responder estas questões, foi necessário realizar uma revisão sistemática, que segundo Lakatos e Marconi (2001) é uma metodologia de pesquisa específica, desenvolvida formalmente, para levantamento e avaliação de evidências pertencentes a um determinado foco de pesquisa. $O$ processo de condução da pesquisa em uma revisão sistemática segue uma seqüência bem definida de passos metodológicos, de acordo com um protocolo desenvolvido previamente.

Uma revisão sistemática é um meio de avaliar e interpretar todas as pesquisas relevantes disponíveis para uma pesquisa particular de uma questão ou tópico de área ou fenômeno de interesse. 
As bases de dados pesquisadas durante a revisão sistemática são apresentadas abaixo, seguidas de uma breve descrição e do endereço da internet para acesso.

- $\quad$ Scirus (http://www.scirus.com): mecanismo de pesquisa científica na internet que inclui mais de 450 milhões de materiais científicos em diferentes áreas do conhecimento;

- Research Communications for Scientists and Engineers (http://www.osti.gov/eprints): plataforma que proporciona acesso a diferentes bases de dados em engenharia e ciências;

- Find Articles (http://www.findarticles.com): acesso a milhões de artigos de centenas de publicações de alto nível;

- Science Direct (http://www.sciencedirect.com): proporciona acesso a mais de 2000 revistas conceituadas e a centenas de livros, handbooks e trabalhos para referência;

- IEEE Explore (http://ieeexplore.ieee.org): proporciona acesso integral à literatura mundial de mais alta qualidade técnica;

- Scholar Google (http://scholar.google.com): pesquisa de literatura acadêmica em artigos revisados por especialistas (peer-rewiewed), teses, livros, resumos e artigos de editoras acadêmicas, organizações profissionais, bibliotecas de prépublicações, universidades e outras entidades acadêmicas

A revisão sistemática foi realizada com o objetivo de identificar os métodos, ferramentas e banco de dados mais utilizados para os estudos que utilizam a ACV. Para isso, foi feita uma pesquisa na internet, buscando artigos internacionais, escritos na língua inglesa utilizando as expressões: "life cicle assessment method", "LCA method", "life cycle assessment methodology" e "LCA methodology". 
As seleções de artigos levantados para a leitura seguiram alguns critérios como: considerar somente artigos internacionais, teses, dissertações, relatórios e monografias, sendo que os artigos nacionais, artigos de revistas, congressos e eventos internacionais foram descartados. O período considerado para a revisão sistemática foi de 15 anos, ou seja, os artigos publicados entre 1994 e 2009.

Os artigos encontrados foram salvos e catalogados de maneira simples em uma planilha de dados do Excel (Microsoft). Cada artigo foi cadastrado (ANEXO A) com as seguintes informações; título, autor(es), referência, ano, país, métodos citados, categorias de impactos, cadeia de impacto (midpoint ou endpoint), ferramentas utilizadas e banco de dados.

Quando um "termo" (método, ferramenta, banco de dados, categoria de impactos), era citado mais de uma vez no mesmo artigo, este era contabilizado uma só vez, alguns autores não colocaram versão/ano, do método, ferramenta e banco de dados utilizado, mesmo assim, foi contabilizado, separando-se dos mesmos métodos, ferramentas e banco de dados que tinha sua versão/ano descritos.

Além da revisão sistemática da ACV, este trabalho de mestrado apresenta um estudo de Avaliação de Ciclo de Vida - ACV comparativo baseado na estrutura metodológica da série ISO 14.040, e nas normas brasileiras NBR ISO 14.041, 14.042 e 14.044 e no método EDIP.

O método EDIP (Environmental Design of Industrial Products) é o resultado de um programa cooperativo entre uma universidade, a indústria e as autoridades dinamarquesas com o objetivo de projetar produtos mais limpos (WENZEL et al., 2001). 
A ACV será aplicada a um componente específico de uma lavadora de roupa, produto classificado como sendo da "linha branca", presente na maioria das residências de todos os países.

Os dados do ciclo de vida para a lavadora de roupas e o cesto da lavadora de roupa, foram obtidos através de bibliografias e principalmente de fonte primária através do acesso do banco de dados de uma empresa de eletrodomésticos e principalmente do banco de dados do software GABI v. 4.3.

O componente escolhido foi o cesto da lavadora de roupa, que tem a função primária de acondicionar as roupas dentro do produto, para que possam passar pelo processo completo de lavagem.

O cesto de roupa é um componente essencial para diferenciar os produtos da linha branca voltados para o processo de lavagem de roupas, pois os produtos que possuem o cesto de roupa podem oferecer aos consumidores o processo de centrifugação que tem a finalidade de retirar a unidade da roupa, a fim de acelerar seu processo de secagem.

O mercado de lavadoras oferece esta função de centrifugação devido à existência do cesto no produto, já os produtos que não possuem o cesto de roupa, ou seja, não oferecem esta função de centrifugar a roupa, são conhecidos popularmente como "tanquinhos" ou lavadoras semi-automáticas.

As lavadoras de roupas oferecidas no mercado nacional possuem cestos em aço inox ou em plástico, com a mesma capacidade ${ }^{6}$, no caso 8 kilos de roupa seca, isso possibilita que seja realizado um estudo comparativo de ACV, para verificar os potenciais impactos gerados para cada tipo de cesto.

\footnotetext{
${ }^{6}$ Capacidade de uma lavadora de roupa é medida em kilos de roupa seca que podem ser lavados em único ciclo de lavagem.
} 
O dois modelos de produtos, são produzidos pela a mesma empresa, sendo assim, aspectos como o processo de montagem do produto e movimentação interna dos componentes são os mesmos.

O método científico aplicado para aplicação da ACV é definido como Hipotético dedutivo e para este trabalho tem como base a técnica de Avaliação de Ciclo de Vida - ACV, normalizada pela ISO e pela ABNT no Brasil e o método EDIP. A série de normas ISO 14040, determinam as fases e os procedimentos gerais da execução de um estudo de ACV

Segundo a NBR ISO 14040 (2006), a Avaliação do Ciclo de Vida é a compilação e a avaliação das entradas (inputs), saídas (outputs) e os potenciais impactos ambientais do sistema de um produto durante o seu ciclo de vida.

Os dados do ciclo de vida para a lavadora de roupas e o cesto da lavadora de roupa, foram obtidos através de bibliografias e principalmente de fonte primária através do acesso do banco de dados do Centro de Desenvolvimento e Memória (CDM) da empresa e principalmente do banco de dados do software GABI v. 4.3.

Devido a sua característica em apoiar a compreensão ambiental sobre os produtos, a ACV para este estudo é a ferramenta mais indicada, para que possamos compreender as diferenças das características ambientais dos componentes, neste caso, os cestos da lavadora de roupa.

No método EDIP, o inventário, em termos de quantidade e tipo de emissão é traduzido em impactos ambientais conhecidos. Assim, o inventário é transformado em uma lista de itens consumidos e de potenciais para impactos no meio ambiente.

O inventário foi dividido em dois grupos principais: 
- Potencial da emissão: aquecimento global, diminuição da camada de ozônio, acidificação, ecotoxicidade e toxicidade humana.

- Consumo de recursos: consumo de energia e exaustão de recursos naturais.

Utilizando-se das categorias de impacto foi realizado o cálculo dos potenciais impactos conforme o método EDIP.

Cálculo das contribuições potenciais de cada categoria de impacto selecionada. Os cálculos são feitos a partir da quantidade do elemento encontrada, de acordo com a unidade funcional, multiplicado pelo fator de equivalência que este elemento apresenta segundo o método, para a categoria de impacto avaliada.

\section{$E P=Q . E F$}

Onde:

$\mathbf{E P}=$ Potencial de impacto

$\mathbf{Q}=$ Quantidade do elemento

$\mathbf{E F}=$ Fator de equivalência do elemento para o impacto selecionado

Para a quantificação e posterior interpretação dos impactos, utilizou-se o método EDIP. Para a classificação dos insumos designados no inventário, foram selecionadas as seguintes categorias:

- Consumo de recursos renováveis e não renováveis

- Consumo de Energia.

Seguindo o método EDIP, para uma avaliação quantitativa dos impactos gerados foram selecionadas as seguintes categorias de impactos relativos às emissões do ciclo de vida:

- Potencial de aquecimento Global 
- Acidificação;

- Eutrofização;

- Ecotoxicidade;

- Toxicidade Humana.

O método EDIP está sendo usado para este estudo, devido as suas características de mid point, além de modelar quantitativamente os resultados reduzindo as incertezas de outros métodos que consideram um único indicador e as categorias end point.

Além disso, o método EDIP possibilita a comparação entre dois produtos semelhantes como é o caso do objeto de estudo, possui uma facilidade para a compreensão dos dados gerados por ser um método que apresenta publicação em livro e que possibilita transparência e estudo mais aprofundado do método, trazendo em sua literatura exemplos que facilitam a compreensão da aplicação do método na prática. 


\section{Resultados}

\subsection{Revisão Sistemática da ACV}

Para a revisão sistemática sobre a Avaliação do Ciclo de Vida - ACV foram obtidos os resultados abaixo:

- Do total de 120 artigos cadastrados, 21 artigos não citavam qualquer método ou ferramenta utilizada para a aplicação da ACV;

- Não há um consenso entre os autores sobre a aplicação da ACV, pois alguns autores descrevem a ACV como sendo um método e outros descrevem a ACV como sendo uma ferramenta;

- Nenhum artigo informou todos os critérios utilizados para o estudo da ACV, como exemplo muitos citam o método utilizado, mas não informam as categorias de impactos considerados no estudo;

- Em 120 artigos analisado, foram citados 113 métodos diferentes para o estudo de ACV;

- Foram citadas 88 categorias de impactos diferentes, sendo que muitas tinham o mesmo objetivo, mas eram descritas de forma diferente pelos autores;

- As cadeias de impacto (midpoint ou endpoint) são citadas em apenas $12 \%$ dos artigos.

Os resultados dos dados compilados na planilha Excel (Microsoft), foram convertidos em gráficos para melhor compreensão dos resultados.

O gráfico 01 mostra o percentual de artigos que informam o método, a categoria de impacto, as cadeias de impacto (midpoint ou endpoint), as ferramentas 
utilizadas e o banco de dados. Os métodos utilizados são informados em $68 \%$ dos artigos pesquisados, entretanto, $12 \%$ dos autores informaram a cadeia de impacto (midpoint ou endpoint).

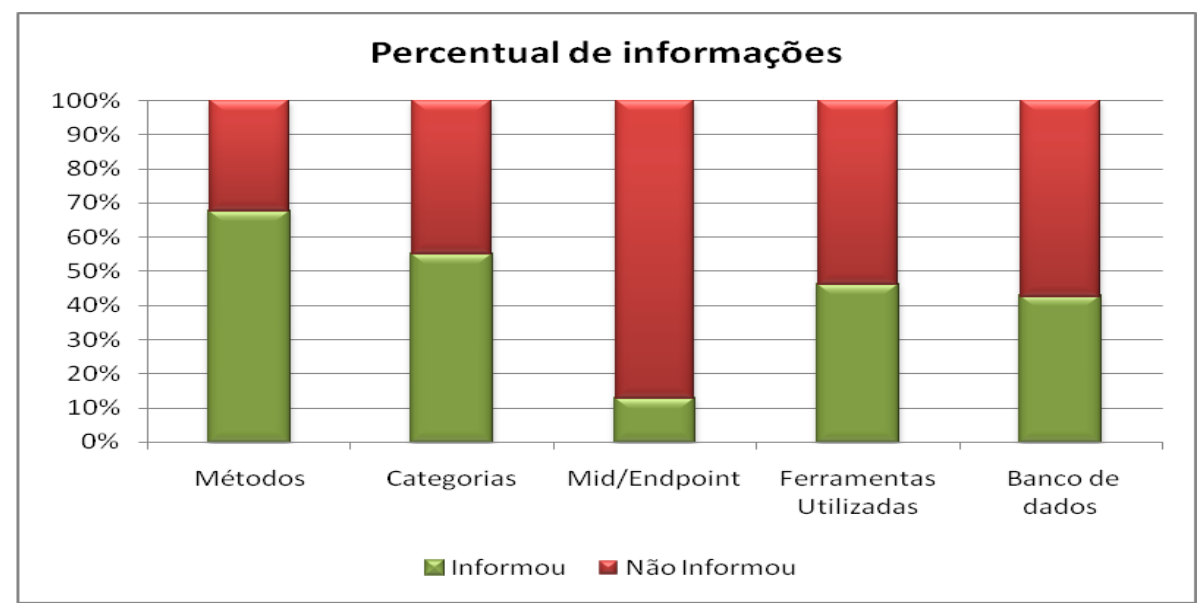

Gráfico 1 - Percentual de informações dos autores

O gráfico 02 , mostra os principais métodos citados em cada artigo, lembrando que, os métodos que possuem versão/ano, foram separados. Foram colocados no gráfico, os 10 métodos mais citados, sendo que no total foram citados 113 métodos diferentes.

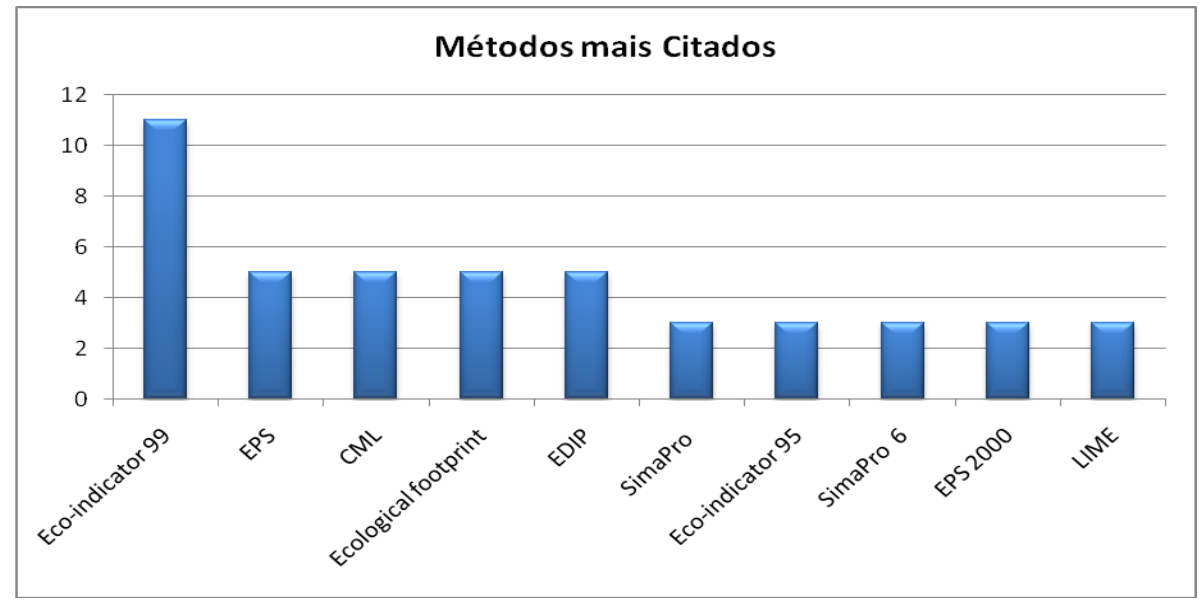

Gráfico 2 - Principais métodos citados

No gráfico 03, estão indicadas as principais categorias de impacto descrito pelos autores para o estudo de ACV realizado, sendo que nos 120 artigos 
analisados, foram citados 88 "categorias de impactos" diferentes. Muitas categorias citadas têm o mesmo objetivo, mas são descritas pelos autores de forma diferente.

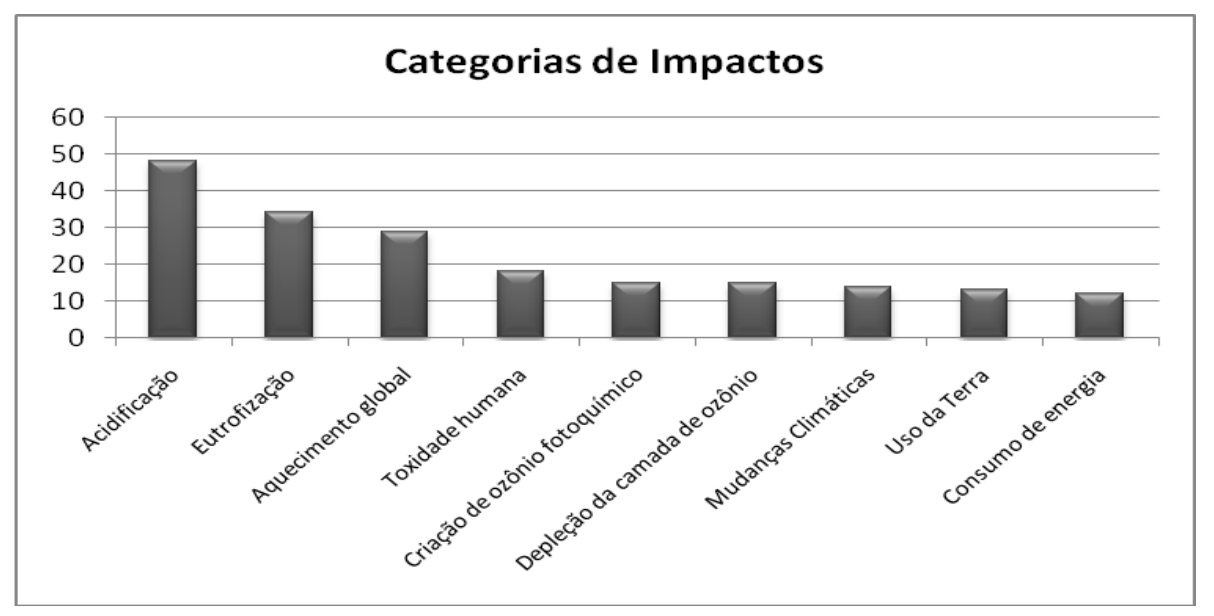

Gráfico 3 - Principais Categorias de Impacto

Poucos artigos informaram se os estudos realizados eram para as categorias de impactos midpoint e/ou endpoint, apenas 15 autores informaram conforme mostra o gráfico 04 .

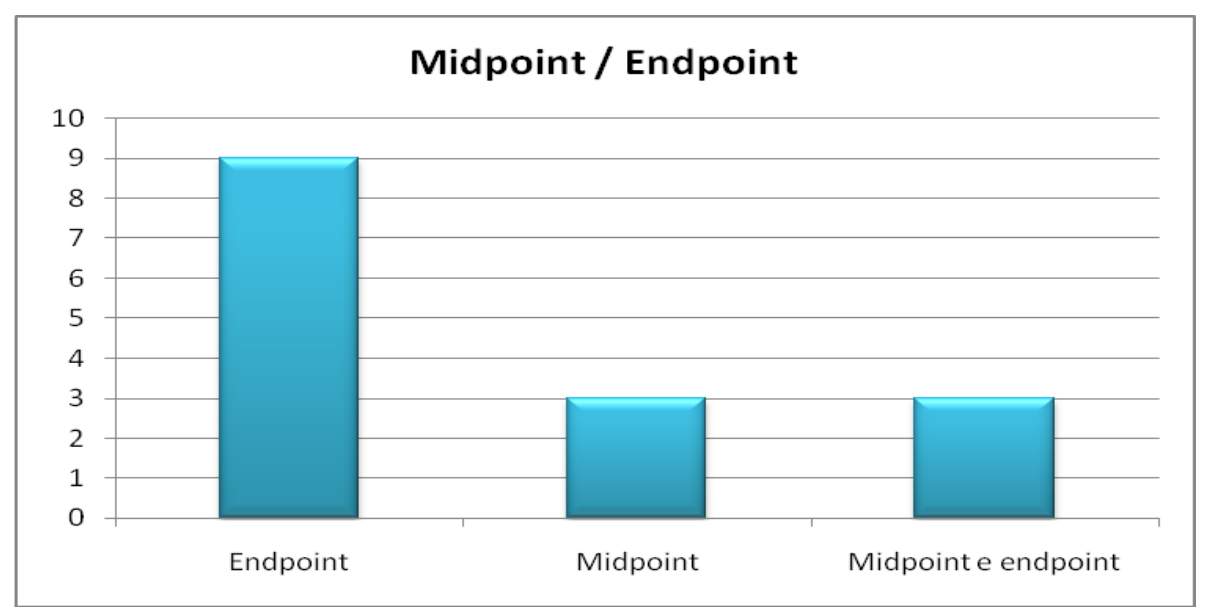

Gráfico 4 - Cadeias de impacto.

O gráfico 05 , mostra as ferramentas mais citadas nos artigos analisados, as ferramentas que possuem versão/ano, foram contabilizadas separadamente. O eco- 
indicator foi a ferramenta mais citada nos artigos, mesmo sendo separado por versão, esta ferramenta está entre as duas mais citadas.

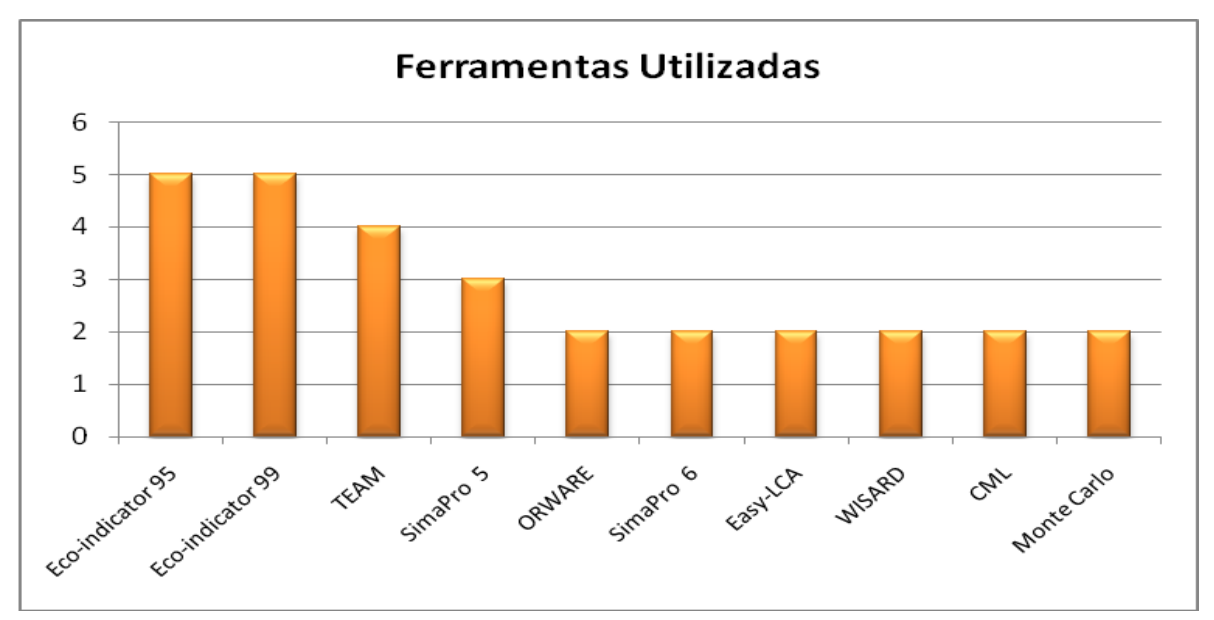

Gráfico 5 - Principais Ferramentas

Alguns autores informaram no artigo, quais foram os bancos de dados utilizados para o inventário, o gráfico 06 mostra os principais bancos de dados utilizados dentre 49 bancos de dados citados.

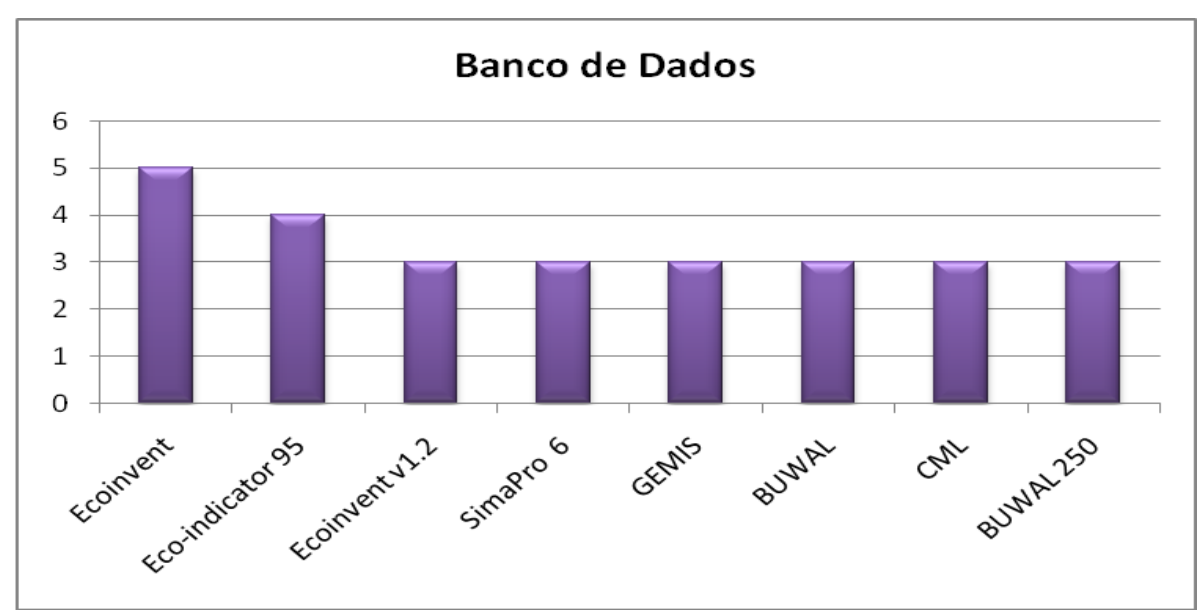

Gráfico 6 - Principais Banco de dados

A distribuição anual dos estudos é apresentada no gráfico 07 , onde podemos observar um aumento na quantidade de publicações entre os anos de 1994 e 2008, sendo que os anos de 2005 e 2008 apresentam uma maior quantidade de publicações relacionada as "palavras-chave" utilizadas. 


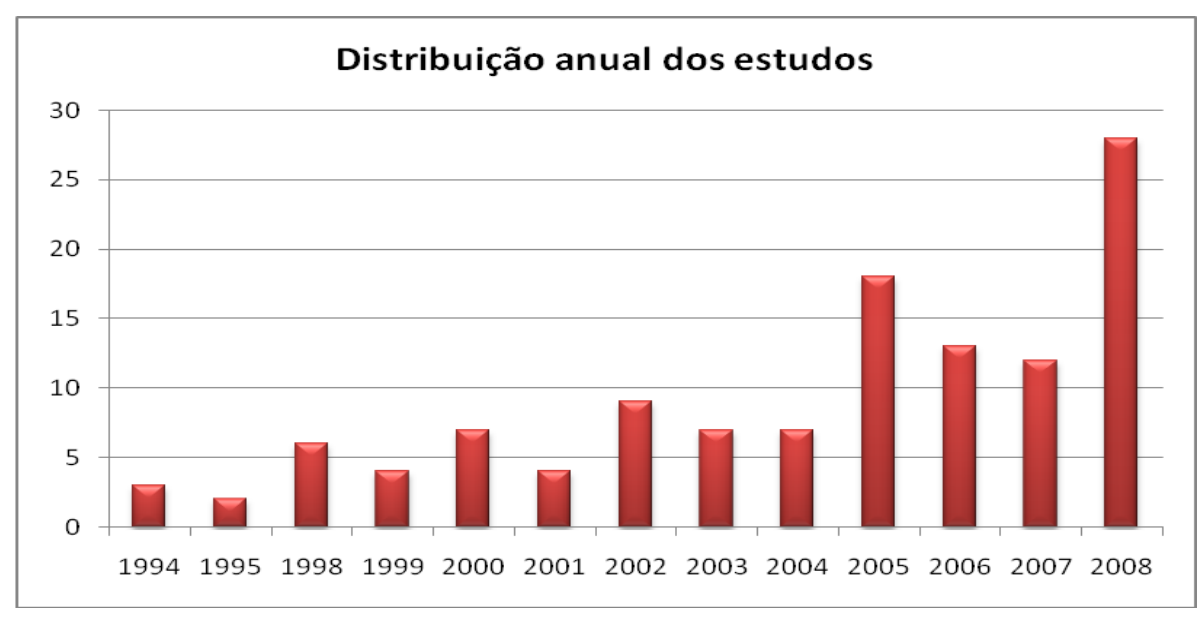

Gráfico 7 - Distribuição anual dos artigos pesquisados

A maioria dos autores descreve a importância da ACV como uma ferramenta de gerenciamento ambiental, mas conforme os resultados da revisão sistemática pode-se concluir que não há um consenso quanto aos melhores métodos, ferramentas e banco de dados a serem utilizados.

Muitos pesquisadores utilizam recursos que estão mais facilmente acessíveis, mas esses recursos não são necessariamente considerados como os melhores para o estudo em questão.

\subsection{Estudo de Caso: Cesto da Lavadora de Roupa}

\subsubsection{Definição do objetivo e do escopo}

O objetivo deste estudo é comparar os potenciais impactos ambientais do ciclo de vida de um cesto de plástico e um cesto de aço inox da lavadora de roupa.

\section{Função do sistema}

A função primária do cesto de roupa é acondicionar a roupa dentro do produto, para o processo de lavagem. Outra característica importante do cesto, é que ele tem um papel fundamental na diferenciação na classificação das lavadoras de roupa, 
pois, as lavadoras que possuem o cesto oferecem ao consumidor o ciclo de centrifugação.

A centrifugação é a etapa do ciclo da lavadora que faz a eliminação do excesso de água da roupa através do uso da força centrifuga, onde o cesto gira através do eixo do mecanismo em alta rotação, forçando a roupa úmida contra as paredes do cesto, deixando sair somente o excesso de água.

Este processo de retirada do excesso de água antes da criação do processo de centrifugação era feito através da utilização de rolos, que as lavadoras mais antigas ofereciam, ou através da torção manual. Deste modo, com a criação do cesto e o sistema de centrifugação não foi mais necessário a intervenção do consumidor para retirar o excesso de água da roupa.

\section{Unidade Funcional}

Quantidade de roupa em massa acondicionada e centrifugada durante 0 período de uso do cesto no período de vida do produto. Esta quantidade é de 4368 kilos, considerando que o consumidor utiliza o produto 3 vezes por semana com 8 kilos de roupa seca durante 7 anos de vida útil.

\section{Fluxo de referência}

Para atender a unidade funcional considerada, são necessários dois cestos plásticos e um cesto inox

\section{Sistema do Produto}

As unidades de processo que compõe o sistema do produto serão divididas entre os dois tipos de cesto, sendo que não foi autorizado imagens do fluxo produtivo e dos equipamentos utilizados para a produção dos dois cestos pelo fabricante. 
Para o cesto em aço inox o sistema do produto é composto pelas seguintes atividades, ilustrado na figura 22 :

Atividade 1: Processo de extração do minério e beneficiamento, composto por: Extração mineral, Processo de fragmentação, Classificação, Enriquecimento, Processo pré-extrativo Armazenamento, redução, aciaria, lingotamento contínuo, laminação a quente, laminação a frio, recozimento e decapagem,

Atividade 2: Transporte rodoviário de caminhão da siderúrgica até a indústria de manufatura, a siderúrgica está situada na cidade de Timóteo - MG e percorre um trajeto de $865 \mathrm{Km}$ até a cidade de Rio Claro, onde se encontra a Indústria de manufatura.

Atividade 3: Processo Industrial do cesto: consiste em dois fluxos paralelos, um para a produção do fundo do cesto que é conformado através do processo de estampagem por prensa mecânica com ferramenta de 5 estágios e posteriormente estocado. Outro fluxo para a produção da lateral do cesto, que consiste no corte, furação e calandra. União do fundo do cesto com a lateral através do processo de rebordagem, para este fluxo é utilizado um equipamento exclusivamente desenvolvido para a confecção da lateral do cesto.

Atividade 4: Montagem do cesto na lavadora, a partir da montagem do cesto no produto, o processo de fabricação do produto, os testes feitos na linha de montagem que necessitam do funcionamento do cesto e o processo de embalagem, são iguais para as lavadoras, independente do material do cesto.

Atividade 5: Transporte do produto acabado para a Indústria, através de transporte rodoviário, saindo de Rio Claro - SP para os três centros de distribuição e armazenagem de produtos, em média são percorridos 537,4 km. 
Atividade 6: Uso do produto pelo consumidor, considerado como o ciclo de vida da lavadora, estimado por 7 anos pelo fabricante da lavadora, onde o cesto é fundamental para o ciclo de centrifugação.

Atividade 7: Disposição final do cesto ou do produto, devido à troca ou quebra.

Para o cesto Plástico o sistema do produto é composto pelas seguintes atividades:

Atividade 1: Extração da matéria-prima e beneficiamento do plástico

Atividade 2: Transporte rodoviário da Indústria de beneficiamento à indústria de manufatura, a matéria-prima é transportada de Paulínia-SP para Rio Claro, percorrendo um trajeto de $76 \mathrm{~km}$.

Atividade 3: Produção do cesto plástico através do processo de conformação em molde por injeção;

Atividade 4: Montagem do cesto na lavadora, a partir da montagem do cesto no produto, o processo de fabricação do produto, os testes feitos na linha de montagem que necessitam do funcionamento do cesto e o processo de embalagem, são iguais para as lavadoras, independente do material do cesto.

Atividade 5: Transporte do produto acabado para a Indústria, através de transporte rodoviário, saindo de Rio Claro para os três centros de distribuição e armazenagem de produtos, em média são percorridos 537,4km.

Atividade 6: Uso do produto pelo consumidor, considerado como o ciclo de vida da lavadora, estimado por 7 anos pelo fabricante da lavadora, onde o cesto é fundamental para o ciclo de centrifugação.

Atividade 7: Disposição final do cesto ou do produto, devido a troca ou quebra. 
Após a conformação em molde por processo de injeção (atividade 3), a peça já possui seu formato desejado, não necessitando de uma junção com outras partes, como acontece no cesto em aço inox.

Durante o processo de injeção, pequenas variações do processo, podem afetar no produto final, tornando a peça não conforme para a montagem na lavadora de roupa, por isso, há um processo de reciclagem do material para ser utilizado em outros componentes da lavadora, o cesto não pode receber material reciclado em sua composição, devido à criticidade técnica do item. 


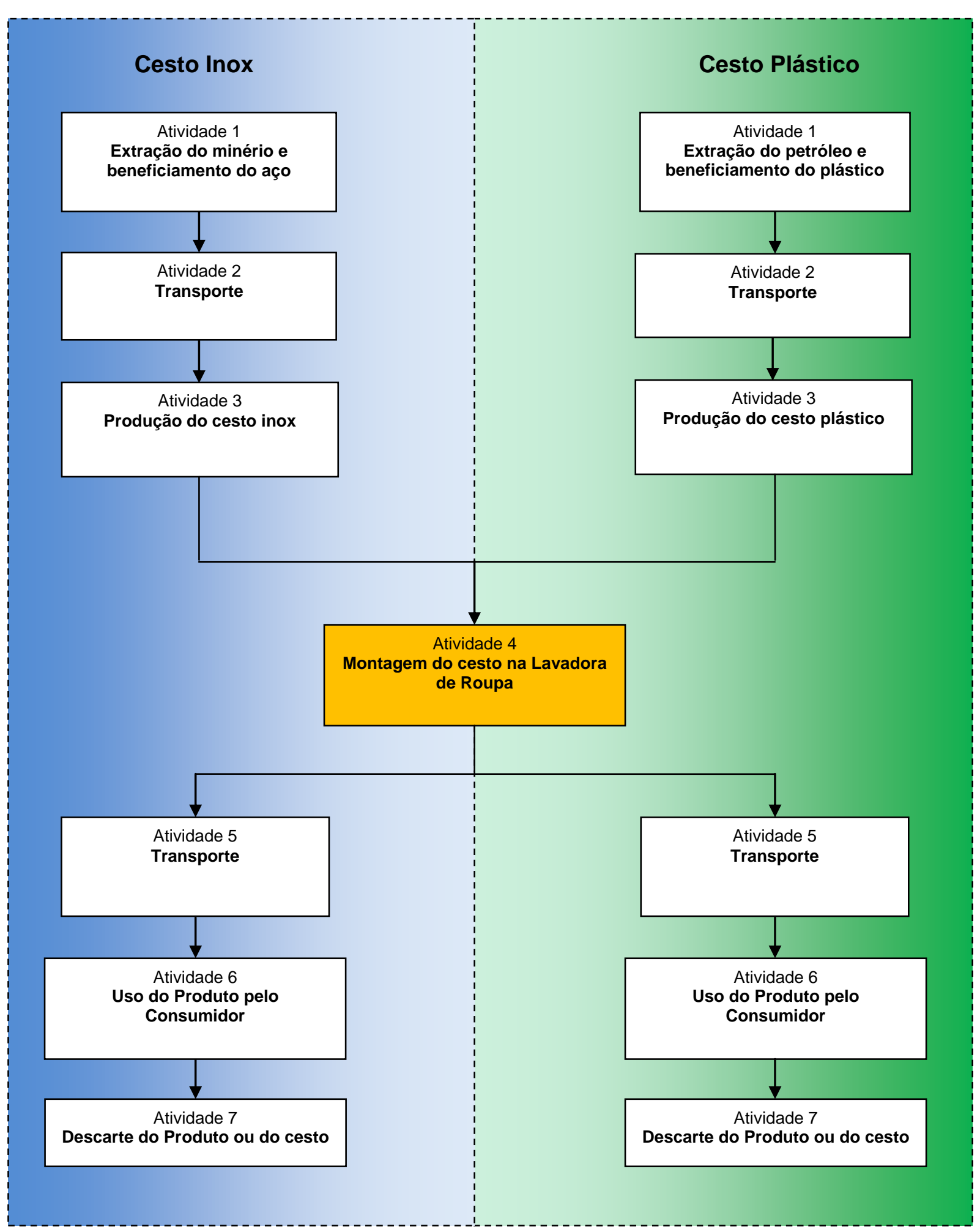

Figura 22 - Sistemas do Cesto Inox e Plástico 


\subsubsection{Tipo de dados utilizados}

Os dados das atividades principais do ciclo de vida dos dois tipos de cesto da lavadora, que correspondem às unidades de processo, foram adquiridos diretamente no processo, sendo os demais completados pela bibliografia e por consulta a especialistas.

Os dados da extração de matéria-prima e do consumo de caminhões foram obtidos a partir do banco de dados do EDIP, com o uso do software GABI v4.3. Os dados do consumo de diesel, pelo banco de dados do EDIP, são avaliados com base na distância percorrida pelo veículo a diesel e pela carga transportada.

Os dados de peso da carga e de distância percorrida são de fonte primária. A origem dos dados primários é datada de até dez anos, com um ano de amostragem e geograficamente compatível com a área de estudo.

A base principal da avaliação do sistema de produto é o fluxo de massa das entradas e das saídas; contudo o consumo de energia elétrica também é contabilizado.

\subsubsection{Tipo de categorias de impactos}

Dentre as categorias indicadas pelo EDIP, as selecionadas para este estudo são:

- Consumo de Recursos Renováveis;

- Consumo de Recursos Não Renováveis;

- Consumo de Energia;

- Potencial de Aquecimento Global;

- Acidificação; 
- Eutrofização;

- Ecotoxicidade;

- Toxicidade Humana.

\subsubsection{Escopo geográfico}

O componente em análise é montado em lavadoras que são comercializadas no Brasil.

Como as atividades do ciclo de vida da lavadora de roupa acontecem dentro do território nacional, a questão geográfica está focada no Brasil.

\subsubsection{Escopo temporal}

Os dados coletados para este estudo poderão ser utilizados por um período de 5 anos, pois não há previsão de grandes alterações no conceito e tecnologia do cesto da lavadora de roupa.

\subsubsection{Escopo tecnológico}

A tecnologia utilizada para a confecção dos cestos é uma tecnologia conhecida e atualmente utilizada nas indústrias. No processo do cesto plástico, envolve a tecnologia de injeção de termoplásticos, sendo necessária a utilização de uma injetora e um molde para materiais plásticos.

Para o processo do cesto inox, é utilizado um equipamento para a confecção da lateral do cesto, o conceito deste equipamento está em uso a mais de 10 anos, onde há a manutenção preventiva tanto para o equipamento, como para as ferramentas necessárias para o processo. Para a confecção do fundo do cesto, a tecnologia utilizada é a estampagem a frio por uso de matrizes e ferramentas 


\subsubsection{Fronteira do sistema}

A fronteira do sistema foi definida pelo critério de corte de insumos inferiores a $5 \%$ da quantidade da massa de material consumido pelo sistema do produto, e pelo potencial de impacto ambiental da cadeia produtiva do insumo utilizado.

O uso do diesel no transporte, devido à relevância ambiental, também foi avaliado.

\subsubsection{Limitações}

O estudo da avaliação do ciclo de vida (ACV) do cesto de plástico e de inox da lavadora apresentou ao longo da sua realização, algumas limitações importantes que devem ser consideradas e são comentadas neste capítulo.

Como não foi possível a obtenção de dados na empresa que fabrica os cestos, a maior parte dos dados utilizados para a elaboração do inventário do ciclo de vida foi composta por dados secundários, de bases de dados internacionais, principalmente européias. Assim, as informações obtidas na base de dados do software GABI v 4.3, foi utilizada para a elaboração do inventário.

Os dados primários utilizados estão relacionados, principalmente, ao consumo de recursos na fase de uso (energia elétrica e água). Entretanto, como a matriz energética européia é muito diversa da brasileira, que é predominantemente hidrelétrica, optou-se pela não quantificação dos impactos ambientais do consumo de energia na fase de uso da lavadora, deixando somente esse valor de consumo.

Adicionalmente, não foram encontrados dados para a produção e injeção do polipropileno separadamente nas bases de dados do software GABI. Dessa forma, produção e injeção foram consideradas como um único processo e integrarão uma das fases do ciclo de vida do cesto plástico da lavadora. Deve-se citar, ainda, que o 
polipropileno utilizado pela empresa contém uma substância denominada "talco", do qual não foram obtidas informações sobre consumo de recursos e que foi, dessa forma, desconsiderada da análise em função da sua baixa concentração no polipropileno. Como os processos foram considerados conjuntamente, aferiu-se que as perdas do processo de injeção já estavam sendo consideradas nos resultados da base de dados.

É importante considerar, ainda, que a lavadora e os cestos podem ter o seu ciclo de vida entendido além dos 7 anos previstos nesse estudo, mesmo que ocorra uma menor freqüência de uso. Entretanto, como não foi possível obter esses dados com precisão, optou-se pela não consideração desse prolongamento da vida útil do produto. Adicionalmente, o cesto pode apresentar outras funções após o seu fim de vida.

Considerou-se que, após a vida útil dos cestos, todos seriam encaminhados para destinação final em aterro sanitário. Embora haja a possibilidade de reciclagem dos cestos, ela não foi levada em consideração devido à falta de dados concretos sobre a porcentagem de cestos que são reciclados. Por outro lado, como a destinação de grande parte dos resíduos sólidos no Brasil ainda é realizada em locais não adequados (lixões a céu aberto ou aterro controlado), o impacto ambiental da destinação nesses locais deve ser maior do que aquela observada em aterro sanitário e considerada nesse estudo.

Apesar dos dados obtidos na empresa para o transporte da matéria-prima sejam bastante confiáveis, os dados relativos ao transporte do produto para os centros de distribuição foram obtidos por meio da realização da média ponderada entre as distâncias médias percorridas das fábricas até os centros de distribuição. Da mesma forma, o transporte dos centros de distribuição para as lojas varejistas e 
para a residência dos consumidores não foi considerado nesse estudo, dado a diversidade de produtos que podem ser transportados nessas entregas e também a grande variabilidade de distâncias percorridas, além da capacidade do caminhão.

Adicionalmente, o diesel utilizado como padrão foi o da Europa e deve-se considerar que o diesel brasileiro apresenta maior porcentagem de enxofre, o que ocasiona um impacto potencialmente maior.

Finalmente, optou-se pela realização da normalização dos dados dos impactos potenciais obtidos para que os resultados pudessem ser comparados, de forma a se determinar a fase do ciclo de vida que apresenta o maior potencial de impacto ambiental, assim como quais são as categorias de impacto que mais contribuem para essa situação. Como não existem referências de normalização para o Brasil, foram utilizados os dados da Europa, de acordo com o método EDIP.

Durante a fase avaliação não foi encontrada, nas tabelas do EDIP, a maioria $\underline{\text { dos fatores de caracterização das substâncias emitidas para os ciclos de vida do }}$ cesto plástico. Deve-se verificar se essas substâncias, emitidas naquelas quantidades, são relevantes para o estudo, e se sim, deve-se procurar os fatores de caracterização em outras fontes de dados. 


\subsubsection{Análise de Inventário}

A análise do inventário deste trabalho foi realizada de acordo com os insumos e emissões desde a produção da matéria-prima para a produção dos dois cestos, até o descarte.

Para a análise do inventário, foram considerados dois cestos plásticos, pois durante a fase de uso do produto, os produtos que recebem o cesto plástico costumam a ter uma troca devido a manchas ou falhas do componente. O cesto inox normalmente não há troca durante sua fase de uso.

As tabelas contendo o inventário do ciclo de vida do cesto plástico e do cesto inox estão nos anexos B e C, respectivamente.

Em todo o ciclo de vida do cesto plástico e do cesto inox podemos observar que há emissão dos seguintes substâncias para a atmosfera: Monóxido de Carbono (CO); Óxido Nitroso $\left(\mathrm{N}_{2} \mathrm{O}\right)$; Metano $\left(\mathrm{CH}_{4}\right)$; Dióxido de Carbono $\left(\mathrm{CO}_{2}\right)$ e Halon $\left(\mathrm{CBrF}_{3}\right)$, substâncias que contribuem principalmente para o aquecimento global.

A tabela 05 mostra os valores das emissões atmosféricas através das fases do ciclo de vida do cesto plástico. As grandes emissões de substâncias para a atmosfera estão concentradas nas fases de transporte da matéria-prima e transporte de produtos emitidos pelos caminhões, uma parte das emissões, principalmente de $\mathrm{CO}_{2}$, está concentrada na fase de uso onde há o consumo de energia para o funcionamento do produto. 
Capítulo 5: Resultados

\begin{tabular}{|c|c|c|c|c|c|}
\hline Fases do ciclo de vida & CO & $\mathrm{N}_{2} \mathrm{O}$ & $\mathrm{CH}_{4}$ & $\mathrm{CO}_{2}$ & $\mathrm{CBrF}_{3}$ \\
\hline Produção da Matéria-Prima & $7,98 \mathrm{E}+00$ & $1,04 \mathrm{E}+01$ & $4,85 E+02$ & $1,03 E+04$ & $2,94 \mathrm{E}+00$ \\
\hline Transporte da Matéria-Prima & $2,72 E+05$ & $2,95 \mathrm{E}+05$ & $2,79 E+04$ & $6,33 \mathrm{E}+07$ & $0,00 E+00$ \\
\hline Transporte do Produto & $1,92 \mathrm{E}+06$ & $2,09 E+06$ & $1,98 \mathrm{E}+05$ & $4,47 E+08$ & $0,00 E+00$ \\
\hline Fase de uso & $6,64 \mathrm{E}+01$ & $5,30 E+02$ & $2,50 E+04$ & $2,40 E+05$ & $6,85 E+00$ \\
\hline Disposição & $9,25 \mathrm{E}-01$ & $7,13 \mathrm{E}-01$ & $1,74 E+03$ & $6,27 E+02$ & $3,22 \mathrm{E}-02$ \\
\hline To & $2,19 E+06$ & $2,38 E+06$ & $2,53 E+05$ & $5,11 E+08$ & $9,82 E+00$ \\
\hline
\end{tabular}

Tabela 5 - Quantidade de substâncias emitidas para atmosfera no ciclo de vida do cesto plástico

A tabela 06 demonstra os valores de emissões atmosféricas para o ciclo de vida do cesto inox. Do mesmo modo que o cesto plástico, as fases de transporte de matéria-prima e transporte de produto são os principais fatores de emissão de substâncias para a atmosfera.

\begin{tabular}{|c|c|c|c|c|c|}
\hline Fases do ciclo de vida & $\mathrm{CO}$ & $\mathrm{N}_{2} \mathrm{O}$ & $\mathrm{CH}_{4}$ & $\mathrm{CO}_{2}$ & $\mathrm{CBrF}_{3}$ \\
\hline Produção da Matéria-Prima & $2,95 \mathrm{E}+01$ & $9,44 \mathrm{E}+01$ & $7,75 \mathrm{E}+02$ & $2,45 E+04$ & $0,00 E+00$ \\
\hline Transporte da Matéria-Prima & $2,77 E+06$ & $3,00 \mathrm{E}+06$ & $2,84 \mathrm{E}+05$ & $6,44 \mathrm{E}+08$ & $0,00 E+00$ \\
\hline Transporte do Produto & $1,72 E+06$ & $1,87 E+06$ & $1,77 E+05$ & $4,00 E+08$ & $0,00 E+00$ \\
\hline Fase de uso & $6,64 \mathrm{E}+01$ & $5,30 E+02$ & $2,50 E+04$ & $2,40 E+05$ & $6,85 E+00$ \\
\hline Disposição & $7,38 \mathrm{E}-01$ & $6,15 \mathrm{E}-01$ & $2,13 E+00$ & $6,88 \mathrm{E}+01$ & $2,84 \mathrm{E}-02$ \\
\hline Total & $4,49 E+06$ & $4,87 E+06$ & $4,87 E+05$ & $1,04 \mathrm{E}+09$ & $6,88 E+00$ \\
\hline
\end{tabular}

Tabela 6 - Quantidade de substâncias emitidas para atmosfera no ciclo de vida do cesto Inox

Comparando os valores totais das tabelas 5 e 6 , verifica-se que os resultados para as emissões do ciclo de vida do cesto inox correspondem, aproximadamente, ao dobro das emissões do ciclo de vida dos cestos plásticos.

A avaliação dos impactos é realizada de modo quantitativo e qualitativo. A avaliação quantitativa é baseada na metodologia do EDIP, descrito por Wenzel, et. al. (1997), onde o inventário é traduzido na quantificação das potenciais contribuições às categorias de impactos selecionadas.

As categorias selecionadas para o estudo foram o consumo de recursos: renováveis, não renováveis e energia; já para os potenciais de impactos foram 
estudados os correspondentes ao: potencial de aquecimento global, potencial de formação de ozônio fotoquímico, potencial de acidificação, potencial de eutrofização, potencial de ecotoxicidade e toxicidade humana e por último a parte de resíduos sólidos.

Os resultados para as categorias de impacto são apresentados a seguir:

Consumo de Energia

Conforme mostra o gráfico 08 , do total de consumo de energia do ciclo de vida de dos cestos, $52 \%$ do consumo total é para o cesto inox e $48 \%$ é para os dois cestos plásticos.

O consumo de energia para a produção do cesto inox é maior que para o cesto plástico, pois como o cesto inox é formado por duas partes, o consumo de energia é necessário para a estampagem do fundo do cesto, para a conformação da lateral e a união das duas peças.

Para o cesto plástico, o consumo de energia é maior no processo de injeção do plástico no molde, mesmo considerando dois cestos plásticos no estudo, o cesto inox apresentou maior consumo de energia.

A fase de uso do produto para ambos os cestos gera a mesma quantidade de consumo de energia, ou seja, ambos os tipos de cestos não interferem no consumo de energia do produto final. 


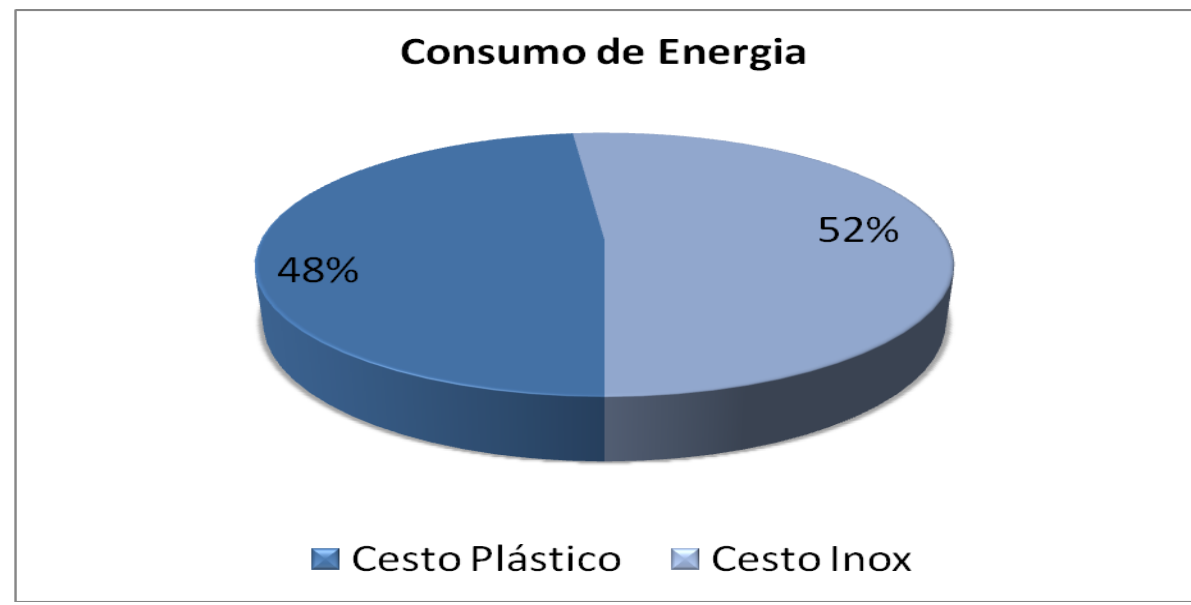

Gráfico 8 - Percentual de Consumo de Energia

Consumo de Recursos Renováveis

O consumo de recursos renováveis para o ciclo de vida do cesto plástico representa 49\%, quanto o consumo de recursos renováveis para o cesto inox representa 51\%, conforme ilustrado no gráfico 09.

O maior consumo está na fase de produção da matéria-prima e na fase de uso do produto, onde o consumo de água é grande devido à característica do produto.

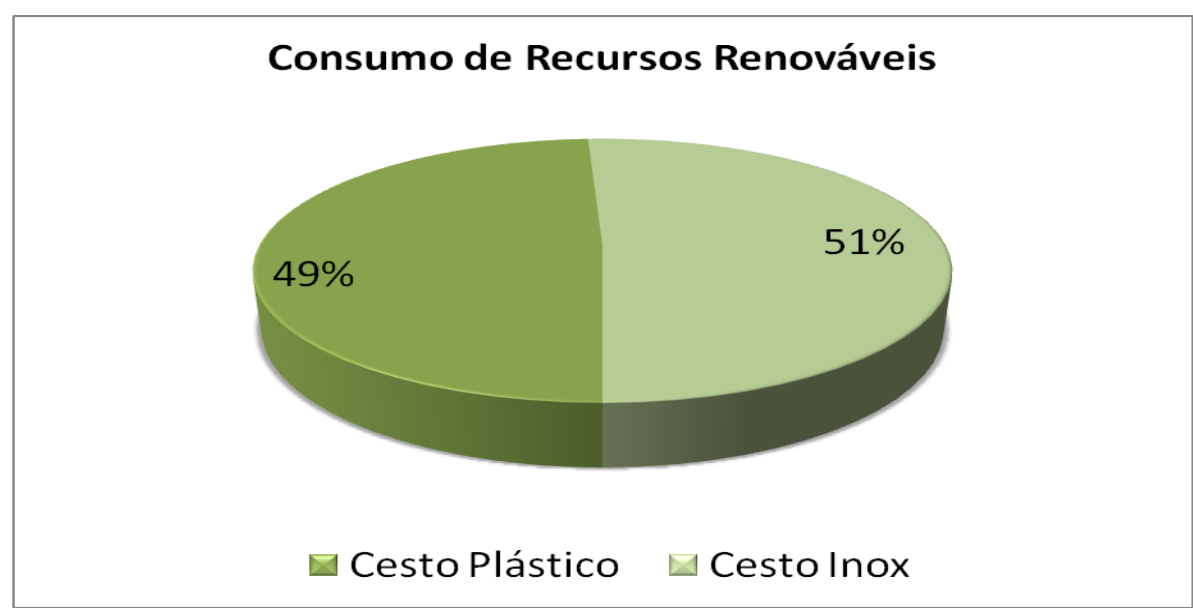

Gráfico 9 - Percentual de Consumo de Recursos Renováveis 
Para o consumo de recursos não renováveis, do total consumido para a produção dos dois tipos de cestos, $67 \%$ dos recursos não renováveis são utilizados no cesto e aço inox e 33\% são utilizados no cesto plástico. Mesmo considerando dois cestos plásticos no estudo, o cesto inox consome o dobro de recursos não renováveis, conforme mostra o gráfico 08 .

As fases de produção da matéria-prima e transportes são as fases que mais consomem recursos não renováveis, devido ao consumo de minérios e petróleo para a produção do polipropileno e para a produção de diesel para o transporte.

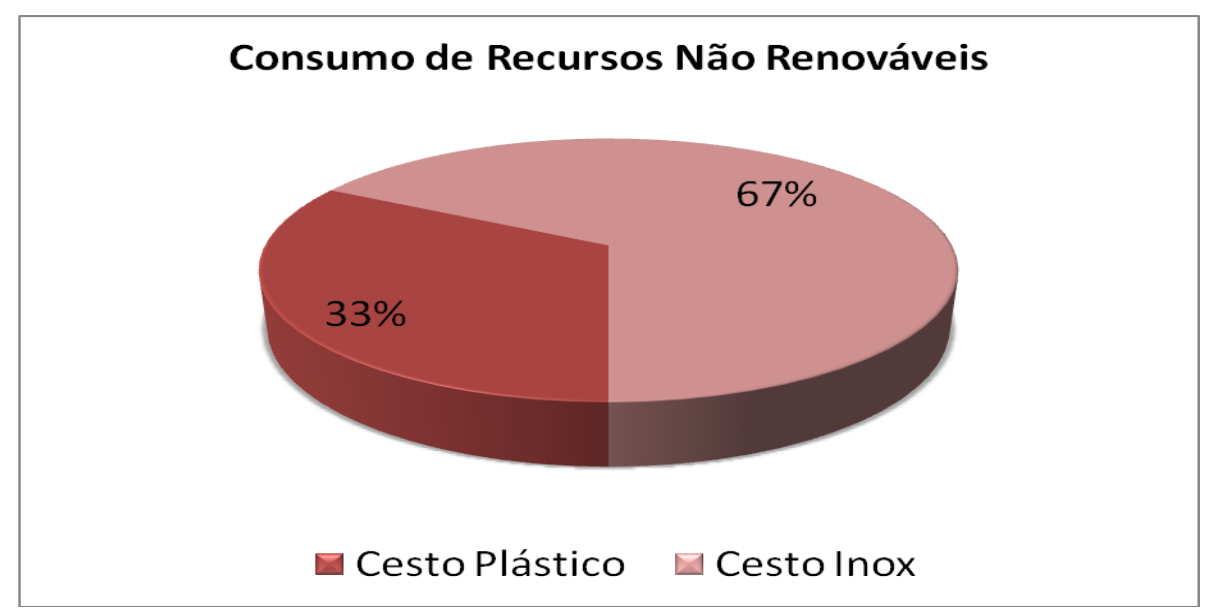

Gráfico 10 - Percentual de consumo de Recursos Não Renováveis

\subsubsection{Avaliação de Impacto}

\section{Potencial de Aquecimento Global}

Conforme ilustrado na tabela 07 os valores mais significativos para a contribuição do potencial de aquecimento global, estão nas fases de transporte da matéria-prima e no transporte do produto. 
Isso ocorre devido à grande quantidade de dióxido de carbono $\left(\mathrm{CO}_{2}\right)$, monóxido de carbono $(\mathrm{CO})$ e óxido nitroso $\left(\mathrm{C}_{2} \mathrm{O}\right)$ emitidos pelos caminhões e a grande distância percorrida.

\begin{tabular}{lcc}
\hline Unidade de Processo & $\begin{array}{c}\text { Aquecimento Global do Plástico } \\
\left(\mathrm{KgCO}_{\mathbf{2}} / \mathbf{2} \text { cestos plástico }\right)\end{array}$ & $\begin{array}{c}\text { Aquecimento Global do Aço Inox } \\
\left(\mathrm{KgCO}_{\mathbf{2}} / \mathbf{1} \text { cesto inox }\right)\end{array}$ \\
\hline Produção Matéria-Prima & $1,08 \mathrm{E}+04$ & $2,54 \mathrm{E}+04$ \\
Transporte matéria-prima & $6,38 \mathrm{E}+07$ & $6,50 \mathrm{E}+08$ \\
Produção do cesto & $0,00 \mathrm{E}+00$ & $0,00 \mathrm{E}+00$ \\
Transporte Produto & $4,51 \mathrm{E}+08$ & $4,04 \mathrm{E}+08$ \\
Fase de uso & $2,66 \mathrm{E}+05$ & $2,66 \mathrm{E}+05$ \\
Disposição & $2,37 \mathrm{E}+03$ & $7,23 \mathrm{E}+01$ \\
\hline TOTAL & $\mathbf{5 , 1 6 E + 0 8}$ & $\mathbf{1 , 0 5 E + 0 9}$ \\
\hline \hline
\end{tabular}

Tabela 7 - Potencial de Aquecimento Global

No gráfico 11 é possível visualizar que os maiores valores se encontram nas fases de transporte. Há uma grande diferença entre os dois cestos na fase de transporte da matéria-prima, isso ocorre devido às diferentes distâncias entre as indústrias que produzem a matéria-prima, para a indústria de manufatura do cesto.

A distância percorrida para a matéria-prima do cesto inox até a indústria de manufatura é em média de $865 \mathrm{~km}$, por outro lado, a distância média percorrida para a matéria-prima do cesto plástico é de $67 \mathrm{~km}$. 


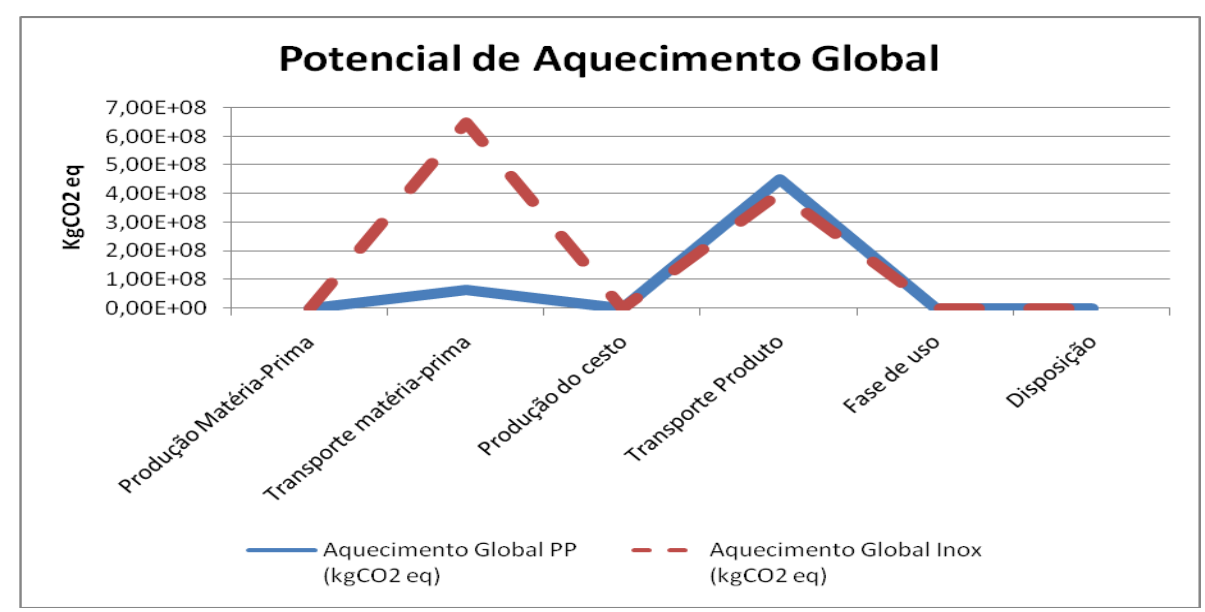

Gráfico 11 - Potencial de Aquecimento Global

$\mathrm{Na}$ fase de transporte do produto a média percorrida até os grandes centros de distribuição é de 537 km, a pequena diferença nos resultados entre os dois cestos, é devido ao peso final do produto.

A fase de uso do produto também tem uma contribuição significativa para o potencial de aquecimento global, devido às emissões geradas para a produção de energia elétrica para o funcionamento do produto.

\section{Potencial de Formação de Ozônio Fotoquímico}

Na tabela 08, podemos observar que nas fases de transporte da matéria-prima e o transporte do produto as emissões de hidrocarbonetos e monóxido de carbono (CO) que contribuem para a formação de ozônio são maiores, seguidos pelas fases de disposição e produção da matéria-prima.

\begin{tabular}{lcc}
\hline \hline \multicolumn{1}{c}{ Unidade de Processo } & $\begin{array}{c}\text { Formação de Ozônio do Plástico } \\
\text { (Kg C2H4 / } \mathbf{2} \text { cestos plástico) }\end{array}$ & $\begin{array}{c}\text { Formação de Ozônio do Aço } \\
\text { Inox (Kg C2H4 / 1 cesto inox) }\end{array}$ \\
\hline Produção Matéria-Prima & $2,68 \mathrm{E}-01$ & $1,18 \mathrm{E}+00$ \\
Transporte matéria-prima & $4,33 \mathrm{E}+03$ & $4,41 \mathrm{E}+04$ \\
Produção do cesto & $0,00 \mathrm{E}+00$ & $0,00 \mathrm{E}+00$ \\
Transporte Produto & $3,06 \mathrm{E}+04$ & $2,74 \mathrm{E}+04$ \\
Fase de uso & $8,03 \mathrm{E}+00$ & $8,03 \mathrm{E}+00$ \\
Disposição & $5,01 \mathrm{E}-01$ & $1,18 \mathrm{E}-02$
\end{tabular}


Assim como no gráfico anterior, o cesto inox tem um maior potencial de formação de ozônio fotoquímico como mostra o gráfico 12.

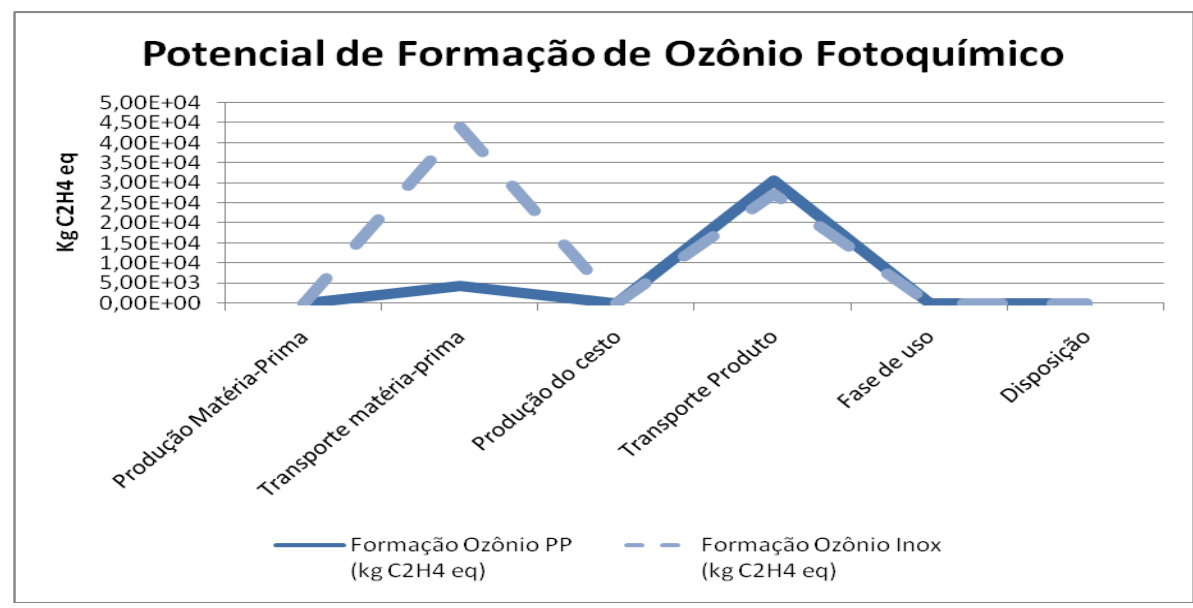

Gráfico 12 - Comparativo do Potencial de Formação de Ozônio Fotoquímico.

\section{Potencial de Acidificação}

$\mathrm{Na}$ tabela 09, as fases de transporte são as que mais contribuem para o potencial de Acidificação, devido às emissões de amônia, oxido de nitrogênio e dióxido de enxofre, emitidos pelo caminhão no transporte.

\begin{tabular}{lcc}
\hline \hline \multicolumn{1}{c}{ Unidade de Processo } & $\begin{array}{c}\text { Potencial de Acidificação do } \\
\text { Plástico (Kg SO2 / } \mathbf{2} \text { cestos } \\
\text { plástico) }\end{array}$ & $\begin{array}{c}\text { Potencial de Acidificação do Aço } \\
\text { Inox (Kg SO2 / 1 cesto inox) }\end{array}$ \\
\hline Produção Matéria-Prima & $1,03 \mathrm{E}+02$ & $1,27 \mathrm{E}+02$ \\
Transporte matéria-prima & $4,58 \mathrm{E}+05$ & $4,67 \mathrm{E}+06$ \\
Produção do cesto & $0,00 \mathrm{E}+00$ & $0,00 \mathrm{E}+00$ \\
Transporte Produto & $3,24 \mathrm{E}+06$ & $2,90 \mathrm{E}+06$ \\
Fase de uso & $1,46 \mathrm{E}+03$ & $1,46 \mathrm{E}+03$ \\
Disposição & $9,96 \mathrm{E}-01$ & $7,97 \mathrm{E}-01$ \\
\hline TOTAL & $\mathbf{3 , 7 0 E + 0 6}$ & $\mathbf{7 , 5 7 E + 0 6}$ \\
\hline \hline
\end{tabular}


A diferença nos valores entre o cesto plástico e o cesto inox, é devido a distância percorrida pelo caminhão necessária para cada tipo de material como ilustrado no gráfico 13.

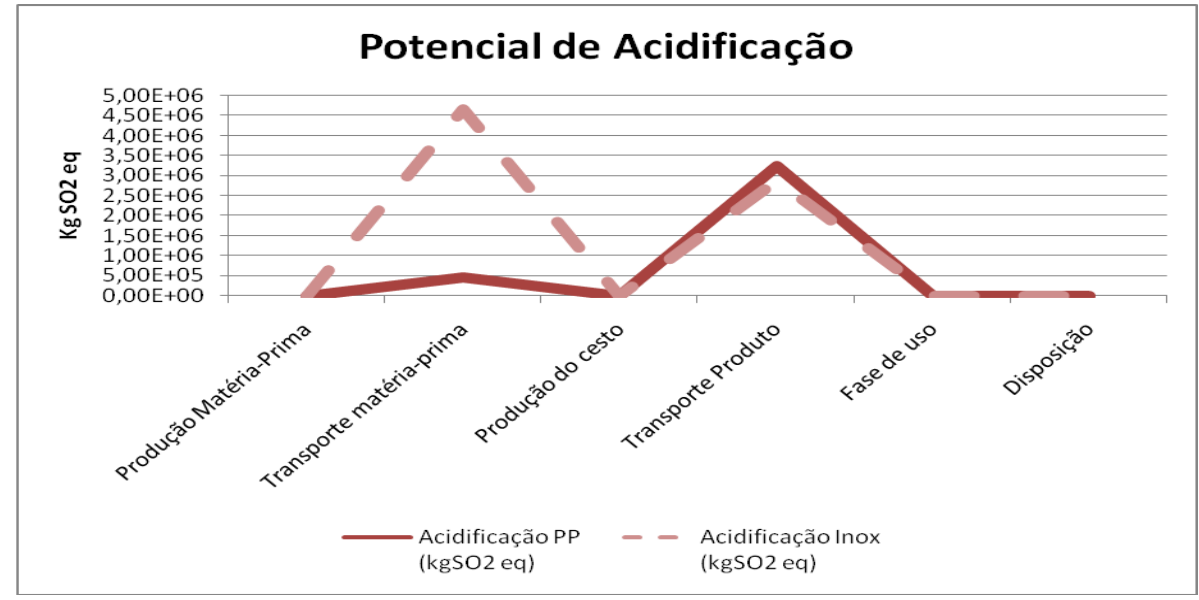

Gráfico 13 - Comparativo do Potencial de Acidificação

\section{Potencial de Eutrofização}

A contribuição para o potencial de eutrofização (tabela 10) ocorre nas fases de produção de matéria-prima, transporte do produto, produção de matéria-prima e uso do produto emissões para o ar de Amônia, óxido de nitrogênio e óxido nitroso.

\begin{tabular}{lcc}
\hline \multicolumn{1}{c}{ Unidade de Processo } & $\begin{array}{c}\text { Potencial de Eutrofização do } \\
\text { Plástico (2 cestos plástico) }\end{array}$ & $\begin{array}{c}\text { Potencial de Eutrofização do Aço } \\
\text { Inox (Kg NO3 / 1 cesto inox) }\end{array}$ \\
\hline Produção Matéria-Prima & $7,80 \mathrm{E}+01$ & $5,12 \mathrm{E}+01$ \\
Transporte matéria-prima & $8,83 \mathrm{E}+05$ & $8,99 \mathrm{E}+06$ \\
Produção do cesto & $0,00 \mathrm{E}+00$ & $0,00 \mathrm{E}+00$ \\
Transporte Produto & $6,24 \mathrm{E}+06$ & $5,58 \mathrm{E}+06$ \\
Fase de uso & $9,80 \mathrm{E}+02$ & $9,80 \mathrm{E}+02$ \\
Disposição & $1,54 \mathrm{E}+01$ & $1,34 \mathrm{E}+00$ \\
\hline TOTAL & $\mathbf{7 , 1 3 E + 0 6}$ & $\mathbf{1 , 4 6 E + 0 7}$ \\
\hline \hline
\end{tabular}


O gráfico 14 ilustra o potencial de eutrofização para os dois tipos de cesto, como nos gráficos anteriores as fases de transporte são as mais representativas.

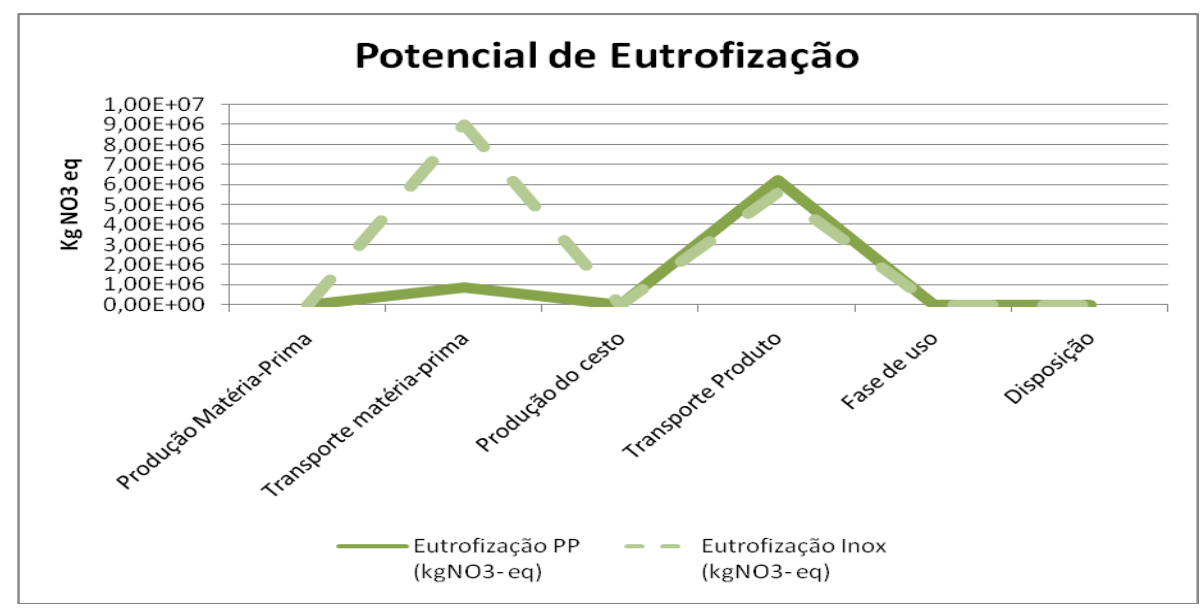

Gráfico 14 - Comparativo do Potencial de Eutrofização

\section{Potencial de Ecotoxicidade}

Os resultados para o potencial de ecotoxicidade para o cesto plástico e para o cesto inox estão representados respectivamente nas tabelas 11 e 12.

As fases de produção de matéria-prima, fase de uso e disposição, são as que mais causam ecotoxicidade hídrica e ecotoxicidade crônica para o solo. Para a fase de produção da matéria-prima esta contribuição acontece devido às emissões inerentes ao processo produtivo. Para a fase de uso, as emissões acontecem por causa da água drenada pela lavadora após o processo de lavagem. Para a fase de disposição, os componentes são descartados em aterros sanitários.

\begin{tabular}{lccc}
\hline \hline Unidade de Processo & $\begin{array}{c}\text { Ecotoxicidade crônica } \\
\text { na água para o Plástico } \\
\left(\mathbf{m}^{\mathbf{3}} / \mathbf{K g}\right)\end{array}$ & $\begin{array}{c}\text { Ecotoxicidade aguda na } \\
\text { água para o Plástico } \\
\left(\mathbf{m}^{3} / \mathbf{K g}\right)\end{array}$ & $\begin{array}{c}\text { Ecotoxicidade crônica } \\
\text { no solo para o Plástico } \\
\left(\mathbf{m}^{3} / \mathbf{K g}\right)\end{array}$ \\
\hline Produção Matéria-Prima & $1,72 \mathrm{E}+08$ & $1,91 \mathrm{E}+01$ & $1,89 \mathrm{E}+04$ \\
Transporte matéria-prima & $8,00 \mathrm{E}+03$ & $0,00 \mathrm{E}+00$ & $4,57 \mathrm{E}+03$ \\
Produção do cesto & $0,00 \mathrm{E}+00$ & $0,00 \mathrm{E}+00$ & $0,00 \mathrm{E}+00$ \\
Transporte Produto & $8,00 \mathrm{E}+03$ & $0,00 \mathrm{E}+00$ & $4,57 \mathrm{E}+03$ \\
Fase de uso & $1,72 \mathrm{E}+08$ & $2,93 \mathrm{E}+03$ & $1,89 \mathrm{E}+04$
\end{tabular}




\begin{tabular}{llll} 
Disposição & $1,71 \mathrm{E}+08$ & $9,39 \mathrm{E}+02$ & $1,89 \mathrm{E}+04$ \\
\hline TOTAL & $\mathbf{5 , 1 4 E + 0 8}$ & $\mathbf{3 , 8 9 E + 0 3}$ & $\mathbf{6 , 5 9 E + 0 4}$ \\
\hline
\end{tabular}

Tabela 11 - Ecotoxicidade para o Plástico

\begin{tabular}{lccc}
\hline Unidade de Processo & $\begin{array}{c}\text { Ecotoxicidade crônica } \\
\text { na água para o Aço Inox } \\
\left(\mathbf{m}^{\mathbf{3}} \mathbf{K g}\right)\end{array}$ & $\begin{array}{c}\text { Ecotoxicidade aguda na } \\
\text { água para o Aço Inox } \\
\left(\mathbf{m}^{\mathbf{3}} \mathbf{K} \mathbf{~}\right)\end{array}$ & $\begin{array}{c}\text { Ecotoxicidade crônica } \\
\text { no solo para o Aço Inox } \\
\left(\mathbf{m}^{3} / \mathbf{K g}\right)\end{array}$ \\
\hline Produção Matéria-Prima & $2,72 \mathrm{E}+08$ & $1,37 \mathrm{E}+02$ & $8,02 \mathrm{E}+06$ \\
Transporte matéria-prima & $8,00 \mathrm{E}+03$ & $0,00 \mathrm{E}+00$ & $4,57 \mathrm{E}+03$ \\
Produção do cesto & $0,00 \mathrm{E}+00$ & $0,00 \mathrm{E}+00$ & $0,00 \mathrm{E}+00$ \\
Transporte Produto & $8,00 \mathrm{E}+03$ & $0,00 \mathrm{E}+00$ & $4,57 \mathrm{E}+03$ \\
Fase de uso & $1,72 \mathrm{E}+08$ & $2,93 \mathrm{E}+03$ & $1,89 \mathrm{E}+04$ \\
Disposição & $1,72 \mathrm{E}+08$ & $4,35 \mathrm{E}+03$ & $1,89 \mathrm{E}+04$ \\
\hline TOTAL & $\mathbf{6 , 1 5 E + 0 8}$ & $\mathbf{7 , 4 2 E + 0 3}$ & $\mathbf{8 , 0 7 E + 0 6}$ \\
\hline \hline
\end{tabular}

Tabela 12 - Ecotoxicidade para o Aço Inox

\section{Potencial de Toxicidade Humana}

Os resultados para o potencial de toxicidade humana para o cesto plástico e para o cesto inox estão representados respectivamente nas tabelas 13 e 14 .

As contribuições para a toxicidade humana para o ar, água e solo, podem ser descrita a cada fase do ciclo de vida do cesto. Na fase de produção da matériaprima todas as emissões são devido aos gases e resíduos gerados durante todo o processo de fabricação. Nas duas fases de transporte, as emissões para o ar são maiores devido aos gases emitidos pelo processo de queima do diesel no motor do caminhão. Para a fase de uso, as emissões ocorrem devido ao processo de funcionamento do produto que drena a água para o sistema de esgoto ou pode ser drenado diretamente para o solo, isso depende muito de como o consumidor utiliza 0 produto. $\mathrm{Na}$ fase de disposição, o cesto inox ou plástico é descartado diretamente no aterro sanitário. 
Capítulo 5: Resultados

\begin{tabular}{lccc}
\hline Unidade de Processo & $\begin{array}{c}\text { Toxicidade Humana via } \\
\text { ar para o Plástico } \\
\left(\mathbf{m}^{3} / \mathbf{K g}\right)\end{array}$ & $\begin{array}{c}\text { Toxicidade Humana via } \\
\text { água para o Plástico } \\
\left(\mathbf{m}^{3} / \mathbf{K g}\right)\end{array}$ & $\begin{array}{c}\text { Toxicidade Humana via } \\
\text { solo para o Plástico } \\
\left(\mathbf{m}^{\mathbf{3}} \mathbf{K g}\right)\end{array}$ \\
\hline Produção Matéria-Prima & $2,37 \mathrm{E}+11$ & $2,24 \mathrm{E}+08$ & $1,81 \mathrm{E}+05$ \\
Transporte matéria-prima & $1,00 \mathrm{E}+10$ & $2,31 \mathrm{E}+03$ & $1,40 \mathrm{E}+04$ \\
Produção do cesto & $0,00 \mathrm{E}+00$ & $0,00 \mathrm{E}+00$ & $0,00 \mathrm{E}+00$ \\
Transporte Produto & $1,00 \mathrm{E}+10$ & $2,31 \mathrm{E}+03$ & $1,40 \mathrm{E}+04$ \\
Fase de uso & $2,36 \mathrm{E}+11$ & $2,24 \mathrm{E}+08$ & $1,81 \mathrm{E}+05$ \\
Disposição & $2,36 \mathrm{E}+11$ & $2,24 \mathrm{E}+08$ & $1,81 \mathrm{E}+05$ \\
\hline TOTAL & $\mathbf{7 , 2 9 E + 1 1}$ & $\mathbf{6 , 7 1 E + 0 8}$ & $\mathbf{5 , 7 2 E + 0 5}$ \\
\hline
\end{tabular}

Tabela 13 - Toxicidade Humana para o Plástico

\begin{tabular}{|c|c|c|c|}
\hline Unidade de Processo & $\begin{array}{l}\text { Toxicidade Humana via } \\
\text { ar para o aço Inox } \\
\left(\mathrm{m}^{3 /} / \mathrm{Kg}\right)\end{array}$ & $\begin{array}{l}\text { Toxicidade Humana via } \\
\text { água para o aço Inox } \\
\left(\mathrm{m}^{3} / \mathrm{Kg}\right)\end{array}$ & $\begin{array}{c}\text { Toxicidade Humana via } \\
\text { solo para o aço Inox } \\
\left(\mathrm{m}^{3} / \mathrm{Kg}\right)\end{array}$ \\
\hline Produção Matéria-Prima & $3,26 \mathrm{E}+11$ & $3,02 \mathrm{E}+08$ & $3,41 \mathrm{E}+05$ \\
\hline Transporte matéria-prima & $1,00 \mathrm{E}+10$ & $2,31 \mathrm{E}+03$ & $1,40 \mathrm{E}+04$ \\
\hline Produção do cesto & $0,00 \mathrm{E}+00$ & $0,00 \mathrm{E}+00$ & $0,00 \mathrm{E}+00$ \\
\hline Transporte Produto & $1,00 \mathrm{E}+10$ & $2,31 \mathrm{E}+03$ & $1,40 \mathrm{E}+04$ \\
\hline Fase de uso & $2,36 \mathrm{E}+11$ & $2,24 \mathrm{E}+08$ & $1,81 \mathrm{E}+05$ \\
\hline Disposição & $2,36 \mathrm{E}+11$ & $2,24 \mathrm{E}+08$ & $1,81 \mathrm{E}+05$ \\
\hline TOTAL & $8,18 E+11$ & $7,50 E+08$ & $7,31 E+05$ \\
\hline
\end{tabular}

Tabela 14 - Toxicidade Humana para o Aço Inox 


\section{Conclusões}

O trabalho atingiu seu objetivo geral, identificando através de uma revisão sistemática, quais os principais métodos de ACV citado pelas literaturas internacionais e a aplicação da ACV em um estudo de caso comparativo entre dois tipos de cesto da lavadora de roupa, de plástico e inox.

Durante a revisão sistemática realizada para a identificação dos principais métodos de ACV utilizados, o estudo mostrou que há uma grande variedade de métodos citados em artigos. Da mesma forma, foram identificadas diversas categorias de impacto, sendo que muitas tinham o mesmo objetivo, mas possuíam nomenclaturas diferentes.

Nenhum dos artigos analisados informou todos os critérios utilizados para o estudo da ACV, por exemplo, o estudo descreve o método utilizado, mas não informa as categorias de impacto consideradas no estudo.

Outro aspecto observado no estudo, é que não há um consenso entre os autores quanto à forma de aplicação da ACV, pois uma parte dos autores descreve a ACV como sendo uma ferramenta e outra parte dos autores descreve a ACV como uma metodologia. Entretanto, a norma ISO descreve a ACV como uma técnica formatada em uma estrutura metodológica.

Para o estudo de caso comparativo entre os dois tipos de cesto para a lavadora de roupa o método EDIP, mostrou-se fácil de ser aplicado e transparente para a identificação dos potenciais impactos ambientais gerados por cada tipo de cesto produzido.

A utilização da metodologia da ACV, por meio do método EDIP, permitiu uma avaliação quantitativa dos principais impactos ambientais gerados ao longo do ciclo 
de vida dos cestos da lavadora, permitindo acompanhar o comportamento ambiental de cada unidade de processo.

Mesmo sendo considerados dois cestos plásticos versus um cesto de inox para o estudo, o cesto de inox apresenta maiores potenciais de impacto ambiental. Este resultado se deve principalmente à distância entre o fabricante da matéria-prima do aço e a indústria de manufatura que é em média de $865 \mathrm{Km}$, enquanto, o fornecedor da matéria-prima plástica é em média de $76 \mathrm{Km}$.

O consumo de energia para a produção do cesto inox é maior que para o cesto plástico, pois o cesto inox é formado por duas partes e isso reflete no consumo de energia para a estampagem do fundo do cesto, para a conformação da lateral e a união das duas peças. O cesto plástico é formado de uma única peça durante o processo de injeção. Considerado que a geração de energia elétrica é um fator que contribui para o potencial de aquecimento global.

É viável a análise da indústria de manufatura, junto com o fornecedor da matéria-prima, para o desenvolvimento de um material que não fosse passível de manchas, o que diminuiria significativamente a quantidade de trocas do cesto plástico no produto durante a fase de uso.

Desconsiderando as fases de transporte como forma exploratória do estudo, os resultados dos potenciais impactos dos cestos foram obtidos os seguintes:

- Para todas as categorias de impacto relativas às emissões do ciclo de vida dos cestos, a fase de uso do produto foi a que teve valores mais expressivos em ambos os cestos; 
- $\mathrm{Na}$ fase de produção de matéria-prima, as categorias de potencial de aquecimento global, formação de ozônio, potencial de acidificação e consumo de recursos foram maiores no ciclo de vida do cesto de aço inox;

- Somente a categoria de potencial de eutrofização foi maior no ciclo de vida do cesto de plástico em relação ao cesto de aço inox.

O cesto inox praticamente não gera troca na fase de uso como o cesto plástico, mas os resultados mostram que um cesto inox equivale a dois cestos plásticos.

Assim, este estudo de caso possibilita não apenas a comparação entre os impactos gerados pelos componentes analisados, mas também para os demais componentes que fazem parte do produto.

Portanto, este trabalho pode contribuir como forma de conhecimento aos métodos de ACV e em sua aplicação em um estudo de caso comparativo. 


\section{Referências Bibliográficas}

AGUAR, V. C. O desenvolvimento da usabilidade de interfaces em projetos - um estudo de caso em lavadora de roupa. Dissertação (Mestrado) -Universidade Federal de São Carlos, 2004;

ASSOCIAÇÃO BRASILEIRA DE NORMAS TÉCNICAS. NBR ISO 14001 Sistema de Gestão Ambiental - Especificações e diretrizes para uso. Brasil: ABNT. 2004, 27p;

ASSOCIAÇÃO BRASILEIRA DE NORMAS TÉCNICAS. NBR ISO 14040 Gestão Ambiental - Avaliação do Ciclo de Vida - Princípios e estrutura. Brasil: ABNT. 2001, 10p;

ASSOCIAÇÃO BRASILEIRA DE NORMAS TÉCNICAS. NBR ISO 14042. Gestão Ambiental - Avaliação do ciclo de vida - avaliação do impacto do ciclo de vida, 2004, 17p;

ASSOCIAÇÃO BRASILEIRA DE NORMAS TÉCNICAS. NBR ISO 14062. Gestão Ambiental - Integração de aspectos ambientais no projeto e desenvolvimento do produto, 2004, 26p;

BARRETO, A. P. L.; COELHO, E. A.; MELO, H. S.; CASTELO, L. A.; ALCANTARA, S. S. Ciclo de vida dos produtos: Certificação e rotulagem ambiental. XXVII Encontro Nacional de Engenharia de Produção, Foz de Iguaçu, 2007.

BHANDER, G.; HAUSCHILD, M.; MCALOONE, T. Implementing life cycle assessment in product development. Environment progress (vol. 22, no04); 2003. p.255-267;

BOSSEL, H. Indictors for sustainable development: Theory, method, applications. Canadá: International Institute for Sustainable Development, 1999, $125 p$.

BRUSEKE, F.J. (1995) O problema do desenvolvimento sustentável. CAVALCANTI, C. Desenvolvimento e natureza: estudos para uma sociedade sustentável. São Paulo: Cortez, p.29-53.

CAMPOS, L. M. S. SGADA - Sistema de Gestão e Avaliação de Desempenho Ambiental: Uma Proposta de Implementação. 2001. 220 f. Tese de doutorado - Engenharia de Produção e Sistemas, Universidade Federal de Santa Catarina, Florianópolis, 2001.

CHEHEBE, J.R. Análise do ciclo de vida dos produtos: ferramenta gerencial da ISO 14000. Rio de Janeiro: Qualitymark Ed., CNI, 1997. 120p.

DONAIRE, D. Gestão ambiental na empresa. 2.ed. São Paulo: Atlas, 1999. 
ELETROBRÁS. Site institucional. Disponível em http://www.eletrobras.gov.br/ELB/procel/main.asp?TeamlD=\%7B95F19022-F8BB4991-862A-1C116F13AB71\%7D. Acesso em 24/04/2009.

FEDERAÇÃO DAS INDÚSTRIAS DO ESTADO DE SÃO PAULO - FIESP. Melhore a competitividade com o Sistema de Gestão Ambiental - SGA. São Paulo : FIESP, 2007. 84p. : il. - (Normas e Manuais Técnicos)

FERREIRA, J.V.R. Análise do ciclo de vida dos produtos. Instituto Politécnico de Viseu, 2004;

GRI. Global Reporting Initiative: Sustainability reporting guidelines, 2006, Disponível em: <www.globalreporting.org> Acesso em: 28/12/2006; http://roteiroromanceado.com/cruzadas/historia/ancestrais/publicacoes/imagens/tecn ologia.html acesso em 17/04/08;

INTERNATIONAL ORGANIZTION FOR STANDARDIZATION. ISO 14040: Environmental Management - Life cycle assessment - principles and framework. Switzerland, 2006, 20p;

JENSEN, A. A., HOFFMAN, L.; MOLLER, B. T.; SCHMIDT, A.; CHRISTIANSEN, K.; ELKINGTON, J.; VAN DIJK, F. Life cycle assessment: a guide to approaches, experiences and information sources, European Environmental Agency (EEA), 1997.

KATES, R. W; PARRIS, T. M; LEISEROWITZ, A. A. What is Sustainable Development? : Goals, indicators, values and practices. Environment: Science and Policy for Sustainable Development, Volume 47, Número 3, paginas 8-21, 2005;

KMITA, S; et. al. Investigação da aplicação do ecodesign em medidores elétricos. Anais P\&D 2000. FEEVALE, Novo Hamburgo, RS, 2000;

LAKATOS, E. M. , MARCONI, M A Metodologia do trabalho científico. 6.ed. São Paulo : Atlas, 2001. 231 p.

MANZINI, E.; VEZZOLI, C. O desenvolvimento de Produtos Sustentáveis: Os requisitos ambientais dos produtos Industriais. São Paulo: Edusp, 2002, 368;

MALAGUTI, C. Requisitos ambientais para o desenvolvimento de produtos: manual técnico. São Paulo: CSPD, 2005. 76;

MILLANI, T.J. (2007) Subsídios à Avaliação do Ciclo de Vida do pescado: avaliação ambiental das atividades de piscicultura e pesque-pague, estudo de caso na bacia hidrográfica do rio Mogi-Guaçu. 140p. Dissertação (Mestrado) Escola de Engenharia de São Carlos, Universidade de São Paulo, 2007.

MOREIRA, M. S. Estratégia e Implantação de Sistema Ambiental: Modelo ISO 14000. Belo Horizonte: Desenvolvimento Gerencial, 2001, 288p.

NOVAK, L. A. Avaliação de custos e impactos ambientais de produtos, 2006, Dissertação (Mestrado em Engenharia) - Programa de Pós graduação em 
Engenharia Mecânica e de Materiais, Universidade Tecnológica Federal do Paraná, Curitiba, 2006.

OMETTO, A. R. (2005). Avaliação do ciclo de vida do álcool etílico hidratado combustível pelos métodos EDIP, Exergia e Emergia. Tese de Doutorado - Escola de Engenharia de São Carlos, Universidade de São Paulo, São Carlos, 2005;

RAMOS, J. Alternativas para o projeto ecológico de produtos. Florianópolis, 2001. 163p. Tese (Doutorado em Engenharia de Produção)- Programa de Pós-graduação em Engenharia de Produção, UFSC, 2001;

RÉGIS, F. R. Ecodesign: Potencialidades do Bambu. Monografia Universidade de Salvador, Salvador, 2004, 75p;

SACHS, I. (1993) Estratégias de transição para o século XXI: Desenvolvimento e meio ambiente. São Paulo: Studio Nobel, Fundação do desenvolvimento administrativo (cidade aberta).

SILVA, J. O. Formação da equipe aplicada ao desenvolvimento de produtos: Proposta de uma Sistemática baseada nas atividades do projeto alinhadas ao Perfil do Indivíduo, necessário para desempenhar as atividades. Tese (Doutorado em Engenharia de Produção) - Programa de Pós-Graduação em Engenharia de Produção, 197 páginas. UFSC, 2007;

TAKEDA, A. Levantamento de métodos de avaliação de impacto de ciclo de vida (AICV) e análise comparativa dos métodos mais utilizados. Monografia (Graduação em Engenharia Ambiental) - Escola de Engenharia de São Carlos, Universidade de São Paulo, São Carlos, 2008;

TEIXEIRA, M.G. Aplicação de conceitos da ecologia Industrial para a produção de materiais ecológicos: o exemplo do resíduo de madeira. Dissertação de Mestrado - Universidade Federal Bahia, Salvador, 2005, 159p;

TORRES, C. A. R. Ambiente-se: Caderno de conscientização ambiental. Petrobrás, 1997, 37p;

TUKKER, A; EDER, P. Eco-design: European State of the Art - Part II. European Science and Technology Observatory, Luxembourg, 2000;

KRAEMER, M.E.P. Gestão ambiental: um enfoque no desenvolvimento sustentável. Itajaí, 2003;

KURK, F; MCNAMARA, C. Better by Design: An Innovation Guide. Minnesota; Minnesota Pollution Control Agency, 2006, 33p;

WENZEL, H.; HAUSCHILD, M.; ALTING, L. (1997). Environmental Assessment of Products. Bonton/Dordrecht/London: Kluwer Academic Publisehrs. v.1. 
Anexo A - Levantamento Bibliográfico - Análise Sistemática

\section{Anexo A}

\begin{tabular}{|c|c|c|c|c|c|c|c|c|c|}
\hline Título & Autor (es) & Referencia & Ano & País & $\begin{array}{l}\text { Métodos } \\
\text { citados }\end{array}$ & $\begin{array}{l}\text { Categorias de } \\
\text { Impactos }\end{array}$ & $\begin{array}{c}\text { Mid / } \\
\text { Endpoint }\end{array}$ & $\begin{array}{l}\text { Ferramentas } \\
\text { Utilizadas }\end{array}$ & Banco de dados \\
\hline \multirow{3}{*}{$\begin{array}{l}\text { A comparison of three methods for } \\
\text { impact analysis and } \\
\text { evaluation }\end{array}$} & \multirow{3}{*}{$\begin{array}{l}\text { Henrikke Baumannt } \\
\text { and Tomas Rydberg }\end{array}$} & \multirow{3}{*}{$\begin{array}{l}\text { University of Technology, } \\
\text { S-412 } 96 \text { Grteborg, } \\
\text { Sweden }\end{array}$} & \multirow{3}{*}{1994} & \multirow{3}{*}{ Suécia } & ECO & & & & \multirow{3}{*}{ Ecoinvent } \\
\hline & & & & & ET & & & & \\
\hline & & & & & EPS & & & & \\
\hline \multirow{20}{*}{$\begin{array}{l}\text { A critical review of building } \\
\text { environmental assessment tools }\end{array}$} & \multirow{20}{*}{$\begin{array}{c}\text { Appu Haapio, Pertti } \\
\text { Viitaniemi }\end{array}$} & \multirow{20}{*}{$\begin{array}{c}\text { Environmental Impact } \\
\text { Assessment Review } 28 \\
\text { (2008) 469-482 }\end{array}$} & \multirow{20}{*}{2008} & \multirow{20}{*}{ Finlândia } & GaBi & & & BEAT 2002 & \\
\hline & & & & & \multirow{19}{*}{ SimaPro } & & & BeCost & \\
\hline & & & & & & & & BEES 4.0 & \\
\hline & & & & & & & & BREEAM & \\
\hline & & & & & & & & EcoEffect & \\
\hline & & & & & & & & Eco-Profile & \\
\hline & & & & & & & & Eco-Quantum & \\
\hline & & & & & & & & Envest 2 & \\
\hline & & & & & & & & EQUER & \\
\hline & & & & & & & & ESCALE & \\
\hline & & & & & & & & LEGEP & \\
\hline & & & & & & & & LEED & \\
\hline & & & & & & & & PAPOOSE & \\
\hline & & & & & & & & TEAM & \\
\hline & & & & & & & & BEQUEST & \\
\hline & & & & & & & & CRISP & \\
\hline & & & & & & & & IEA Annex 31 & \\
\hline & & & & & & & & PRESCO & \\
\hline & & & & & & & & Environmental Status & \\
\hline & & & & & & & & Model (Miljöstatus) & \\
\hline A fuzzy logic approach for the impact & B. Gonza'lez, B. & Resources, Conservation & 2002 & Espanha & TRUNC & Eutrofização & & Fuzzy logic & LCAiT 3.0 \\
\hline
\end{tabular}


Anexo A - Levantamento Bibliográfico - Análise Sistemática

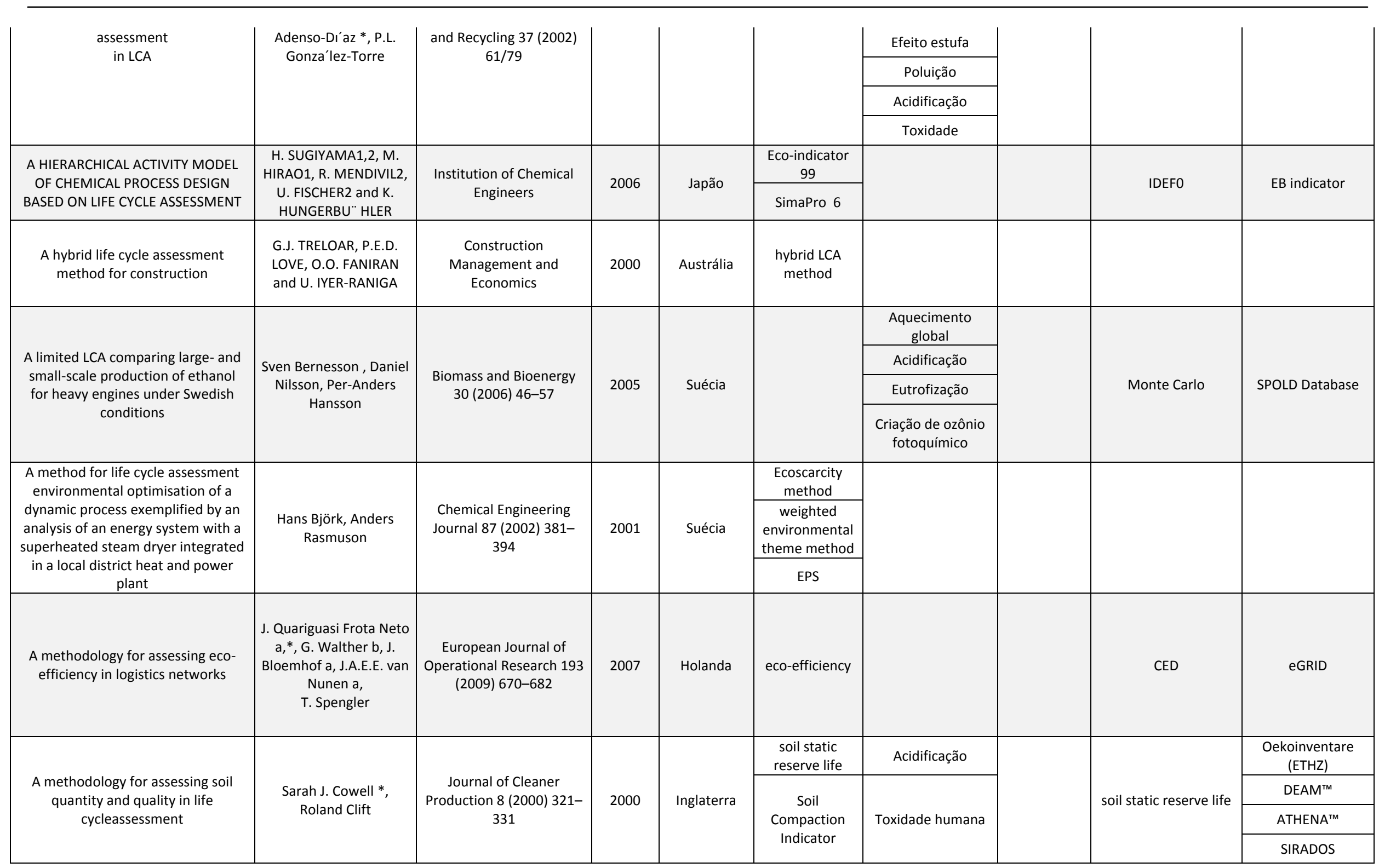


Anexo A - Levantamento Bibliográfico - Análise Sistemática

\begin{tabular}{|c|c|c|c|c|c|c|c|c|c|}
\hline & & & & & & & & & Ecoinvent \\
\hline & & & & & & & & & GEMIS \\
\hline \multirow{3}{*}{$\begin{array}{c}\text { A new life cycle impact assessment } \\
\text { approach for buildings }\end{array}$} & \multirow{3}{*}{ Zhuguo Li } & \multirow{3}{*}{$\begin{array}{l}\text { Building and Environment } \\
41 \text { (2006) 1414-1422 }\end{array}$} & \multirow{3}{*}{2005} & \multirow{3}{*}{ Japão } & \multirow{3}{*}{ LIME } & $\begin{array}{l}\text { Emissões } \\
\text { Atmosféricas }\end{array}$ & \multirow{3}{*}{ Endpoint } & & \\
\hline & & & & & & $\begin{array}{l}\text { Consumo de } \\
\text { Recursos }\end{array}$ & & & \\
\hline & & & & & & Uso da Terra & & & \\
\hline \multirow{3}{*}{$\begin{array}{c}\text { A Practical Method for } \\
\text { Quantifying Eco-efficiency } \\
\text { Using Eco-design Support } \\
\text { Tools }\end{array}$} & \multirow{3}{*}{$\begin{array}{l}\text { Yoshinori Kobayashi, } \\
\text { Hideki Kobayashi, } \\
\text { Akinori Hongu, and } \\
\text { Kiyoshi Sanehira }\end{array}$} & \multirow{3}{*}{$\begin{array}{c}\text { Journal of Industrial } \\
\text { Ecology }\end{array}$} & \multirow{3}{*}{2005} & \multirow{3}{*}{$\begin{array}{l}\text { Estados } \\
\text { Unidos }\end{array}$} & LIME & \multirow{3}{*}{$\begin{array}{l}\text { Consumo de } \\
\text { energia }\end{array}$} & \multirow{3}{*}{ Endpoint } & Easy-LCA & \multirow{3}{*}{ LIME } \\
\hline & & & & & Easy-LCA & & & CPlanner & \\
\hline & & & & & BASF & & & 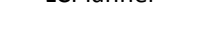 & \\
\hline $\begin{array}{l}\text { A proposed tool to integrate } \\
\text { environmental and } \\
\text { economical assessments of products }\end{array}$ & $\begin{array}{l}\text { Kumaran D. Senthila, } \\
\text { S.K. Onga, A.Y.C. Neea, } \\
\text { Reginald B.H. Tan }\end{array}$ & $\begin{array}{l}\text { Environmental Impact } \\
\text { Assessment Review } \\
23 \text { (2003) 51-72 }\end{array}$ & 2002 & Singapura & LCECA & & & & \\
\hline \multirow{3}{*}{$\begin{array}{l}\text { A review of life cycle assessment } \\
\text { (LCA) on some food products }\end{array}$} & \multirow{3}{*}{$\begin{array}{c}\text { Poritosh Roy *, Daisuke } \\
\text { Nei, Takahiro Orikasa, } \\
\text { Qingyi Xu, Hiroshi } \\
\text { Okadome, } \\
\text { Nobutaka Nakamura, } \\
\text { Takeo Shiina }\end{array}$} & \multirow{3}{*}{$\begin{array}{c}\text { Journal of Food } \\
\text { Engineering } 90 \text { (2009) 1- } \\
10\end{array}$} & \multirow{3}{*}{2008} & \multirow{3}{*}{ Japão } & $\begin{array}{l}\text { Ecological } \\
\text { footprint }\end{array}$ & Acidificação & \multirow{3}{*}{ Endpoint } & & \multirow{3}{*}{ Ecoinvent } \\
\hline & & & & & LIME & $\begin{array}{l}\text { Formação de foto } \\
\text { oxidantes }\end{array}$ & & & \\
\hline & & & & & LIME2 & $\begin{array}{c}\text { Consumo de } \\
\text { energia }\end{array}$ & & & \\
\hline \multirow{2}{*}{$\begin{array}{c}\text { A simple life cycle assessment } \\
\text { method for green product } \\
\text { conceptual design }\end{array}$} & \multirow{2}{*}{$\begin{array}{c}\text { Jahau Lewis Chen, Chid } \\
\text { Wei Liau }\end{array}$} & \multirow{2}{*}{$\begin{array}{c}\text { Departament of } \\
\text { Machanical Engeneering }\end{array}$} & \multirow{2}{*}{2001} & \multirow{2}{*}{ Taiwan } & \multirow{2}{*}{ EDIP } & & & SimaPro & \\
\hline & & & & & & & & Eco-indicator 95 & \\
\hline \multirow{5}{*}{$\begin{array}{l}\text { A streamlined life cycle assessment } \\
\text { on the fabrication of WCeCo cermets }\end{array}$} & \multirow{5}{*}{$\begin{array}{l}\text { Yuhong Xiong, Ki Lau, } \\
\text { Xiaoying Zhou, Julie M. } \\
\text { Schoenung }\end{array}$} & \multirow{5}{*}{$\begin{array}{c}\text { Journal of Cleaner } \\
\text { Production } 16(2008) \\
1118 \mathrm{e} 1126\end{array}$} & \multirow{5}{*}{2007} & \multirow{5}{*}{$\begin{array}{l}\text { Estados } \\
\text { Unidos }\end{array}$} & $\begin{array}{c}\text { eGRID } \\
\text { database for } \\
2002 \\
\end{array}$ & $\begin{array}{l}\text { Uso de recursos } \\
\text { renovávies }\end{array}$ & & & Ecoinvent \\
\hline & & & & & & $\begin{array}{l}\text { Uso de recursos } \\
\text { não renováveis }\end{array}$ & & & \multirow{4}{*}{$\begin{array}{l}\text { Australian Life } \\
\text { Cycle Inventory } \\
\text { Database }\end{array}$} \\
\hline & & & & & AHP & $\begin{array}{c}\text { Consumo de } \\
\text { energia }\end{array}$ & & & \\
\hline & & & & & & $\begin{array}{c}\text { Aquecimento } \\
\text { Global }\end{array}$ & & & \\
\hline & & & & & & Acidificação & & & \\
\hline
\end{tabular}


Anexo A - Levantamento Bibliográfico - Análise Sistemática

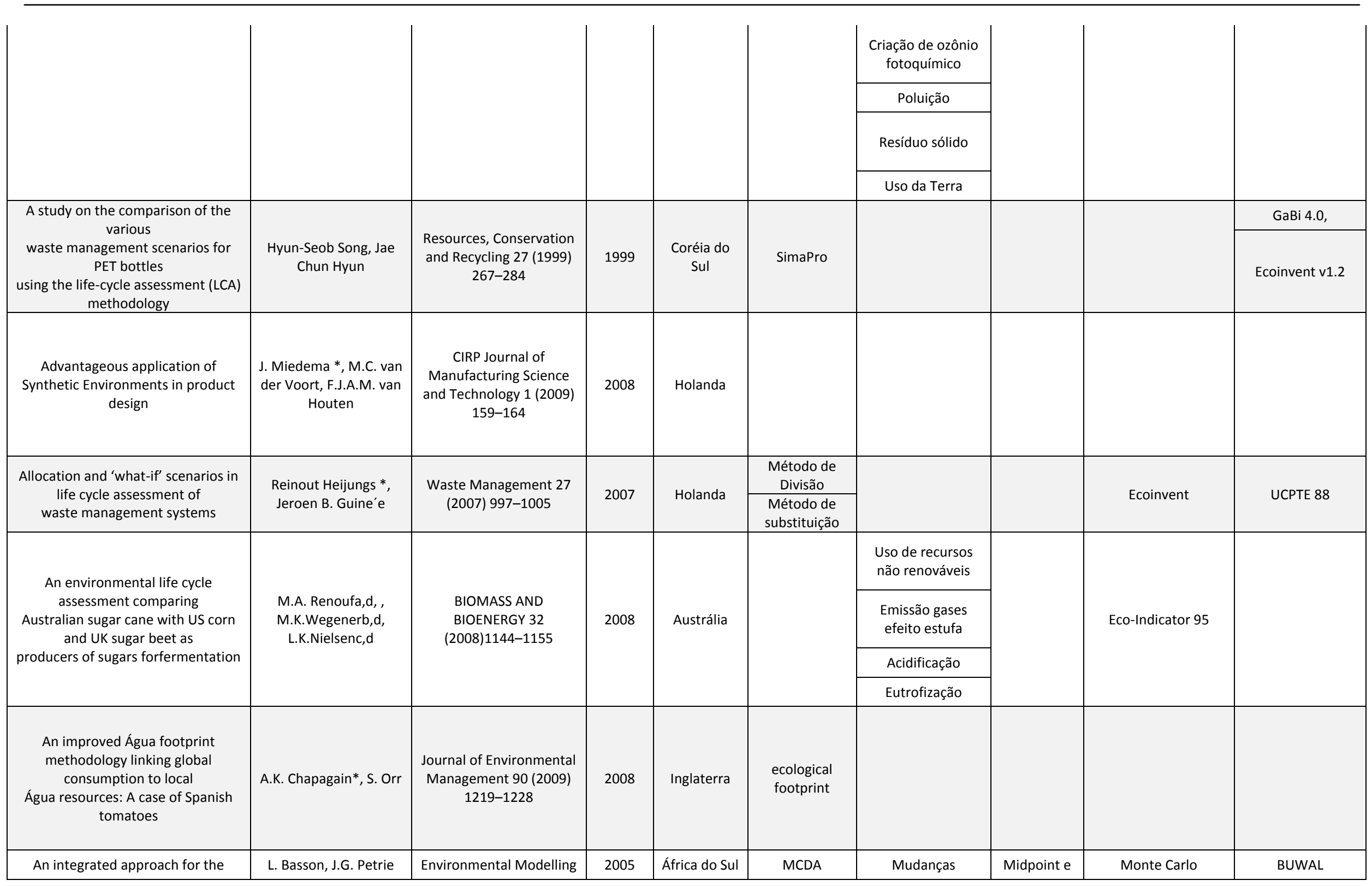


Anexo A - Levantamento Bibliográfico - Análise Sistemática

\begin{tabular}{|c|c|c|c|c|c|c|c|c|c|}
\hline \multirow{9}{*}{$\begin{array}{l}\text { consideration of uncertainty in } \\
\text { decision } \\
\text { making supported by Life Cycle } \\
\text { Assessment }\end{array}$} & & \multirow[t]{9}{*}{$\begin{array}{c}\text { \& Software } 22(2007) \\
167 e 176\end{array}$} & & & & Climáticas & \multirow[t]{9}{*}{ endpoint } & & \\
\hline & & & & & \multirow{8}{*}{$\begin{array}{l}\text { Eco-Indicator } \\
99\end{array}$} & Emissão de Toxinas & & & \\
\hline & & & & & & Acidificação & & & \\
\hline & & & & & & Eutrofização & & & \\
\hline & & & & & & Uso da Terra & & & \\
\hline & & & & & & $\begin{array}{l}\text { Riscos à saúde } \\
\text { Humana }\end{array}$ & & & \\
\hline & & & & & & $\begin{array}{l}\text { Danos a qualidade } \\
\text { do ecosistema }\end{array}$ & & & \\
\hline & & & & & & Danos aos minerais & & & \\
\hline & & & & & & $\begin{array}{l}\text { Uso de recursos } \\
\text { não renováveis }\end{array}$ & & & \\
\hline \multirow{4}{*}{$\begin{array}{c}\text { An LCA of alternative wasteÁgua } \\
\text { sludge } \\
\text { treatment scenarios }\end{array}$} & \multirow{4}{*}{$\begin{array}{c}\text { Young-Jin Suh *, Patrick } \\
\text { Rousseaux }\end{array}$} & \multirow{4}{*}{$\begin{array}{l}\text { Resources, Conservation } \\
\text { and Recycling (2001) }\end{array}$} & \multirow{4}{*}{2001} & \multirow{4}{*}{ França } & & $\begin{array}{l}\text { Criação de ozônio } \\
\text { fotoquímico }\end{array}$ & & & \multirow{4}{*}{ BUWAL } \\
\hline & & & & & & Eutrofização & & & \\
\hline & & & & & & $\begin{array}{l}\text { Ecotoxidade } \\
\text { marítima }\end{array}$ & & & \\
\hline & & & & & & $\begin{array}{l}\text { Ecotoxidade } \\
\text { Terrestre } \\
\end{array}$ & & & \\
\hline \multirow{3}{*}{$\begin{array}{l}\text { An LCA study of a primary aluminum } \\
\text { supply chain }\end{array}$} & \multirow{3}{*}{$\begin{array}{l}\text { Reginald B.H. Tan, } \\
\text { Hsien H. Khoo }\end{array}$} & \multirow{3}{*}{$\begin{array}{c}\text { Journal of Cleaner } \\
\text { Production } 13(2005) \\
607 \mathrm{e} 618\end{array}$} & \multirow{3}{*}{2003} & \multirow{3}{*}{ Singapura } & \multirow{3}{*}{ EDIP/UMIP 96} & $\begin{array}{l}\text { Aquecimento } \\
\text { global }\end{array}$ & & \multirow{3}{*}{ SimaPro 5} & Eco-indicator 95 \\
\hline & & & & & & Acidificação & & & Idemat 96 \\
\hline & & & & & & $\begin{array}{l}\text { Toxidade humana } \\
\text { do ar }\end{array}$ & & & Eco-indicator 97 \\
\hline \multirow{4}{*}{$\begin{array}{l}\text { An overview of sustainability } \\
\text { assessment methodologies }\end{array}$} & \multirow{4}{*}{$\begin{array}{l}\text { Rajesh Kumar Singh, } \\
\text { H.R. Murty, S.K. Gupta, } \\
\text { A.K. Dikshit }\end{array}$} & \multirow{4}{*}{$\begin{array}{l}\text { ecological indicators } 9 \\
\text { (2009) } 189-212\end{array}$} & \multirow{4}{*}{2008} & \multirow{4}{*}{ Índia } & Eco-Index & & & \multirow{4}{*}{$\begin{array}{c}\text { COMPLIMENT } \\
\text { PSI }\end{array}$} & \\
\hline & & & & & Eco-Points & & & & \\
\hline & & & & & Eco-Scan & & & & \\
\hline & & & & & $\begin{array}{c}\text { Eco-indicator } \\
99 \\
\end{array}$ & & & & \\
\hline \multirow{2}{*}{$\begin{array}{l}\text { Analysis of effects of an objective } \\
\text { function on environmental } \\
\text { and economic performance of a } \\
\text { Água network system using life }\end{array}$} & \multirow{2}{*}{$\begin{array}{l}\text { Seong-Rin Lim, } \\
\text { Donghee Park, Jong } \\
\text { Moon Park }\end{array}$} & \multirow{2}{*}{$\begin{array}{c}\text { Chemical Engineering } \\
\text { Journal } 144(2008) 368- \\
378\end{array}$} & \multirow[t]{2}{*}{2008} & \multirow[t]{2}{*}{$\begin{array}{l}\text { Coréia do } \\
\text { Sul }\end{array}$} & \multirow[t]{2}{*}{ CML 2001} & $\begin{array}{c}\text { Depleção de } \\
\text { recursos abióticos }\end{array}$ & & \multirow[t]{2}{*}{ CML 2001} & \multirow[t]{2}{*}{ ISA } \\
\hline & & & & & & Acidificação & & & \\
\hline
\end{tabular}


Anexo A - Levantamento Bibliográfico - Análise Sistemática

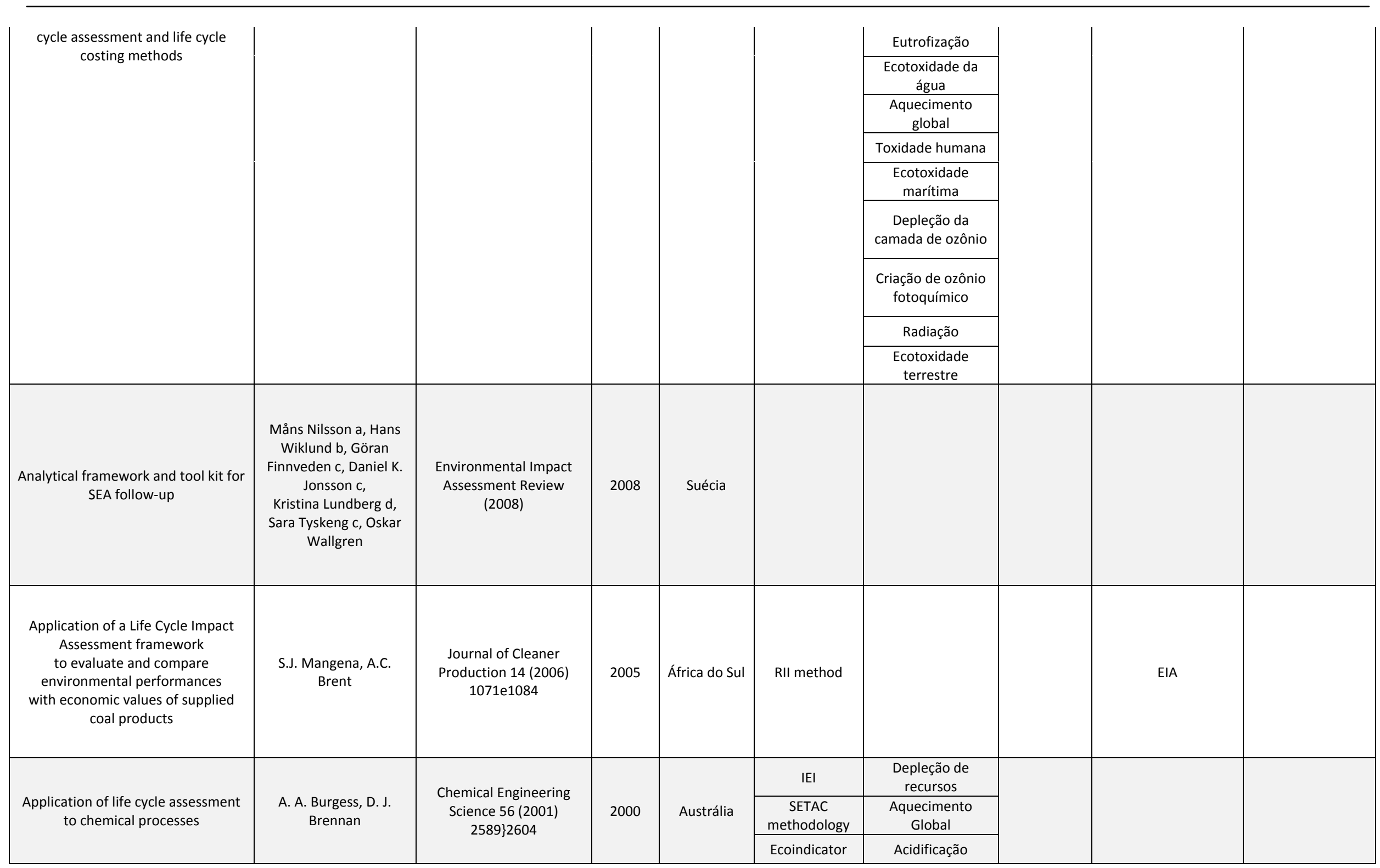


Anexo A - Levantamento Bibliográfico - Análise Sistemática

\begin{tabular}{|c|c|c|c|c|c|c|c|c|c|}
\hline & & & & & & $\begin{array}{l}\text { Criação de ozônio } \\
\text { fotoquímico }\end{array}$ & & & \\
\hline \multirow{3}{*}{$\begin{array}{l}\text { Application of Results of Ceramic } \\
\text { Tiles Life Cycle } \\
\text { Assessment due to Energy Savings } \\
\text { and Environment } \\
\text { Protection }\end{array}$} & \multirow{3}{*}{$\begin{array}{l}\text { Verica Hocenski, Zeljko } \\
\text { Hocenski, Suzana } \\
\text { Vasilic }\end{array}$} & \multirow{3}{*}{$\begin{array}{c}\text { Faculty of Electrical } \\
\text { Engineering, University of } \\
\text { J.J. Strossmayer in Osijek, } \\
\text { Croatia }\end{array}$} & \multirow{3}{*}{2006} & \multirow{3}{*}{ Croácia } & \multirow{3}{*}{$\begin{array}{l}\text { Eco-indicator } \\
99\end{array}$} & Consumo de água & & \multirow{3}{*}{ Eco-it } & \multirow{3}{*}{ Eco-indicator 95} \\
\hline & & & & & & Consumo de Gás & & & \\
\hline & & & & & & $\begin{array}{l}\text { Mudanças } \\
\text { Climáticas }\end{array}$ & & & \\
\hline \multirow{4}{*}{$\begin{array}{c}\text { Application of the Life Cycle } \\
\text { Assessment methodology to } \\
\text { agricultural production: an example } \\
\text { of sugar beet } \\
\text { production with different forms of } \\
\text { nitrogen fertilisers }\end{array}$} & \multirow{4}{*}{$\begin{array}{l}\text { F. Brentrup, J. Ku" sters, } \\
\text { H. Kuhlmann, J. Lammel }\end{array}$} & \multirow{4}{*}{$\begin{array}{c}\text { European Journal of } \\
\text { Agronomy } 14 \text { (2001) 221- } \\
233\end{array}$} & \multirow{4}{*}{2000} & \multirow{4}{*}{ Alemanha } & \multirow{4}{*}{$\begin{array}{l}\text { Eco-indicator } \\
95\end{array}$} & $\begin{array}{c}\text { Aquecimento } \\
\text { Global }\end{array}$ & & \multirow{4}{*}{ Eco-indicator 95} & \multirow{4}{*}{ Eco-indicator 95} \\
\hline & & & & & & Acidificação & & & \\
\hline & & & & & & Eutrofização & & & \\
\hline & & & & & & poluição & & & \\
\hline \multirow{3}{*}{$\begin{array}{c}\text { Applications of life cycle assessment } \\
\text { to NatureWorksTM } \\
\text { polylactide (PLA) production }\end{array}$} & \multirow{3}{*}{$\begin{array}{l}\text { Erwin T.H. Vinka,Karl R. } \\
\text { Ra' bagob,David A. } \\
\text { Glassnerb,Patrick R. } \\
\text { Gruberb }\end{array}$} & \multirow{3}{*}{$\begin{array}{l}\text { Polymer Degradation and } \\
\text { Stability } 80 \text { (2003) 403- } \\
419\end{array}$} & \multirow{3}{*}{2002} & \multirow{3}{*}{ Holanda } & \multirow{3}{*}{ APME } & $\begin{array}{l}\text { Uso de recursos } \\
\text { não renováveis }\end{array}$ & & \multirow{3}{*}{ PLA ecoprofiles } & \\
\hline & & & & & & $\begin{array}{c}\text { Gases do efeito } \\
\text { estufa }\end{array}$ & & & \\
\hline & & & & & & Consumo de água & & & \\
\hline \multirow{7}{*}{$\begin{array}{l}\text { Assessing alternative aquaculture } \\
\text { technologies: life cycle assessment of } \\
\text { salmonid } \\
\text { culture systems in Canada }\end{array}$} & \multirow{7}{*}{$\begin{array}{c}\text { Nathan W. Ayer, Peter } \\
\text { H. Tyedmers }\end{array}$} & \multirow{7}{*}{$\begin{array}{c}\text { Journal of Cleaner } \\
\text { Production } 17 \text { (2009) } \\
362-373\end{array}$} & \multirow{7}{*}{2008} & \multirow{7}{*}{ Canadá } & \multirow{7}{*}{$\begin{array}{c}\begin{array}{c}\text { ecological } \\
\text { footprint }\end{array} \\
\text { SimaPro } 7.0\end{array}$} & $\begin{array}{l}\text { Depleção de } \\
\text { recursos abióticos }\end{array}$ & \multirow{7}{*}{ Midpoint } & \multirow{7}{*}{ CML 2 Baseline 2000} & GEMIS \\
\hline & & & & & & $\begin{array}{c}\text { Aquecimento } \\
\text { global }\end{array}$ & & & \multirow{6}{*}{ SimaPro 7.0} \\
\hline & & & & & & Toxidade humana & & & \\
\hline & & & & & & marine Toxidade & & & \\
\hline & & & & & & Acidificação & & & \\
\hline & & & & & & Eutrofização & & & \\
\hline & & & & & & $\begin{array}{c}\text { Consumo de } \\
\text { energia }\end{array}$ & & & \\
\hline \multirow{4}{*}{$\begin{array}{c}\text { Assessing environmental } \\
\text { performance by combining } \\
\text { life cycle assessment, multi-criteria } \\
\text { analysis } \\
\text { and environmental performance } \\
\text { indicators }\end{array}$} & & & & & & $\begin{array}{c}\text { Aquecimento } \\
\text { Global }\end{array}$ & & MCA & \\
\hline & & Journal of Cleaner & & & & Acidificação & & & \\
\hline & Kroeze a, W. Jawjit & $\begin{array}{c}\text { Production } 15 \text { (2007) } \\
1787 \text { e1796 }\end{array}$ & 2006 & Holanda & COMPLIMENT & Eutrofização & Midpoint & EPIs & \\
\hline & & & & & & $\begin{array}{l}\text { Criação de ozônio } \\
\text { fotoquímico }\end{array}$ & & & \\
\hline
\end{tabular}


Anexo A - Levantamento Bibliográfico - Análise Sistemática

\begin{tabular}{|c|c|c|c|c|c|c|c|c|}
\hline & & & & & & Toxidade humana & & \\
\hline \multirow{5}{*}{$\begin{array}{l}\text { Assessment of the environmental } \\
\text { impact of carnivorous finfish } \\
\text { production } \\
\text { systems using life cycle assessment }\end{array}$} & \multirow{5}{*}{$\begin{array}{l}\text { J. Aubin, E. } \\
\text { Papatryphon, H.M.G. } \\
\text { van der Werf, S. } \\
\text { Chatzifotis }\end{array}$} & \multirow{5}{*}{$\begin{array}{l}\text { Journal of Cleaner } \\
\text { Production } 17 \text { (2009) } \\
\text { 354-361 }\end{array}$} & \multirow{5}{*}{2008} & \multirow{5}{*}{ França } & \multirow{5}{*}{ SimaPro 6} & $\begin{array}{c}\text { Consumo de } \\
\text { energia }\end{array}$ & \multirow{5}{*}{ SimaPro 6} & \multirow{5}{*}{ SimaPro 6} \\
\hline & & & & & & Eutrofização & & \\
\hline & & & & & & $\begin{array}{l}\text { Mudanças } \\
\text { Climáticas }\end{array}$ & & \\
\hline & & & & & & Acidificação & & \\
\hline & & & & & & Consumo de água & & \\
\hline \multirow{8}{*}{$\begin{array}{l}\text { Building energy performance: A LCA } \\
\text { case study of } \\
\text { kenaf-fibres insulation board }\end{array}$} & \multirow{8}{*}{$\begin{array}{l}\text { Fulvio Ardente, Marco } \\
\text { Beccali, Maurizio } \\
\text { Cellura, Marina } \\
\text { Mistretta }\end{array}$} & \multirow{8}{*}{$\begin{array}{l}\text { Energy and Buildings } 40 \\
\text { (2008) } 1-10\end{array}$} & \multirow{8}{*}{2006} & \multirow{8}{*}{ Itália } & & $\begin{array}{c}\text { Consumo de } \\
\text { energia }\end{array}$ & & \multirow{8}{*}{ GEMIS } \\
\hline & & & & & & $\begin{array}{c}\text { Aquecimento } \\
\text { Global }\end{array}$ & & \\
\hline & & & & & & $\begin{array}{l}\text { Criação de ozônio } \\
\text { fotoquímico }\end{array}$ & & \\
\hline & & & & & & Nutrificação & & \\
\hline & & & & & & Acidificação & & \\
\hline & & & & & & $\begin{array}{l}\text { Depleção da } \\
\text { camada de ozônio }\end{array}$ & & \\
\hline & & & & & & Consumo de água & & \\
\hline & & & & & & $\begin{array}{l}\text { Geração de } \\
\text { resíduos }\end{array}$ & & \\
\hline $\begin{array}{l}\text { Challenges in the new millennium: } \\
\text { product discovery and } \\
\text { design, enterprise and supply chain } \\
\text { optimization, global } \\
\text { life cycle assessment }\end{array}$ & Ignacio E. Grossmann & $\begin{array}{l}\text { Computers and Chemical } \\
\text { Engineering } 29 \text { (2004) } \\
\text { 29-39 }\end{array}$ & 2004 & $\begin{array}{l}\text { Estados } \\
\text { Unidos }\end{array}$ & PSE & & & \\
\hline \multirow{3}{*}{$\begin{array}{l}\text { Characterisation and Normalisation } \\
\text { Factors for Life Cycle Impact } \\
\text { Assessment } \\
\text { Mined Abiotic Resources Categories } \\
\text { in South Africa } \\
\text { The manufacturing of catalytic } \\
\text { converter exhaust systems as a case }\end{array}$} & \multirow{3}{*}{$\begin{array}{l}\text { Kerwin Strauss, Alan C } \\
\text { Brent and Sibbele } \\
\text { Hietkamp }\end{array}$} & \multirow{3}{*}{$\begin{array}{l}\text { Int J LCA } 11 \text { (3) } 162-171 \\
\qquad(2006)\end{array}$} & \multirow{3}{*}{2006} & \multirow{3}{*}{ África do Sul } & CML & Recursos minerais & \multirow{3}{*}{ Eco-indicator 99} & \multirow{3}{*}{$\mathrm{CML}$} \\
\hline & & & & & $\begin{array}{c}\text { Eco-indicator } \\
99 \\
\end{array}$ & & & \\
\hline & & & & & RMEE & energia & & \\
\hline
\end{tabular}


Anexo A - Levantamento Bibliográfico - Análise Sistemática

\begin{tabular}{|c|c|c|c|c|c|c|c|c|c|}
\hline study & & & & & & & & & \\
\hline \multirow{3}{*}{$\begin{array}{l}\text { Characterizing the change of land- } \\
\text { use based on flora: application } \\
\text { for EIA and LCA }\end{array}$} & \multirow{3}{*}{$\begin{array}{l}\text { Joost G. Vogtla"nder, } \\
\text { Erwin Lindeijer, Jan- } \\
\text { Philip Maria Witte, } \\
\text { Charles Hendriks }\end{array}$} & \multirow{3}{*}{$\begin{array}{l}\text { Journal of Cleaner } \\
\text { Production } 12 \text { (2004) 47- } \\
57\end{array}$} & \multirow{3}{*}{2002} & \multirow{3}{*}{ Holanda } & $\begin{array}{l}\text { Eco-indicator } \\
99\end{array}$ & $\begin{array}{l}\text { habitat para as } \\
\text { plantas }\end{array}$ & \multirow{3}{*}{ Endpoint } & & \multirow{3}{*}{ EIA } \\
\hline & & & & & \multirow[b]{2}{*}{ EVR } & $\begin{array}{l}\text { habitat para as } \\
\text { pessoas }\end{array}$ & & & \\
\hline & & & & & & $\begin{array}{l}\text { Produção de } \\
\text { comida e energia }\end{array}$ & & & \\
\hline $\begin{array}{l}\text { Cleaner production tools: LCA and } \\
\text { beyond }\end{array}$ & T. Ekvall & $\begin{array}{l}\text { Journal of Cleaner } \\
\text { Production } 10(2002) \\
403-406\end{array}$ & 2002 & Suécia & & & & & \\
\hline $\begin{array}{l}\text { Cleaner products in the Nordic } \\
\text { countries } \\
\text { based on the life cycle assessment } \\
\text { approach }\end{array}$ & Tomas Rydberg & $\begin{array}{l}\text { J. Cleaner Prod., Vol. 3, } \\
\text { No. 1-2, pp. 101-105, } \\
1995\end{array}$ & 1995 & Suécia & & & & LCAiT, EPS & \\
\hline \multirow{6}{*}{$\begin{array}{c}\text { Combining lifecycle and risk } \\
\text { assessments of mineral } \\
\text { waste reuse scenarios for decision } \\
\text { making support }\end{array}$} & \multirow{6}{*}{$\begin{array}{l}\text { Enrico Benetto, Ligia } \\
\text { Tiruta-Barna, Yves } \\
\text { Perrodin }\end{array}$} & \multirow{6}{*}{$\begin{array}{l}\text { Environmental Impact } \\
\text { Assessment Review } 27 \\
\text { (2007) 266-285 }\end{array}$} & \multirow{6}{*}{2006} & \multirow{6}{*}{ França } & $\begin{array}{l}\text { Ecological Risk } \\
\text { Assessment }\end{array}$ & Acidificação & \multirow{6}{*}{$\begin{array}{l}\text { Midpoint e } \\
\text { endpoint }\end{array}$} & CML & \multirow{6}{*}{$\begin{array}{l}\text { Ecological Risk } \\
\text { Assessment (ERA), }\end{array}$} \\
\hline & & & & & $\begin{array}{l}\text { Integrated } \\
\text { Environmental } \\
\text { Assessment }\end{array}$ & Eutrofização & & \multirow{5}{*}{ EDIP } & \\
\hline & & & & & CML & \multirow{4}{*}{ Ecotoxidade } & & & \\
\hline & & & & & EDIP & & & & \\
\hline & & & & & Ecoindicator & & & & \\
\hline & & & & & Impact 2005 & & & & \\
\hline \multirow{4}{*}{$\begin{array}{l}\text { Comparative analysis of the life cycle } \\
\text { impact assessment of available } \\
\text { cement inventories in the EU }\end{array}$} & \multirow{4}{*}{$\begin{array}{l}\text { Alejandro Josa, Antonio } \\
\text { Aguado, Arnaldo } \\
\text { Cardim, Ewan Byars }\end{array}$} & \multirow{4}{*}{$\begin{array}{c}\text { Cement and Concrete } \\
\text { Research } 37(2007) 781- \\
788\end{array}$} & \multirow{4}{*}{2007} & \multirow{4}{*}{ Espanha } & \multirow{4}{*}{ CML 1992} & $\begin{array}{l}\text { Gases do efeito } \\
\text { estufa }\end{array}$ & \multirow{4}{*}{$\begin{array}{l}\text { Midpoint e } \\
\text { endpoint }\end{array}$} & \multirow{4}{*}{ CML 1992} & \\
\hline & & & & & & Acidificação & & & \\
\hline & & & & & & Eutrofização & & & \\
\hline & & & & & & poluição & & & \\
\hline $\begin{array}{l}\text { Comparative environmental analysis } \\
\text { of waste brominated plastic }\end{array}$ & $\begin{array}{l}\text { M. Bientinesi, L. } \\
\text { Petarca }\end{array}$ & $\begin{array}{l}\text { Waste Management } 29 \\
\text { (2009) 1095-1102 }\end{array}$ & 2008 & Itália & $\begin{array}{l}\text { Eco-indicator } \\
99 \\
\end{array}$ & & & Ecoinvent 99 & Ecoins \\
\hline
\end{tabular}


Anexo A - Levantamento Bibliográfico - Análise Sistemática

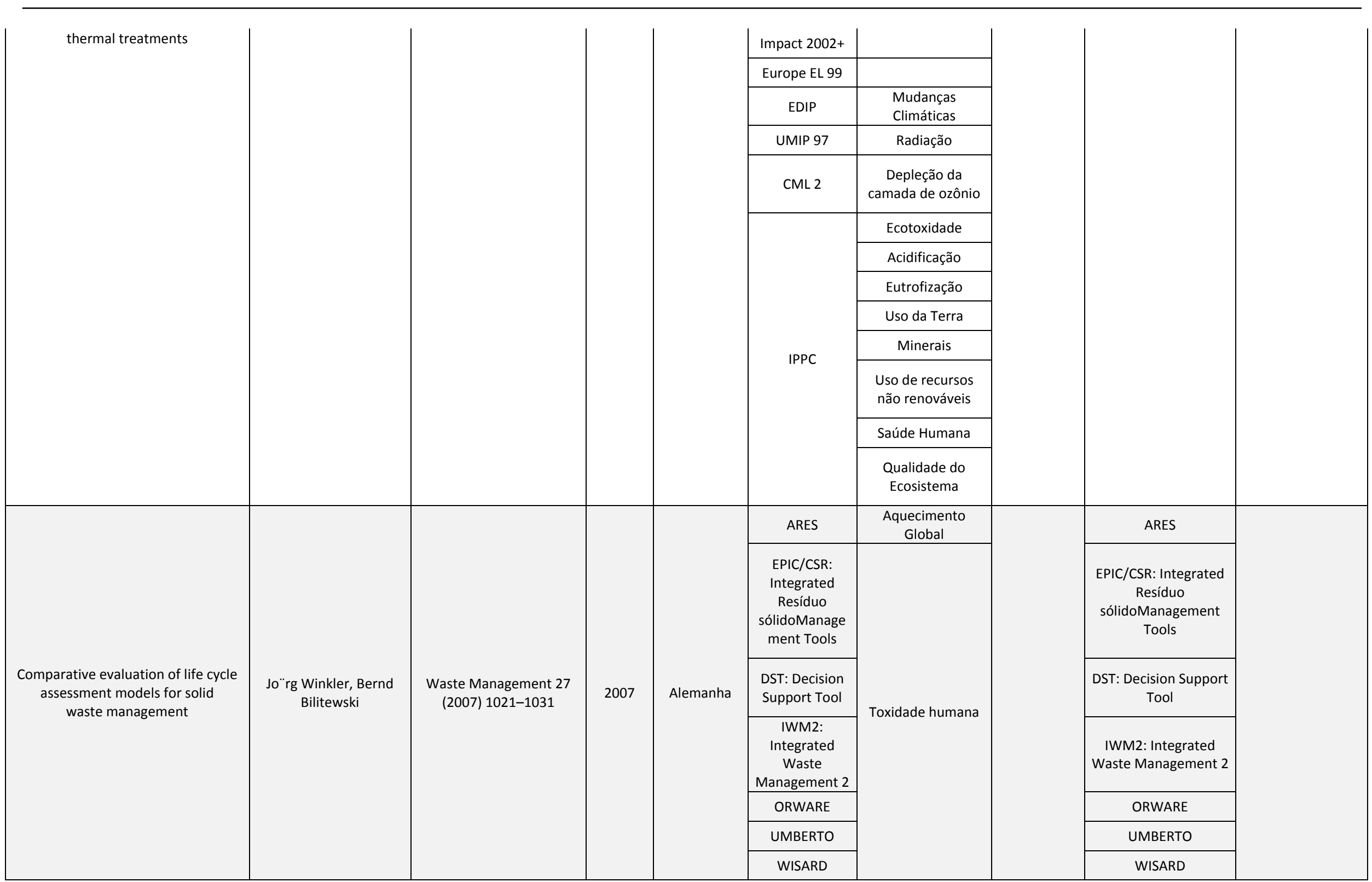


Anexo A - Levantamento Bibliográfico - Análise Sistemática

\begin{tabular}{|c|c|c|c|c|c|c|c|c|}
\hline \multirow{2}{*}{$\begin{array}{l}\text { Comparison of environmental } \\
\text { impacts of building structures with in } \\
\text { situ cast } \\
\text { floors and with precast concrete } \\
\text { floors }\end{array}$} & \multirow{2}{*}{$\begin{array}{l}\text { Belinda Lo' pez-Mesa*, } \\
\text { A' ngel Pitarch, Ana } \\
\text { Toma's, Teresa Gallego }\end{array}$} & \multirow{2}{*}{$\begin{array}{l}\text { Building and Environment } \\
44 \text { (2009) 699-712 }\end{array}$} & \multirow[b]{2}{*}{2008} & \multirow[b]{2}{*}{ Espanha } & EPS 2000 & Uso da Terra & & Eco-indicator 99 \\
\hline & & & & & SimaPro 7.0 & Ruído & & EPS 2000 \\
\hline $\begin{array}{l}\text { Comparison of the } \\
\text { Acidificaçãoimpact from } \\
\text { emissions with different regional } \\
\text { origin in life-cycle } \\
\text { assessment }\end{array}$ & $\begin{array}{l}\text { Jose'Potting, Wolfgang } \\
\text { Scho"pp, Kornelis Blok } \\
\text { Michael Hauschild a }\end{array}$ & $\begin{array}{l}\text { Journal of Hazardous } \\
\text { Materials } 611998.155- \\
162\end{array}$ & 1998 & Holanda & RAINS & Acidificação & & \\
\hline \multirow{4}{*}{$\begin{array}{l}\text { Comparison of the environmental } \\
\text { impact of } \\
\text { incineration and Uso da Terraing in } \\
\text { São Paulo } \\
\text { City as determined by LCA }\end{array}$} & \multirow{4}{*}{$\begin{array}{l}\text { Mara Regina Mendes, } \\
\text { Toshiya Aramaki } \\
\text { Keisuke Hanaki }\end{array}$} & \multirow{4}{*}{$\begin{array}{l}\text { Resources, Conservation } \\
\text { and Recycling } 41 \text { (2004) } \\
47-63\end{array}$} & \multirow{4}{*}{2003} & \multirow{4}{*}{ Japão } & ISW-2 & $\begin{array}{l}\text { Emissões para a } \\
\text { água }\end{array}$ & & ISW-2 \\
\hline & & & & & \multirow{3}{*}{ ORWARE } & $\begin{array}{l}\text { Aquecimento } \\
\text { global }\end{array}$ & & \\
\hline & & & & & & Acidificação & & ORWARE \\
\hline & & & & & & Nutrificação & & \\
\hline $\begin{array}{l}\text { Counting Biodiversidade waste in } \\
\text { industrial eco-efficiency: fisheries } \\
\text { case study }\end{array}$ & $\begin{array}{l}\text { J.H. Martin Willison, } \\
\text { Raymond P. Co^te }\end{array}$ & $\begin{array}{c}\text { Journal of Cleaner } \\
\text { Production } 17 \text { (2009) } \\
348-353\end{array}$ & 2008 & Canadá & & & & \\
\hline \multirow{6}{*}{$\begin{array}{c}\text { Critical review of } \\
\text { techniques and } \\
\text { life cycle analysis and assessment } \\
\text { their application to commercial } \\
\text { activities }\end{array}$} & \multirow{6}{*}{$\begin{array}{l}\text { Jacquetta J. Lee, P. } \\
\text { O'Callaghan, D. Allen }\end{array}$} & \multirow{6}{*}{$\begin{array}{l}\text { Resources, Conservation } \\
\text { and Recycling } 13 \text { ( 1995) } \\
\quad 37-56\end{array}$} & \multirow{6}{*}{1994} & \multirow{6}{*}{ Inglaterra } & EPS & $\begin{array}{l}\text { Conservação de } \\
\text { energia }\end{array}$ & \multirow{6}{*}{ Endpoint } & \\
\hline & & & & & EMPA/BUS & Poluição do ar & & \\
\hline & & & & & \multirow{4}{*}{ REPA } & Poluição da água & & \\
\hline & & & & & & Resíduo sólido & & \\
\hline & & & & & & $\begin{array}{l}\text { Uso de matéria- } \\
\text { prima }\end{array}$ & & \\
\hline & & & & & & Origem da água & & \\
\hline $\begin{array}{l}\text { Decisions to reduce greenhouse } \\
\text { gases from agriculture and product } \\
\text { transport: } \\
\text { LCA case study of organic and } \\
\text { conventional wheat }\end{array}$ & $\begin{array}{l}\text { Kyle Meisterling, } \\
\text { Constantine Samaras, } \\
\text { Vanessa Schweizer }\end{array}$ & $\begin{array}{l}\text { Journal of Cleaner } \\
\text { Production } 17 \text { (2009) } \\
222-230\end{array}$ & 2008 & $\begin{array}{l}\text { Estados } \\
\text { Unidos }\end{array}$ & EIO-LCA & $\begin{array}{l}\text { Aquecimento } \\
\text { global }\end{array}$ & & EIO-LCA \\
\hline
\end{tabular}


Anexo A - Levantamento Bibliográfico - Análise Sistemática

\begin{tabular}{|c|c|c|c|c|c|c|c|c|c|}
\hline \multirow{9}{*}{$\begin{array}{l}\text { Design of environmentally conscious } \\
\text { absorption cooling systems } \\
\text { via multi-objective optimization and } \\
\text { life cycle assessment }\end{array}$} & \multirow{9}{*}{$\begin{array}{l}\text { Berhane } \mathrm{H} \text {. } \\
\text { Gebreslassie, Gonzalo } \\
\text { Guillén-Gosálbez, } \\
\text { Laureano Jiménez, } \\
\text { Dieter Boer }\end{array}$} & \multirow{9}{*}{$\begin{array}{l}\text { Applied Energy } x x x(2008) \\
\text { xxx-xxx }\end{array}$} & \multirow{9}{*}{2008} & \multirow{9}{*}{ Espanha } & \multirow{9}{*}{$\begin{array}{l}\text { Eco-indicator } \\
\qquad 99\end{array}$} & $\begin{array}{l}\text { Mudanças } \\
\text { Climáticas }\end{array}$ & & \multirow{9}{*}{ Eco-indicator 99} & \multirow{9}{*}{ Eco-indicator 99} \\
\hline & & & & & & Radiação & & & \\
\hline & & & & & & $\begin{array}{c}\text { Depleção da } \\
\text { camada de ozônio }\end{array}$ & & & \\
\hline & & & & & & Ecotoxidade & & & \\
\hline & & & & & & Acidificação & & & \\
\hline & & & & & & Eutrofização & & & \\
\hline & & & & & & Uso da Terra & & & \\
\hline & & & & & & $\begin{array}{c}\text { Extração de } \\
\text { minerais }\end{array}$ & & & \\
\hline & & & & & & $\begin{array}{l}\text { Extração de } \\
\text { combustíveis } \\
\text { fósseis }\end{array}$ & & & \\
\hline \multirow{4}{*}{$\begin{array}{l}\text { Developing an LCA guide for } \\
\text { decision support }\end{array}$} & \multirow{4}{*}{$\begin{array}{l}\text { Jeroen B. GuineÂe, } \\
\text { Gjalt Huppes and } \\
\text { Reinout Heijungs }\end{array}$} & \multirow{4}{*}{$\begin{array}{c}\text { Environmental } \\
\text { Management and } \\
\text { Health, Vol. } 12 \text { No. } 3 \text {, } \\
\text { 2001, } \\
\text { pp. } 301-311 .\end{array}$} & \multirow{4}{*}{2001} & \multirow{4}{*}{ Holanda } & \multirow{4}{*}{$\mathrm{CML}$} & $\begin{array}{l}\text { Ecotoxidade da } \\
\text { água } \\
\end{array}$ & \multirow{4}{*}{ Endpoint } & \multirow{4}{*}{ USES 2.0} & \\
\hline & & & & & & $\begin{array}{c}\text { Ecotoxidade } \\
\text { marítima }\end{array}$ & & & \\
\hline & & & & & & Toxidade humana & & & \\
\hline & & & & & & $\begin{array}{l}\text { Ecotoxidade } \\
\text { terrestre }\end{array}$ & & & \\
\hline \multirow{4}{*}{$\begin{array}{l}\text { Developing benchmarks for } \\
\text { consumer-oriented life cycle } \\
\text { assessment-based environmental } \\
\text { information on products, } \\
\text { services and consumption patterns }\end{array}$} & \multirow{4}{*}{$\begin{array}{l}\text { Ari Nissinen, Juha } \\
\text { Gro"nroos, Eva } \\
\text { Heiskanen, Asmo } \\
\text { Honkanen, } \\
\text { Juha-Matti Katajajuuri, } \\
\text { Sirpa Kurppa, Timo } \\
\text { Ma“"kinen, Ilmo } \\
\text { Ma"enpa"a" e, } \\
\text { Jyri Seppa"la", Pa"ivi } \\
\text { Timonen, Kirsi Usva, } \\
\text { Yrjo“ Virtanen, Pasi } \\
\text { Voutilainen } \\
\end{array}$} & \multirow{4}{*}{$\begin{array}{c}\text { Journal of Cleaner } \\
\text { Production } 15 \text { (2007) } \\
538 \mathrm{e} 549\end{array}$} & \multirow{4}{*}{2006} & \multirow{4}{*}{ Finlândia } & \multirow{4}{*}{ Liisa } & $\begin{array}{l}\text { Mudanças } \\
\text { Climáticas }\end{array}$ & & & \\
\hline & & & & & & $\begin{array}{l}\text { Tropospheric } \\
\text { ozone formation }\end{array}$ & & & \\
\hline & & & & & & Acidificação & & & Liisa \\
\hline & & & & & & $\begin{array}{l}\text { Eutrofização } \\
\text { aquática }\end{array}$ & & & \\
\hline \multirow{3}{*}{$\begin{array}{l}\text { Development of a life cycle } \\
\text { assessment tool for construction and } \\
\text { maintenance } \\
\text { of asphalt pavements }\end{array}$} & \multirow{3}{*}{$\begin{array}{l}\text { Yue Huang, Roger Bird, } \\
\text { Oliver Heidrich }\end{array}$} & \multirow{3}{*}{$\begin{array}{c}\text { Journal of Cleaner } \\
\text { Production } 17 \text { (2009) } \\
283-296\end{array}$} & \multirow{3}{*}{2008} & \multirow{3}{*}{ Inglaterra } & \multirow{3}{*}{$\mathrm{CML}$} & $\begin{array}{l}\text { Depleção dos } \\
\text { minerais }\end{array}$ & & \multirow{3}{*}{ CML } & \multirow{3}{*}{ CML } \\
\hline & & & & & & $\begin{array}{l}\text { Depleção dos } \\
\text { combustiveis } \\
\text { fósseis }\end{array}$ & & & \\
\hline & & & & & & $\begin{array}{l}\text { Aquecimento } \\
\text { Global }\end{array}$ & & & \\
\hline
\end{tabular}


Anexo A - Levantamento Bibliográfico - Análise Sistemática

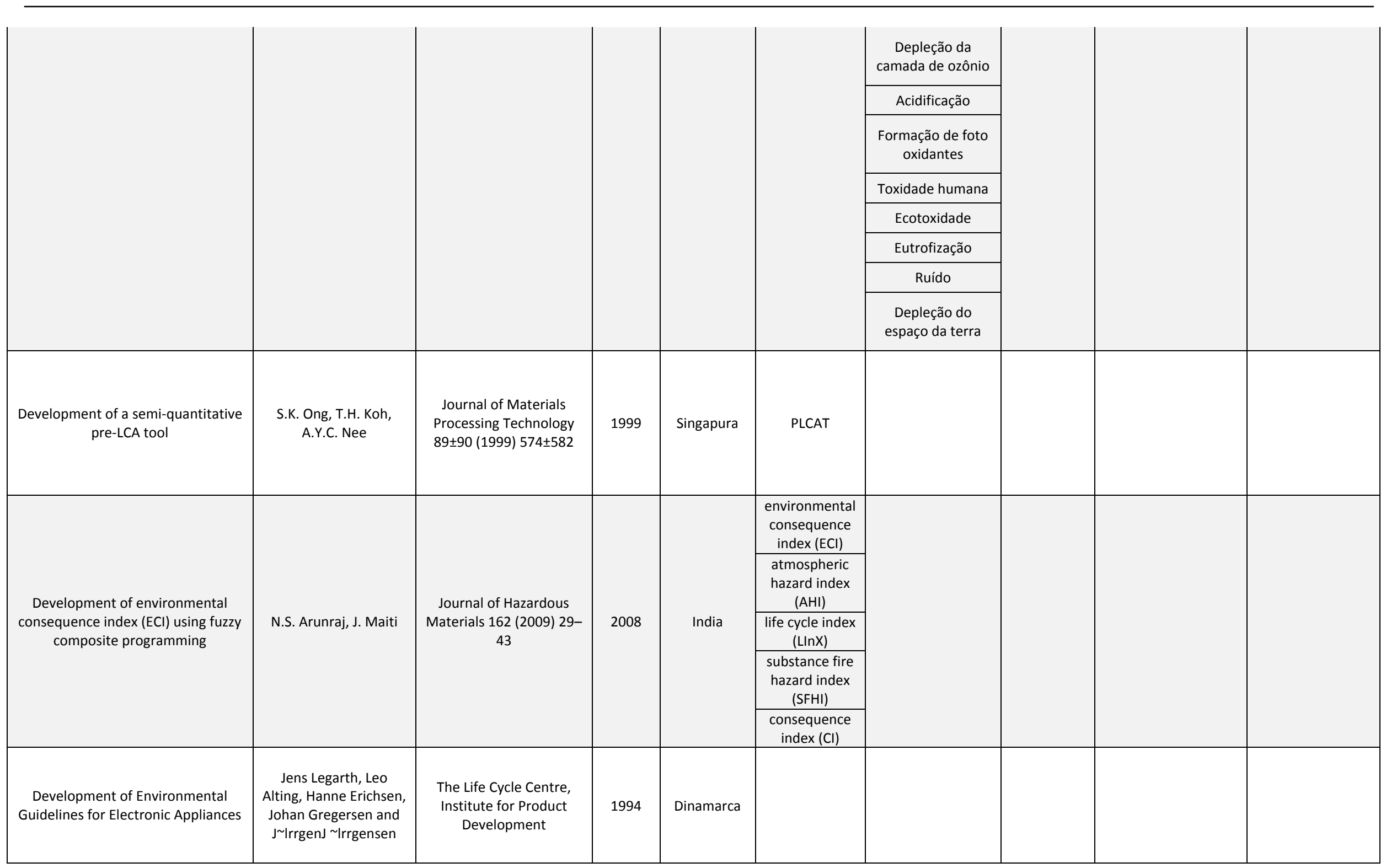


Anexo A - Levantamento Bibliográfico - Análise Sistemática

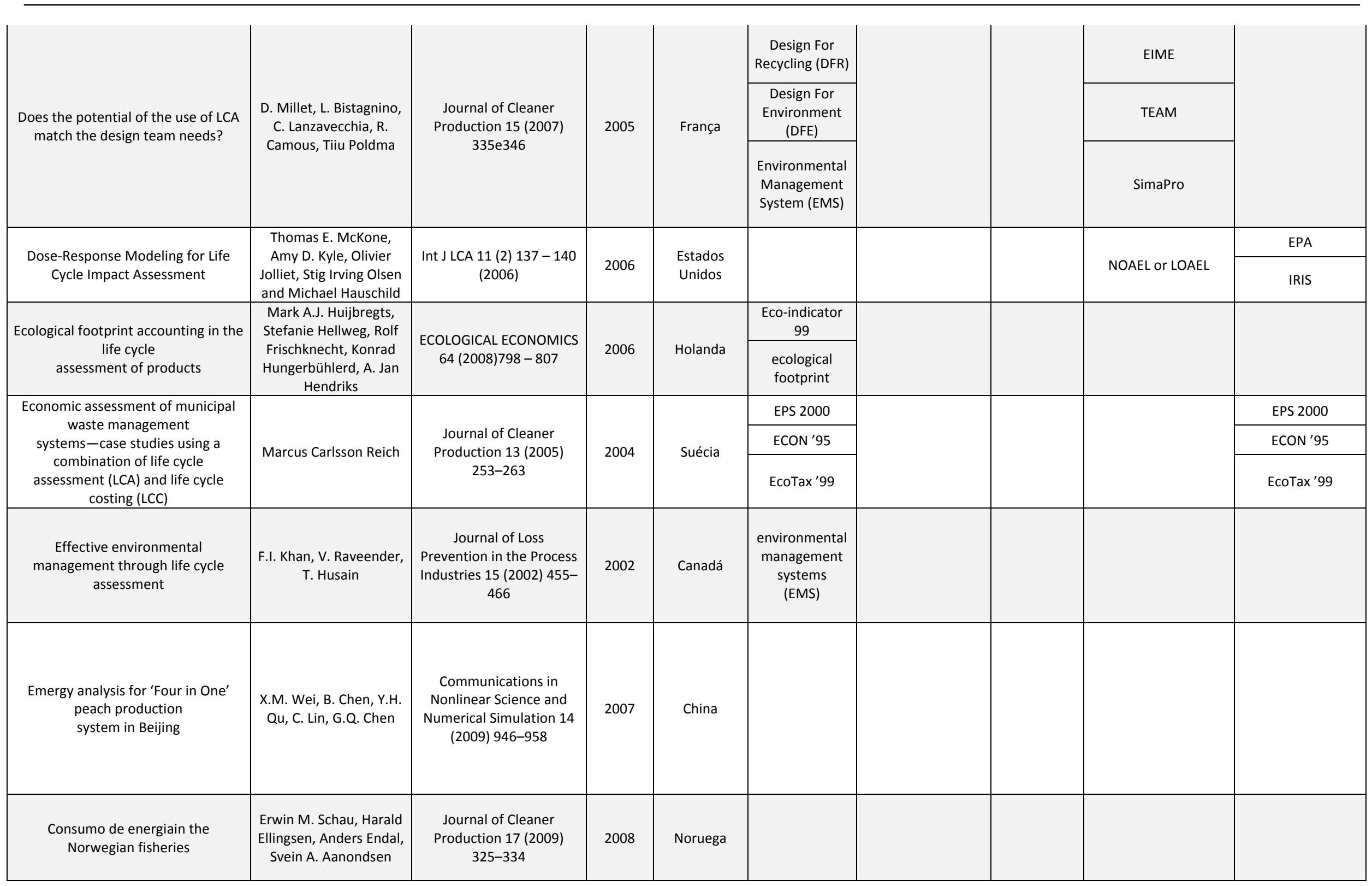


Anexo A - Levantamento Bibliográfico - Análise Sistemática

\begin{tabular}{|c|c|c|c|c|c|c|c|c|}
\hline \multirow{2}{*}{$\begin{array}{l}\text { Engineering design of green hybrid } \\
\text { energy production and supply chains }\end{array}$} & \multirow{2}{*}{ Hossam A. Gabbar } & \multirow{2}{*}{$\begin{array}{c}\text { Environmental Modelling } \\
\text { \& Software } 24 \text { (2009) } \\
423-435\end{array}$} & \multirow{2}{*}{2008} & \multirow{2}{*}{ Japão } & \multirow{2}{*}{$\begin{array}{l}\text { Process object } \\
\text { oriented } \\
\text { modeling } \\
\text { (POOM), }\end{array}$} & & \multirow{2}{*}{$\frac{\text { CAPE-ModE }}{\text { ESN }}$} & \\
\hline & & & & & & & & \\
\hline \multirow{5}{*}{$\begin{array}{l}\text { Environmental analysis of the } \\
\text { Norwegian fisheryand aquaculture } \\
\text { industry-A preliminary study } \\
\text { focusing on farmed salmon }\end{array}$} & \multirow{5}{*}{$\begin{array}{l}\text { H. Ellingsen, } \\
\text { J.O.Olaussen, I.B.Utne }\end{array}$} & & \multirow{5}{*}{2008} & \multirow{5}{*}{ Noruega } & $\begin{array}{l}\text { LCS - Life cycle } \\
\text { screening }\end{array}$ & $\begin{array}{l}\text { Mudanças } \\
\text { Climáticas }\end{array}$ & & ETH-ESU 96 \\
\hline & & & & & \multirow{4}{*}{ LCA qualitative } & Acidificação & & \multirow{4}{*}{ BUWAL 250} \\
\hline & & & & & & Eutrofização & & \\
\hline & & & & & & $\begin{array}{c}\text { Consumo de } \\
\text { energia }\end{array}$ & & \\
\hline & & & & & & Água & & \\
\hline $\begin{array}{c}\text { Environmental and economic life } \\
\text { cycle assessment for sewage sludge } \\
\text { treatment } \\
\text { processes in Japan }\end{array}$ & $\begin{array}{l}\text { Jinglan Hong, Jingmin } \\
\text { Hong, Masahiro Otaki, } \\
\text { Olivier Jolliet }\end{array}$ & $\begin{array}{l}\text { Waste Management } 29 \\
\text { (2009) 696-703 }\end{array}$ & 2008 & $\begin{array}{l}\text { Estados } \\
\text { Unidos }\end{array}$ & & & & \\
\hline \multirow{7}{*}{$\begin{array}{l}\text { Environmental assessment of ue gas } \\
\text { cleaning processes of municipal } \\
\text { Resíduo sólidoincinerators by means } \\
\text { of the life cycle assessment approach }\end{array}$} & \multirow{7}{*}{$\begin{array}{l}\text { Jacques Chevalier, } \\
\text { Patrick Rousseaux, } \\
\text { Val.erie Benoit, } \\
\text { Belkacem Benadda }\end{array}$} & \multirow{7}{*}{$\begin{array}{c}\text { Chemical Engineering } \\
\text { Science } 58 \text { (2003) } 2053- \\
2064\end{array}$} & \multirow{7}{*}{2002} & \multirow{7}{*}{ França } & CLM & $\begin{array}{c}\text { Gases do efeito } \\
\text { estufa }\end{array}$ & & \multirow{7}{*}{ BUWAL } \\
\hline & & & & & \multirow{6}{*}{ ELECTRE IS } & Acidificação & & \\
\hline & & & & & & Toxidade humana & & \\
\hline & & & & & & $\begin{array}{l}\text { Toxidade humana } \\
\text { da Água }\end{array}$ & & \\
\hline & & & & & & $\begin{array}{l}\text { Ecotoxidade da } \\
\text { água }\end{array}$ & & \\
\hline & & & & & & Uso da Terra & & \\
\hline & & & & & & $\begin{array}{l}\text { Depleção de } \\
\text { recursos }\end{array}$ & & \\
\hline \multirow{4}{*}{$\begin{array}{l}\text { Environmental assessment of biogas } \\
\text { co- or tri-generation units by life } \\
\text { cycle analysis methodology }\end{array}$} & \multirow{4}{*}{ C. Chevalier, F. Meunier } & \multirow{4}{*}{$\begin{array}{c}\text { Applied Thermal } \\
\text { Engineering } 25 \text { (2005) } \\
\text { 3025-3041 }\end{array}$} & \multirow{4}{*}{2005} & \multirow{4}{*}{ França } & $\begin{array}{c}\text { Eco-indicator } \\
99\end{array}$ & $\begin{array}{c}\text { Depleção de } \\
\text { recursos }\end{array}$ & \multirow{4}{*}{ Eco-indicator 99} & \multirow{4}{*}{$\mathrm{CML}$} \\
\hline & & & & & \multirow{3}{*}{ Spriensma } & $\begin{array}{l}\text { Mudanças } \\
\text { Climáticas }\end{array}$ & & \\
\hline & & & & & & Acidificação & & \\
\hline & & & & & & Eutrofização & & \\
\hline $\begin{array}{l}\text { Environmental assessment of } \\
\text { different advanced oxidation }\end{array}$ & $\begin{array}{l}\text { Iva’́n Mun oz, Joan } \\
\text { Rieradevall, Francesc }\end{array}$ & $\begin{array}{c}\text { Chemosphere } 62 \text { (2006) } \\
\text { 9-16 } \\
\end{array}$ & 2005 & Espanha & & $\begin{array}{l}\text { Aquecimento } \\
\text { global }\end{array}$ & & BUWAL 250 \\
\hline
\end{tabular}


Anexo A - Levantamento Bibliográfico - Análise Sistemática

\begin{tabular}{|c|c|c|c|c|c|c|c|c|c|}
\hline \multirow[t]{7}{*}{$\begin{array}{l}\text { processes applied to a bleaching } \\
\text { Kraft mill effluent }\end{array}$} & \multirow[t]{7}{*}{$\begin{array}{l}\text { Torrades, Jose' Peral, } \\
\text { Xavier Dome 'nech }\end{array}$} & & & & & $\begin{array}{l}\text { Depleção da } \\
\text { camada de ozônio }\end{array}$ & & & CEFIC \\
\hline & & & & & & $\begin{array}{c}\text { Eutrofização } \\
\text { aquática }\end{array}$ & & & \multirow{6}{*}{ IVAM } \\
\hline & & & & & & Acidificação & & & \\
\hline & & & & & & Toxidade humana & & & \\
\hline & & & & & & Toxidade da água & & & \\
\hline & & & & & & $\begin{array}{l}\text { Criação de ozônio } \\
\text { fotoquímico }\end{array}$ & & & \\
\hline & & & & & & $\begin{array}{l}\text { Depleção de } \\
\text { recursos abióticos }\end{array}$ & & & \\
\hline \multirow{5}{*}{$\begin{array}{l}\text { Environmental assessment of } \\
\text { rebuilding and possible performance } \\
\text { improvements effect on a national } \\
\text { scale }\end{array}$} & \multirow{5}{*}{$\begin{array}{c}\text { Martin Erlandsson, Per } \\
\text { Levin }\end{array}$} & \multirow{5}{*}{$\begin{array}{l}\text { Building and Environment } \\
39 \text { (2004) 1453-1465 }\end{array}$} & \multirow{5}{*}{2004} & \multirow{5}{*}{ Suécia } & EDIP & Acidificação & \multirow{5}{*}{ Endpoint } & & \\
\hline & & & & & \multirow{4}{*}{ BUWAL } & Eutrofização & & & \\
\hline & & & & & & $\begin{array}{l}\text { Mudanças } \\
\text { Climáticas }\end{array}$ & & & \\
\hline & & & & & & $\begin{array}{l}\text { Criação de ozônio } \\
\text { fotoquímico }\end{array}$ & & & \\
\hline & & & & & & Biodiversidade & & & \\
\hline \multirow{8}{*}{$\begin{array}{l}\text { Environmental assessment of } \\
\text { Resíduo sólidoUso da Terraing } \\
\text { technologies by means of LCA- } \\
\text { modeling }\end{array}$} & \multirow{8}{*}{$\begin{array}{l}\text { Simone Manfredi, } \\
\text { Thomas H. Christensen }\end{array}$} & \multirow{8}{*}{$\begin{array}{l}\text { Waste Management } 29 \\
\qquad \text { (2009) 32-43 }\end{array}$} & \multirow{8}{*}{2008} & \multirow{8}{*}{ Dinamarca } & & $\begin{array}{c}\text { Aquecimento } \\
\text { Global }\end{array}$ & & \multirow{8}{*}{ EASEWASTE } & \\
\hline & & & & & & $\begin{array}{l}\text { Criação de ozônio } \\
\text { fotoquímico }\end{array}$ & & & \\
\hline & & & & & & $\begin{array}{l}\text { Depleção da } \\
\text { camada de ozônio }\end{array}$ & & & \\
\hline & & & & & & Acidificação & & & \\
\hline & & & & & & Nutrificação & & & \\
\hline & & & & & & $\begin{array}{l}\text { Toxidade humana } \\
\text { do solo }\end{array}$ & & & \\
\hline & & & & & & Toxidade da água & & & \\
\hline & & & & & & Toxidade do ar & & & \\
\hline
\end{tabular}


Anexo A - Levantamento Bibliográfico - Análise Sistemática

\begin{tabular}{|c|c|c|c|c|c|c|c|c|}
\hline & & & & & & $\begin{array}{l}\text { Ecotoxidade } \\
\text { crônica da água }\end{array}$ & & \\
\hline & & & & & & Uso da Terra & & \\
\hline \multirow{5}{*}{$\begin{array}{c}\text { Environmental assessment of } \\
\text { Resíduo sólidoUso da Terraing } \\
\text { technologies } \\
\text { by means of LCA-modeling }\end{array}$} & \multirow{5}{*}{$\begin{array}{l}\text { Simone Manfredi, } \\
\text { Thomas H. Christensen }\end{array}$} & \multirow{5}{*}{$\begin{array}{l}\text { Waste Management } 29 \\
\text { (2009) } 32-43\end{array}$} & \multirow{5}{*}{2008} & \multirow{5}{*}{ Dinamarca } & \multirow{5}{*}{$\begin{array}{c}\text { Environmental } \\
\text { Assessment of } \\
\text { Solid } \\
\text { Waste Systems } \\
\text { and } \\
\text { Technologies } \\
\text { (EASEWASTE) }\end{array}$} & $\begin{array}{c}\text { Aquecimento } \\
\text { Global }\end{array}$ & & \\
\hline & & & & & & Nutrificação & & \\
\hline & & & & & & $\begin{array}{l}\text { Depleção da } \\
\text { camada de ozônio }\end{array}$ & & \\
\hline & & & & & & $\begin{array}{l}\text { Criação de ozônio } \\
\text { fotoquímico }\end{array}$ & & \\
\hline & & & & & & Acidificação & & \\
\hline \multirow{8}{*}{$\begin{array}{l}\text { Environmental assessment tools for } \\
\text { the evaluation and improvement of } \\
\text { European livestock production } \\
\text { systems }\end{array}$} & \multirow{8}{*}{$\begin{array}{l}\text { Niels Halberg, Hayo } \\
\text { M.G. van der Werf, } \\
\text { Claudine Basset-Mens, } \\
\text { Randi Dalgaard, Imke } \\
\text { J.M. de Boer }\end{array}$} & \multirow{8}{*}{$\begin{array}{l}\text { Livestock Production } \\
\text { Science } 96 \text { (2005) 33-50 }\end{array}$} & \multirow{8}{*}{2005} & \multirow{8}{*}{ Dinamarca } & $\begin{array}{l}\text { Green } \\
\text { accounts for } \\
\text { farms }\end{array}$ & Eutrofização & \multirow{8}{*}{ IRENA } & \\
\hline & & & & & Ecopoints & $\begin{array}{l}\text { Mudanças } \\
\text { Climáticas }\end{array}$ & & \\
\hline & & & & & $\begin{array}{l}\text { Environmental } \\
\text { Management } \\
\text { for Agriculture }\end{array}$ & Acidificação & & \\
\hline & & & & & DIALECTE & Toxidade Terrestre & & \\
\hline & & & & & LCAE & $\begin{array}{l}\text { Uso de recursos } \\
\text { não renováveis }\end{array}$ & & \\
\hline & & & & & $\begin{array}{c}\text { LCA for } \\
\text { Environmental } \\
\text { farm } \\
\text { management }\end{array}$ & Uso da Terra & & \\
\hline & & & & & $\begin{array}{l}\text { Ecological } \\
\text { Footprint } \\
\end{array}$ & \multirow{2}{*}{ Uso de pesticidas } & & \\
\hline & & & & & IPCC & & & \\
\hline \multirow{3}{*}{$\begin{array}{l}\text { Environmental evaluation of transfer } \\
\text { and treatment of excess } \\
\text { pig slurry by life cycle assessment }\end{array}$} & \multirow{3}{*}{$\begin{array}{c}\text { Santiago Lopez- } \\
\text { Ridaura, Hayo van der } \\
\text { Werf, Jean Marie } \\
\text { Paillat, Bertrand Le Bris }\end{array}$} & \multirow{3}{*}{$\begin{array}{l}\text { Journal of Environmental } \\
\text { Management } 90 \text { (2009) } \\
\qquad 1296-1304\end{array}$} & \multirow{3}{*}{2008} & \multirow{3}{*}{ França } & \multirow{3}{*}{ SimaPro 6} & Eutrofização & \multirow{3}{*}{ SimaPro 6} & BUWAL 250 \\
\hline & & & & & & Acidificação & & ETH-ESU \\
\hline & & & & & & $\begin{array}{l}\text { Mudanças } \\
\text { Climáticas }\end{array}$ & & IDEMAT \\
\hline
\end{tabular}


Anexo A - Levantamento Bibliográfico - Análise Sistemática

\begin{tabular}{|c|c|c|c|c|c|c|c|c|}
\hline & & & & & & $\begin{array}{l}\text { Uso de recursos } \\
\text { não renováveis }\end{array}$ & & SimaPro 6 \\
\hline \multirow{6}{*}{$\begin{array}{l}\text { Environmental impact assessment of } \\
\text { agricultural production } \\
\text { systems using the life cycle } \\
\text { assessment (LCA) methodology II. } \\
\text { The application to } \mathrm{N} \text { fertilizer use in } \\
\text { winter wheat production systems }\end{array}$} & \multirow{6}{*}{$\begin{array}{l}\text { F. Brentrup, J. Küsters, } \\
\text { J. Lammela, P. } \\
\text { Barraclough, H. } \\
\text { Kuhlmann }\end{array}$} & \multirow{6}{*}{$\begin{array}{l}\text { Europ. J. Agronomy } 20 \\
\text { (2004) 265-279 }\end{array}$} & \multirow{6}{*}{2003} & \multirow{6}{*}{ Alemanha } & \multirow{6}{*}{ EcoX } & $\begin{array}{l}\text { Depleção de } \\
\text { recursos abióticos }\end{array}$ & & \\
\hline & & & & & & Uso da Terra & & \\
\hline & & & & & & $\begin{array}{l}\text { Mudanças } \\
\text { Climáticas }\end{array}$ & & \\
\hline & & & & & & Toxidade & & \\
\hline & & & & & & Acidificação & & \\
\hline & & & & & & Eutrofização & & \\
\hline \multirow{7}{*}{$\begin{array}{l}\text { Environmental impact assessment of } \\
\text { agricultural production } \\
\text { systems using the life cycle } \\
\text { assessment methodology } \\
\text { I. Theoretical concept of a LCA } \\
\text { method tailored to } \\
\text { crop production }\end{array}$} & \multirow{7}{*}{$\begin{array}{l}\text { F. Brentrup, J. Küsters, } \\
\text { H. Kuhlmann, J. Lammel }\end{array}$} & \multirow{7}{*}{$\begin{array}{l}\text { Europ. J. Agronomy } 20 \\
\text { (2004) 247-264 }\end{array}$} & \multirow{7}{*}{2003} & \multirow{7}{*}{ Alemanha } & $\begin{array}{l}\text { indicators for } \\
\text { Depleção de } \\
\text { recursos (RDI) }\end{array}$ & $\begin{array}{l}\text { Depleção de } \\
\text { recursos abióticos }\end{array}$ & Eco Management & \\
\hline & & & & & $\begin{array}{l}\text { environmental } \\
\text { impacts (EcoX) }\end{array}$ & Uso da Terra & \multirow{6}{*}{ EMAS } & \\
\hline & & & & & \multirow{5}{*}{ RAINS } & $\begin{array}{l}\text { Mudanças } \\
\text { Climáticas }\end{array}$ & & \\
\hline & & & & & & Toxidade humana & & \\
\hline & & & & & & Ecotoxidade & & \\
\hline & & & & & & Acidificação & & \\
\hline & & & & & & Eutrofização & & \\
\hline \multirow{3}{*}{$\begin{array}{c}\text { Environmental Impact Evaluation of } \\
\text { Feeds Prepared from Food Residues } \\
\text { Using } \\
\text { Life Cycle Assessment }\end{array}$} & \multirow{3}{*}{$\begin{array}{c}\text { Akifumi Ogino, Hiroyuki } \\
\text { Hirooka, Atsuo } \\
\text { Ikeguchi, Yasuo Tanaka, } \\
\text { Miyoko Waki, } \\
\text { Hiroshi Yokoyama, and } \\
\text { Tomoyuki Kawashima } \\
\end{array}$} & \multirow{3}{*}{$\begin{array}{c}\text { J. Environ. Qual. 36:1061- } \\
1068 \text { (2007). }\end{array}$} & \multirow{3}{*}{2007} & \multirow{3}{*}{$\begin{array}{l}\text { Estados } \\
\text { Unidos }\end{array}$} & JEMAI-LCA & $\begin{array}{l}\text { Emissão gases } \\
\text { efeito estufa }\end{array}$ & & JEMAI-LCA \\
\hline & & & & & & Consumo de água & & \\
\hline & & & & & SimaPro & $\begin{array}{c}\text { Consumo de } \\
\text { Energia }\end{array}$ & & SimaPro \\
\hline $\begin{array}{c}\text { Environmental impact minimization } \\
\text { of a total wasteÁgua treatment } \\
\text { network system from a life cycle } \\
\text { perspective }\end{array}$ & $\begin{array}{l}\text { Seong-Rin Lim, Jong } \\
\text { Moon Park }\end{array}$ & $\begin{array}{c}\text { Journal of Environmental } \\
\text { Management } 90 \text { (2009) } \\
1454-1462\end{array}$ & 2008 & $\begin{array}{l}\text { Estados } \\
\text { Unidos }\end{array}$ & EPS 2000 & & & \\
\hline
\end{tabular}


Anexo A - Levantamento Bibliográfico - Análise Sistemática

\begin{tabular}{|c|c|c|c|c|c|c|c|c|c|}
\hline $\begin{array}{c}\text { Environmental Impact of Information } \\
\text { and Communication } \\
\text { Technologies Including Rebound } \\
\text { Effects }\end{array}$ & $\begin{array}{l}\text { Kazue Ichino Takahashi, } \\
\text { Hidetoshi Tatemichi, } \\
\text { Tohoru Tanaka and } \\
\text { Shiro Nishi }\end{array}$ & & 2004 & Japão & & & & Easy-LCA & \\
\hline $\begin{array}{c}\text { Environmental Impacts Evaluation of } \\
\text { Electricity Grid Mix Systems } \\
\text { in Four Selected Countries Using A } \\
\text { Life Cycle Assessment Point of View }\end{array}$ & $\begin{array}{l}\text { Anugerah Widiyanto, } \\
\text { Seizo Kato, Naoki } \\
\text { Maruyama, Akira } \\
\text { Nishimura and Sate } \\
\text { Sampattagul }\end{array}$ & $\begin{array}{l}\text { Envlronmentaii Conscious } \\
\text { Design and Inverse } \\
\text { ManUtaCturing } \\
\text { Tokyo. Japan, 8ecember } \\
\text { 8-11.2003 }\end{array}$ & 2003 & Japão & Lca -NETS & & & & \\
\hline \multirow{9}{*}{$\begin{array}{l}\text { Environmental impacts of cocoa } \\
\text { production and processing } \\
\text { in Ghana: life cycle assessment } \\
\text { approach }\end{array}$} & \multirow{9}{*}{$\begin{array}{l}\text { Augustine Ntiamoah, } \\
\text { George Afrane }\end{array}$} & \multirow{9}{*}{$\begin{array}{c}\text { Journal of Cleaner } \\
\text { Production } 16(2008) \\
1735 \mathrm{e} 1740\end{array}$} & \multirow{9}{*}{2008} & \multirow{9}{*}{ Gana } & \multirow{9}{*}{ CML 2001} & $\begin{array}{l}\text { Depleção de } \\
\text { recursos abióticos }\end{array}$ & \multirow{9}{*}{ Endpoint } & & Ecoinvent \\
\hline & & & & & & Acidificação & & & \multirow{8}{*}{ GaBi 4} \\
\hline & & & & & & Eutrofização & & & \\
\hline & & & & & & $\begin{array}{l}\text { Ecotoxidade da } \\
\text { água }\end{array}$ & & & \\
\hline & & & & & & $\begin{array}{c}\text { Aquecimento } \\
\text { global }\end{array}$ & & & \\
\hline & & & & & & Toxidade humana & & & \\
\hline & & & & & & $\begin{array}{l}\text { Depleção da } \\
\text { camada de ozônio }\end{array}$ & & & \\
\hline & & & & & & $\begin{array}{l}\text { Criação de ozônio } \\
\text { fotoquímico }\end{array}$ & & & \\
\hline & & & & & & $\begin{array}{l}\text { Ecotoxidade } \\
\text { terrestre }\end{array}$ & & & \\
\hline \multirow{3}{*}{$\begin{array}{l}\text { Environmental impacts of the } \\
\text { Japanese beef-fattening system with } \\
\text { different } \\
\text { feeding lengths as evaluated by a } \\
\text { life-cycle assessment method }\end{array}$} & \multirow{3}{*}{$\begin{array}{l}\text { A. Ogino, K. Kaku, T. } \\
\text { Osada, and K. Shimada }\end{array}$} & \multirow{3}{*}{$\begin{array}{l}\text { National Institute of } \\
\text { Livestock and Grassland } \\
\text { Science, Tsukuba, Ibaraki } \\
\text { 305-0901, Japan }\end{array}$} & \multirow{3}{*}{2004} & \multirow{3}{*}{ Japão } & & $\begin{array}{l}\text { Aquecimento } \\
\text { Global }\end{array}$ & & & \multirow{3}{*}{ JEMAI-LCA } \\
\hline & & & & & & Acidificação & & & \\
\hline & & & & & & Eutrofização & & & \\
\hline $\begin{array}{c}\text { Environmental life cycle assessment } \\
\text { of the microfiltration process }\end{array}$ & $\begin{array}{l}\text { N. Tangsubkul, K. } \\
\text { Parameshwaran, S. }\end{array}$ & $\begin{array}{l}\text { Journal of Membrane } \\
\text { Science } 284 \text { (2006) 214- }\end{array}$ & 2006 & Austrália & & $\begin{array}{l}\text { Aquecimento } \\
\text { Global }\end{array}$ & & GaBi 4 & GaBi 4 \\
\hline
\end{tabular}


Anexo A - Levantamento Bibliográfico - Análise Sistemática

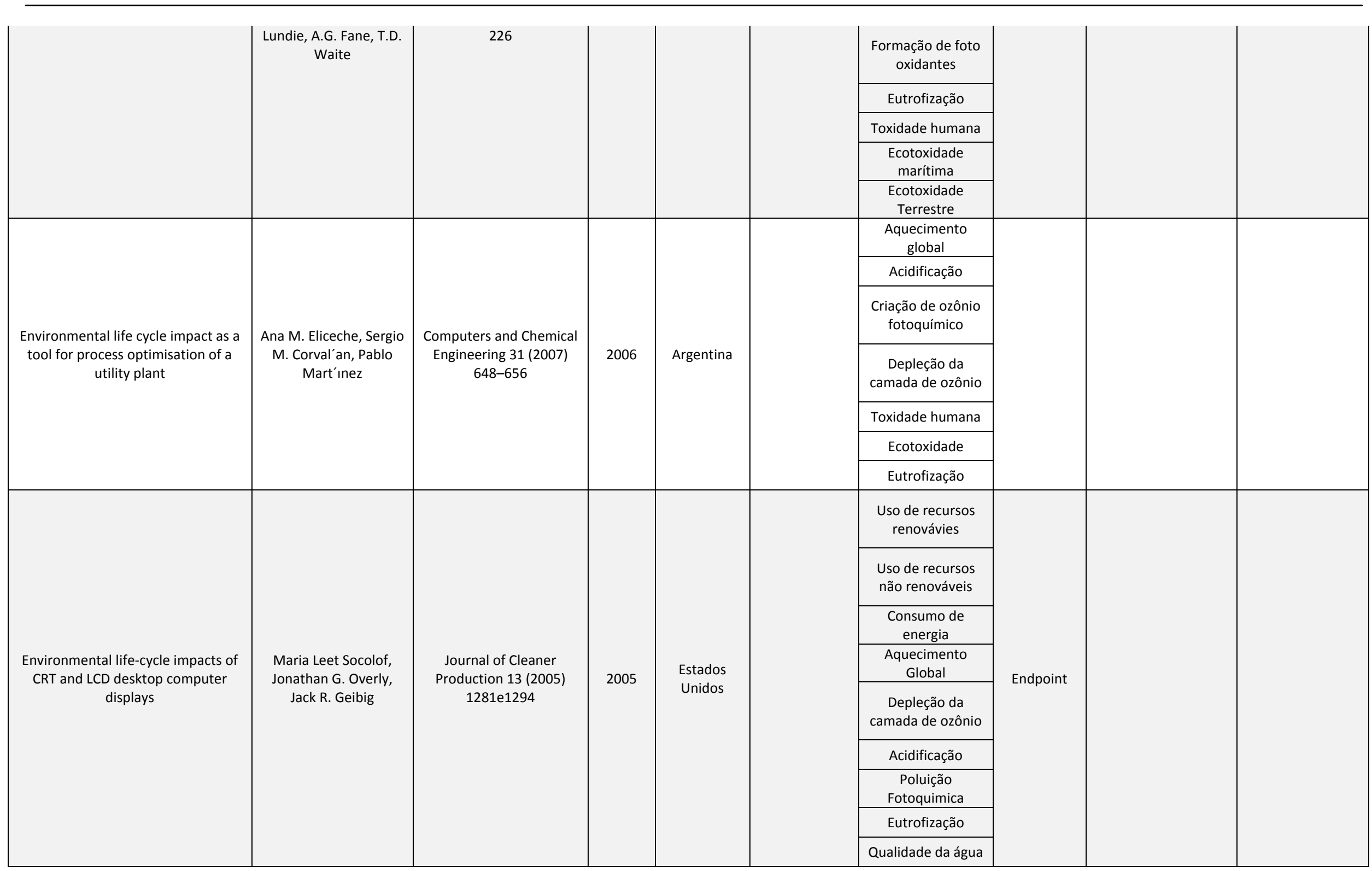


Anexo A - Levantamento Bibliográfico - Análise Sistemática

\begin{tabular}{|c|c|c|c|c|c|c|c|c|}
\hline & & & & & & Resíduo sólido & & \\
\hline & & & & & & Resíduos Perigosos & & \\
\hline & & & & & & Lixo Radioativo & & \\
\hline & & & & & & Radioatividade & & \\
\hline & & & & & & odor & & \\
\hline & & & & & & $\begin{array}{c}\text { Ecotoxidade da } \\
\text { água }\end{array}$ & & \\
\hline & & & & & & $\begin{array}{l}\text { Ecotoxidade } \\
\text { Terrestre } \\
\end{array}$ & & \\
\hline \multirow{6}{*}{$\begin{array}{l}\text { Environmental performance } \\
\text { comparison of wet and thermal } \\
\text { routes for phosphate fertilizer } \\
\text { production using LCA e A Brazilian } \\
\text { experience }\end{array}$} & \multirow{6}{*}{$\begin{array}{l}\text { Gil Anderi da Silva, Luiz } \\
\text { Alexandre Kulay }\end{array}$} & \multirow{6}{*}{$\begin{array}{c}\text { Journal of Cleaner } \\
\text { Production } 13 \text { (2005) } \\
1321 \mathrm{e} 1325\end{array}$} & \multirow{6}{*}{2005} & \multirow{6}{*}{ Brasil } & CML 2 & $\begin{array}{c}\text { Aquecimento } \\
\text { Global }\end{array}$ & TEAM & \multirow{6}{*}{ ETH-ESU } \\
\hline & & & & & \multirow{5}{*}{ SimaPro 5} & $\begin{array}{c}\text { Depleção da } \\
\text { camada de ozônio }\end{array}$ & \multirow{5}{*}{ SimaPro 5} & \\
\hline & & & & & & Toxidade humana & & \\
\hline & & & & & & $\begin{array}{l}\text { Ecotoxidade da } \\
\text { água }\end{array}$ & & \\
\hline & & & & & & Acidificação & & \\
\hline & & & & & & Eutrofização & & \\
\hline \multirow{3}{*}{$\begin{array}{c}\text { Environmental Supply-Chain } \\
\text { Management versus Life Cycle } \\
\text { Analysis (LCA) Method Eco-indicator } \\
\text { 95: a Relative Business Perspective } \\
\text { versus an Absolute Environmental } \\
\text { Perspective } \\
\end{array}$} & \multirow{3}{*}{ M.H. Nagel } & \multirow{3}{*}{$\begin{array}{l}\text { Faculty of Industrial } \\
\text { Design Engineering, } \\
\text { Department of } \\
\text { Engineering Design }\end{array}$} & \multirow{3}{*}{2000} & \multirow{3}{*}{ Holanda } & \multirow{3}{*}{$\begin{array}{l}\text { Eco-indicator } \\
\quad 95\end{array}$} & Acidificação & \multirow{3}{*}{ Eco-indicator 95} & \multirow{3}{*}{ IDEMAT } \\
\hline & & & & & & poluição & & \\
\hline & & & & & & $\begin{array}{c}\text { Gases do efeito } \\
\text { estufa }\end{array}$ & & \\
\hline \multirow{8}{*}{$\begin{array}{l}\text { Estimation of environmental impact } \\
\text { of conversion to organic agriculture } \\
\text { in Hamburg using the Life-Cycle- } \\
\text { Assessment method }\end{array}$} & \multirow{8}{*}{$\begin{array}{l}\text { Guido Haas, Uwe Geier, } \\
\text { Bettina Frieben and } \\
\text { Ulrich Köpke }\end{array}$} & \multirow{8}{*}{$\begin{array}{l}\text { Institute of Organic } \\
\text { Agriculture, University of } \\
\text { Bonn, Katzenburgweg 3, } \\
\text { D-53115 Bonn, Germany }\end{array}$} & \multirow{8}{*}{2005} & \multirow{8}{*}{ Alemanha } & & Eutrofização & & \multirow{8}{*}{ GEMIS 2.1} \\
\hline & & & & & & $\begin{array}{l}\text { Depleção de } \\
\text { recursos }\end{array}$ & & \\
\hline & & & & & & $\begin{array}{l}\text { Aquecimento } \\
\text { global }\end{array}$ & & \\
\hline & & & & & & Acidificação & & \\
\hline & & & & & & $\begin{array}{l}\text { Proteção da água } \\
\text { potável }\end{array}$ & & \\
\hline & & & & & & Toxidade humana & & \\
\hline & & & & & & Biodiversidade & & \\
\hline & & & & & & Uso da terra & & \\
\hline
\end{tabular}


Anexo A - Levantamento Bibliográfico - Análise Sistemática

\begin{tabular}{|c|c|c|c|c|c|c|c|c|}
\hline & & & & & & imagem & & \\
\hline & & & & & & Proteção do solo & & \\
\hline $\begin{array}{l}\text { Estimation of the environmental } \\
\text { credit for the recycling of granulated } \\
\text { blast furnace slag based on LCA }\end{array}$ & $\begin{array}{l}\text { Kun-Mo Leea, Pil-Ju } \\
\text { Park }\end{array}$ & $\begin{array}{c}\text { Resources, Conservation } \\
\text { and Recycling } 44 \text { (2005) } \\
139-151\end{array}$ & 2004 & $\begin{array}{c}\text { Coréia do } \\
\text { Sul }\end{array}$ & $\begin{array}{l}\text { Eco-indicator } \\
\quad 99\end{array}$ & $\begin{array}{l}\text { Aquecimento } \\
\text { global }\end{array}$ & Eco-indicator 99 & Eco-indicator 99 \\
\hline $\begin{array}{c}\text { EU COST Action 628: life cycle } \\
\text { assessment (LCA) of textile products, } \\
\text { eco-efficiency and definition of best } \\
\text { available technology (BAT) of textile } \\
\text { processing }\end{array}$ & $\begin{array}{l}\text { Eija Nieminen, Michael } \\
\text { Linke, Marion Tobler, } \\
\text { Bob Vander Beke }\end{array}$ & $\begin{array}{c}\text { Journal of Cleaner } \\
\text { Production } 15 \text { (2007) } \\
1259 \mathrm{e} 1270\end{array}$ & 2006 & Finlândia & & & & \\
\hline $\begin{array}{l}\text { European characterization factors for } \\
\text { Saúde Humana damage of PM10 and } \\
\text { ozone in life cycle impact assessment }\end{array}$ & $\begin{array}{l}\text { Rosalie van Zelma, } \\
\text { Mark A.J. Huijbregtsa, } \\
\text { Henri A. den } \\
\text { Hollanderc, } \\
\text { Hans A. van Jaarsveldd, } \\
\text { Ferd J. Sautere, Jaap } \\
\text { Struijsb, Harm J. van } \\
\text { Wijnenc, } \\
\text { Dik van de Meenta, }\end{array}$ & $\begin{array}{c}\text { Atmospheric } \\
\text { Environment } 42 \text { (2008) } \\
441-453\end{array}$ & 2007 & Holanda & & & & \\
\hline $\begin{array}{l}\text { Evaluating offshore technologies for } \\
\text { produced Água management using } \\
\text { GreenPro-I-a risk-based life cycle } \\
\text { analysis for green and clean process } \\
\text { selection and design }\end{array}$ & $\begin{array}{l}\text { Rehan Sadiq, Faisal I. } \\
\text { Khan, Brian Veitch }\end{array}$ & $\begin{array}{c}\text { Computers and Chemical } \\
\text { Engineering } 29(2005) \\
1023-1039\end{array}$ & 2005 & Canadá & GreenPro-1 & & & \\
\hline $\begin{array}{l}\text { Evaluation of the environmental } \\
\text { impacts of apple production using }\end{array}$ & $\begin{array}{l}\text { L. Mila` i Canals, G.M. } \\
\text { Burnip, S.J. Cowell }\end{array}$ & $\begin{array}{l}\text { Agriculture, Ecosystems } \\
\text { and Environment } 114\end{array}$ & 2005 & Espanha & EDIP & $\begin{array}{l}\text { Mudanças } \\
\text { Climáticas }\end{array}$ & & \\
\hline
\end{tabular}


Anexo A - Levantamento Bibliográfico - Análise Sistemática

\begin{tabular}{|c|c|c|c|c|c|c|c|c|}
\hline \multirow[t]{5}{*}{$\begin{array}{l}\text { Life Cycle Assessment (LCA): Case } \\
\text { study in New Zealand }\end{array}$} & & \multirow[t]{5}{*}{ (2006) 226-238 } & & & & $\begin{array}{c}\text { Formação de foto } \\
\text { oxidantes }\end{array}$ & & \\
\hline & & & & & & Acidificação & & \\
\hline & & & & & & Nutrificação & & \\
\hline & & & & & & Toxidade humana & & \\
\hline & & & & & & $\begin{array}{c}\text { Toxidade } \\
\text { eocológica }\end{array}$ & & \\
\hline \multirow{4}{*}{$\begin{array}{l}\text { Evaluation of Two Simplified Life } \\
\text { Cycle Assessment Methods }\end{array}$} & \multirow{4}{*}{$\begin{array}{l}\text { Elisabeth Hochschorner } \\
\text { and Göran Finnveden }\end{array}$} & \multirow{4}{*}{$\begin{array}{c}\text { Int J LCA } 20038 \text { (3) } 119- \\
128(2003)\end{array}$} & \multirow{4}{*}{2003} & \multirow{4}{*}{ Suécia } & ERPA & $\begin{array}{c}\text { Aquecimento } \\
\text { Global }\end{array}$ & & \\
\hline & & & & & \multirow{3}{*}{ MECO } & Acidificação & & \\
\hline & & & & & & Eutrofização & & \\
\hline & & & & & & $\begin{array}{l}\text { Formação de foto } \\
\text { oxidantes }\end{array}$ & & \\
\hline $\begin{array}{l}\text { International expert group on life } \\
\text { cycle assessment for integrated } \\
\text { waste management }\end{array}$ & $\begin{array}{c}\text { Bernie Thomas, Forbes } \\
\text { McDougal }\end{array}$ & $\begin{array}{l}\text { Journal of Cleaner } \\
\text { Production } 13 \text { (2005) } \\
\text { 321-326 }\end{array}$ & 2005 & Inglaterra & ExternE & & MSW-DST & \\
\hline $\begin{array}{c}\text { Uso da Terra indicators in life cycle } \\
\text { assessment. Case study: } \\
\text { The environmental impact of } \\
\text { Mediterranean greenhouses }\end{array}$ & $\begin{array}{l}\text { A. Anto'n, F. Castells, } \\
\text { J.I. Mont }\end{array}$ & $\begin{array}{c}\text { Journal of Cleaner } \\
\text { Production } 15 \text { (2007) } 432 \\
\text { e } 438\end{array}$ & 2005 & Espanha & $\begin{array}{l}\text { LCAGAPS } \\
\text { method }\end{array}$ & Uso da Terra & Eco-Indicator 99 & Ecoinvent v1.2 \\
\hline \multirow{6}{*}{$\begin{array}{l}\text { LCA of integrated MSW management } \\
\text { systems: Case study of } \\
\text { the Bologna District }\end{array}$} & \multirow{6}{*}{$\begin{array}{l}\text { P. Buttol, P. Masoni, A. } \\
\text { Bonoli, S. Goldoni, V. } \\
\text { Belladonna, C. } \\
\text { Cavazzuti }\end{array}$} & \multirow{6}{*}{$\begin{array}{l}\text { Waste Management } 27 \\
\text { (2007) 1059-1070 }\end{array}$} & \multirow{6}{*}{2007} & \multirow{6}{*}{ Itália } & & $\begin{array}{c}\text { Gases do efeito } \\
\text { estufa }\end{array}$ & \multirow{6}{*}{ WISARD } & \\
\hline & & & & & & Acidificação & & \\
\hline & & & & & & Eutrofização & & \\
\hline & & & & & & $\begin{array}{l}\text { Depleção de } \\
\text { recursos não } \\
\text { renováveis }\end{array}$ & & \\
\hline & & & & & & Ecotoxidade & & \\
\hline & & & & & & Toxidade humana & & \\
\hline \multirow{2}{*}{$\begin{array}{l}\text { LCA: A decision support tool for } \\
\text { environmental assessment of MSW } \\
\text { management systems }\end{array}$} & \multirow{2}{*}{$\begin{array}{l}\text { Chalita Liamsanguan, } \\
\text { Shabbir H. Gheewala }\end{array}$} & \multirow{2}{*}{$\begin{array}{l}\text { Journal of Environmental } \\
\text { Management } 87 \text { (2008) } \\
132-138\end{array}$} & \multirow[b]{2}{*}{2007} & \multirow[b]{2}{*}{ Tailândia } & & $\begin{array}{c}\text { Consumo de } \\
\text { Energia }\end{array}$ & & \multirow[b]{2}{*}{ BUWAL 300} \\
\hline & & & & & & $\begin{array}{l}\text { Emissão gases } \\
\text { efeito estufa }\end{array}$ & & \\
\hline
\end{tabular}


Anexo A - Levantamento Bibliográfico - Análise Sistemática

\begin{tabular}{|c|c|c|c|c|c|c|c|c|}
\hline \multirow{5}{*}{$\begin{array}{l}\text { Life cycle analysis applied to the } \\
\text { assessment of the environmental } \\
\text { impact of alternative synthetic } \\
\text { processes. The dimethylcarbonate } \\
\text { case: part } 1\end{array}$} & \multirow{5}{*}{$\begin{array}{l}\text { Michele Aresta, } \\
\text { Michele Galatola }\end{array}$} & \multirow{5}{*}{$\begin{array}{c}\text { Journal of Cleaner } \\
\text { Production } 7 \text { (1999) 181- } \\
193\end{array}$} & \multirow{5}{*}{1998} & \multirow{5}{*}{ Itália } & E-LCA & $\begin{array}{c}\text { Gases do efeito } \\
\text { estufa }\end{array}$ & \multirow{5}{*}{ Eco-indicator 95} & \multirow{5}{*}{ Eco-indicator 95} \\
\hline & & & & & \multirow{4}{*}{$\begin{array}{l}\text { Eco-indicator } \\
\quad 95\end{array}$} & $\begin{array}{l}\text { Depleção da } \\
\text { camada de ozônio }\end{array}$ & & \\
\hline & & & & & & Acidificação & & \\
\hline & & & & & & Nutrificação & & \\
\hline & & & & & & $\begin{array}{l}\text { Criação de ozônio } \\
\text { fotoquímico }\end{array}$ & & \\
\hline $\begin{array}{l}\text { Life cycle assessment as a tool for } \\
\text { controlling the development of } \\
\text { technical activities: application to the } \\
\text { remediation of a site } \\
\text { contaminated by sulfur }\end{array}$ & $\begin{array}{l}\text { A. Blanc, H. Me'tivier- } \\
\text { Pignon, R. Gourdon, P. } \\
\text { Rousseaux }\end{array}$ & $\begin{array}{c}\text { Advances in } \\
\text { Environmental Research } \\
8 \text { (2004) 613-627 }\end{array}$ & 2003 & França & & & & \\
\hline \multirow{9}{*}{$\begin{array}{l}\text { Life cycle assessment of a national } \\
\text { policy proposal - The case of } \\
\text { a Swedish waste incineration tax }\end{array}$} & \multirow{9}{*}{$\begin{array}{l}\text { Anna E. Bjo"rklund, } \\
\text { Go"ran Finnveden }\end{array}$} & \multirow{9}{*}{$\begin{array}{l}\text { Waste Management } 27 \\
\text { (2007) 1046-1058 }\end{array}$} & \multirow{9}{*}{2007} & \multirow{9}{*}{ Suécia } & CML 2000 & $\begin{array}{l}\text { Aquecimento } \\
\text { global }\end{array}$ & \multirow{9}{*}{ SimaPro 5} & \multirow{9}{*}{ SimaPro 5} \\
\hline & & & & & Eco-indicator & $\begin{array}{l}\text { Depleção da } \\
\text { camada de ozônio }\end{array}$ & & \\
\hline & & & & & \multirow{7}{*}{ EPS } & $\begin{array}{l}\text { Criação de ozônio } \\
\text { fotoquímico }\end{array}$ & & \\
\hline & & & & & & Acidificação & & \\
\hline & & & & & & Eutrofização & & \\
\hline & & & & & & $\begin{array}{c}\text { Ecotoxidade da } \\
\text { água }\end{array}$ & & \\
\hline & & & & & & $\begin{array}{l}\text { Emissões para o } \\
\text { solo }\end{array}$ & & \\
\hline & & & & & & $\begin{array}{l}\text { Ecotoxidade } \\
\text { marítima }\end{array}$ & & \\
\hline & & & & & & $\begin{array}{l}\text { Ecotoxidade } \\
\text { terrestre }\end{array}$ & & \\
\hline
\end{tabular}


Anexo A - Levantamento Bibliográfico - Análise Sistemática

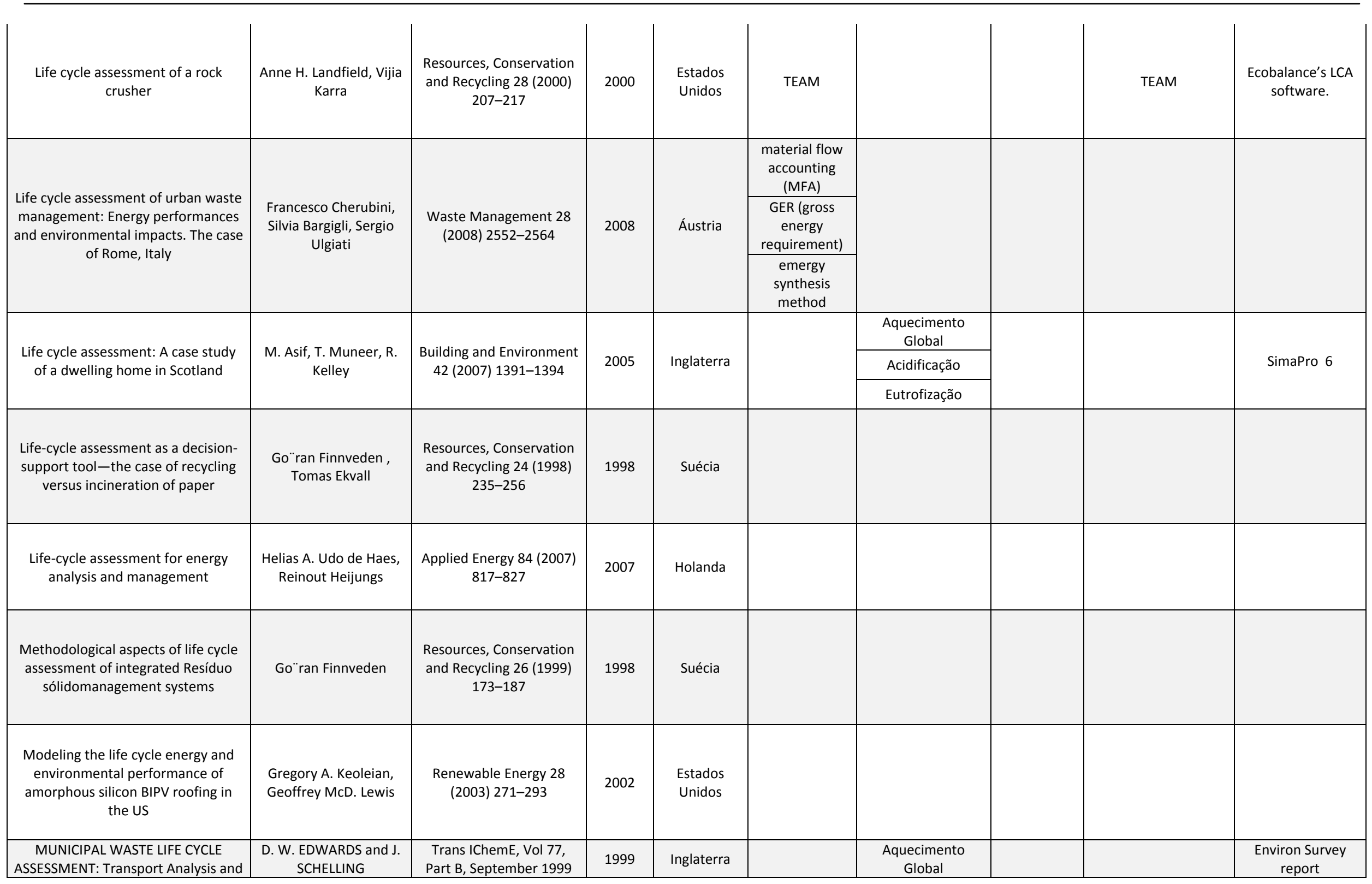


Anexo A - Levantamento Bibliográfico - Análise Sistemática

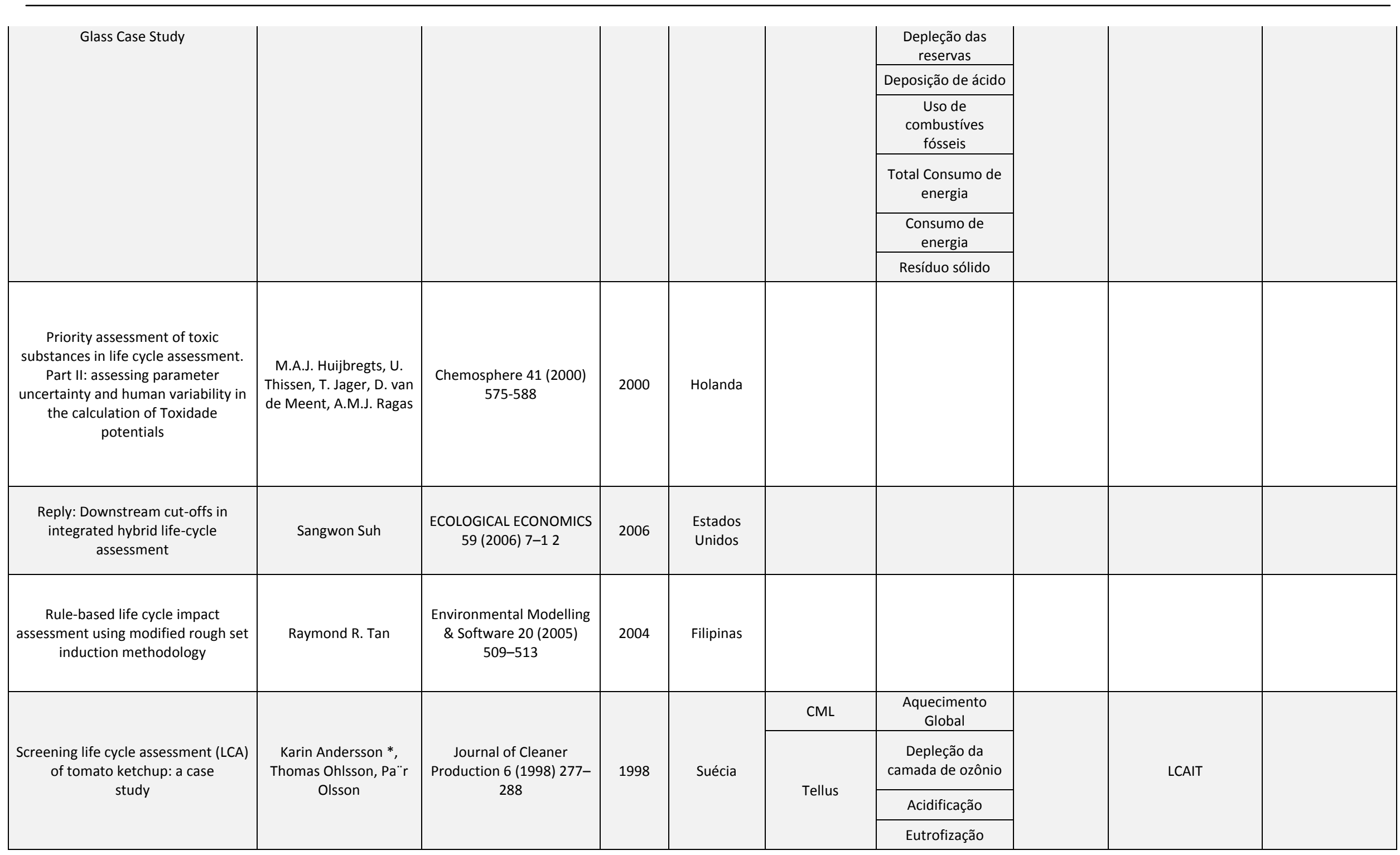


Anexo A - Levantamento Bibliográfico - Análise Sistemática

\begin{tabular}{|c|c|c|c|c|c|c|c|c|c|}
\hline & & & & & & $\begin{array}{l}\text { Formação de foto } \\
\text { oxidantes }\end{array}$ & & & \\
\hline & & & & & & Toxidade humana & & & \\
\hline $\begin{array}{l}\text { The basis for a method to integrate } \\
\text { work } \\
\text { environment in life cycle } \\
\text { assessments }\end{array}$ & $\begin{array}{l}\text { Ann-Beth Antonsson } \\
\text { and Helene Carlsson }\end{array}$ & $\begin{array}{l}\text { J. Cleaner Prod. Vol. 3, } \\
\text { No. 4, pp. 215-220, } 1995\end{array}$ & 1995 & Suécia & IARC'10 & & & & \\
\hline $\begin{array}{l}\text { The feasibility of including } \\
\text { sustainability in LCA for product } \\
\text { development }\end{array}$ & $\begin{array}{c}\text { Karin Andersson, } \\
\text { Merete Høgaas Eide, } \\
\text { Ulrika Lundqvist, Berit } \\
\text { Mattsson }\end{array}$ & $\begin{array}{c}\text { Journal of Cleaner } \\
\text { Production } 6 \text { (1998) 289- } \\
298\end{array}$ & 1998 & Suécia & & & & & \\
\hline $\begin{array}{l}\text { The institutional logic of life cycle } \\
\text { thinking }\end{array}$ & Eva Heiskanen & $\begin{array}{c}\text { Journal of Cleaner } \\
\text { Production } 10(2002) \\
427-437\end{array}$ & 2002 & Finlândia & & & & & \\
\hline $\begin{array}{l}\text { The use of life cycle methods by } \\
\text { seven major companies }\end{array}$ & $\begin{array}{l}\text { A.H. Verschoor, L. } \\
\text { Reijnders }\end{array}$ & $\begin{array}{c}\text { Journal of Cleaner } \\
\text { Production } 7 \text { (1999) 375- } \\
382\end{array}$ & 1999 & Holanda & EPS & & & ELU & EPS \\
\hline $\begin{array}{l}\text { USE OF LIFE CYCLE ASSESSMENT TO } \\
\text { DEVELOP INDUSTRIAL ECOLOGIES- } \\
\text { A CASE STUDY Graphics Paper }\end{array}$ & $\begin{array}{l}\text { A. HART, R. CLIFT, S. } \\
\text { RIDDLESTONE and J. } \\
\text { BUNTIN }\end{array}$ & $\begin{array}{l}\text { Process Safety and } \\
\text { Environmental } \\
\text { Protection, 83(B4): 359- } \\
363\end{array}$ & 2005 & Inglaterra & & & & & \\
\hline \multirow{3}{*}{$\begin{array}{l}\text { Using LCA to evaluate impacts and } \\
\text { resources conservation potential of } \\
\text { composting: A case study of the Asti } \\
\text { District in Italy }\end{array}$} & \multirow{3}{*}{ Gian Andrea Blengini } & \multirow{3}{*}{$\begin{array}{c}\text { Resources, Conservation } \\
\text { and Recycling } 52 \text { (2008) } \\
1373-1381\end{array}$} & \multirow{3}{*}{2008} & \multirow{3}{*}{ Itália } & \multirow{3}{*}{ Eco-Indicator } & Recursos da terre & \multirow{3}{*}{ Midpoint } & \multirow{3}{*}{ SimaPro 7} & I-LCA \\
\hline & & & & & & Recursos da água & & & \multirow[t]{2}{*}{ SALCA Region 3} \\
\hline & & & & & & Recursos do ar & & & \\
\hline
\end{tabular}

Tabela 15 - Anexo A - Levantamento Bibliográfico para análise sistemática. 


\section{Anexo B}

\begin{tabular}{|c|c|c|c|}
\hline Substâncias & $\begin{array}{c}\text { Quantidade } \\
\text { para } 1 \mathrm{Kg} \text { de } \\
\text { polipropileno }\end{array}$ & $\begin{array}{c}\text { Quantidade } \\
\text { para } 2 \text { cestos } \\
(5,7 \mathrm{Kg})\end{array}$ & $\begin{array}{l}\text { Unidade de } \\
\text { Referência }\end{array}$ \\
\hline \multicolumn{4}{|l|}{ PRODUÇÃO DO POLIPROPILENO } \\
\hline \multicolumn{4}{|l|}{ ENTRADAS } \\
\hline Óleo Cru & $1,20 \mathrm{E}+00$ & $6,84 \mathrm{E}+00$ & $\mathrm{Kg}$ \\
\hline Energia primária de hidroelétrica (Recurso de Energia Renovável) & $8,10 \mathrm{E}-01$ & $4,62 E+00$ & MJ \\
\hline Gás Natural (Recurso de gás natural) & $4,48 \mathrm{E}-01$ & $2,55 \mathrm{E}+00$ & $\mathrm{Kg}$ \\
\hline Carvão Duro & $5,90 \mathrm{E}-02$ & 3,36E-01 & $\mathrm{Kg}$ \\
\hline Carvão Marrom & $5,70 \mathrm{E}-02$ & $3,25 \mathrm{E}-01$ & $\mathrm{Kg}$ \\
\hline Cloreto de sódio (Recursos não renováveis) & $5,00 \mathrm{E}-03$ & $2,85 \mathrm{E}-02$ & $\mathrm{Kg}$ \\
\hline Processo e água refrescante (Materiais Operacionais) & $3,10 \mathrm{E}-03$ & 1,77E-02 & $\mathrm{Kg}$ \\
\hline Bauxita (Recursos não renováveis) & $4,00 \mathrm{E}-04$ & $2,28 \mathrm{E}-03$ & $\mathrm{Kg}$ \\
\hline Minério de Ferro (Recursos não renováveis) & $3,00 \mathrm{E}-04$ & $1,71 \mathrm{E}-03$ & $\mathrm{Kg}$ \\
\hline Calcário (carbonato de cálcio) (Recursos não renováveis) & $2,00 \mathrm{E}-04$ & $1,14 \mathrm{E}-03$ & $\mathrm{Kg}$ \\
\hline Areia de Quartzo (Recursos não renováveis) & $3,00 \mathrm{E}-05$ & $1,71 \mathrm{E}-04$ & $\mathrm{Kg}$ \\
\hline Minério de Urânio & $2,20 \mathrm{E}-06$ & $1,25 \mathrm{E}-05$ & $\mathrm{Kg}$ \\
\hline TOTAL ENTRADA & $2,58 \mathrm{E}+00$ & $1,47 E+01$ & \\
\hline \multicolumn{4}{|l|}{ SAÍDAS } \\
\hline Dióxido de carbono (Emissões inorgânicas para o ar) & $1,80 \mathrm{E}+00$ & $1,03 \mathrm{E}+01$ & $\mathrm{Kg}$ \\
\hline Polipropileno granulado (PP) (Plásticos) & $1,00 E+00$ & $5,70 E+00$ & $\mathrm{Kg}$ \\
\hline Dióxido de enxofre (Emissões inorgânicas para o ar) & $1,10 \mathrm{E}-02$ & $6,27 \mathrm{E}-02$ & $\mathrm{Kg}$ \\
\hline Óxido de Nitrogênio (Emissões inorgânicas para o ar) & $1,00 \mathrm{E}-02$ & $5,70 \mathrm{E}-02$ & $\mathrm{Kg}$ \\
\hline NMVOC (não especificado) (Grupo NMVOC para o ar) & $9,60 \mathrm{E}-03$ & $5,47 E-02$ & $\mathrm{Kg}$ \\
\hline Metano (Emissões orgânicas para o ar (grupo VOC)) & $3,40 \mathrm{E}-03$ & $1,94 \mathrm{E}-02$ & $\mathrm{Kg}$ \\
\hline Pó (não especificado) (Partículas para o ar) & $2,00 \mathrm{E}-03$ & $1,14 \mathrm{E}-02$ & $\mathrm{Kg}$ \\
\hline Sulfato (Emissões inorgânicas para água fresca) & $1,70 \mathrm{E}-03$ & $9,69 \mathrm{E}-03$ & $\mathrm{Kg}$ \\
\hline Cloreto (Emissões inorgânicas para água fresca) & $8,00 \mathrm{E}-04$ & $4,56 \mathrm{E}-03$ & $\mathrm{Kg}$ \\
\hline Monóxido de carbono (Emissões inorgânicas para o ar) & $7,00 \mathrm{E}-04$ & $3,99 \mathrm{E}-03$ & $\mathrm{Kg}$ \\
\hline Demanda de oxigênio químico (Medidas analíticas para a água fresca) & $4,00 \mathrm{E}-04$ & $2,28 \mathrm{E}-03$ & $\mathrm{Kg}$ \\
\hline Metais (não especificado) (Partículas para água fresca) & $3,00 \mathrm{E}-04$ & $1,71 \mathrm{E}-03$ & $\mathrm{Kg}$ \\
\hline Total de carbono orgânico restrito (Medidas analíticas para a água fresca) & $3,00 \mathrm{E}-04$ & $1,71 \mathrm{E}-03$ & $\mathrm{Kg}$ \\
\hline \multicolumn{4}{|l|}{ Sais inorgânicos e Ácidos (não especificado) (Emissões inorgânicas para água } \\
\hline fresca) & 2,90E-04 & $1,65 \mathrm{E}-03$ & $\mathrm{Kg}$ \\
\hline Componentes orgânicos (não especificado) (Emissões orgânicas para água fresca) & $2,50 \mathrm{E}-04$ & $1,43 \mathrm{E}-03$ & $\mathrm{Kg}$ \\
\hline Sólidos (suspenso) (Partículas para água fresca) & $2,00 \mathrm{E}-04$ & $1,14 \mathrm{E}-03$ & $\mathrm{Kg}$ \\
\hline Ferro (Metais pesados para água fresca) & $1,70 \mathrm{E}-04$ & $9,69 \mathrm{E}-04$ & $\mathrm{Kg}$ \\
\hline Alumínio (+III) (Emissões inorgânicas para água fresca) & $1,20 \mathrm{E}-04$ & $6,84 \mathrm{E}-04$ & $\mathrm{Kg}$ \\
\hline Demanda de oxigênio biológico (Medidas analíticas para a água fresca) & $6,00 \mathrm{E}-05$ & $3,42 \mathrm{E}-04$ & $\mathrm{Kg}$ \\
\hline Bário (Emissões inorgânicas para água fresca) & $5,80 \mathrm{E}-05$ & $3,31 \mathrm{E}-04$ & $\mathrm{Kg}$ \\
\hline Cloreto de Hidrogênio (Emissões inorgânicas para o ar) & $4,00 \mathrm{E}-05$ & $2,28 \mathrm{E}-04$ & $\mathrm{Kg}$ \\
\hline Óleo (não especificado) (Hidrocarbonetos para a água fresca) & $4,00 \mathrm{E}-05$ & $2,28 \mathrm{E}-04$ & $\mathrm{Kg}$ \\
\hline \multicolumn{4}{|l|}{ Total de carbono orgânico restrito dissolvido (Medidas analíticas para a água } \\
\hline fresca) & $3,00 \mathrm{E}-05$ & $1,71 \mathrm{E}-04$ & $\mathrm{Kg}$ \\
\hline Nitrato (Emissões inorgânicas para água fresca) & $2,00 \mathrm{E}-05$ & $1,14 \mathrm{E}-04$ & $\mathrm{Kg}$ \\
\hline \multicolumn{4}{|l|}{ Hidrocarbonetos aromáticos (não especificado) (Hidrocarbonetos para a água } \\
\hline fresca) & $1,70 \mathrm{E}-05$ & $9,69 \mathrm{E}-05$ & $\mathrm{Kg}$ \\
\hline Fosfato (Emissões inorgânicas para água fresca) & $1,35 \mathrm{E}-05$ & $7,70 \mathrm{E}-05$ & $\mathrm{Kg}$ \\
\hline Amônio / Amônia (Emissões inorgânicas para água fresca) & $1,00 \mathrm{E}-05$ & $5,70 \mathrm{E}-05$ & $\mathrm{Kg}$ \\
\hline Hidrocarbonetos aromáticos (não especificado) (Grupo NMVOC para o ar) & $1,00 \mathrm{E}-05$ & $5,70 \mathrm{E}-05$ & $\mathrm{Kg}$ \\
\hline Sulfeto de hidrogênio (Emissões inorgânicas para o ar) & $1,00 \mathrm{E}-05$ & $5,70 \mathrm{E}-05$ & $\mathrm{Kg}$ \\
\hline Nitrogênio (Emissões inorgânicas para água fresca) & $1,00 \mathrm{E}-05$ & $5,70 \mathrm{E}-05$ & $\mathrm{Kg}$ \\
\hline Nitrogênio orgânico restrito (Emissões inorgânicas para água fresca) & $6,90 \mathrm{E}-06$ & $3,93 \mathrm{E}-05$ & $\mathrm{Kg}$ \\
\hline Óxido nitroso (gás do riso) (Emissões inorgânicas para o ar) & $5,70 \mathrm{E}-06$ & $3,25 \mathrm{E}-05$ & $\mathrm{Kg}$ \\
\hline Metais (não especificado) (Partículas para o ar) & $5,00 \mathrm{E}-06$ & $2,85 \mathrm{E}-05$ & $\mathrm{Kg}$ \\
\hline Benzeno (Grupo NMVOC para o ar) & $4,40 \mathrm{E}-06$ & $2,51 \mathrm{E}-05$ & $\mathrm{Kg}$ \\
\hline Fenol (Hidrocarbonetos para a água fresca) & $2,60 \mathrm{E}-06$ & $1,48 \mathrm{E}-05$ & $\mathrm{Kg}$ \\
\hline Tolueno (benzeno de metil) (Hidrocarbonetos para a água fresca) & $2,30 \mathrm{E}-06$ & $1,31 \mathrm{E}-05$ & $\mathrm{Kg}$ \\
\hline Cromo (não especificado) (Metais pesados para água fresca) & $1,40 \mathrm{E}-06$ & $7,98 \mathrm{E}-06$ & $\mathrm{Kg}$ \\
\hline Zinco (+II) (Metais pesados para água fresca) & $1,40 \mathrm{E}-06$ & $7,98 \mathrm{E}-06$ & $\mathrm{Kg}$ \\
\hline
\end{tabular}




\begin{tabular}{|c|c|c|c|}
\hline Fluoreto de hidrogênio (Emissões inorgânicas para o ar) & $1,00 \mathrm{E}-06$ & $5,70 \mathrm{E}-06$ & $\mathrm{Kg}$ \\
\hline Níquel (+II) (Metais pesados para o ar) & $9,60 \mathrm{E}-07$ & $5,47 \mathrm{E}-06$ & $\mathrm{Kg}$ \\
\hline Amônia (Emissões inorgânicas para o ar) & $8,30 \mathrm{E}-07$ & $4,73 E-06$ & $\mathrm{Kg}$ \\
\hline Chumbo (+II) (Metais pesados para água fresca) & $7,70 \mathrm{E}-07$ & $4,39 \mathrm{E}-06$ & $\mathrm{Kg}$ \\
\hline Níquel (+II) (Metais pesados para água fresca) & $6,70 \mathrm{E}-07$ & $3,82 \mathrm{E}-06$ & $\mathrm{Kg}$ \\
\hline Cobre (+II) (Metais pesados para água fresca) & $6,50 \mathrm{E}-07$ & $3,71 \mathrm{E}-06$ & $\mathrm{Kg}$ \\
\hline Sulfureto (Emissões inorgânicas para água fresca) & $6,10 \mathrm{E}-07$ & $3,48 \mathrm{E}-06$ & $\mathrm{Kg}$ \\
\hline Zinco (+II) (Metais pesados para o ar) & $4,20 \mathrm{E}-07$ & 2,39E-06 & $\mathrm{Kg}$ \\
\hline Arsênico (+V) (Metais pesados para água fresca) & $2,60 \mathrm{E}-07$ & $1,48 \mathrm{E}-06$ & $\mathrm{Kg}$ \\
\hline Hidrocarbonetos aromáticos policíclicos (Hidrocarbonetos para a água fresca) & $2,50 \mathrm{E}-07$ & $1,43 E-06$ & $\mathrm{Kg}$ \\
\hline Halon (1301) (Emissões Orgânicas halogenadas para o ar) & $9,20 \mathrm{E}-08$ & $5,24 \mathrm{E}-07$ & $\mathrm{Kg}$ \\
\hline Chumbo (+II) (Metais pesados para o ar) & $8,80 \mathrm{E}-08$ & $5,02 \mathrm{E}-07$ & $\mathrm{Kg}$ \\
\hline Cianeto (Emissões inorgânicas para água fresca) & $8,00 \mathrm{E}-08$ & $4,56 \mathrm{E}-07$ & $\mathrm{Kg}$ \\
\hline \multicolumn{4}{|l|}{ Componente halogênio orgânico absorvível (Medidas analíticas para a água } \\
\hline fresca) & $7,50 \mathrm{E}-08$ & $4,28 \mathrm{E}-07$ & $\mathrm{Kg}$ \\
\hline Cádmio (+II) (Metais pesados para água fresca) & $2,80 \mathrm{E}-08$ & $1,60 \mathrm{E}-07$ & $\mathrm{Kg}$ \\
\hline Manganês (+II) (Metais pesados para o ar) & $2,70 \mathrm{E}-08$ & $1,54 \mathrm{E}-07$ & $\mathrm{Kg}$ \\
\hline Mercúrio (+II) (Metais pesados para o ar) & $2,30 \mathrm{E}-08$ & $1,31 \mathrm{E}-07$ & $\mathrm{Kg}$ \\
\hline \multicolumn{4}{|l|}{ Hidrocarbonetos clorados (não especificado) (Emissões Orgânicas halogenadas } \\
\hline para a água fresca) & $2,10 \mathrm{E}-08$ & $1,20 \mathrm{E}-07$ & $\mathrm{Kg}$ \\
\hline Cádmio (+II) (Metais pesados para o ar) & $1,80 \mathrm{E}-08$ & 1,03E-07 & $\mathrm{Kg}$ \\
\hline Hidrocarbonetos aromáticos policíclicos (Grupo PAH para o ar) & $1,70 \mathrm{E}-08$ & $9,69 \mathrm{E}-08$ & $\mathrm{Kg}$ \\
\hline Mercúrio (+II) (Metais pesados para água fresca) & $1,30 \mathrm{E}-09$ & 7,41E-09 & $\mathrm{Kg}$ \\
\hline \multicolumn{4}{|l|}{ Hidrocarbonetos halogenados (não especificado) (Emissões Orgânicas } \\
\hline halogenadas para o ar) & $2,10 \mathrm{E}-10$ & $1,20 \mathrm{E}-09$ & $\mathrm{Kg}$ \\
\hline TOTAL SAÍDA & $2,84 \mathrm{E}+00$ & $1,62 \mathrm{E}+01$ & \\
\hline \multicolumn{4}{|l|}{ TRANSPORTE MATÉRIA-PRIMA } \\
\hline \multicolumn{4}{|l|}{ ENTRADA } \\
\hline Diesel (produto do petróleo) & $1,84 \mathrm{E}-03$ & $1,99 \mathrm{E}+04$ & $\mathrm{Kg}$ \\
\hline TOTAL ENTRADA & $1,84 \mathrm{E}-03$ & $1,99 E+04$ & \\
\hline \multicolumn{4}{|l|}{ SAÍDA } \\
\hline Carga (Outros) & $1,00 \mathrm{E}+00$ & $1,08 \mathrm{E}+07$ & $\mathrm{Kg}$ \\
\hline Dióxido de carbono (Emissões inorgânicas para o ar) & $5,84 \mathrm{E}-03$ & $6,33 E+04$ & $\mathrm{Kg}$ \\
\hline Óxido de Nitrogênio (Emissões inorgânicas para o ar) & $6,01 \mathrm{E}-05$ & $6,51 E+02$ & $\mathrm{Kg}$ \\
\hline Monóxido de carbono (Emissões inorgânicas para o ar) & $1,26 \mathrm{E}-05$ & $1,36 \mathrm{E}+02$ & $\mathrm{Kg}$ \\
\hline NMVOC (não especificado) (Grupo NMVOC para o ar) & $4,08 \mathrm{E}-06$ & $4,41 E+01$ & $\mathrm{Kg}$ \\
\hline Pó (PM2.5) (Partículas para o ar) & 2,31E-06 & $2,50 \mathrm{E}+01$ & $\mathrm{Kg}$ \\
\hline Dióxido de enxofre (Emissões inorgânicas para o ar) & $1,84 \mathrm{E}-07$ & $1,99 \mathrm{E}+00$ & $\mathrm{Kg}$ \\
\hline Metano (Emissões orgânicas para o ar (grupo VOC)) & $1,03 \mathrm{E}-07$ & $1,12 \mathrm{E}+00$ & $\mathrm{Kg}$ \\
\hline Óxido nitroso (gás do riso) (Emissões inorgânicas para o ar) & $8,52 \mathrm{E}-08$ & $9,22 \mathrm{E}-01$ & $\mathrm{Kg}$ \\
\hline Benzeno (Grupo NMVOC para o ar) & $7,18 \mathrm{E}-08$ & $7,78 \mathrm{E}-01$ & $\mathrm{Kg}$ \\
\hline Amônia (Emissões inorgânicas para o ar) & $3,40 \mathrm{E}-08$ & $3,68 \mathrm{E}-01$ & $\mathrm{Kg}$ \\
\hline Xileno (benzeno de dimetil) (Grupo NMVOC para o ar) & $2,32 \mathrm{E}-08$ & $2,51 \mathrm{E}-01$ & $\mathrm{Kg}$ \\
\hline Tolueno (benzeno de metil) (Grupo NMVOC para o ar) & $1,38 \mathrm{E}-08$ & $1,49 \mathrm{E}-01$ & $\mathrm{Kg}$ \\
\hline TOTAL SAÍDA & $1,01 \mathrm{E}+00$ & $1,09 \mathrm{E}+07$ & \\
\hline \multicolumn{4}{|l|}{ PROCESSO DE INJEÇÃO } \\
\hline \multicolumn{4}{|l|}{ ENTRADAS } \\
\hline Energia (Energia elétrica) & $6,64 \mathrm{E}+00$ & $3,79 \mathrm{E}+01$ & MJ \\
\hline Água refrigerada (materiais operacionais) & $4,41 E+00$ & $2,51 E+01$ & $\mathrm{Kg}$ \\
\hline Plástico granulado (não especificado) (Plásticos) & $1,02 \mathrm{E}+00$ & $5,81 \mathrm{E}+00$ & $\mathrm{Kg}$ \\
\hline TOTAL ENTRADA & $1,21 \mathrm{E}+01$ & $6,88 \mathrm{E}+01$ & \\
\hline \multicolumn{4}{|l|}{ SAÍDAS } \\
\hline Vapor (Emissões inorgânicas para o ar) & $4,41 \mathrm{E}+00$ & $2,51 \mathrm{E}+01$ & $\mathrm{Kg}$ \\
\hline Peça Plástica (não especificado) [Peça Plásticas] & $1,00 \mathrm{E}+00$ & $5,70 \mathrm{E}+00$ & $\mathrm{Kg}$ \\
\hline Disposição do lixo industrial municipal (resíduo do consumidor) & $2,00 \mathrm{E}-02$ & $1,14 \mathrm{E}-01$ & $\mathrm{Kg}$ \\
\hline TOTAL SAÍDA & $5,43 E+00$ & $3,10 \mathrm{E}+01$ & \\
\hline \multicolumn{4}{|l|}{ TRANSPORTE PRODUTO } \\
\hline \multicolumn{4}{|l|}{ ENTRADA } \\
\hline Diesel (produto do petróleo) & $1,84 \mathrm{E}-03$ & $1,41 \mathrm{E}+05$ & $\mathrm{Kg}$ \\
\hline TOTAL ENTRADA & $1,84 \mathrm{E}-03$ & $1,41 E+05$ & \\
\hline SAÍDA & & & \\
\hline
\end{tabular}


Anexo B - Inventário do Cesto Plástico

\begin{tabular}{|c|c|c|c|}
\hline Carga (Outros) & $1,00 E+00$ & $7,66 \mathrm{E}+07$ & $\mathrm{Kg}$ \\
\hline Dióxido de carbono (Emissões inorgânicas para o ar) & $5,84 \mathrm{E}-03$ & $4,47 E+05$ & $\mathrm{Kg}$ \\
\hline Óxido de Nitrogênio (Emissões inorgânicas para o ar) & $6,01 \mathrm{E}-05$ & $4,60 \mathrm{E}+03$ & $\mathrm{Kg}$ \\
\hline Monóxido de carbono (Emissões inorgânicas para o ar) & $1,26 \mathrm{E}-05$ & $9,61 \mathrm{E}+02$ & $\mathrm{Kg}$ \\
\hline NMVOC (não especificado) (Grupo NMVOC para o ar) & $4,08 \mathrm{E}-06$ & $3,12 E+02$ & $\mathrm{Kg}$ \\
\hline Pó (PM2.5) (Partículas para o ar) & 2,31E-06 & $1,77 E+02$ & $\mathrm{Kg}$ \\
\hline Dióxido de enxofre (Emissões inorgânicas para o ar) & $1,84 \mathrm{E}-07$ & $1,41 \mathrm{E}+01$ & $\mathrm{Kg}$ \\
\hline Metano (Emissões orgânicas para o ar (grupo VOC)) & $1,03 \mathrm{E}-07$ & $7,90 \mathrm{E}+00$ & $\mathrm{Kg}$ \\
\hline Óxido nitroso (gás do riso) (Emissões inorgânicas para o ar) & $8,52 \mathrm{E}-08$ & $6,52 \mathrm{E}+00$ & $\mathrm{Kg}$ \\
\hline Benzeno (Grupo NMVOC para o ar) & $7,18 \mathrm{E}-08$ & $5,50 \mathrm{E}+00$ & $\mathrm{Kg}$ \\
\hline Amônia (Emissões inorgânicas para o ar) & $3,40 \mathrm{E}-08$ & $2,60 \mathrm{E}+00$ & $\mathrm{Kg}$ \\
\hline Xileno (benzeno de dimetil) (Grupo NMVOC para o ar) & $2,32 \mathrm{E}-08$ & $1,78 \mathrm{E}+00$ & $\mathrm{Kg}$ \\
\hline Tolueno (benzeno de metil) (Grupo NMVOC para o ar) & $1,38 \mathrm{E}-08$ & $1,05 \mathrm{E}+00$ & $\mathrm{Kg}$ \\
\hline TOTAL SAÍDA & $1,01 \mathrm{E}+00$ & $7,70 \mathrm{E}+07$ & \\
\hline \multicolumn{4}{|l|}{ FASE DE USO } \\
\hline \multicolumn{4}{|l|}{ ENTRADAS } \\
\hline Água & $8,90 \mathrm{E}+00$ & $9,72 \mathrm{E}+03$ & $\mathrm{Kg}$ \\
\hline Energia primária de hidroelétrica (Recurso de Energia Renovável) & $1,76 \mathrm{E}-01$ & $1,92 \mathrm{E}+02$ & MJ \\
\hline Carvão Duro & 1,29E-01 & $1,41 E+02$ & $\mathrm{Kg}$ \\
\hline Óleo Cru & $4,69 \mathrm{E}-03$ & $5,12 \mathrm{E}+00$ & $\mathrm{Kg}$ \\
\hline Gás Natural (Recurso de gás natural) & $2,49 \mathrm{E}-03$ & $2,72 E+00$ & $\mathrm{Kg}$ \\
\hline Carvão Marrom & $1,72 \mathrm{E}-03$ & $1,88 \mathrm{E}+00$ & $\mathrm{Kg}$ \\
\hline Madeira (Recurso de energias renováveis) & $1,25 \mathrm{E}-03$ & $1,37 \mathrm{E}+00$ & $\mathrm{Kg}$ \\
\hline Minério de Urânio & $5,19 \mathrm{E}-07$ & $5,67 \mathrm{E}-04$ & $\mathrm{Kg}$ \\
\hline TOTAL ENTRADA & $9,21 \mathrm{E}+00$ & $1,01 \mathrm{E}+04$ & \\
\hline \multicolumn{4}{|l|}{ SAÍDAS } \\
\hline Energia (Energia elétrica) & $1,00 \mathrm{E}+00$ & $1,09 \mathrm{E}+03$ & MJ \\
\hline Dióxido de carbono (Emissões inorgânicas para o ar) & $2,20 \mathrm{E}-01$ & $2,40 E+02$ & $\mathrm{Kg}$ \\
\hline Cloreto (Emissões inorgânicas para água fresca) & $1,41 \mathrm{E}-03$ & $1,54 \mathrm{E}+00$ & $\mathrm{Kg}$ \\
\hline Sulfato (Emissões inorgânicas para água fresca) & $9,52 \mathrm{E}-04$ & $1,04 \mathrm{E}+00$ & $\mathrm{Kg}$ \\
\hline Dióxido de enxofre (Emissões inorgânicas para o ar) & $9,46 \mathrm{E}-04$ & $1,03 E+00$ & $\mathrm{Kg}$ \\
\hline Metano (Emissões orgânicas para o ar (grupo VOC)) & $9,16 \mathrm{E}-04$ & $1,00 \mathrm{E}+00$ & $\mathrm{Kg}$ \\
\hline $\begin{array}{l}\text { Sais inorgânicos e Ácidos (não especificado) (Emissões inorgânicas para água } \\
\text { fresca) }\end{array}$ & $7,76 \mathrm{E}-04$ & $8,48 \mathrm{E}-01$ & $\mathrm{Kg}$ \\
\hline Óxido de Nitrogênio (Emissões inorgânicas para o ar) & $5,59 \mathrm{E}-04$ & $6,11 \mathrm{E}-01$ & $\mathrm{Kg}$ \\
\hline Alumínio (+III) (Emissões inorgânicas para água fresca) & $2,06 \mathrm{E}-04$ & $2,25 \mathrm{E}-01$ & $\mathrm{Kg}$ \\
\hline Ferro (Metais pesados para água fresca) & $6,46 \mathrm{E}-05$ & 7,06E-02 & $\mathrm{Kg}$ \\
\hline Cloreto de Hidrogênio (Emissões inorgânicas para o ar) & $6,32 \mathrm{E}-05$ & $6,90 \mathrm{E}-02$ & $\mathrm{Kg}$ \\
\hline NMVOC (não especificado) (Grupo NMVOC para o ar) & $4,49 E-05$ & 4,90E-02 & $\mathrm{Kg}$ \\
\hline Monóxido de carbono (Emissões inorgânicas para o ar) & $3,04 \mathrm{E}-05$ & $3,32 \mathrm{E}-02$ & $\mathrm{Kg}$ \\
\hline Metais (não especificado) (Partículas para água fresca) & $2,25 \mathrm{E}-05$ & $2,45 \mathrm{E}-02$ & $\mathrm{Kg}$ \\
\hline Sólidos (suspenso) (Partículas para água fresca) & $1,84 \mathrm{E}-05$ & $2,01 \mathrm{E}-02$ & $\mathrm{Kg}$ \\
\hline Bário (Emissões inorgânicas para água fresca) & $1,70 \mathrm{E}-05$ & $1,86 \mathrm{E}-02$ & $\mathrm{Kg}$ \\
\hline Metais (não especificado) (Partículas para o ar) & $1,69 \mathrm{E}-05$ & $1,85 \mathrm{E}-02$ & $\mathrm{Kg}$ \\
\hline Fosfato (Emissões inorgânicas para água fresca) & $1,23 \mathrm{E}-05$ & $1,35 \mathrm{E}-02$ & $\mathrm{Kg}$ \\
\hline Fluoreto de hidrogênio (Emissões inorgânicas para o ar) & $6,72 \mathrm{E}-06$ & $7,33 \mathrm{E}-03$ & $\mathrm{Kg}$ \\
\hline Óleo (não especificado) (Hidrocarbonetos para a água fresca) & $6,27 \mathrm{E}-06$ & $6,84 \mathrm{E}-03$ & $\mathrm{Kg}$ \\
\hline Nitrato (Emissões inorgânicas para água fresca) & $5,05 \mathrm{E}-06$ & $5,51 \mathrm{E}-03$ & $\mathrm{Kg}$ \\
\hline Pó (não especificado) (Partículas para o ar) & $4,53 \mathrm{E}-06$ & $4,95 \mathrm{E}-03$ & $\mathrm{Kg}$ \\
\hline Total de carbono orgânico restrito (Medidas analíticas para a água fresca) & $3,64 \mathrm{E}-06$ & $3,98 \mathrm{E}-03$ & $\mathrm{Kg}$ \\
\hline Hidrocarbonetos aromáticos (não especificado) (Grupo NMVOC para o ar) & 2,79E-06 & $3,05 \mathrm{E}-03$ & $\mathrm{Kg}$ \\
\hline Zinco (+II) (Metais pesados para água fresca) & 2,07E-06 & $2,26 \mathrm{E}-03$ & $\mathrm{Kg}$ \\
\hline Cromo (não especificado) (Metais pesados para água fresca) & $2,06 \mathrm{E}-06$ & $2,25 \mathrm{E}-03$ & $\mathrm{Kg}$ \\
\hline Óxido nitroso (gás do riso) (Emissões inorgânicas para o ar) & $1,52 \mathrm{E}-06$ & $1,65 \mathrm{E}-03$ & $\mathrm{Kg}$ \\
\hline Amônia (Emissões inorgânicas para o ar) & $1,24 \mathrm{E}-06$ & $1,35 \mathrm{E}-03$ & $\mathrm{Kg}$ \\
\hline Chumbo (+II) (Metais pesados para água fresca) & $1,04 \mathrm{E}-06$ & $1,14 \mathrm{E}-03$ & $\mathrm{Kg}$ \\
\hline Níquel (+II) (Metais pesados para água fresca) & 1,04E-06 & 1,13E-03 & $\mathrm{Kg}$ \\
\hline Cobre (+II) (Metais pesados para água fresca) & $1,03 \mathrm{E}-06$ & $1,13 \mathrm{E}-03$ & $\mathrm{Kg}$ \\
\hline Demanda de oxigênio químico (Medidas analíticas para a água fresca) & $1,03 \mathrm{E}-06$ & $1,12 \mathrm{E}-03$ & $\mathrm{Kg}$ \\
\hline Amônio / Amônia (Emissões inorgânicas para água fresca) & $5,10 \mathrm{E}-07$ & $5,57 \mathrm{E}-04$ & $\mathrm{Kg}$ \\
\hline Arsênico $(+V)$ (Metais pesados para água fresca) & $4,16 \mathrm{E}-07$ & $4,54 \mathrm{E}-04$ & $\mathrm{Kg}$ \\
\hline Nitrogênio (Emissões inorgânicas para água fresca) & $2,57 \mathrm{E}-07$ & $2,80 \mathrm{E}-04$ & $\mathrm{Kg}$ \\
\hline
\end{tabular}


Hidrocarbonetos aromáticos (não especificado) (Hidrocarbonetos para a água fresca)

Níquel (+II) (Metais pesados para o ar)

Benzeno (Grupo NMVOC para o ar)

Zinco (+II) (Metais pesados para o ar)

Chumbo (+II) (Metais pesados para o ar)

Demanda de oxigênio biológico (Medidas analíticas para a água fresca)

Fenol (Hidrocarbonetos para a água fresca)

Nitrogênio orgânico restrito (Emissões inorgânicas para água fresca)

Tolueno (benzeno de metil) (Hidrocarbonetos para a água fresca)

Total de carbono orgânico restrito dissolvido (Medidas analíticas para a água

fresca)

Manganês (+II) (Metais pesados para o ar)

Cádmio (+II) (Metais pesados para água fresca)

Mercúrio (+II) (Metais pesados para o ar)

Sulfureto (Emissões inorgânicas para água fresca)

Hidrocarbonetos aromáticos policíclicos (Grupo PAH para o ar)

Hidrocarbonetos aromáticos policíclicos (Hidrocarbonetos para a água fresca)

Cianeto (Emissões inorgânicas para água fresca)

Cádmio (+II) (Metais pesados para o ar)

Halon (1301) (Emissões orgânicas halogenadas para o ar)

Componente halogênio orgânico absorvível (Medidas analíticas para a água

fresca)

Mercúrio (+II) (Metais pesados para água fresca)

Hidrocarbonetos clorados (não especificado) (Emissões orgânicas halogenadas para a água fresca)

Hidrocarbonetos halogenados (não especificado) (Emissões orgânicas

halogenadas para o ar)

2,02E-07

$2,21 \mathrm{E}-04$

$1,45 \mathrm{E}-07$

$1,59 \mathrm{E}-04$

$7,89 \mathrm{E}-08$

$8,62 \mathrm{E}-05$

$7,78 \mathrm{E}-08$

$8,50 \mathrm{E}-05$

4,39E-08

3,61E-08

4,79E-05

3,82E-05

2,89E-08 3,16E-05

2,80E-08 3,05E-05

2,62E-08

2,86E-05

2,49E-08

1,09E-08

2,72E-05

8,21E-09

1,19E-05

7,80E-09

$3,68 \mathrm{E}-09$

$8,97 \mathrm{E}-06$

$8,52 \mathrm{E}-06$

4,02E-06

3,06E-09

3,34E-06

2,29E-09 2,50E-06

1,62E-09

$1,76 \mathrm{E}-06$

1,12E-09

1,22E-06

$8,22 \mathrm{E}-10$

8,97E-07

3,26E-07

2,99E-10

2,74E-07

$1,36 \mathrm{E}-11 \quad 1,48 \mathrm{E}-08 \quad \mathrm{Kg}$

ENTRADAS

\begin{tabular}{|c|c|c|c|}
\hline Polipropileno (PP, não especificado) (resíduo do consumidor) & $1,00 \mathrm{E}+00$ & $5,70 \mathrm{E}+00$ & $\mathrm{Kg}$ \\
\hline Óleo Cru & $4,22 \mathrm{E}-03$ & $2,41 \mathrm{E}-02$ & $\mathrm{Kg}$ \\
\hline Energia primária de hidroelétrica (Recurso de Energia Renovável) & $1,81 \mathrm{E}-03$ & $1,03 \mathrm{E}-02$ & MJ \\
\hline Gás Natural (Recurso de gás natural) & $2,40 \mathrm{E}-04$ & 1,37E-03 & $\mathrm{Kg}$ \\
\hline Carvão Marrom & $6,48 \mathrm{E}-05$ & $3,69 \mathrm{E}-04$ & $\mathrm{Kg}$ \\
\hline Carvão Duro & $6,06 \mathrm{E}-05$ & $3,45 \mathrm{E}-04$ & $\mathrm{Kg}$ \\
\hline Processo de água (materiais operacionais) & $9,00 \mathrm{E}-07$ & $5,13 \mathrm{E}-06$ & $\mathrm{Kg}$ \\
\hline Madeira (Recurso de energias renováveis) & $5,93 \mathrm{E}-07$ & $3,38 \mathrm{E}-06$ & $\mathrm{Kg}$ \\
\hline Minério de Urânio & $1,58 \mathrm{E}-08$ & $9,01 \mathrm{E}-08$ & $\mathrm{Kg}$ \\
\hline TOTAL ENTRADA & $1,01 E+00$ & $5,74 E+00$ & \\
\hline \multicolumn{4}{|l|}{ SAÍDAS } \\
\hline Total de carbono orgânico restrito (Medidas analíticas para a água fresca) & $6,81 \mathrm{E}-01$ & $3,88 \mathrm{E}+00$ & $\mathrm{Kg}$ \\
\hline Dióxido de carbono (Emissões inorgânicas para o ar) & $1,10 \mathrm{E}-01$ & $6,27 \mathrm{E}-01$ & $\mathrm{Kg}$ \\
\hline Metano (Emissões orgânicas para o ar (grupo VOC)) & $1,22 \mathrm{E}-02$ & $6,95 \mathrm{E}-02$ & $\mathrm{Kg}$ \\
\hline Nitrato (Emissões inorgânicas para água fresca) & $2,43 E-03$ & $1,39 \mathrm{E}-02$ & $\mathrm{Kg}$ \\
\hline Cloreto (Emissões inorgânicas para água fresca) & $1,52 \mathrm{E}-03$ & $8,66 \mathrm{E}-03$ & $\mathrm{Kg}$ \\
\hline Sulfato (Emissões inorgânicas para água fresca) & 1,19E-03 & $6,78 \mathrm{E}-03$ & $\mathrm{Kg}$ \\
\hline Zinco (+II) (Metais pesados para água fresca) & $6,06 \mathrm{E}-04$ & $3,45 \mathrm{E}-03$ & $\mathrm{Kg}$ \\
\hline Óxido de Nitrogênio (Emissões inorgânicas para o ar) & $1,98 \mathrm{E}-04$ & $1,13 \mathrm{E}-03$ & $\mathrm{Kg}$ \\
\hline Carbono (não especificado) (Emissões orgânicas para o solo industrial) & $1,45 \mathrm{E}-04$ & $8,27 \mathrm{E}-04$ & $\mathrm{Kg}$ \\
\hline \multicolumn{4}{|l|}{ Sais inorgânicos e Ácidos (não especificado) (Emissões inorgânicas para água } \\
\hline fresca) & $1,11 \mathrm{E}-04$ & $6,33 \mathrm{E}-04$ & $\mathrm{Kg}$ \\
\hline NMVOC (não especificado) (Grupo NMVOC para o ar) & $8,95 \mathrm{E}-05$ & $5,10 \mathrm{E}-04$ & $\mathrm{Kg}$ \\
\hline Monóxido de carbono (Emissões inorgânicas para o ar) & $8,11 \mathrm{E}-05$ & $4,62 \mathrm{E}-04$ & $\mathrm{Kg}$ \\
\hline Cobre (+II) (Metais pesados para água fresca) & 4,39E-05 & $2,50 \mathrm{E}-04$ & $\mathrm{Kg}$ \\
\hline Dióxido de enxofre (Emissões inorgânicas para o ar) & $3,58 \mathrm{E}-05$ & $2,04 \mathrm{E}-04$ & $\mathrm{Kg}$ \\
\hline Amônio / Amônia (Emissões inorgânicas para água fresca) & $1,53 \mathrm{E}-05$ & $8,72 \mathrm{E}-05$ & $\mathrm{Kg}$ \\
\hline Pó (não especificado) (Partículas para o ar) & $1,36 \mathrm{E}-05$ & $7,75 \mathrm{E}-05$ & $\mathrm{Kg}$ \\
\hline Sólidos (suspenso) (Partículas para água fresca) & $1,22 \mathrm{E}-05$ & $6,95 \mathrm{E}-05$ & $\mathrm{Kg}$ \\
\hline Mercúrio (+II) (Metais pesados para água fresca) & $1,16 \mathrm{E}-05$ & $6,61 \mathrm{E}-05$ & $\mathrm{Kg}$ \\
\hline Óleo (não especificado) (Hidrocarbonetos para a água fresca) & $5,62 \mathrm{E}-06$ & $3,20 \mathrm{E}-05$ & $\mathrm{Kg}$ \\
\hline
\end{tabular}


Cádmio (+II) (Metais pesados para água fresca)

Ferro (Metais pesados para água fresca)

Hidrocarbonetos clorados (não especificado) (Emissões orgânicas halogenadas para a água fresca)

\begin{tabular}{|c|c|c|}
\hline $1,86 \mathrm{E}-10$ & $1,06 \mathrm{E}-09$ & $\mathrm{Kg}$ \\
\hline $1,38 \mathrm{E}-10$ & $7,87 \mathrm{E}-10$ & $\mathrm{Kg}$ \\
\hline $2,02 \mathrm{E}-11$ & $1,15 \mathrm{E}-10$ & $\mathrm{Kg}$ \\
\hline $3,94 \mathrm{E}-12$ & $2,25 \mathrm{E}-11$ & $\mathrm{Kg}$ \\
\hline $2,25 \mathrm{E}-14$ & $1,28 \mathrm{E}-13$ & $\mathrm{Kg}$ \\
\hline $8,10 \mathrm{E}-01$ & $4,62 E+00$ & \\
\hline
\end{tabular}

Hidrocarbonetos aromáticos policíclicos (Grupo PAH para o ar)

Manganês (+II) (Metais pesados para o ar)

Hidrocarbonetos halogenados (não especificado) (Emissões orgânicas halogenadas para o ar)

Policlorinato dibenzeno-p-dioxina (2,3,7,8 - TCDD) (Emissões orgânicas halogenadas para o ar) 
Anexo C

\begin{tabular}{|c|c|c|c|}
\hline Substâncias & $\begin{array}{l}\text { Quantidade } \\
\text { para } 1 \mathrm{Kg} \text { de } \\
\text { Aço Inox }\end{array}$ & $\begin{array}{c}\text { Quantidade } \\
\text { para } 1 \text { cesto } \\
(5,098 \mathrm{Kg})\end{array}$ & $\begin{array}{l}\text { Unidade de } \\
\text { Referência }\end{array}$ \\
\hline \multicolumn{4}{|l|}{ PRODUÇÃO AÇO INOX } \\
\hline Água (Água de poço) [Água] & $3,21 \mathrm{E}+01$ & $1,63 \mathrm{E}+02$ & $\mathrm{Kg}$ \\
\hline Água (Água da superfície) [Água] & $1,66 \mathrm{E}+01$ & $8,45 E+01$ & $\mathrm{Kg}$ \\
\hline Ar (Recursos renováveis) & $1,26 \mathrm{E}+01$ & $6,45 \mathrm{E}+01$ & $\mathrm{Kg}$ \\
\hline Rocha inerte (Recursos não renováveis) & $9,70 E+00$ & $4,95 \mathrm{E}+01$ & $\mathrm{Kg}$ \\
\hline Água [Água] & $4,40 E+00$ & $2,24 \mathrm{E}+01$ & $\mathrm{Kg}$ \\
\hline Energia primária de energia solar (Recurso de energias renováveis) & $4,25 E+00$ & $2,17 E+01$ & MJ \\
\hline Energia primária de hidroelétricas (Recurso de energias renováveis) & $3,29 \mathrm{E}+00$ & $1,68 \mathrm{E}+01$ & MJ \\
\hline Cromo ore (Recursos não renováveis) & $3,21 \mathrm{E}+00$ & $1,63 \mathrm{E}+01$ & $\mathrm{Kg}$ \\
\hline Minério de Níquel (Recursos não renováveis) & $1,96 \mathrm{E}+00$ & $9,99 \mathrm{E}+00$ & $\mathrm{Kg}$ \\
\hline Minério de Níquel (1.6\%) (Recursos não renováveis) & $1,85 E+00$ & $9,43 E+00$ & $\mathrm{Kg}$ \\
\hline Calcário (carbonato de cálcio) (Recursos não renováveis) & $8,95 \mathrm{E}-01$ & $4,56 \mathrm{E}+00$ & $\mathrm{Kg}$ \\
\hline Refugo de aço (Resíduo para reciclagem) & $6,73 \mathrm{E}-01$ & $3,43 E+00$ & $\mathrm{Kg}$ \\
\hline Dióxido de carbono (Recursos renováveis) & 4,57E-01 & $2,33 \mathrm{E}+00$ & $\mathrm{Kg}$ \\
\hline Areia de Quartzo (Recursos não renováveis) & $2,31 \mathrm{E}-01$ & $1,18 \mathrm{E}+00$ & $\mathrm{Kg}$ \\
\hline Cloreto de sódio (Recursos não renováveis) & $1,25 \mathrm{E}-01$ & $6,35 \mathrm{E}-01$ & $\mathrm{Kg}$ \\
\hline Minério de Manganês (R.O.M.) (Recursos não renováveis) & $8,94 \mathrm{E}-02$ & 4,56E-01 & $\mathrm{Kg}$ \\
\hline Água refrigerada (materiais operacionais) & $8,84 \mathrm{E}-02$ & $4,51 \mathrm{E}-01$ & $\mathrm{Kg}$ \\
\hline Energia primária de energia eólica (Recurso de energias renováveis) & $8,25 \mathrm{E}-02$ & $4,20 \mathrm{E}-01$ & MJ \\
\hline Terra (Recursos não renováveis) & $7,01 \mathrm{E}-02$ & $3,57 \mathrm{E}-01$ & $\mathrm{Kg}$ \\
\hline Lignito do Canadá & 2,15E-02 & $1,10 \mathrm{E}-01$ & $\mathrm{Kg}$ \\
\hline Metais preciosos (Recursos não renováveis) & $2,10 \mathrm{E}-02$ & 1,07E-01 & $\mathrm{Kg}$ \\
\hline Agregado Natural (Recursos não renováveis) & $1,75 \mathrm{E}-02$ & $8,92 \mathrm{E}-02$ & $\mathrm{Kg}$ \\
\hline Basalto (Recursos não renováveis) & $5,20 \mathrm{E}-03$ & $2,65 \mathrm{E}-02$ & $\mathrm{Kg}$ \\
\hline Poço de Metano (Recurso de gás natural) & 3,93E-03 & $2,00 \mathrm{E}-02$ & $\mathrm{Kg}$ \\
\hline Energia primária de geotérmicas (Recurso de energias renováveis) & 3,33E-03 & $1,70 \mathrm{E}-02$ & MJ \\
\hline Água (Água do mar) [Água] & $3,32 \mathrm{E}-03$ & $1,69 \mathrm{E}-02$ & $\mathrm{Kg}$ \\
\hline Minério de Ferro (Recursos não renováveis) & $3,06 \mathrm{E}-03$ & $1,56 \mathrm{E}-02$ & $\mathrm{Kg}$ \\
\hline Mineral pesado (barytes) (Recursos não renováveis) & 2,31E-03 & $1,18 \mathrm{E}-02$ & $\mathrm{Kg}$ \\
\hline Cloreto de magnésio (40\%) (Recursos não renováveis) & $1,53 \mathrm{E}-03$ & $7,82 \mathrm{E}-03$ & $\mathrm{Kg}$ \\
\hline Minério de cobre (0.14\%) (Recursos não renováveis) & $1,05 \mathrm{E}-03$ & $5,37 \mathrm{E}-03$ & $\mathrm{Kg}$ \\
\hline Bentonita (Recursos não renováveis) & $9,36 \mathrm{E}-04$ & 4,77E-03 & $\mathrm{Kg}$ \\
\hline Petróleo do Brasil (recurso do petróleo) & $4,96 \mathrm{E}-04$ & $2,53 \mathrm{E}-03$ & $\mathrm{Kg}$ \\
\hline Bauxita (Recursos não renováveis) & $4,03 \mathrm{E}-04$ & $2,06 \mathrm{E}-03$ & $\mathrm{Kg}$ \\
\hline Gás natural do Brasil (Recurso de gás natural) & $3,21 \mathrm{E}-04$ & $1,64 \mathrm{E}-03$ & $\mathrm{Kg}$ \\
\hline Barro (Recursos não renováveis) & $3,19 \mathrm{E}-04$ & $1,62 \mathrm{E}-03$ & $\mathrm{Kg}$ \\
\hline Minério de Chumbo - Zinco (4.6\%-0.6\%) (Recursos não renováveis) & 2,01E-04 & $1,02 \mathrm{E}-03$ & $\mathrm{Kg}$ \\
\hline Carvão duro do Brasil & $1,23 \mathrm{E}-04$ & $6,28 \mathrm{E}-04$ & $\mathrm{Kg}$ \\
\hline Gesso (Gesso natural) (Recursos não renováveis) & $1,18 \mathrm{E}-04$ & $6,02 \mathrm{E}-04$ & $\mathrm{Kg}$ \\
\hline Zinco - Minério de cobre (4.07\%-2.59\%) (Recursos não renováveis) & $1,04 \mathrm{E}-04$ & $5,32 \mathrm{E}-04$ & $\mathrm{Kg}$ \\
\hline Zinco - Chumbo - Minério de cobre (12\%-3\%-2\%) (Recursos não renováveis) & $5,53 \mathrm{E}-05$ & $2,82 \mathrm{E}-04$ & $\mathrm{Kg}$ \\
\hline \multicolumn{4}{|l|}{ Minério de cobre, ouro e prata $(1,0 \% \mathrm{Cu} ; 0,4 \mathrm{~g} / \mathrm{t} \mathrm{Au} ; 66 \mathrm{~g} / \mathrm{t} \mathrm{Ag})$ (Recursos não } \\
\hline renováveis) & $3,37 \mathrm{E}-05$ & $1,72 \mathrm{E}-04$ & $\mathrm{Kg}$ \\
\hline \multicolumn{4}{|l|}{ Minério de cobre, molibdênio, ouro e prata $(1,13 \% \mathrm{Cu} ; 0,02 \% \mathrm{Mo} ; 0,01 \mathrm{~g} / \mathrm{t} \mathrm{Au}$; } \\
\hline 2,86 g/t Ag) (Recursos não renováveis) & 2,82E-05 & $1,44 \mathrm{E}-04$ & $\mathrm{Kg}$ \\
\hline Urânio natural & $2,51 \mathrm{E}-05$ & $1,28 \mathrm{E}-04$ & $\mathrm{Kg}$ \\
\hline Madeira (Recurso de energias renováveis) & $2,46 \mathrm{E}-05$ & $1,25 \mathrm{E}-04$ & $\mathrm{Kg}$ \\
\hline \multicolumn{4}{|l|}{ Minério de cobre, ouro e prata $(1,1 \% \mathrm{Cu} ; 0,01 \mathrm{~g} / \mathrm{t} \mathrm{Au} ; 2,86 \mathrm{~g} / \mathrm{t} \mathrm{Ag}$ ) (Recursos } \\
\hline não renováveis) & $2,05 \mathrm{E}-05$ & $1,05 \mathrm{E}-04$ & $\mathrm{Kg}$ \\
\hline Minério de Ferro (65\%) (Recursos não renováveis) & 1,99E-05 & $1,01 \mathrm{E}-04$ & $\mathrm{Kg}$ \\
\hline Turfa (Recursos não renováveis) & $1,84 \mathrm{E}-05$ & $9,38 \mathrm{E}-05$ & $\mathrm{Kg}$ \\
\hline Molibdênio (Mo 0,24\%) (Recursos não renováveis) & $1,72 \mathrm{E}-05$ & $8,79 \mathrm{E}-05$ & $\mathrm{Kg}$ \\
\hline IImenite (minério de titânio) (Recursos não renováveis) & $1,21 \mathrm{E}-05$ & $6,18 \mathrm{E}-05$ & $\mathrm{Kg}$ \\
\hline \multicolumn{4}{|l|}{ Minério de cobre, ouro e prata $(1,16 \% \mathrm{Cu} ; 0,002 \mathrm{~g} / \mathrm{t} \mathrm{Au} ; 1,06 \mathrm{~g} / \mathrm{t} \mathrm{Ag}$ ) (Recursos } \\
\hline não renováveis) & $1,16 \mathrm{E}-05$ & $5,91 \mathrm{E}-05$ & $\mathrm{Kg}$ \\
\hline Minério de titânio (Recursos não renováveis) & $8,76 \mathrm{E}-06$ & 4,47E-05 & $\mathrm{Kg}$ \\
\hline Minério de cobre (1.2\%) (Recursos não renováveis) & $3,49 \mathrm{E}-06$ & $1,78 \mathrm{E}-05$ & $\mathrm{Kg}$ \\
\hline Minério de Fosfato (Recursos não renováveis) & $3,31 \mathrm{E}-06$ & $1,69 \mathrm{E}-05$ & $\mathrm{Kg}$ \\
\hline Água (Água potável) [Água] & $2,66 \mathrm{E}-06$ & $1,36 \mathrm{E}-05$ & $\mathrm{Kg}$ \\
\hline Ferro (Recursos não renováveis) & $1,69 \mathrm{E}-06$ & $8,62 \mathrm{E}-06$ & $\mathrm{Kg}$ \\
\hline Magnésio (Carbonato de magnésio) (Recursos não renováveis) & $1,45 \mathrm{E}-06$ & $7,40 \mathrm{E}-06$ & $\mathrm{Kg}$ \\
\hline Poço de gás (Recurso de gás natural) & $1,24 \mathrm{E}-06$ & $6,30 \mathrm{E}-06$ & $\mathrm{Kg}$ \\
\hline Minério de Manganês (Recursos não renováveis) & $9,84 \mathrm{E}-07$ & $5,02 \mathrm{E}-06$ & $\mathrm{Kg}$ \\
\hline
\end{tabular}


Cloreto de Potássio (Recursos não renováveis)

Minério de Caulim (Recursos não renováveis)

Sulfato de sódio (Recursos não renováveis)

Minério de Colemanite (Recursos não renováveis)

Fluorspar (fluoreto de cálcio; fluorita) (Recursos não renováveis)

Combustíveis renováveis (Recurso de energias renováveis)

Púmice cru (Recursos não renováveis)

Dolomita (Recursos não renováveis)

Talco (Recursos não renováveis)

Minerais de fósforo (Recursos não renováveis)

Enxofre (Recursos não renováveis)

Enxofre (garantido) (Recursos não renováveis)

Minério de fósforo (29\% P2O5) (Recursos não renováveis)

Água (Água de lago) [Água]

Minério de cobre (Recursos não renováveis)

Água ((Água com lodo do rio)) [Água]

Cloreto de cálcio (Recursos não renováveis)

Minério de Zinco (Sulfureto) (Recursos não renováveis)

Bário Sulfato (Recursos não renováveis)

Minério de cobre (4\%) (Recursos não renováveis)

Zinco - Chumbo ore (4.21\%-4.96\%) (Recursos não renováveis)

Ardósia (Recursos não renováveis)

Minério de estanho (Recursos não renováveis)

Olivina (Recursos não renováveis)

Chumbo (Recursos não renováveis)

Ferro Manganês (Recursos não renováveis)

TOTAL ENTRADA

SAÍDAS

Cripton (Kr85) (Emissões radioativas para o ar)

Hidrogênio (H3) (Emissões radioativas para água fresca)

Radon ( $\mathrm{Rn} 222)$ (Emissões radioativas para o ar)

Rádio (Ra226) (Emissões radioativas para água fresca)

Xenon (Xe133) (Emissões radioativas para o ar)

Hidrogênio (H3) (Emissões radioativas para o ar)

Argônio (Ar41) (Emissões radioativas para o ar)

Xenon (Xe135) (Emissões radioativas para o ar)

Carbono (C14) (Emissões radioativas para o ar)

Água (água de rio) [Água]

Resíduos de calor (Outras emissões para o ar)

Césio (Cs137) (Emissões radioativas para água fresca)

Sobrecarga (depositado) (Bens de estoque)

Descarga (Outras emissões para o ar)

Urânio (Emissões radioativas para água fresca)

Xenon (Xe135m) (Emissões radioativas para o ar)

Cobalto (Co60) (Emissões radioativas para água fresca)

Dióxido de carbono (Emissões inorgânicas para o ar)

Vapor (Emissões inorgânicas para o ar)

lodine (I129) (Emissões radioativas para água fresca)

Resíduos de calor (Outras emissões para água fresca)

Tailings (Bens de estoque)

Xenon (Xe138) (Emissões radioativas para o ar)

Césio (Cs134) (Emissões radioativas para água fresca)

Carbono (C14) (Emissões radioativas para água fresca)

Estrôncio ( $\mathrm{Sr90}$ ) (Emissões radioativas para água fresca)

Xenon (Xe133m) (Emissões radioativas para o ar)

Cripton (Kr85m) (Emissões radioativas para o ar)

Escória (Resíduo para reciclagem)

Ar utilizado (Outras emissões para o ar)

Aço Inox (bobina) [Metais]

Manganês (Mn54) (Emissões radioativas para água fresca)

Xenon (Xe131m) (Emissões radioativas para o ar)

Energia primária não proveniente de hidroelétrica (Outras emissões para água fresca)

Demanda de oxigênio químico (Medidas analíticas para a água fresca)

Oxigênio (Recursos renováveis)

Urânio (total) (Emissões radioativas para o ar)

Resíduos (não especificado) (resíduo do consumidor)

Cromo com escória (Disposição de resíduos perigosos)

Urânio (U238) (Emissões radioativas para o ar)

Plutônio (Pu alpha) (Emissões radioativas para água fresca)

Escória (Produção de chapa de ferro) (Resíduo para reciclagem)

$8,81 \mathrm{E}-07$

$3,89 \mathrm{E}-07$

$2,51 \mathrm{E}-07$

2,18E-07

1,00E-07

4,79E-08

$3,78 \mathrm{E}-08$

2,15E-08

7,68E-09

5,84E-09

1,62E-09

$8,32 \mathrm{E}-10$

5,56E-10

3,65E-11

2,50E-12

$1,78 \mathrm{E}-12$

8,08E-13

$6,27 \mathrm{E}-14$

7,89E-15

2,11E-15

7,19E-16

$7,12 \mathrm{E}-16$

6,84E-16

4,23E-16

$7,70 \mathrm{E}-17$

3,85E-17

9,27E+01

$1,09 \mathrm{E}+06$

$4,31 \mathrm{E}+04$

$1,59 \mathrm{E}+04$

$4,81 \mathrm{E}+02$

$1,45 \mathrm{E}+02$

$1,26 \mathrm{E}+02$

$6,45 \mathrm{E}+01$

$4,10 \mathrm{E}+01$

$2,96 \mathrm{E}+01$

$2,47 \mathrm{E}+01$

$1,69 \mathrm{E}+01$

$1,37 \mathrm{E}+01$

$1,29 \mathrm{E}+01$

$1,00 \mathrm{E}+01$

$8,48 \mathrm{E}+00$

$7,19 \mathrm{E}+00$

$6,35 \mathrm{E}+00$

$4,81 \mathrm{E}+00$

$4,49 \mathrm{E}+00$

$4,22 \mathrm{E}+00$

$3,00 \mathrm{E}+00$

$2,53 \mathrm{E}+00$

$1,63 \mathrm{E}+00$

$1,51 \mathrm{E}+00$

$1,48 \mathrm{E}+00$

$1,42 \mathrm{E}+00$

$1,16 \mathrm{E}+00$

$1,11 \mathrm{E}+00$

$1,05 \mathrm{E}+00$

$1,02 \mathrm{E}+00$

$1,00 \mathrm{E}+00$

9,85E-01

8,90E-01

5,50E-01

4,93E-01

3,42E-01

2,63E-01

2,44E-01

2,03E-01

1,25E-01

1,17E-01

8,35E-02
4,49E-06

1,98E-06

1,28E-06

1,11E-06

5,11E-07

2,44E-07

1,93E-07

1,10E-07

3,91E-08

2,98E-08

8,24E-09

4,24E-09

2,83E-09

$1,86 \mathrm{E}-10$

1,27E-11

9,07E-12

4,12E-12

3,20E-13

4,02E-14

1,07E-14

3,67E-15

3,63E-15

3,49E-15

2,16E-15

3,92E-16

1,96E-16

4,73E+02

$5,56 \mathrm{E}+06$

$2,20 E+05$

$8,09 E+04$

$2,45 E+03$

$7,37 \mathrm{E}+02$

$6,41 E+02$

$3,29 E+02$

2,09E+02

$1,51 \mathrm{E}+02$

$1,26 \mathrm{E}+02$

$8,61 \mathrm{E}+01$

$6,98 \mathrm{E}+01$

$6,57 \mathrm{E}+01$

$5,10 \mathrm{E}+01$

$4,32 \mathrm{E}+01$

$3,67 \mathrm{E}+01$

$3,24 \mathrm{E}+01$

$2,45 \mathrm{E}+01$

2,29E+01

$2,15 E+01$

$1,53 \mathrm{E}+01$

$1,29 \mathrm{E}+01$

$8,29 \mathrm{E}+00$

$7,69 \mathrm{E}+00$

$7,53 \mathrm{E}+00$

$7,24 \mathrm{E}+00$

$5,92 \mathrm{E}+00$

$5,66 \mathrm{E}+00$

$5,36 \mathrm{E}+00$

$5,21 \mathrm{E}+00$

$5,10 \mathrm{E}+00$

$5,02 \mathrm{E}+00$

$4,54 \mathrm{E}+00$

$2,80 \mathrm{E}+00$

$2,51 \mathrm{E}+00$

$1,74 \mathrm{E}+00$

$1,34 \mathrm{E}+00$

$1,24 \mathrm{E}+00$

$1,03 \mathrm{E}+00$

6,36E-01

5,94E-01

4,26E-01

$\mathrm{Bq}$

$\mathrm{Bq}$
$\mathrm{Bq}$

$\mathrm{Bq}$

$\mathrm{Bq}$

$\mathrm{Bq}$
$\mathrm{Bq}$

$\mathrm{Bq}$

$\mathrm{Bq}$

$\mathrm{Bq}$

$\mathrm{Bq}$

$\mathrm{Kg}$

$\mathrm{MJ}$

$\mathrm{Bq}$

$\mathrm{Kg}$

$\mathrm{Kg}$

$\mathrm{Bq}$

$\mathrm{Bq}$

$\mathrm{Bq}$

$\mathrm{Kg}$

$\mathrm{Kg}$

$\mathrm{Bq}$

MJ

$\mathrm{Kg}$

$\mathrm{Bq}$

$\mathrm{Bq}$

$\mathrm{Bq}$

$\mathrm{Bq}$

$\mathrm{Bq}$

$\mathrm{Bq}$

$\mathrm{Kg}$

$\mathrm{Kg}$

$\mathrm{Kg}$

$\mathrm{Bq}$
$\mathrm{Bq}$

MJ

$\mathrm{Kg}$

$\mathrm{Kg}$

$\mathrm{Bq}$

$\mathrm{Kg}$

$\mathrm{Kg}$

$\mathrm{Bq}$

$\mathrm{Bq}$ 
Cloreto (Emissões inorgânicas para água fresca)

Urânio (U234) (Emissões radioativas para o ar)

lodine (I129) (Emissões radioativas para o ar)

Pedregulho rolante (Resíduo para reciclagem)

Escória (Mn 6,5\%) (Resíduo para reciclagem)

Curium ( $\mathrm{Cm}$ alpha) (Emissões radioativas para água fresca)

Resíduo de tratamento (mineral, depositado) (Bens de estoque)

Filtro de pó (Resíduo para reciclagem)

Barro [Resíduos perigosos]

Cálcio (+II) (Emissões inorgânicas para água fresca)

Rutênio (Ru106) (Emissões radioativas para água fresca)

Amerício (Am241) (Emissões radioativas para água fresca)

Resíduos de Água [Resíduos perigosos para reaproveitamento]

Dióxido de enxofre (Emissões inorgânicas para o ar)

Sódio (+I) (Emissões inorgânicas para água fresca)

Césio (Cs137) (Emissões radioativas para o ar)

Xenon (Xe137) (Emissões radioativas para o ar)

Cobalto (Co58) (Emissões radioativas para água fresca)

Sólidos (suspenso) (Partículas para água fresca)

lodine (I131) (Emissões radioativas para o ar)

Espólio (depositado) (Bens de estoque)

Césio (Cs134) (Emissões radioativas para o ar)

Escória de carvão de forno (Resíduo para reciclagem)

Cloreto (Emissões inorgânicas para água do mar)

Óxido de Nitrogênio (Emissões inorgânicas para o ar)

Metano (Emissões orgânicas para o ar (grupo VOC))

Resíduos de demolição (depositado) (Bens de estoque)

Radioativo tailings (Resíduo Radioativo)

Estanhoder rolante (Resíduo para reciclagem)

Anodos (usado) [Metais]

Água (Reservatório de água) (materiais operacionais)

Urânio (U235) (Emissões radioativas para o ar)

Escória (contendo metais preciosos) (Resíduo para reciclagem)

Monóxido de carbono (Emissões inorgânicas para o ar)

Cromo (+III) (Metais pesados para água fresca)

Sulfato (Emissões inorgânicas para água fresca)

Ferro (Metais pesados para água fresca)

Energia primários não usada de geotérmicas (Outras emissões para água fresca)

Pó (não especificado) (Partículas para o ar)

Cobalto (Co60) (Emissões radioativas para o ar)

Energia primária não usada de energia solar (Outras emissões para o ar)

Gesso (FDI) (Resíduo para reciclagem)

Oxigênio (Emissões inorgânicas para o ar)

Escória [Resíduos perigosos]

Demanda de oxigênio biológico (Medidas analíticas para a água fresca)

Nitrogênio (atmosférico Nitrogênio) (Emissões inorgânicas para o ar)

Fluorida (Emissões inorgânicas para água fresca)

Pó (PM2.5) (Partículas para o ar)

Energia primária não proveniente de energia eólica (Outras emissões para o ar)

NMVOC (não especificado) (Grupo NMVOC para o ar)

Ocupação de área florestal

Antimônio (Sb124) (Emissões radioativas para água fresca)

[Sólidos (suspenso) (Partículas para água do mar)]

lodine (I131) (Emissões radioativas para água fresca)

Antimônio (Sb125) (Emissões radioativas para água fresca)

Escória (depositado) (Bens de estoque)

Propano (Grupo NMVOC para o ar)

Etano (Grupo NMVOC para o ar)

Amônio (Emissões inorgânicas para o ar)

Lama Vermelha (seco) (Disposição de resíduos perigosos)

Carbonato (Emissões inorgânicas para água do mar)

Cloreto de Hidrogênio (Emissões inorgânicas para o ar)

Resíduos perigosos (não especificado) [Resíduos perigosos]

Resíduos minerais (resíduo do consumidor)

Amônio / Amônia (Emissões inorgânicas para água fresca)

Pó (PM10) (Partículas para o ar)

Óxido nitroso (gás do riso) (Emissões inorgânicas para o ar)

Cobalto (Co58) (Emissões radioativas para o ar)

Prata $(\mathrm{Ag} 110 \mathrm{~m})$ (Emissões radioativas para água fresca)

Sulfato (Emissões inorgânicas para água do mar)

Água refrigerada (Resíduo para reciclagem)

Magnésio (+III) (Emissões inorgânicas para água fresca)
$7,94 \mathrm{E}-02$

$6,90 \mathrm{E}-02$

$6,32 \mathrm{E}-02$

$5,16 \mathrm{E}-02$

$4,55 \mathrm{E}-02$

$3,86 \mathrm{E}-02$

$3,57 \mathrm{E}-02$

$3,22 \mathrm{E}-02$

$3,10 \mathrm{E}-02$

$3,06 \mathrm{E}-02$

2,91E-02

$2,91 \mathrm{E}-02$

$2,46 \mathrm{E}-02$

$1,99 \mathrm{E}-02$

$1,88 \mathrm{E}-02$

$1,65 \mathrm{E}-02$

$1,26 \mathrm{E}-02$

$1,13 \mathrm{E}-02$

$1,11 \mathrm{E}-02$

9,51E-03

$8,25 \mathrm{E}-03$

$8,10 \mathrm{E}-03$

$8,04 \mathrm{E}-03$

$7,92 \mathrm{E}-03$

$7,08 \mathrm{E}-03$

$6,08 \mathrm{E}-03$

$5,94 \mathrm{E}-03$

4,89E-03

4,50E-03

4,33E-03

3,83E-03

3,33E-03

2,97E-03

2,90E-03

2,28E-03

$2,14 \mathrm{E}-03$

1,90E-03

$1,83 \mathrm{E}-03$

$1,64 \mathrm{E}-03$

$1,29 \mathrm{E}-03$

9,99E-04

$9,68 \mathrm{E}-04$

9,11E-04

5,59E-04

5,53E-04

$5,28 \mathrm{E}-04$

5,02E-04

3,90E-04

3,90E-04

$3,41 \mathrm{E}-04$

$3,13 \mathrm{E}-04$

3,03E-04

2,46E-04

2,16E-04

2,07E-04

1,91E-04

$1,55 \mathrm{E}-04$

$1,36 \mathrm{E}-04$

$1,14 \mathrm{E}-04$

$1,09 \mathrm{E}-04$

1,00E-04

$9,13 \mathrm{E}-05$

$8,46 \mathrm{E}-05$

$8,00 \mathrm{E}-05$

7,11E-05

5,95E-05

5,79E-05

5,09E-05

$4,43 \mathrm{E}-05$

4,31E-05

3,86E-05

3,67E-05
4,05E-01

3,52E-01

$3,22 \mathrm{E}-01$

2,63E-01

2,32E-01

1,97E-01

1,82E-01

1,64E-01

$1,58 \mathrm{E}-01$

1,56E-01

1,49E-01

1,49E-01

1,25E-01

1,01E-01

9,57E-02

$8,43 \mathrm{E}-02$

$6,44 \mathrm{E}-02$

5,78E-02

5,65E-02

4,85E-02

4,21E-02

4,13E-02

4,10E-02

4,04E-02

3,61E-02

3,10E-02

3,03E-02

2,49E-02

2,29E-02

2,21E-02

1,95E-02

$1,70 \mathrm{E}-02$

1,52E-02

$1,48 \mathrm{E}-02$

1,16E-02

1,09E-02

9,69E-03

9,34E-03

8,37E-03

$6,57 \mathrm{E}-03$

5,09E-03

4,94E-03

4,65E-03

2,85E-03

2,82E-03

2,69E-03

2,56E-03

1,99E-03

1,99E-03

$1,74 \mathrm{E}-03$

1,59E-03

$1,55 \mathrm{E}-03$

$1,25 \mathrm{E}-03$

1,10E-03

1,05E-03

9,75E-04

$7,88 \mathrm{E}-04$

6,96E-04

5,82E-04

5,58E-04

5,11E-04

4,66E-04

4,31E-04

$4,08 \mathrm{E}-04$

$3,62 \mathrm{E}-04$

3,03E-04

2,95E-04

2,59E-04

2,26E-04

2,20E-04

1,97E-04

$1,87 \mathrm{E}-04$ 
Amônia (Emissões inorgânicas para o solo industrial)

Óleo (não especificado) (Emissões orgânicas para o solo industrial)

VOC (não especificado) (Emissões orgânicas para o ar (grupo VOC))

Fluoreto de hidrogênio (Emissões inorgânicas para o ar)

Butano (Grupo NMVOC para o ar)

Sólidos (dissolvido) (Medidas analíticas para a água fresca)

Menos terra devido à erosão da água (Partículas para água fresca)

Resíduos Orgânicos (resíduo do consumidor)

Pentano (n-Pentano) (Grupo NMVOC para o ar)

Nitrato (Emissões inorgânicas para água fresca)

Carbonato (Emissões inorgânicas para água fresca)

Estrôncio (Metais pesados para o solo industrial)

Cloro (dissolvido) (Emissões inorgânicas para água fresca)

Nitrogênio (Emissões inorgânicas para água fresca)

Xileno (benzeno de dimetil) (Grupo NMVOC para o ar)

Urânio Depledado (Resíduo Radioativo)

Escória (conversão de urânio) (Resíduo Radioativo)

Sulfureto (Emissões inorgânicas para água do mar)

Alumínio (+III) (Emissões inorgânicas para água fresca)

Resíduos Radioativos (Resíduo Radioativo)

Níquel (+II) (Metais pesados para o ar)

Amônia (Emissões inorgânicas para o ar)

Sulfeto de hidrogênio (Emissões inorgânicas para o ar)

Cloreto (Emissões inorgânicas para o solo industrial)

Formaldeído (Metanol) (Grupo NMVOC para o ar)

Metanol (Hidrocarbonetos para a água fresca)

Demanda de oxigênio químico (Medidas analíticas para água do mar)

Antimônio (Sb124) (Emissões radioativas para o ar)

Plutônio (Pu alpha) (Emissões radioativas para o ar)

Resíduos radioativos médios e leves (Resíduo Radioativo)

Fosfato (Emissões inorgânicas para água fresca)

Potássio (+l) (Emissões inorgânicas para o solo industrial)

Hidrogênio (Emissões inorgânicas para o ar)

Alcano (não especificado) (Grupo NMVOC para o ar)

Total de carbono orgânico restrito (Medidas analíticas para a água fresca)

Areia (Produção de Alumina) (Bens de estoque)

Resíduo altamente radioativo (Resíduo Radioativo)

Butano (n-Butâno) (Grupo NMVOC para o ar)

Sulfureto (Emissões inorgânicas para o solo industrial)

Sódio (+I) (Emissões inorgânicas para água do mar)

Carbono, limites orgânicos (Emissões orgânicas para água fresca)

Alcano (não especificado) (Grupo NMVOC para o ar)

Ácido acético (Grupo NMVOC para o ar)

Estrôncio (Metais pesados para água fresca)

Etil Benzeno (Grupo NMVOC para o ar)

Ferro Sulfato (produtos inorgânicos)

Sulfureto (Emissões inorgânicas para água fresca)

Compostos de Boro (não especificado) (Emissões inorgânicas para o ar)

Fósforo (Emissões inorgânicas para o solo industrial)

Benzeno (Grupo NMVOC para o ar)

Gesso (Minerais)

Óleo (não especificado) (Hidrocarbonetos para água do mar)

Níquel (+II) (Metais pesados para o solo industrial)

Cobre (+II) (Metais pesados para o ar)

Manganês (+II) (Metais pesados para o ar)

CaF2 (baixa radioatividade) (Resíduo Radioativo)

Nitrogênio orgânico restrito (Emissões inorgânicas para água fresca)

Zinco (+II) (Metais pesados para o ar)

Vanádio (+III) (Metais pesados para o ar)

Manganês (+II) (Metais pesados para água fresca)

Resíduos para disposição (não especificado) [Resíduos para disposição]

Tolueno (benzeno de metil) (Grupo NMVOC para o ar)

Etanol (Grupo NMVOC para o ar)

Bário (Emissões inorgânicas para o ar)

Metanol (Grupo NMVOC para o ar)

Nitrogênio (Recursos renováveis)

Resíduos neutralizados (resíduos produzidos no ciclo de vida)

Bário (Emissões inorgânicas para água do mar)

Cálcio (+II) (Emissões inorgânicas para o solo industrial)

Cobalto (Metais pesados para o ar)

Manganês (+II) (Metais pesados para o solo industrial)

Aldeído (não especificado) (Grupo NMVOC para o ar)
1,86E-04

1,70E-04

1,65E-04

1,65E-04

1,62E-04

1,60E-04

1,56E-04

1,45E-04

1,36E-04

1,32E-04

1,32E-04

1,18E-04

1,17E-04

1,12E-04

1,06E-04

9,75E-05

9,42E-05

9,23E-05

$8,68 \mathrm{E}-05$

8,45E-05

$8,18 \mathrm{E}-05$

7,60E-05

$6,75 \mathrm{E}-05$

6,45E-05

5,79E-05

5,63E-05

5,51E-05

5,25E-05

5,11E-05

5,04E-05

4,92E-05

4,85E-05

4,70E-05

4,60E-05

4,55E-05

4,25E-05

4,25E-05

4,11E-05

3,73E-05

3,14E-05

2,96E-05

2,63E-05

2,58E-05

2,58E-05

2,53E-05

2,52E-05

2,39E-05

1,96E-05

1,92E-05

1,90E-05

1,89E-05

1,85E-05

1,80E-05

1,61E-05

1,57E-05

1,42E-05

1,42E-05

1,36E-05

1,33E-05

1,26E-05

1,19E-05

1,17E-05

1,10E-05

1,08E-05

1,04E-05

1,03E-05

9,96E-06

8,15E-06

$7,78 \mathrm{E}-06$

7,52E-06

$6,98 \mathrm{E}-06$

6,70E-06 
Gesso (contaminado) (Resíduo para reciclagem)

Natrium oxide (Disposição de resíduos perigosos)

Sulfato (Emissões inorgânicas para o solo industrial)

Enxofreic Ácido (Emissões inorgânicas para água fresca)

Boro (Emissões inorgânicas para água fresca)

Acet Aldeído (Etanol) (Grupo NMVOC para o ar)

Acetona (dimetilacetona) (Grupo NMVOC para o ar)

Óleo (não especificado) (Hidrocarbonetos para a água fresca)

Disposição do lixo industrial municipal (resíduo do consumidor)

Hexano (isômero) (Grupo NMVOC para o ar)

Hidrocarbonetos aromáticos policíclicos (Grupo PAH para o ar)

Chumbo (+II) (Metais pesados para o ar)

Cloro (Emissões inorgânicas para o ar)

Bromo (Emissões inorgânicas para o ar)

Fenol (Hidrocarbonetos para água do mar)

Zinco (+II) (Metais pesados para água do mar)

Potássio (Emissões inorgânicas para água fresca)

Resíduos perigosos (depósito subterrâneo) [Resíduos perigosos]

Fluorida (não especificado) (Emissões inorgânicas para o ar)

Heptane (isômero) (Grupo NMVOC para o ar)

Hidrocarbonetos aromáticos policíclicos (Hidrocarbonetos para a água fresca)

Cromo (+III) (Metais pesados para o ar)

Chumbo (+II) (Metais pesados para água fresca)

Oxalate (Produção de Alumina) [Resíduos perigosos]

Cloreto (não especificado) (Emissões inorgânicas para o ar)

Molibdênio (Metais pesados para água fresca)

Papel (não especificado) (resíduo do consumidor)

Cobre (+II) (Metais pesados para o solo industrial)

Ferro (Metais pesados para água do mar)

Cobre (+II) (Metais pesados para água fresca)

Fluoridas (Emissões inorgânicas para o ar)

Componente halogênio orgânico absorvível (Medidas analíticas para a água

fresca)

Propano (propileno) (Grupo NMVOC para o ar)

Bário (Emissões inorgânicas para água fresca)

Hidrocarbonetos aromáticos (não especificado) (Grupo NMVOC para o ar)

Hidrocarbonetos (não especificado) (Hidrocarbonetos para a água fresca)

Benzeno (Hidrocarbonetos para água do mar)

Ácido acético (Hidrocarbonetos para a água fresca)

Fluorida (Emissões inorgânicas para o solo industrial)

Selênio (Metais pesados para o ar)

Cobalto (Metais pesados para o solo industrial)

Octano (Grupo NMVOC para o ar)

Estanho (+IV) (Metais pesados para o ar)

Sulfeto (Emissões inorgânicas para água fresca)

Cloro (Emissões inorgânicas para o solo industrial)

Demanda de oxigênio biológico (Medidas analíticas para água do mar)

Total de carbono orgânico restrito (Medidas analíticas para água do mar)

Arsênico (+V) (Metais pesados para o ar)

Mercúrio (+II) (Metais pesados para o ar)

Níquel (+II) (Metais pesados para água fresca)

Cromo (não especificado) (Metais pesados para o ar)

Hidróxido (Emissões inorgânicas para água fresca)

Xileno (isômero; dimetil Benzeno) (Hidrocarbonetos para a água fresca)

Tolueno (benzeno de metil) (Hidrocarbonetos para água do mar)

Cromo (não especificado) (Metais pesados para água fresca)

Magnésio (+III) (Emissões inorgânicas para o solo industrial)

Fenol (Hidrocarbonetos para a água fresca)

R 114 (dichlorotetrafluoroEtano) (Emissões orgânicas halogenadas para o ar)

R 11 (trichlorofluoroMetano) (Emissões orgânicas halogenadas para o ar)

Xileno (isômero; dimetil Benzeno) (Hidrocarbonetos para água do mar)

Fósforo (Emissões inorgânicas para água fresca)

Zinco (+II) (Metais pesados para água fresca)

Benzeno (Hidrocarbonetos para a água fresca)

Cálcio (+II) (Emissões inorgânicas para água do mar)

Vanádio (+III) (Metais pesados para água fresca)

Partículas de Silicato (Emissões inorgânicas para água fresca)

Cádmio (+II) (Metais pesados para água fresca)

Cromo (não especificado) (Metais pesados para água do mar)

Sódio (+I) (Emissões inorgânicas para o solo industrial)

Hélio (Emissões inorgânicas para o ar)

Nitrato (Emissões inorgânicas para água do mar)
$1,28 \mathrm{E}-06$

$1,26 \mathrm{E}-06$

1,22E-06

1,12E-06

1,10E-06

1,07E-06

1,06E-06

1,03E-06

1,02E-06

9,92E-07

9,08E-07

$9,08 \mathrm{E}-07$

8,92E-07

8,91E-07

7,86E-07

7,81E-07

7,77E-07

7,21E-07

6,41E-07

6,27E-07

6,21E-07

5,35E-07

5,14E-07

5,07E-07

5,00E-07

4,91E-07

4,87E-07

4,86E-07

4,79E-07

4,71E-07

4,58E-07

4,54E-07

4,50E-07

4,38E-07

4,07E-07

4,04E-07

3,96E-07

3,85E-07

3,59E-07

3,50E-07

3,47E-07

3,45E-07

3,34E-07

3,33E-07

3,33E-07

3,09E-07

3,09E-07

3,07E-07

2,90E-07

2,87E-07

2,64E-07

2,44E-07

2,40E-07

2,37E-07

2,35E-07

2,11E-07

1,93E-07

1,88E-07

1,83E-07

1,82E-07

1,81E-07

1,81E-07

1,73E-07

1,72E-07

1,67E-07

1,63E-07

1,38E-07

1,35E-07

1,34E-07

1,31E-07

1,30E-07
6,54E-06

6,42E-06

$6,22 \mathrm{E}-06$

5,69E-06

5,60E-06

5,46E-06

5,43E-06

5,24E-06

5,20E-06

5,06E-06

4,63E-06

4,63E-06

4,55E-06

4,54E-06

4,01E-06

3,98E-06

3,96E-06

3,68E-06

3,27E-06

3,20E-06

3,17E-06

2,73E-06

2,62E-06

2,59E-06

2,55E-06

2,50E-06

2,48E-06

2,48E-06

2,44E-06

2,40E-06

2,33E-06

2,31E-06

2,30E-06

2,23E-06

2,08E-06

2,06E-06

2,02E-06

1,96E-06

1,83E-06

1,78E-06

1,77E-06

1,76E-06

1,70E-06

1,70E-06

1,70E-06

1,57E-06

1,57E-06

1,57E-06

1,48E-06

1,46E-06

1,35E-06

1,24E-06

1,22E-06

1,21E-06

1,20E-06

1,08E-06

9,82E-07

9,57E-07

9,35E-07

9,30E-07

9,23E-07

9,22E-07

8,81E-07

8,77E-07

8,51E-07

8,30E-07

7,02E-07

6,87E-07

6,81E-07

$6,68 \mathrm{E}-07$

6,65E-07 
Molibdênio (Metais pesados para o ar)

Enxofreic Ácido (Emissões inorgânicas para o ar)

$1,11 \mathrm{E}-07$

$5,95 \mathrm{E}-07$

Tolueno (benzeno de metil) (Hidrocarbonetos para a água fresca)

$1,09 \mathrm{E}-07$

Cromo (+III) (Metais pesados para o solo industrial)

1,04E-07

$5,66 \mathrm{E}-07$

Ferro (Metais pesados para o solo industrial)

$5,53 \mathrm{E}-07$

$9,54 \mathrm{E}-08$

Magnésio (Emissões inorgânicas para água do mar

9,27E-08

$5,30 \mathrm{E}-07$

$4,86 \mathrm{E}-07$

Selênio (Metais pesados para água fresca)

Alumínio (+III) (Emissões inorgânicas para o solo industrial)

$8,78 \mathrm{E}-08$

$8,47 \mathrm{E}-08$

$7,38 \mathrm{E}-08$

Amônia (Emissões inorgânicas para água fresca)

Titânio (Metais pesados para água fresca)

Naftalina (Emissões Orgânicas para água do mar)

Cromo (não especificado) (Metais pesados para o solo industrial)

$7,34 \mathrm{E}-08$

$7,32 \mathrm{E}-08$

$7,28 \mathrm{E}-08$

$6,64 \mathrm{E}-08$

Cobre (+II) (Metais pesados para água do mar)

Ferro (Metais pesados para o ar)

Zinco (+II) (Metais pesados para o solo industrial)

Resíduos líquidos (resíduo do consumidor)

Mercaptan (não especificado) (Grupo NMVOC para o ar)

Manganês (+II) (Metais pesados para água do mar)

Etil Benzeno (Hidrocarbonetos para água do mar)

Ácido (calculado com $\mathrm{H}+$ ) (Emissões inorgânicas para água fresca)

R 22 (chlorodifluoroMetano) (Emissões orgânicas halogenadas para o ar)

Metais pesados para o ar (não especificado) (Metais pesados para o ar)

Estrôncio (Metais pesados para água do mar)

Cádmio (+II) (Metais pesados para o ar)

R 12 (dichlorodifluoroMetano) (Emissões orgânicas halogenadas para o ar)

Cobalto (Metais pesados para água do mar)

Hidrocarbonetos aromáticos (não especificado) (Hidrocarbonetos para a água

fresca)

Níquel (+II) (Metais pesados para água do mar)

Antimônio (Metais pesados para o ar)

Arsênico (+V) (Metais pesados para água do mar)

Óleo utilizado [Resíduos perigosos para reaproveitamento]

Monóxido de Nitrogênio (Emissões inorgânicas para o ar)

Cádmio (+II) (Metais pesados para água do mar)

Cianeto de Hidrogênio (Ácido prússico) (Emissões inorgânicas para o ar)

Vanádio (+III) (Metais pesados para água do mar)

R 13 (chlorotrifluoroMetano) (Emissões orgânicas halogenadas para o ar)

$6,34 \mathrm{E}-08$

$6,13 \mathrm{E}-08$

$5,87 \mathrm{E}-08$

5,33E-08

5,01E-08

4,99E-08

4,42E-08

4,31E-08

4,12E-08

4,11E-08

3,98E-08

3,94E-08

3,89E-08

4,72E-07

$4,48 \mathrm{E}-07$

4,32E-07

3,76E-07

3,74E-07

$3,73 \mathrm{E}-07$

3,71E-07

3,39E-07

3,23E-07

3,13E-07

2,99E-07

2,72E-07

2,55E-07

2,54E-07

2,25E-07

2,20E-07

2,10E-07

2,09E-07

2,03E-07

2,01E-07

1,98E-07

3,87E-08

3,84E-08

1,97E-07

3,50E-08

3,48E-08

1,96E-07

$1,79 \mathrm{E}-07$

1,77E-07

3,04E-08 1,55E-07

2,98E-08

1,55E-07

$\begin{array}{ll}2,93 \mathrm{E}-08 & 1,49 \mathrm{E}-07 \\ 2,75 \mathrm{E}-08 & 1,40 \mathrm{E}-07\end{array}$

2,67E-08 1,36E-07

$2,47 \mathrm{E}-08 \quad 1,26 \mathrm{E}-07$

$2,18 \mathrm{E}-08$

$1,11 \mathrm{E}-07$

fresca)

Plutônio como produto residual (Resíduo Radioativo)

Etano (etileno) (Grupo NMVOC para o ar)

Chumbo (+II) (Metais pesados para água do mar)

Etil Benzeno (Hidrocarbonetos para a água fresca)

Arsênico (+V) (Metais pesados para o solo industrial)

Sódio Hipoclorídrico (Emissões inorgânicas para água fresca)

Plástico (não especificado) (Resíduo para reciclagem)

Metais pesados para água (não especificado) (Metais pesados para água fresca)

Cianeto (não especificado) (Emissões inorgânicas para o ar)

Brometo (Emissões inorgânicas para o solo industrial)

Ciclohexano (hexahydro Benzeno) (Grupo NMVOC para o ar)

Cloreto de Hidrogênio (Emissões inorgânicas para água fresca)

Cobalto (Metais pesados para água fresca)

Fluorine (Emissões inorgânicas para água fresca)

Clorometâno (cloreto de metil) (Emissões orgânicas halogenadas para a água

fresca)

Ácido acético (Hidrocarbonetos para água do mar)

Chumbo (+II) (Metais pesados para o solo industrial)

Sais neutros (Emissões inorgânicas para água fresca)

Dióxido de Nitrogênio (Emissões inorgânicas para o ar)

Hidrogênio Bromo (Ácido bromídrico) (Emissões inorgânicas para o ar)

Berílio (Emissões inorgânicas para o ar)

Naftalina (Emissões orgânicas para água fresca)

Cloreto de vinil (VCM; chloroetano) (Emissões orgânicas halogenadas para o ar)

Cianeto (Emissões inorgânicas para água fresca)

Hidrocarbonetos aromáticos (não especificado) (Hidrocarbonetos para água do mar)

Criseno (Hidrocarbonetos para água do mar)

$1,66 \mathrm{E}-08$

$1,55 \mathrm{E}-08$

$1,43 \mathrm{E}-08$

1,31E-08

1,25E-08

$1,18 \mathrm{E}-08$

$1,18 \mathrm{E}-08$

$1,18 \mathrm{E}-08$

1,12E-08

1,08E-08

1,03E-08

8,66E-09

$7,61 \mathrm{E}-09$

7,33E-09

$8,45 \mathrm{E}-08$

$7,92 \mathrm{E}-08$

$7,29 \mathrm{E}-08$

$6,66 \mathrm{E}-08$

$6,37 \mathrm{E}-08$

6,03E-08

$6,02 \mathrm{E}-08$

6,02E-08

5,69E-08

5,49E-08

5,23E-08

4,41E-08

$3,88 \mathrm{E}-08$

3,74E-08

7,28E-09

$6,25 \mathrm{E}-09$

3,71E-08

3,19E-08

5,89E-09

5,41E-09

$3,00 \mathrm{E}-08$

2,76E-08

4,81E-09 2,45E-08

$4,80 \mathrm{E}-09 \quad 2,45 \mathrm{E}-08$

$4,73 \mathrm{E}-09 \quad 2,41 \mathrm{E}-08$

4,35E-09 2,22E-08

4,03E-09 2,06E-08

3,39E-09

$2,06 \mathrm{E}-08$
$1,73 \mathrm{E}-08$

3,09E-09

1,57E-08

2,96E-09

2,89E-09

$1,51 \mathrm{E}-08$

$1,48 \mathrm{E}-08$

$2,33 \mathrm{E}-09 \quad 1,19 \mathrm{E}-08$

Acenaphthene (Hidrocarbonetos para água do mar)

2,22E-09

$1,13 \mathrm{E}-08$

Berílio (Emissões inorgânicas para água do mar)

1,99E-09

$1,02 \mathrm{E}-08$ 
Mercúrio (+II) (Metais pesados para água fresca)

Naftalina (Grupo PAH para o ar)

Boro (Emissões inorgânicas para água do mar)

carbonyl Sulfureto [Organic intermediate products]

Cromo (+VI) (Metais pesados para o solo industrial)

Enxofre (Emissões inorgânicas para água fresca)

Titânio (Metais pesados para o ar)

Acenaphthylene (Hidrocarbonetos para água do mar)

Benzo \{a\} pireno (Grupo PAH para o ar)

Enxofre (Emissões inorgânicas para água do mar)

Cloreto de sódio (Emissões inorgânicas para água fresca)

Berílio (Emissões inorgânicas para água fresca)

Prata (Metais pesados para água fresca)

Fluoranteno (Hidrocarbonetos para água do mar)

Antraceno (Hidrocarbonetos para água do mar)

Benzofluoranteno (Hidrocarbonetos para água do mar)

Phenanthrene (Grupo PAH para o ar)

Benzo \{a\} Antraceno (Hidrocarbonetos para água do mar)

Ácido propionico (Propano Ácido) (Grupo NMVOC para o ar)

Carbono disulfureto (Emissões inorgânicas para o ar)

Água (desalinizada; desodorizada) (materiais operacionais)

Antimônio (Metais pesados para o solo industrial)

Mercúrio (+II) (Metais pesados para água do mar)

Cádmio (+II) (Metais pesados para o solo industrial)

Tetrafluorometano (Emissões orgânicas halogenadas para o ar)

Cumene (isopropilbenzeno) (Grupo NMVOC para o ar)

Sulfato de zinco (Emissões inorgânicas para o ar)

Estrôncio (Emissões inorgânicas para o ar)

Fluoreno (Grupo NMVOC para o ar)

Antraceno (Hidrocarbonetos para a água fresca)

Tálio (Metais pesados para o ar)

Metais (não especificado) (Partículas para água fresca)

Bromo (Emissões inorgânicas para água fresca)

Acroenída (Grupo NMVOC para o ar)

Enxofre hexafluorida (Emissões inorgânicas para o ar)

Cromo (+VI) (Metais pesados para água fresca)

Alumínio (+III) (Emissões inorgânicas para água do mar)

Acenaphthene (Hidrocarbonetos para a água fresca)

Fluorine (Emissões inorgânicas para o ar)

Cromo (+VI) (Metais pesados para o ar)

Fluoranteno (Grupo NMVOC para o ar)

Estanho (+IV) (Metais pesados para água fresca)

Madeira (Pó) (Partículas para o ar)

Total de carbono orgânico restrito dissolvido (Medidas analíticas para a água fresca)

Criseno (Hidrocarbonetos para a água fresca)

Acenaphthylene (Hidrocarbonetos para a água fresca)

Polychlorinated biphenyls (PCB não especificado) (Emissões orgânicas halogenadas para o ar)

Estanho (+IV) (Metais pesados para água do mar)

Cresol (Metil Fenol) (Hidrocarbonetos para a água fresca)

Prata (Metais pesados para água do mar)

Fluoranteno (Hidrocarbonetos para a água fresca)

Cresol (Metil Fenol) (Hidrocarbonetos para água do mar)

Criseno (Grupo PAH para o ar)

Mercúrio (+II) (Metais pesados para o solo industrial)

Acrilonitrila (Hidrocarbonetos para a água fresca)

Antraceno (Grupo PAH para o ar)

Benzofluoranteno (Grupo PAH para o ar)

Lanthanides (Metais pesados para o ar)

Telúrio (Metais pesados para o ar)

Estireno (Grupo NMVOC para o ar)

Tálio (Metais pesados para água fresca)

Benzo \{a\} Antraceno (Hidrocarbonetos para a água fresca)

Hidrogênio Arsênico (arsine) (Metais pesados para o ar)

Fenol (Grupo NMVOC para o ar)

Benzo \{a\} Antraceno (Grupo PAH para o ar)

Molibdênio (Metais pesados para água do mar)

Benzo \{ghi\} perylene (Grupo PAH para o ar)

Escândio (Emissões inorgânicas para o ar)

Magnésio Cloreto (Emissões inorgânicas para água fresca)

Indeno [1,2,3-cd] pireno (Grupo PAH para o ar)
$1,95 \mathrm{E}-09$

$1,84 \mathrm{E}-09$

$1,57 \mathrm{E}-09$

$1,55 \mathrm{E}-09$

$1,43 \mathrm{E}-09$

$1,11 \mathrm{E}-09$

9,53E-10

8,87E-10

8,64E-10

$8,43 \mathrm{E}-10$

6,76E-10

6,44E-10

6,35E-10

6,16E-10

6,08E-10

5,82E-10

5,77E-10

5,23E-10

$4,78 \mathrm{E}-10$

4,47E-10

4,37E-10

3,94E-10

$3,75 \mathrm{E}-10$

3,70E-10

3,41E-10

2,85E-10

2,63E-10

2,52E-10

$1,81 \mathrm{E}-10$

$1,40 \mathrm{E}-10$

$1,38 \mathrm{E}-10$

1,33E-10

1,30E-10

$1,23 \mathrm{E}-10$

1,03E-10

9,75E-11

9,74E-11

8,77E-11

7,77E-11

5,76E-11

5,70E-11

5,65E-11

4,77E-11

4,74E-11

4,58E-11

3,42E-11

3,29E-11

2,97E-11

2,87E-11

2,48E-11

2,23E-11

2,18E-11

2,16E-11

1,84E-11

1,79E-11

1,75E-11

1,57E-11

1,36E-11

1,22E-11

1,14E-11

1,10E-11

1,06E-11

1,05E-11

9,10E-12

8,81E-12

$8,36 \mathrm{E}-12$

$7,86 \mathrm{E}-12$

6,60E-12

$6,08 \mathrm{E}-12$

5,85E-12
9,95E-09

9,37E-09

8,03E-09

$7,88 \mathrm{E}-09$

7,27E-09

5,65E-09

4,86E-09

4,52E-09

4,40E-09

4,30E-09

$3,45 \mathrm{E}-09$

3,29E-09

3,24E-09

3,14E-09

3,10E-09

2,97E-09

2,94E-09

2,67E-09

2,44E-09

2,28E-09

2,23E-09

2,01E-09

1,91E-09

1,89E-09

1,74E-09

1,45E-09

1,34E-09

$1,28 \mathrm{E}-09$

9,22E-10

$7,16 \mathrm{E}-10$

7,04E-10

$6,79 \mathrm{E}-10$

6,61E-10

6,30E-10

5,25E-10

4,97E-10

4,96E-10

4,47E-10

3,96E-10

2,94E-10

2,91E-10

2,88E-10

2,43E-10

2,42E-10

2,34E-10

$1,74 \mathrm{E}-10$

$1,68 \mathrm{E}-10$

$1,51 \mathrm{E}-10$

$1,46 \mathrm{E}-10$

1,26E-10

$1,14 \mathrm{E}-10$

1,11E-10

$1,10 \mathrm{E}-10$

9,40E-11

9,11E-11

8,92E-11

$8,01 \mathrm{E}-11$

6,93E-11

$6,24 \mathrm{E}-11$

5,79E-11

5,61E-11

5,39E-11

5,37E-11

4,64E-11

4,49E-11

4,26E-11

4,00E-11

3,36E-11

3,10E-11

2,98E-11 
Componentes orgânicos (dissolvido) (Emissões orgânicas para água fresca)

Hidrogênio iodide (Emissões inorgânicas para o ar)

$5,63 \mathrm{E}-12$

$5,27 \mathrm{E}-12$

$5,18 \mathrm{E}-12$

$5,16 \mathrm{E}-12$

Benzofluoranteno (Hidrocarbonetos para a água fresca)

Dibenzeno Antraceno (Grupo PAH para o ar)

Amônio Nitrato (Emissões inorgânicas para o ar)

Metais (não especificado) (Partículas para o ar)

Óleo Combustível (produto do petróleo)

Hexano (isômero) (Hidrocarbonetos para a água fresca)

Titânio (Metais pesados para água do mar)

Composto de cloro orgânico (não especificado) (Emissões orgânicas para água

fresca)

Composto de cloro orgânico (Emissões orgânicas halogenadas para o ar)

1,2-Dibromoetano (Emissões orgânicas halogenadas para a água fresca)

Hexano (isômero) (Hidrocarbonetos para água do mar)

Amina de dietil (etileno, etano e amina) (Grupo NMVOC para o ar)

Policlorinato dibenzeno-p-dioxina (2,3,7,8 - TCDD) (Emissões orgânicas halogenadas para o ar)

Chumbo dióxido (Emissões inorgânicas para o ar)

Trimetilbenzeno (Grupo NMVOC para o ar)

Hidrogênio fosforoso (Emissões inorgânicas para o ar)

Cloreto de vinil (VCM; chloroetano) (Emissões orgânicas halogenadas para a água fresca)

Hexametileno (HMDA) (Grupo NMVOC para o ar)

Componente halogênio orgânico absorvível (Medidas analíticas para água do mar)

Óxido de zinco (Emissões inorgânicas para o ar)

Antimônio (Metais pesados para água fresca)

Óxido de Estanho (Emissões inorgânicas para o ar)

Trioxido de arsênico (Metais pesados para o ar)

Sais inorgânicos e Ácidos (não especificado) (Emissões inorgânicas para água fresca)

R 116 (hexafluoroetano) (Emissões orgânicas halogenadas para o ar)

Dioxina (não especificado) (Emissões orgânicas halogenadas para o ar)

Hidrocarbonetos clorados (não especificado) (Emissões orgânicas halogenadas para a água fresca)

Diclorometâno (Metileno Cloreto) (Emissões orgânicas halogenadas para o ar)

Dicloropropano (Emissões orgânicas halogenadas para a água fresca)

Hidrocarbonetos halogenados (não especificado) (Emissões orgânicas

halogenadas para o ar)

Prata (Metais pesados para o ar)

Palladium (Metais pesados para o ar)

Ródio (Metais pesados para o ar)

Policlorinato dibenzeno-p-dioxina (2,3,7,8 - TCDD) (Emissões orgânicas halogenadas para a água fresca)

Componentes orgânicos (não especificado) (Emissões orgânicas para água fresca)

TOTAL SAÍDA

TRANSPORTE MATÉRIA-PRIMA

ENTRADA

\begin{tabular}{|c|c|c|c|}
\hline Diesel (produto do petróleo) & $1,84 \mathrm{E}-03$ & $2,03 E+05$ & $\mathrm{Kg}$ \\
\hline TOTAL ENTRADA & $1,84 \mathrm{E}-03$ & $2,03 E+05$ & \\
\hline \multicolumn{4}{|l|}{ SAÍDA } \\
\hline Carga (Outros) & $1,00 \mathrm{E}+00$ & $1,10 \mathrm{E}+08$ & $\mathrm{Kg}$ \\
\hline Dióxido de carbono (Emissões inorgânicas para o ar) & $5,84 \mathrm{E}-03$ & $6,44 \mathrm{E}+05$ & $\mathrm{Kg}$ \\
\hline Óxido de Nitrogênio (Emissões inorgânicas para o ar) & $6,01 \mathrm{E}-05$ & $6,63 E+03$ & $\mathrm{Kg}$ \\
\hline Monóxido de carbono (Emissões inorgânicas para o ar) & $1,26 \mathrm{E}-05$ & $1,38 \mathrm{E}+03$ & $\mathrm{Kg}$ \\
\hline NMVOC (não especificado) (Grupo NMVOC para o ar) & $4,08 \mathrm{E}-06$ & $4,49 E+02$ & $\mathrm{Kg}$ \\
\hline Pó (PM2.5) (Partículas para o ar) & 2,31E-06 & $2,54 \mathrm{E}+02$ & $\mathrm{Kg}$ \\
\hline Dióxido de enxofre (Emissões inorgânicas para o ar) & $1,84 \mathrm{E}-07$ & $2,03 E+01$ & $\mathrm{Kg}$ \\
\hline Metano (Emissões orgânicas para o ar (grupo VOC)) & $1,03 \mathrm{E}-07$ & $1,14 \mathrm{E}+01$ & $\mathrm{Kg}$ \\
\hline Óxido nitroso (gás do riso) (Emissões inorgânicas para o ar) & $8,52 \mathrm{E}-08$ & $9,39 E+00$ & $\mathrm{Kg}$ \\
\hline Benzeno (Grupo NMVOC para o ar) & $7,18 \mathrm{E}-08$ & $7,92 \mathrm{E}+00$ & $\mathrm{Kg}$ \\
\hline Amônia (Emissões inorgânicas para o ar) & $3,40 \mathrm{E}-08$ & $3,75 \mathrm{E}+00$ & $\mathrm{Kg}$ \\
\hline Xileno (benzeno de dimetil) (Grupo NMVOC para o ar) & $2,32 \mathrm{E}-08$ & $2,56 \mathrm{E}+00$ & $\mathrm{Kg}$ \\
\hline Tolueno (benzeno de metil) (Grupo NMVOC para o ar) & $1,38 \mathrm{E}-08$ & $1,52 \mathrm{E}+00$ & $\mathrm{Kg}$ \\
\hline TOTAL SAÍDA & $1,01 E+00$ & $1,11 \mathrm{E}+08$ & \\
\hline \multicolumn{4}{|l|}{ ESTAMPAGEM DO FUNDO CESTO } \\
\hline \multicolumn{4}{|l|}{ ENTRADA } \\
\hline Bobina de aço (St) [Metais] & $1,60 \mathrm{E}+00$ & $4,84 \mathrm{E}+00$ & $\mathrm{Kg}$ \\
\hline Energia (Energia elétrica) & $1,01 E+00$ & $3,05 E+00$ & MJ \\
\hline
\end{tabular}

2,87E-11 $\mathrm{Kg}$

2,69E-11

$2,64 \mathrm{E}-11$

2,63E-11

2,50E-11

2,49E-11

4,89E-12

3,75E-12

3,52E-12

3,22E-12

3,02E-12

2,45E-12

2,45E-12

2,41E-12

2,38E-12

2,17E-12

1,91E-11

1,79E-11

1,64E-11

1,54E-11

1,25E-11

1,25E-11

1,23E-11

1,21E-11

1,11E-11

1,78E-12

9,07E-12

7,57E-12

6,41E-12

5,81E-12

5,17E-12

1,55E-12

1,43E-12

1,32E-12

$1,25 \mathrm{E}-12$

$6,58 \mathrm{E}-13$

$6,47 \mathrm{E}-13$

1,43E-14

6,39E-15

4,90E-15

3,20E-15

1,59E-15

1,25E-15

7,99E-16

7,25E-16

$1,14 \mathrm{E}-16$

1,10E-16

3,83E-21

$\mathrm{Kg}$

2,35E-24 1,20E-23

$5,87 \mathrm{E}+06$

$\mathrm{Kg}$

$1,15 \mathrm{E}+06$

1,57E-16

2,24E-17

2,16E-17 


\begin{tabular}{|c|c|c|c|}
\hline Energia Térmica (MJ) [Energia Térmica] & $2,80 \mathrm{E}-01$ & $8,48 \mathrm{E}-01$ & MJ \\
\hline Termoformagem espessa (materiais operacionais) & $6,00 \mathrm{E}-05$ & $1,82 \mathrm{E}-04$ & $\mathrm{Kg}$ \\
\hline TOTAL ENTRADA & $2,89 E+00$ & $8,75 E+00$ & \\
\hline \multicolumn{4}{|l|}{ SAÍDAS } \\
\hline Parte de chapa (St) (Peça de Metal) & $1,00 E+00$ & $3,03 E+00$ & $\mathrm{Kg}$ \\
\hline Refugo de aço (St) (Resíduo para reciclagem) & $6,00 \mathrm{E}-01$ & $1,82 E+00$ & $\mathrm{Kg}$ \\
\hline TOTAL SAÍDA & $1,60 E+00$ & $4,84 E+00$ & \\
\hline \multicolumn{4}{|l|}{ ESTAMPAGEM DA LATERAL DO CESTO } \\
\hline \multicolumn{4}{|l|}{ ENTRADA } \\
\hline Bobina de aço (St) [Metais] & $1,05 \mathrm{E}+00$ & $2,17 \mathrm{E}+00$ & $\mathrm{Kg}$ \\
\hline Energia (Energia elétrica) & $1,75 \mathrm{E}-01$ & $3,62 \mathrm{E}-01$ & MJ \\
\hline Ar comprimido 7 bar (Energia Mecânica) & $7,57 \mathrm{E}-02$ & 1,57E-01 & $\mathrm{Nm} 3$ \\
\hline Óleo Lubrificante (materiais operacionais) & $1,33 \mathrm{E}-04$ & $2,75 \mathrm{E}-04$ & $\mathrm{Kg}$ \\
\hline TOTAL ENTRADA & $1,30 E+00$ & $2,69 E+00$ & \\
\hline \multicolumn{4}{|l|}{ SAÍDAS } \\
\hline Peça de aço (Peça de Metal) & $1,00 E+00$ & $2,07 E+00$ & $\mathrm{Kg}$ \\
\hline Refugo de aço (St) (Resíduo para reciclagem) & $4,90 \mathrm{E}-02$ & $1,01 \mathrm{E}-01$ & $\mathrm{Kg}$ \\
\hline TOTAL SAÍDA & $1,05 \mathrm{E}+00$ & $2,17 E+00$ & \\
\hline \multicolumn{4}{|l|}{ REBORDAGEM DO CESTO } \\
\hline \multicolumn{4}{|l|}{ ENTRADA } \\
\hline Energia (Energia elétrica) & $3,31 \mathrm{E}+00$ & $1,68 \mathrm{E}+01$ & MJ \\
\hline Alojamento de aço (St) [Metais] & $1,36 \mathrm{E}+00$ & $6,93 E+00$ & $\mathrm{Kg}$ \\
\hline TOTAL ENTRADA & $4,67 E+00$ & $2,38 \mathrm{E}+01$ & \\
\hline \multicolumn{4}{|l|}{ SAÍDAS } \\
\hline Peça de aço (Peça de Metal) & $1,00 E+00$ & $5,10 E+00$ & $\mathrm{Kg}$ \\
\hline Refugo de aço (St) (Resíduo para reciclagem) & $3,60 \mathrm{E}-01$ & $1,84 \mathrm{E}+00$ & $\mathrm{Kg}$ \\
\hline TOTAL SAÍDA & $1,36 \mathrm{E}+00$ & $6,93 \mathrm{E}+00$ & \\
\hline \multicolumn{4}{|l|}{ "TRANSPORTE PRODUTO } \\
\hline \multicolumn{4}{|l|}{ ENTRADA } \\
\hline Diesel (produto do petróleo) & $1,84 \mathrm{E}-03$ & $1,26 \mathrm{E}+05$ & $\mathrm{Kg}$ \\
\hline TOTAL ENTRADA & $1,84 \mathrm{E}-03$ & $1,26 E+05$ & \\
\hline \multicolumn{4}{|l|}{ SAÍDA } \\
\hline Carga (Outros) & $1,00 \mathrm{E}+00$ & $6,85 \mathrm{E}+07$ & $\mathrm{Kg}$ \\
\hline Dióxido de carbono (Emissões inorgânicas para o ar) & $5,84 \mathrm{E}-03$ & $4,00 E+05$ & $\mathrm{Kg}$ \\
\hline Óxido de Nitrogênio (Emissões inorgânicas para o ar) & $6,01 \mathrm{E}-05$ & $4,12 \mathrm{E}+03$ & $\mathrm{Kg}$ \\
\hline Monóxido de carbono (Emissões inorgânicas para o ar) & $1,26 \mathrm{E}-05$ & $8,60 E+02$ & $\mathrm{Kg}$ \\
\hline NMVOC (não especificado) (Grupo NMVOC para o ar) & $4,08 \mathrm{E}-06$ & $2,79 E+02$ & $\mathrm{Kg}$ \\
\hline Pó (PM2.5) (Partículas para o ar) & $2,31 \mathrm{E}-06$ & $1,58 \mathrm{E}+02$ & $\mathrm{Kg}$ \\
\hline Dióxido de enxofre (Emissões inorgânicas para o ar) & $1,84 \mathrm{E}-07$ & $1,26 \mathrm{E}+01$ & $\mathrm{Kg}$ \\
\hline Metano (Emissões orgânicas para o ar (grupo VOC)) & $1,03 E-07$ & $7,07 E+00$ & $\mathrm{Kg}$ \\
\hline Óxido nitroso (gás do riso) (Emissões inorgânicas para o ar) & $8,52 \mathrm{E}-08$ & $5,83 E+00$ & $\mathrm{Kg}$ \\
\hline Benzeno (Grupo NMVOC para o ar) & $7,18 \mathrm{E}-08$ & $4,92 \mathrm{E}+00$ & $\mathrm{Kg}$ \\
\hline Amônia (Emissões inorgânicas para o ar) & $3,40 \mathrm{E}-08$ & $2,33 E+00$ & $\mathrm{Kg}$ \\
\hline Xileno (benzeno de dimetil) (Grupo NMVOC para o ar) & $2,32 \mathrm{E}-08$ & $1,59 E+00$ & $\mathrm{Kg}$ \\
\hline Tolueno (benzeno de metil) (Grupo NMVOC para o ar) & $1,38 \mathrm{E}-08$ & $9,42 \mathrm{E}-01$ & $\mathrm{Kg}$ \\
\hline TOTAL SAÍDA & $1,01 E+00$ & $6,89 E+07$ & \\
\hline \multicolumn{4}{|l|}{ FASE DE USO } \\
\hline \multicolumn{4}{|l|}{ ENTRADAS } \\
\hline Água & $8,90 \mathrm{E}+00$ & $9,72 \mathrm{E}+03$ & $\mathrm{Kg}$ \\
\hline Energia primária de hidroelétrica (Recurso de Energia Renovável) & $1,76 \mathrm{E}-01$ & $1,92 \mathrm{E}+02$ & MJ \\
\hline Carvão Duro & $1,29 \mathrm{E}-01$ & $1,41 E+02$ & $\mathrm{Kg}$ \\
\hline Óleo Cru & 4,69E-03 & $5,12 E+00$ & $\mathrm{Kg}$ \\
\hline Gás Natural (Recurso de gás natural) & $2,49 \mathrm{E}-03$ & $2,72 E+00$ & $\mathrm{Kg}$ \\
\hline Carvão Marrom & $1,72 \mathrm{E}-03$ & $1,88 \mathrm{E}+00$ & $\mathrm{Kg}$ \\
\hline Madeira (Recurso de energias renováveis) & $1,25 \mathrm{E}-03$ & $1,37 E+00$ & $\mathrm{Kg}$ \\
\hline Minério de Urânio & $5,19 E-07$ & $5,67 \mathrm{E}-04$ & $\mathrm{Kg}$ \\
\hline TOTAL ENTRADA & $9,21 \mathrm{E}+00$ & $1,01 E+04$ & \\
\hline SAÍDAS & & & \\
\hline Energia (Energia elétrica) & $1,00 E+00$ & $1,09 E+03$ & MJ \\
\hline Dióxido de carbono (Emissões inorgânicas para o ar) & $2,20 \mathrm{E}-01$ & $2,40 E+02$ & $\mathrm{Kg}$ \\
\hline Cloreto (Emissões inorgânicas para água fresca) & $1,41 \mathrm{E}-03$ & $1,54 \mathrm{E}+00$ & $\mathrm{Kg}$ \\
\hline Sulfato (Emissões inorgânicas para água fresca) & $9,52 \mathrm{E}-04$ & $1,04 \mathrm{E}+00$ & $\mathrm{Kg}$ \\
\hline Dióxido de enxofre (Emissões inorgânicas para o ar) & $9,46 \mathrm{E}-04$ & $1,03 E+00$ & $\mathrm{Kg}$ \\
\hline Metano (Emissões orgânicas para o ar (grupo VOC)) & $9,16 \mathrm{E}-04$ & $1,00 E+00$ & $\mathrm{Kg}$ \\
\hline Sais inorgânicos e Ácidos (não especificado) (Emissões inorgân & & & \\
\hline fresca) & $7,76 \mathrm{E}-04$ & $8,48 \mathrm{E}-01$ & $\mathrm{Kg}$ \\
\hline Óxido de Nitrogênio (Emissões inorgânicas para o ar) & $5,59 \mathrm{E}-04$ & $6,11 \mathrm{E}-01$ & $\mathrm{Kg}$ \\
\hline Alumínio (+III) (Emissões inorgânicas para água fresca) & $2,06 \mathrm{E}-04$ & $2,25 \mathrm{E}-01$ & $\mathrm{Kg}$ \\
\hline Ferro (Metais pesados para água fresca) & $6,46 \mathrm{E}-05$ & $7,06 \mathrm{E}-02$ & $\mathrm{Kg}$ \\
\hline Cloreto de Hidrogênio (Emissões inorgânicas para o ar) & $6,32 \mathrm{E}-05$ & $6,90 \mathrm{E}-02$ & $\mathrm{Kg}$ \\
\hline
\end{tabular}


NMVOC (não especificado) (Grupo NMVOC para o ar)

Monóxido de carbono (Emissões inorgânicas para o ar)

Metais (não especificado) (Partículas para água fresca)

Sólidos (suspenso) (Partículas para água fresca)

Bário (Emissões inorgânicas para água fresca)

Metais (não especificado) (Partículas para o ar)

Fosfato (Emissões inorgânicas para água fresca)

Fluoreto de hidrogênio (Emissões inorgânicas para o ar)

Óleo (não especificado) (Hidrocarbonetos para a água fresca)

Nitrato (Emissões inorgânicas para água fresca)

Pó (não especificado) (Partículas para o ar)

Total de carbono orgânico restrito (Medidas analíticas para a água fresca)

Hidrocarbonetos aromáticos (não especificado) (Grupo NMVOC para o ar)

Zinco (+II) (Metais pesados para água fresca)

Cromo (não especificado) (Metais pesados para água fresca)

Óxido nitroso (gás do riso) (Emissões inorgânicas para o ar)

Amônia (Emissões inorgânicas para o ar)

Chumbo (+II) (Metais pesados para água fresca)

Níquel (+II) (Metais pesados para água fresca)

Cobre (+II) (Metais pesados para água fresca)

Demanda de oxigênio químico (Medidas analíticas para a água fresca)

Amônio / Amônia (Emissões inorgânicas para água fresca)

Arsênico (+V) (Metais pesados para água fresca)

Nitrogênio (Emissões inorgânicas para água fresca)

Hidrocarbonetos aromáticos (não especificado) (Hidrocarbonetos para a água fresca)

Níquel (+II) (Metais pesados para o ar

Benzeno (Grupo NMVOC para o ar)

Zinco (+II) (Metais pesados para o ar)

Chumbo (+II) (Metais pesados para o ar)

Demanda de oxigênio biológico (Medidas analíticas para a água fresca)

Fenol (Hidrocarbonetos para a água fresca)

Nitrogênio orgânico restrito (Emissões inorgânicas para água fresca)

Tolueno (benzeno de metil) (Hidrocarbonetos para a água fresca)

Total de carbono orgânico restrito dissolvido (Medidas analíticas para a água

fresca)

Manganês (+II) (Metais pesados para o ar)

Cádmio (+II) (Metais pesados para água fresca)

Mercúrio (+II) (Metais pesados para o ar)

Sulfureto (Emissões inorgânicas para água fresca)

Hidrocarbonetos aromáticos policíclicos (Grupo PAH para o ar)

Hidrocarbonetos aromáticos policíclicos (Hidrocarbonetos para a água fresca)

Cianeto (Emissões inorgânicas para água fresca)

Cádmio (+II) (Metais pesados para o ar)

Halon (1301) (Emissões orgânicas halogenadas para o ar)

Componente halogênio orgânico absorvível (Medidas analíticas para a água fresca)

Mercúrio (+II) (Metais pesados para água fresca)

Hidrocarbonetos clorados (não especificado) (Emissões orgânicas halogenadas para a água fresca)

Hidrocarbonetos halogenados (não especificado) (Emissões orgânicas halogenadas para o ar)

TOTAL SAÍDA

\section{DISPOSIÇÃO}

\section{ENTRADAS}

\begin{tabular}{|c|c|c|c|}
\hline Aço (ECCS) (resíduo do consumidor) & $1,00 \mathrm{E}+00$ & $5,10 \mathrm{E}+00$ & $\mathrm{Kg}$ \\
\hline Óleo Cru & $4,16 \mathrm{E}-03$ & $2,12 \mathrm{E}-02$ & $\mathrm{Kg}$ \\
\hline Energia primária de hidroelétrica (Recurso de Energia Renovável) & $3,43 E-04$ & $1,75 \mathrm{E}-03$ & MJ \\
\hline Gás Natural (Recurso de gás natural) & $1,69 \mathrm{E}-04$ & $8,61 \mathrm{E}-04$ & $\mathrm{Kg}$ \\
\hline Carvão Marrom & $4,58 \mathrm{E}-05$ & $2,33 \mathrm{E}-04$ & $\mathrm{Kg}$ \\
\hline Carvão Duro & $3,55 \mathrm{E}-05$ & $1,81 \mathrm{E}-04$ & $\mathrm{Kg}$ \\
\hline Madeira (Recurso de energias renováveis) & $3,48 \mathrm{E}-07$ & 1,77E-06 & $\mathrm{Kg}$ \\
\hline Minério de Urânio & $4,30 \mathrm{E}-09$ & $2,19 \mathrm{E}-08$ & $\mathrm{Kg}$ \\
\hline TOTAL ENTRADA & $1,00 E+00$ & $5,12 \mathrm{E}+00$ & \\
\hline \multicolumn{4}{|l|}{ SAÍDAS } \\
\hline Ferro (Metais pesados para água fresca) & $6,99 \mathrm{E}-02$ & $3,56 \mathrm{E}-01$ & $\mathrm{Kg}$ \\
\hline Dióxido de carbono (Emissões inorgânicas para o ar) & $1,35 \mathrm{E}-02$ & $6,88 \mathrm{E}-02$ & $\mathrm{Kg}$ \\
\hline Cloreto (Emissões inorgânicas para água fresca) & $8,61 \mathrm{E}-04$ & 4,39E-03 & $\mathrm{Kg}$ \\
\hline Óxido de Nitrogênio (Emissões inorgânicas para o ar) & $1,94 \mathrm{E}-04$ & $9,89 \mathrm{E}-04$ & $\mathrm{Kg}$ \\
\hline Zinco (+II) (Metais pesados para água fresca) & $1,37 \mathrm{E}-04$ & $6,98 \mathrm{E}-04$ & $\mathrm{Kg}$ \\
\hline Cobre (+II) (Metais pesados para água fresca) & $8,96 \mathrm{E}-05$ & $4,57 \mathrm{E}-04$ & $\mathrm{Kg}$ \\
\hline
\end{tabular}

4,90E-02 $\mathrm{Kg}$

$3,32 \mathrm{E}-02$

2,45E-02

2,01E-02

$1,86 \mathrm{E}-02$

$1,85 \mathrm{E}-02$

1,35E-02

$7,33 \mathrm{E}-03$

$6,84 \mathrm{E}-03$

5,51E-03

4,95E-03

$3,98 \mathrm{E}-03$

3,05E-03

2,26E-03

2,25E-03

$1,65 \mathrm{E}-03$

1,35E-03

1,14E-03

1,13E-03

1,13E-03

1,12E-03

5,57E-04

4,54E-04

2,80E-04

2,21E-04

1,59E-04

8,62E-05

$8,50 \mathrm{E}-05$

4,79E-05

$3,94 \mathrm{E}-05$

3,82E-05

3,16E-05

3,05E-05

2,86E-05

2,72E-05

1,19E-05

8,97E-06

8,52E-06

4,02E-06

3,34E-06

2,50E-06

1,76E-06

1,22E-06

8,97E-07

3,26E-07

2,74E-07

$1,48 \mathrm{E}-08$

1,34E+03

1,36E-11

$8,22 \mathrm{E}-10$

2,51E-10

$1,23 \mathrm{E}+00$
$\mathrm{Kg}$

$\mathrm{Kg}$

$\mathrm{Kg}$

$\mathrm{Kg}$

$\mathrm{Kg}$

$\mathrm{Kg}$

$\mathrm{Kg}$

$\mathrm{Kg}$

$\mathrm{Kg}$

$\mathrm{Kg}$

$\mathrm{Kg}$

$\mathrm{Kg}$

$\mathrm{Kg}$ 
NMVOC (não especificado) (Grupo NMVOC para o ar)

Sais inorgânicos e Ácidos (não especificado) (Emissões inorgânicas para água fresca)

Monóxido de carbono (Emissões inorgânicas para o ar)

Dióxido de enxofre (Emissões inorgânicas para o ar)

Metano (Emissões orgânicas para o ar (grupo VOC))

Sólidos (suspenso) (Partículas para água fresca)

Pó (não especificado) (Partículas para o ar)

Óleo (não especificado) (Hidrocarbonetos para a água fresca)

Sulfato (Emissões inorgânicas para água fresca)

Chumbo (+II) (Metais pesados para água fresca)

Cádmio (+II) (Metais pesados para água fresca)

Total de carbono orgânico restrito (Medidas analíticas para a água fresca)

Metais (não especificado) (Partículas para água fresca)

Demanda de oxigênio químico (Medidas analíticas para a água fresca)

Bário (Emissões inorgânicas para água fresca)

Amônio / Amônia (Emissões inorgânicas para água fresca)

Nitrogênio (Emissões inorgânicas para água fresca)

Óxido nitroso (gás do riso) (Emissões inorgânicas para o ar)

Hidrocarbonetos aromáticos (não especificado) (Hidrocarbonetos para a água

fresca)

Zinco (+II) (Metais pesados para o ar)

Nitrato (Emissões inorgânicas para água fresca)

Hidrocarbonetos aromáticos (não especificado) (Grupo NMVOC para o ar)

Nitrogênio orgânico restrito (Emissões inorgânicas para água fresca)

Alumínio (+III) (Emissões inorgânicas para água fresca)

Benzeno (Grupo NMVOC para o ar)

Metais (não especificado) (Partículas para o ar)

Cloreto de Hidrogênio (Emissões inorgânicas para o ar)

Fenol (Hidrocarbonetos para a água fresca)

Tolueno (benzeno de metil) (Hidrocarbonetos para a água fresca)

Demanda de oxigênio biológico (Medidas analíticas para a água fresca)

Níquel (+II) (Metais pesados para o ar)

Sulfureto (Emissões inorgânicas para água fresca)

Fosfato (Emissões inorgânicas para água fresca)

Fluoreto de hidrogênio (Emissões inorgânicas para o ar)

Hidrocarbonetos aromáticos policíclicos (Hidrocarbonetos para a água fresca)

Cromo (não especificado) (Metais pesados para água fresca)

Halon (1301) (Emissões orgânicas halogenadas para o ar)

Chumbo (+II) (Metais pesados para o ar)

Níquel (+II) (Metais pesados para água fresca)

Cianeto (Emissões inorgânicas para água fresca)

Componente halogênio orgânico absorvível (Medidas analíticas para a água

fresca)

Amônia (Emissões inorgânicas para o ar)

Arsênico (+V) (Metais pesados para água fresca)

Cádmio (+II) (Metais pesados para o ar)

Hidrocarbonetos clorados (não especificado) (Emissões orgânicas halogenadas para a água fresca)

Total de carbono orgânico restrito dissolvido (Medidas analíticas para a água fresca)

Hidrocarbonetos aromáticos policíclicos (Grupo PAH para o ar)

Mercúrio (+II) (Metais pesados para o ar)

Manganês (+II) (Metais pesados para o ar)

Mercúrio (+II) (Metais pesados para água fresca)

Hidrocarbonetos halogenados (não especificado) (Emissões orgânicas halogenadas para o ar)

TOTAL SAÍDA

$8,84 \mathrm{E}-05$

8,04E-05

7,24E-05

2,06E-05

1,67E-05

1,19E-05

1,15E-05

5,54E-06

4,00E-06

3,80E-06

1,98E-06

1,91E-06

1,28E-06

6,09E-07

5,26E-07

4,55E-07

4,44E-07

3,77E-07

1,77E-07

1,62E-07

1,36E-07

8,36E-08

7,71E-08

5,90E-08

4,99E-08

4,54E-08

2,95E-08

2,75E-08

2,47E-08

$1,86 \mathrm{E}-08$

6,60E-09

6,52E-09

5,62E-09

3,09E-09

2,72E-09

2,34E-09

9,94E-10

9,80E-10

$8,71 \mathrm{E}-10$

8,17E-10

8,13E-10

4,01E-10

2,79E-10

$1,90 \mathrm{E}-10$

1,82E-10

1,30E-10

1,07E-10

1,55E-11

1,19E-11

2,06E-12

1,15E-13

8,50E-02
4,51E-04

4,10E-04

3,69E-04

1,05E-04

8,51E-05

6,07E-05

5,86E-05

2,82E-05

2,04E-05

1,94E-05

1,01E-05

9,74E-06

6,53E-06

3,10E-06

2,68E-06

2,32E-06

2,26E-06

1,92E-06

9,02E-07

8,26E-07

6,93E-07

4,26E-07

3,93E-07

3,01E-07

2,54E-07

2,31E-07

1,50E-07

1,40E-07

1,26E-07

$9,48 \mathrm{E}-08$

3,36E-08

3,32E-08

2,87E-08

$1,58 \mathrm{E}-08$

1,39E-08

1,19E-08

5,07E-09

5,00E-09

4,44E-09

4,17E-09

4,14E-09

2,04E-09

1,42E-09

9,69E-10

9,28E-10

6,63E-10

5,45E-10

$7,90 \mathrm{E}-11$

6,07E-11

1,05E-11

5,86E-13

4,33E-01
$\mathrm{Kg}$

$\mathrm{Kg}$

$\mathrm{Kg}$

$\mathrm{Kg}$

$\mathrm{Kg}$

$\mathrm{Kg}$

$\mathrm{Kg}$

$\mathrm{Kg}$

$\mathrm{Kg}$

$\mathrm{Kg}$

$\mathrm{Kg}$

$\mathrm{Kg}$

$\mathrm{Kg}$

$\mathrm{Kg}$

$\mathrm{Kg}$

$\mathrm{Kg}$

$\mathrm{Kg}$

$\mathrm{Kg}$

$\mathrm{Kg}$

$\mathrm{Kg}$

$\mathrm{Kg}$

$\mathrm{Kg}$

$\mathrm{Kg}$

$\mathrm{Kg}$

$\mathrm{Kg}$

$\mathrm{Kg}$

$\mathrm{Kg}$

$\mathrm{Kg}$

$\mathrm{Kg}$

$\mathrm{Kg}$

$\mathrm{Kg}$

$\mathrm{Kg}$

$\mathrm{Kg}$

$\mathrm{Kg}$

$\mathrm{Kg}$

$\mathrm{Kg}$

$\mathrm{Kg}$

$\mathrm{Kg}$

$\mathrm{Kg}$

$\mathrm{Kg}$

$\mathrm{Kg}$

$\mathrm{Kg}$

$\mathrm{Kg}$

$\mathrm{Kg}$

$\mathrm{Kg}$

$\mathrm{Kg}$

$\mathrm{Kg}$

$\mathrm{Kg}$

$\mathrm{Kg}$

$\mathrm{Kg}$

Kg

Tabela 17 - Anexo C - Inventário do ciclo de vida do cesto inox 